OAK RIDGE

NATIONAL LABORATORY

MANAGED BY UT-BATTELLE

FOR THE DEPARTMENT OF ENERGY

\title{
Solid State Reactor Final Report
}

\author{
G. T. Mays \\ D. G. O'Connor \\ P. J. Otaduy \\ R. T. Primm III \\ N. C. Gallego \\ J. C. Conklin \\ F. C. Difilippo \\ J. W. Klett \\ T. D. Burchell
}




\section{DOCUMENT AVAILABILITY}

Reports produced after January 1, 1996, are generally available free via the U.S. Department of Energy (DOE) Information Bridge:

Web site: http://www.osti.gov/bridge

Reports produced before January 1,1996 , may be purchased by members of the public from the following source:

National Technical Information Service

5285 Port Royal Road

Springfield, VA 22161

Telephone: 703-605-6000 (1-800-553-6847)

TDD: 703-487-4639

Fax: 703-605-6900

E-mail: info@ntis.fedworld.gov

Web site: http://www.ntis.gov/support/ordernowabout.htm

Reports are available to DOE employees, DOE contractors, Energy Technology Data Exchange (ETDE) representatives, and International Nuclear Information System (INIS) representatives from the following source:

Office of Scientific and Technical Information

P.O. Box 62

Oak Ridge, TN 37831

Telephone: 865-576-8401

Fax: 865-576-5728

E-mail: reports@adonis.osti.gov

Web site: http://www.osti.gov/contact.html

This report was prepared as an account of work sponsored by an agency of the United States Government. Neither the United States government nor any agency thereof, nor any of their employees, makes any warranty, express or implied, or assumes any legal liability or responsibility for the accuracy, completeness, or usefulness of any information, apparatus, product, or process disclosed, or represents that its use would not infringe privately owned rights. Reference herein to any specific commercial product, process, or service by trade name, trademark, manufacturer, or otherwise, does not necessarily constitute or imply its endorsement, recommendation, or favoring by the United States Government or any agency thereof. The views and opinions of authors expressed herein do not necessarily state or reflect those of the United States Government or any agency thereof. 
ORNL/TM-2003/289

Nuclear Energy Research and Development Program

Nuclear Energy Research Initiative

\title{
SOLID STATE REACTOR FINAL REPORT
}

\author{
G. T. Mays \\ D. G. O'Connor \\ P. J. Otaduy \\ R. T. Primm III \\ N. C. Gallego \\ J. C. Conklin \\ F. C. Difilippo \\ J. W. Klett \\ T. D. Burchell
}

NERI Proposal No. 99-0064

Work Proposal No. NEAF 857

Demand-Driven Nuclear Energizer Module

(now designated Solid State Reactor)

November 2003

\author{
Prepared by \\ OAK RIDGE NATIONAL LABORATORY \\ P.O. Box 2008 \\ Oak Ridge, Tennessee 37831-6285 \\ managed by \\ UT-BATTELLE, LLC \\ for the \\ U.S. DEPARTMENT OF ENERGY \\ under contract DE-AC05-00OR22725
}




\section{CONTENTS}

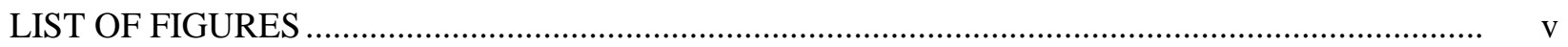

LIST OF TABLES

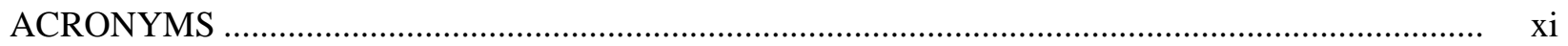

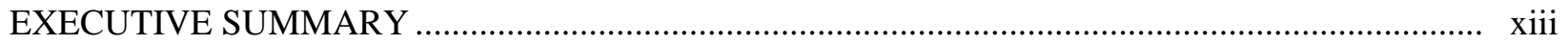

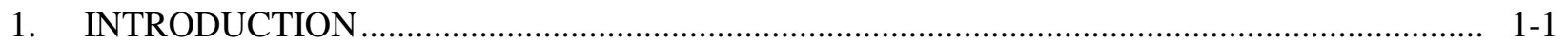

1.1 PRINCIPAL AREAS OF RESEARCH …........................................................ $1-1$

1.2 PRECONCEPTUAL DESIGN FEATURES …....................................................... $1-2$

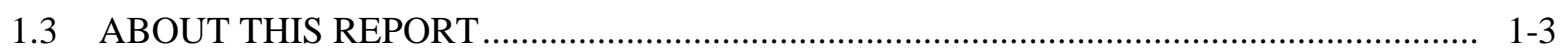

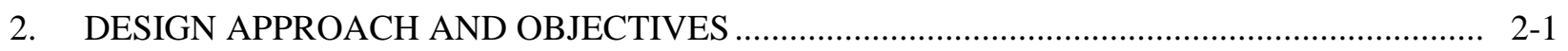

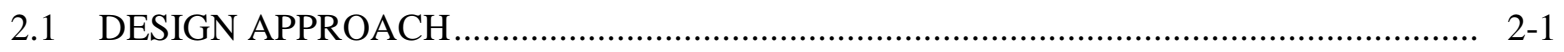

2.2 DESIGN CRITERIA FOR SSR …....................................................................... $2-2$

3. TECHNICAL ISSUES TO BE ADDRESSED BASED UPON DESIGN OBJECTIVES ............. 3-1

3.1 NEUTRONICS/REACTOR CONTROL ISSUES …................................................ $3-1$

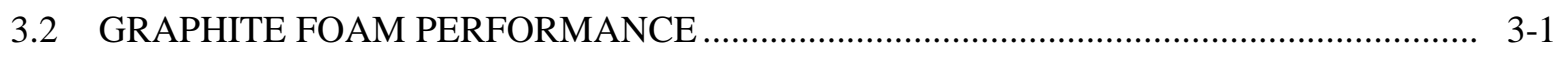

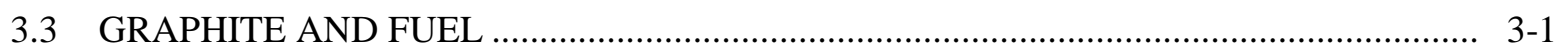

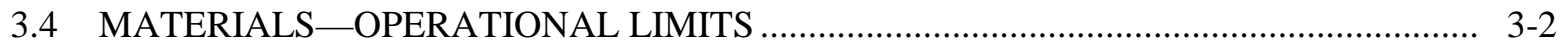

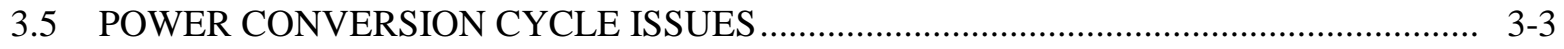

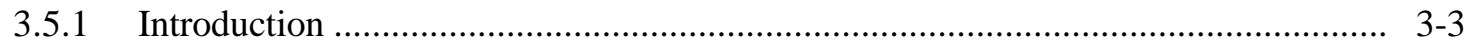

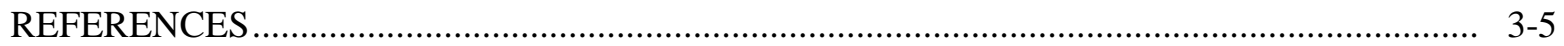

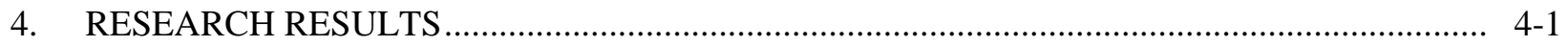

4.1 REACTOR PHYSICS DESIGN STUDIES ................................................................... $4-1$

4.1.1 Review of Results Presented in FY 2000 and FY 2001 Reports ........................... 4-1

4.1.2 Limitations Due to Fuel Fabrication Procedures..................................................... 4-1

4.1.3 Selection of Moderator-to-Fuel Ratio and Uranium Enrichment ............................ 4-3

4.1.4 Reflector Savings and Choice of Reflector ......................................................... 4-4

4.1.5 Consideration of Balance-of-Plant Lifetime and Design Basis Power ....................... 4-5

4.1.6 Selection of Clad and Limitations Due to Clad.................................................... 4-7

4.1.7 Validation with Applicable Critical Experiments ................................................ 4-8

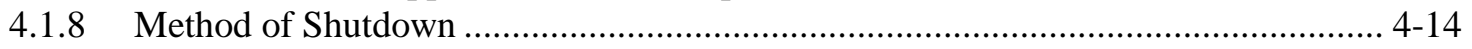

4.1.9 Consequence of Water Ingress Accident ............................................................ 4-15

4.1.10 Consequence of Water Vapor in Coolant During Operation at Full Power .............. 4-18

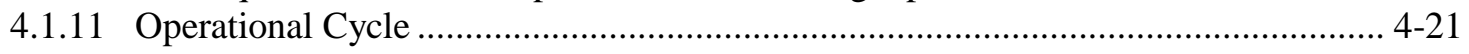

4.2 MATERIALS - GRAPHITE FOAM ......................................................................... $4-21$

4.2.1 Graphite Foam Samples for Irradiation Studies ................................................. 4-21

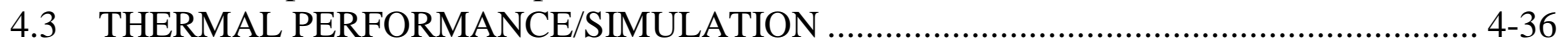

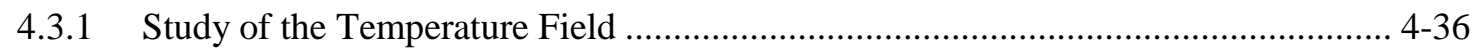

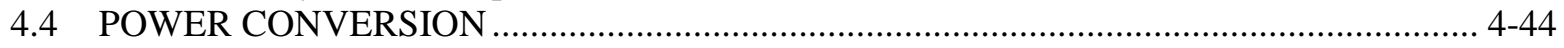

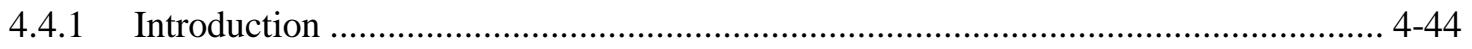

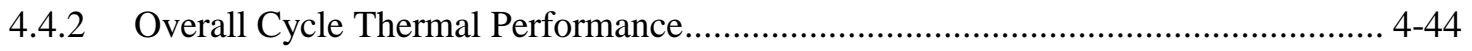

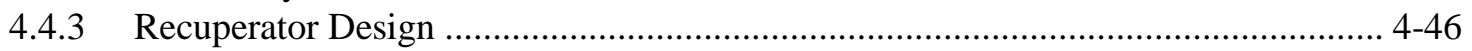

4.4.4 Active Core Heat Transfer Surface Design............................................................ 4-48

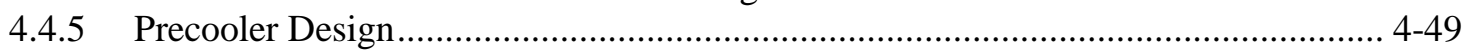

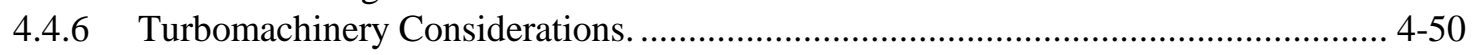

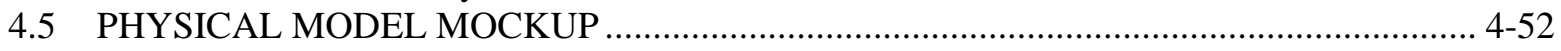

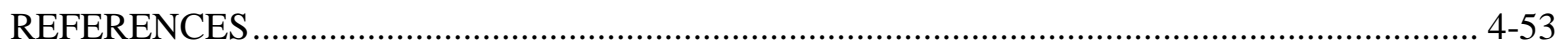




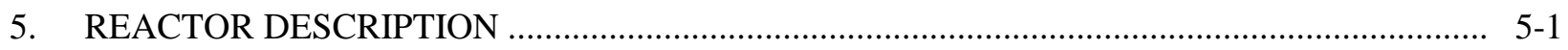

5.1 CORE DESCRIPTION AND DIMENSIONS ........................................................... $5-1$

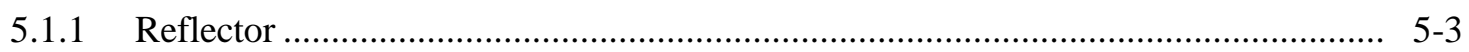

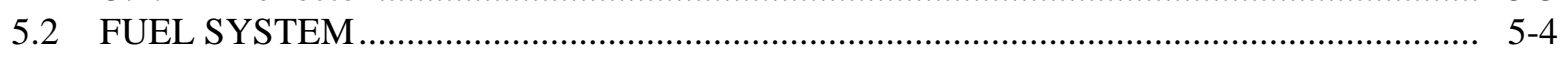

5.2.1 Fuel Stability Over Reactor Lifetime ………………………………………….... 5-4

5.2.2 Reactor Control............................................................................................ $5-4$

5.2.3 Fission Product Containment......................................................................... $5-5$

5.3 REACTOR MATERIALS …………………………………………………….... 5-6

5.3.1 Graphite Foam Description and Characteristics....................................................... 5-6

5.3.2 Reactor Container Material .................................................................................... 5-6

5.3.3 Shielding Considerations .................................................................................... 5-7

5.4 THERMAL ANALYSIS/HEAT REMOVAL FOR THE CONCEPTUAL DESIGN ............ 5-7

5.4.1 Preliminary Core Temperature Profiles …………………………………………. 5-8

5.4.2 Core Temperature and Power Generation Profiles.................................................... 5-8

5.4.3 Core Temperature and Power Generation Profiles at Off-Normal Operation ............ 5-15

5.4.4 Potential for Alternative Core Cooling Configurations............................................... 5-16

5.4.5 Graphite Foam Performance as Heat Transfer Medium............................................ 5-18

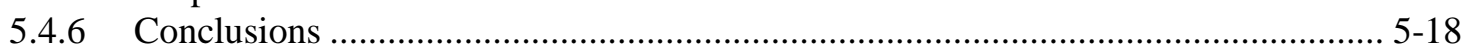

5.5 POWER CONVERSION SYSTEM ………………............................................... 5-18

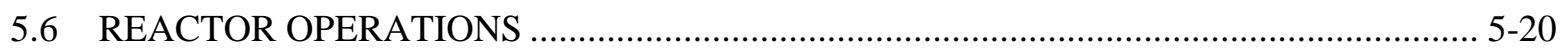

5.6.1 Startup/Shutdown Operations ………………………………………….... 5-20

5.6.2 Transient Analysis ………………………………………………………… 5-20

6. FUTURE RESEARCH AND DEVELOPMENT...................................................................... 6-1

Appendix A MELTING POINT OF ULTRA HIGH TEMPERATURE MATERIALS ....................... A-1

Appendix B NEUTRONIC PARAMETERS AND THEIR TEMPERATURE DEPENDENCE FOR EACH OF THE FOUR MATERIAL REGIONS AND FOUR

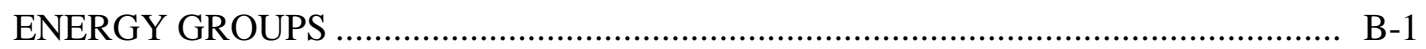

Appendix C SCOPING THERMAL COMPUTATIONS FOR COOLING AT THE BOUNDARIES AND COMPARISON OF SIMPLIFIED INFINITE-CYLINDER 1-D MODEL AND A DETAILED 2-D FINITE ELEMENT MODEL............................... C-1 


\section{LIST OF FIGURES}

Figure

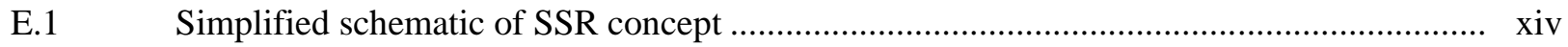

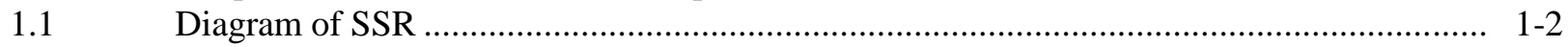

$2.1 \quad$ Integration of nuclear design, thermal-hydraulic design, and materials design .................. 2-1

2.2 General process used to develop the SSR design criteria ........................................... 2-2

3.1 (a) and $(b)$ Gel-cast stainless steel powder impregnated into carbon foam ....................... 3-2

Impact of reflector thickness on reactor volume.......................................................

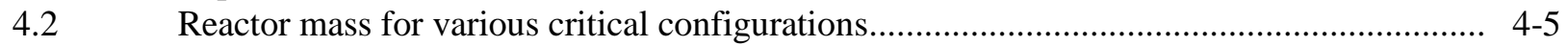

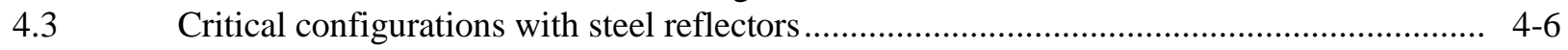

Reactor mass for various steel reflectors .................................................................. 4-6

S.5 Spectral indices for reference fuel ................................................................ $4-9$

4.6 Sectional view of the uranium metal assembly............................................................... 4-10

4.7 Longitudinal section of the critical assembly with structural elements of the facility .......... 4-11

4.8 Cross section of the critical assembly showing the arrangement of channels ...................... 4-12

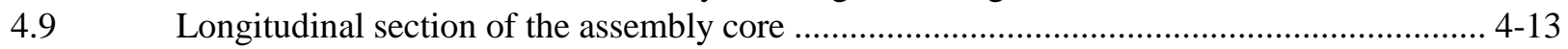

$4.10 \quad$ Rotating control drum design for thermoelectric configuration...................................... 4-15

4.11 Absorption cross section for cadmium at "so-called" cadmium cutoff............................... 4-16

4.12 Effect of cadmium on flooded, fueled foam .............................................................. 4-17

4.13 Cross section view of SSR core and reflector......................................................... 4-17

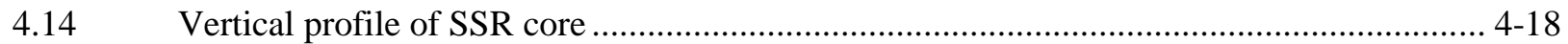

$4.15 \quad$ Reactivity effect of water ingress to reference fuel............................................................ 4-19

4.16 HELIOS model of a segment of the SSR showing shutdown rod "out"............................ 4-19

4.17 Axial view of SSR core and reflector showing shutdown rod construction ....................... 4-20

4.18 Orientation of machined samples within the block of carbon foam .................................. 4-21

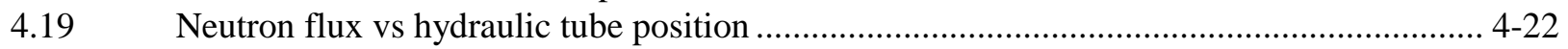

4.20 Results from the swing test for an $\mathrm{SiC}$ monitor to determine actual irradiation temperature of graphite foam samples ............................................................................................ 4-23

4.21 Volume changes $(\Delta \mathrm{V} / \mathrm{V})$ as a function of irradiation dose for graphite foam samples ........ 4-24

4.22 Dimensional changes $(\Delta \mathrm{l} / \mathrm{l})$ as a function of irradiation dose for graphite foam samples ..... 4-24

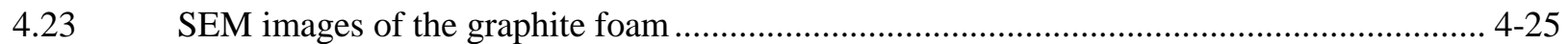

4.24 Cross-polarized light image of graphite foam ligament and junction ............................... 4-25

4.25 A schematic 2-D representation of the postulated microstructural model of graphite

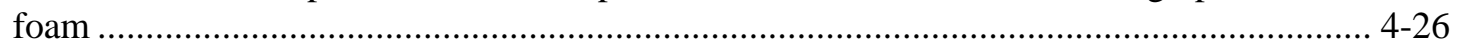

4.26 Radiation damage in graphite showing the induced crystal dimensional strains ................ 4-27

4.27 Schematic representation of initial strain in graphite foam ............................................ 4-27

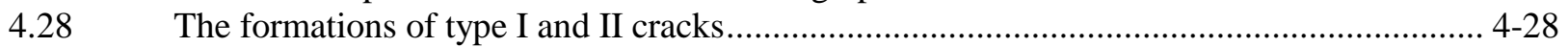

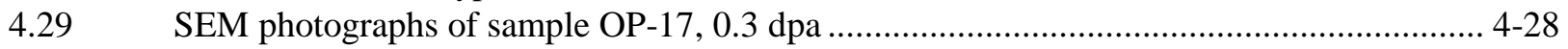

4.30 SEM photographs of sample OP-9, 2.6 dpa ........................................................ 4-29

4.31 An illustration of the graphite cell collapsing around a bubble in the graphite foam, driven by ligament thickening and contraction (type I cracking) and facilitated

by type II cracks ....................................................................................................... 4-29

4.32 Summary of the postulated explanation for the experimentally observed dimensional/ volume changes in graphite foam after neutron irradiation ................................................ 4-31

4.33 Average values of thermal conductivity, as a function of temperature, for nonirradiated

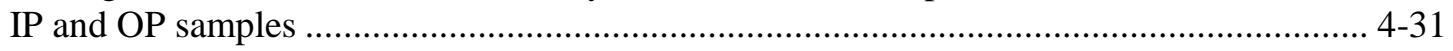

4.34 Temperature dependence of thermal conductivity for nuclear-grade graphite $\mathrm{H} 451 \ldots \ldots . . . . .4-32$

4.35 Thermal conductivity measurements of samples OP-17 after irradiation and after annealing to $1000^{\circ} \mathrm{C}$ and $1200^{\circ} \mathrm{C}$. 
4.36 Thermal conductivity measurements of samples OP-9 after irradiation and after annealing to $1000^{\circ} \mathrm{C}$ and $1200^{\circ} \mathrm{C}$.

4.37 Room temperature conductivity vs irradiation dose for (1) nuclear-grade graphite $\mathrm{H} 451$ and (2) graphite foam (OP-type samples) ....................................................................... 4-34

4.38 Thermal conductivity of commercially available graphite foam (Poco ${ }^{\circledR}$ foam) compared with the thermal conductivity of foam originally produced for this project (nonirradiated samples OP-1, OP-4 and OP-10)

4.39 Radial temperature distributions at midheight point for cooling $(a)$ At the outside reflector boundary (upper curve) and $(b)$ at the core/reflector internal boundary (lower curve).

4.40 (a) Power generation density for $500 \mathrm{~kW}(b)$ Temperature distribution for $500 \mathrm{~kW}$ with cooling only at the core's cylindrical boundary ........................................................ 4-38

4.41 Temperature distribution for $500 \mathrm{~kW}$ with cooling at all of the core's boundaries ............. 4-39

4.42(a) Power generation density's finite-element grid ............................................................. 4-39

4.42 (b) Temperature distribution for $500 \mathrm{~kW}$ with cooling at all of the reflector's outside

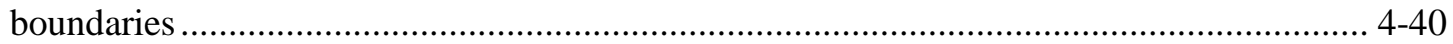

4.43 Schematic, not to scale, of the placement of 33 heat pipes in a 4-ring configuration ........... 4-41

4.44(a) Power generation density and cooling channels grip for $500 \mathrm{~kW}$.................................. 4-41

4.44(b) Temperature distribution with cooling only through the core's channels .......................... 4-42

4.44(c) Midplane cut showing the temperature distribution with cooling only through the core's

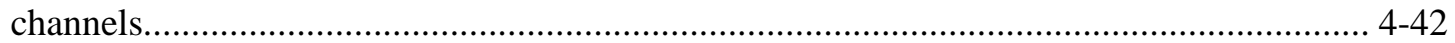

4.44(d) Midplane cut showing the heat flux distribution with cooling only through the core's

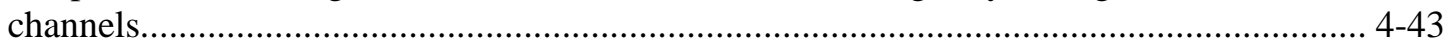

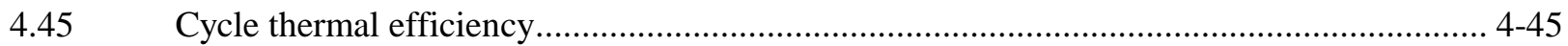

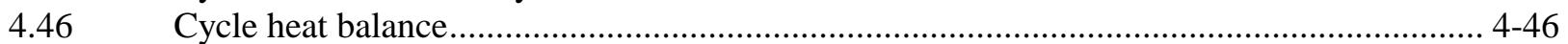

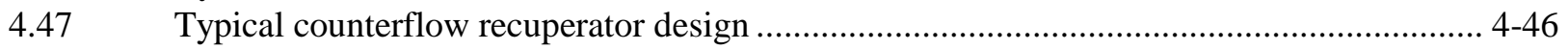

$4.48 \quad$ Recuperator dimensions for a 3\% pressure drop ................................................... 4-47

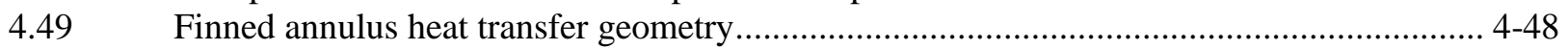

4.50 Core fin geometry effects on pressure drop and thermal conductance .............................. 4-49

4.51 Face area and face velocity as a function of air mass flow rate ........................................ 4-51

4.52 Precooler pressure drop and flow length as a function of air mass flow rate...................... 4-51

4.53 Physical mockup of the SSR core without enclosures and cooling fan .......................... 4-52

$5.1 \quad$ Radial power distribution for solid state reactor......................................................... $5-3$

$5.2 \quad$ Flux profile from HELIOS calculation........................................................... $5-3$

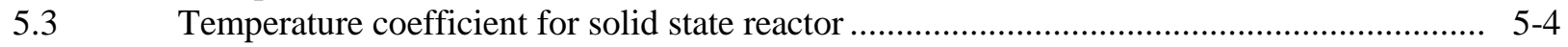

$5.4 \quad$ SEM images of the graphite foam ....................................................................... 5-6

5.5 Acoustic behavior of the graphite foam compared with Pyrell foam used in anechoic chambers

5.6 1-D calculation of radial temperature distributions at the bottom, middle, and top planes for the $500-\mathrm{kW}$ reactor core .................................................................................. $5-8$

5.7 1-D calculation of radial distributions of power flow at the bottom, middle, and top planes

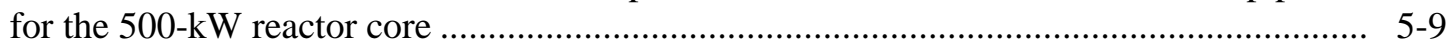

5.8 1-D calculation of radial distribution of thermal conductivity at the bottom, middle, and top planes for the $500-\mathrm{kW}$ reactor core .................................................................. $5-9$

5.9 Neutron fluxes along a diameter in the center of the reactor for the base-case of 500-kW power with $930 \mathrm{~K}$ heat sink................................................................................ 5-10

5.10 Power generation $\left(\mathrm{W} / \mathrm{m}^{3}\right)$ distribution for the base-case of $500-\mathrm{kW}$ power with $930 \mathrm{~K}$ heat sink at the core/reflector boundary ........................................................................ 5-12

5.11 Temperature distribution (K) for the base-case of 500-kW power with $930 \mathrm{~K}$ heat sink

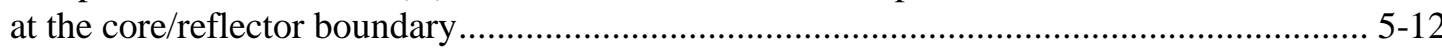

5.12 Dependence of the core-average and peak temperatures with the heat sink temperature at the core/reflector boundary for a power generation of $500 \mathrm{~kW}$ 
5.13 Dependence of the core-average and peak temperatures with the heat sink temperature at the core/reflector boundary for a power generation of $1000 \mathrm{~kW}$

5.14 Reactor's self-adjusting operating trajectory with heat sink at the core/reflector boundary: equilibrium power vs temperatures at the heat sink, core averaged. and peak.

5.15 Reactor's self-adjusting operating trajectory with heat sink at the reflector external boundary: equilibrium power vs temperatures at the heat sink, core/reflector boundary, core averaged, and peak

5.16 Temperature distribution (K) for the Z-20 match-case of $582.15 \mathrm{~kW}$ power with $250^{\circ} \mathrm{C}$ heat sink at the reflector's external boundary.....

5.17 Schematic, not to scale, of the placement of 33 heat pipes in a 4-ring configuration

5.18 Hot-spot temperature increment as a function of hole surface temperature for holes

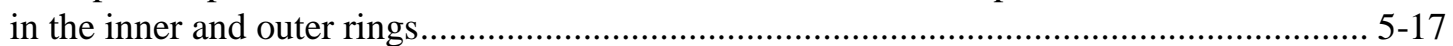

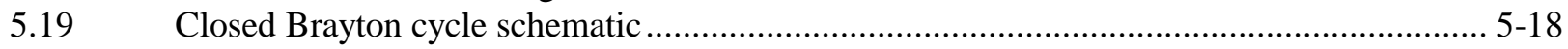

B-1 Percent of the value for $300 \mathrm{~K}$ for the thermal and epithermal energy groups .................. B-3

B-2 Percent of the value for $300 \mathrm{~K}$ for the midfast and fast energy groups............................. B-4

C-1 Thermal conductivity of graphitized foam in radial direction as a function of temperature 


\section{LIST OF TABLES}

Table

Page

4.1 Design parameters for near-zero burnup reactivity swing ............................................ 4-2

4.2 $\mathrm{C} / \mathrm{U}$ ratios for graphite foams with various uranium compounds filling the void space in the foam

4.3 Calculated physics parameters for uranyl sulfate critical experiments ............................ 4-14

Capsule's content and neutron irradiation dose ............................................................ 4-22

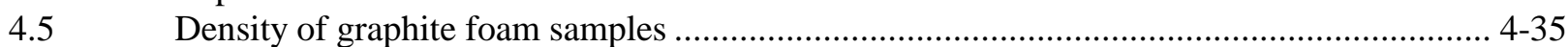

5.1 Characteristics of nuclear energizer module.

5.2 $\mathrm{C} / \mathrm{U}$ ratios for graphite foams with various uranium compounds filling the void space in the foam

5.3 Core-averaged and peak temperatures and neutronic parameters for cooling at the core/reflector cylindrical boundary.

5.4 Core-averaged and peak temperatures and neutronic parameters for cooling at the core/reflector cylindrical boundary....

5.5 Core-averaged and peak temperatures and neutronic parameters for cooling at the reflector's external cylindrical boundary

A.1 Melting point of high-temperature materials in elemental, carbide, oxide, and boride forms

A.2 Melting point of high-temperature materials in nitride, intermetallic, silicide, phosphide, and silicate forms 


\section{ACRONYMS}

$\begin{array}{ll}\text { ANSI } & \text { American National Standards Institute } \\ \text { ASME } & \text { American Society of Mechanical Engineers } \\ \text { CTE } & \text { coefficient of thermal expansion } \\ \text { CVD } & \text { chemical vapor deposition } \\ \text { CVI } & \text { chemical vapor infiltration } \\ \text { 1-D } & \text { one-dimensional } \\ \text { 3-D } & \text { three-dimensional } \\ \text { dpa } & \text { displacement per atom } \\ \text { DOE } & \text { U.S. Department of Energy } \\ \text { EALF } & \text { energy of the average lethargy group for fission } \\ \text { EB-PVD } & \text { electron-beam physical vapor deposition } \\ \text { HFIR } & \text { High Flux Isotope Reactor } \\ \text { HOPG } & \text { highly ordered pyrolytic graphite } \\ \text { IP } & \text { in-plane } \\ \text { ILL } & \text { Institut Laue-Langevin } \\ \text { LWR } & \text { light-water reactor } \\ \text { MCNP } & \text { Monte Carlo N-Particle } \\ \text { MP } & \text { melting point } \\ \text { NASA } & \text { National Aeronautics and Space Administration } \\ \text { NERI } & \text { Nuclear Energy Research Initiative } \\ \text { OP } & \text { out-of-plane } \\ \text { ORNL } & \text { Oak Ridge National Laboratory } \\ \text { R\&D } & \text { research and development } \\ \text { SEM } & \text { scanning electron microscope } \\ \text { SiC } & \text { silicon carbide } \\ \text { SSR } & \text { Solid State Reactor }\end{array}$




\section{EXECUTIVE SUMMARY}

The Solid State Reactor (SSR) is an advanced reactor concept designed to take advantage of Oak Ridge National Laboratory's (ORNL's) recently developed graphite foam that has enhanced heat transfer characteristics and excellent high-temperature mechanical properties, to provide an inherently safe, selfregulated, source of heat for power and other potential applications. This work was funded by the U.S. Department of Energy's Nuclear Energy Research Initiative (NERI) program (Project No. 99-064) from August 1999 through September 30, 2002.

The initial concept of utilizing the graphite foam as a basis for developing an advanced reactor concept envisioned that a suite of reactor configurations and power levels could be developed for several different applications. The initial focus was looking at the reactor as a heat source that was scalable, independent of any heat removal/power conversion process. These applications might include conventional power generation, isotope production and destruction (actinides), and hydrogen production.

Having conducted the initial research on the graphite foam and having performed the scoping parametric analyses from neutronics and thermal-hydraulic perspectives, it was necessary to focus on a particular application that would (1) demonstrate the viability of the overall concept and (2) require a reasonably structured design analysis process that would synthesize those important parameters that influence the concept the most as part of a feasible, working reactor system.

Thus, the application targeted for this concept was supplying power for remote/harsh environments and a design that was easily deployable, simplistic from an operational standpoint, and utilized the new graphite foam. Specifically, a 500-kW(t) reactor concept was pursued that is naturally load following, inherently safe, optimized via neutronic studies to achieve near-zero reactivity change with burnup, and proliferation resistant.

These four major areas of research were undertaken:

1. establishing the design and safety-related basis via neutronic and reactor control assessments with the graphite foam as heat transfer medium;

2. evaluating the thermal performance of the graphite foam for heat removal, reactor stability, reactor operations, and overall core thermal characteristics;

3. characterizing the physical properties of the graphite foam under normal and irradiated conditions to determine any effects on structure, dimensional stability, thermal conductivity, and thermal expansion; and

4. developing a power conversion system design to match the reactor operating parameters.

\section{REACTOR DESCRIPTION}

The reactor core consists of a right circular cylinder of graphite foam impregnated with uranium carbide. The radius of the cylinder is $75 \mathrm{~cm}$. The cylinder is divided into two zones: a central unpoisoned region having a radius of approximately $13 \mathrm{~cm}$ and an outer annular region in which the foam is impregnated with cadmium $(\mathrm{Cd})$ at a density of $86 \mathrm{mg} / \mathrm{cm}^{3}$. The carbon/235 $\mathrm{U}$ ratio is 39 . The uranium ( $20 \%$ enriched U; critical mass of about 4 MTU) exists as $\mathrm{UC}_{2}$. During normal operation, the cadmium is relatively innocuous (the reactor has a fast spectrum). However, should there be ingress of water to the core, the cadmium acts as an effective neutron poison, causing the reactor to be subcritical. One of the principal design goals for the SSR is that it provide power on an as needed basis and shut down automatically when there is no demand. This is accomplished by designing the reactor to have a negative temperature coefficient.

The core is surrounded by a graphite reflector (i.e., normal graphite, not graphite foam). The fuel is to be loaded into the foam's pores, thus minimizing the thermal path length between the fuel and the heat sink. The uranium-impregnated foam would be encased in a "superalloy" steel. The reflector/clad interface temperature is expected to be limited to $900 \mathrm{~K}$. The reflector thickness is approximately $30 \mathrm{~cm}$. 
Shutdown/startup of the reactor would be achieved by control elements in the radial reflector, outside the core clad. The reactor coolant outlet temperature/turbine inlet temperature is $900 \mathrm{~K}$. A simplified schematic of this reactor concept is presented below.

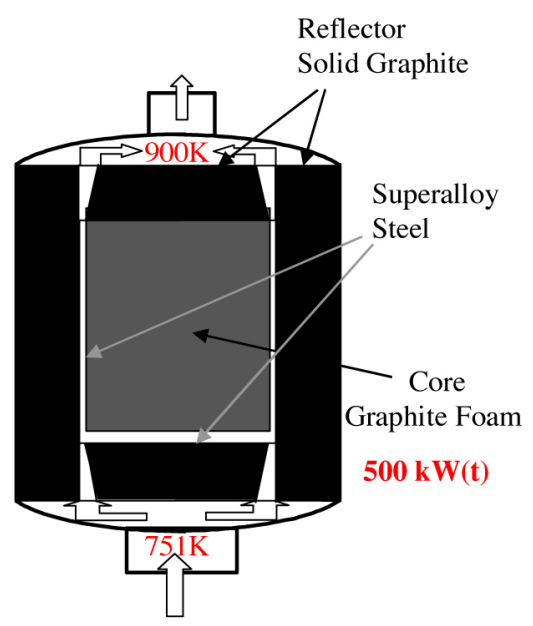

Fig. E.1. Simplified schematic of SSR concept.

\section{MATERIAL EVALUATIONS}

The manufacturing process as employed for graphite foams used in this research induces a preferred alignment of the ligaments of the foam in the $\mathrm{Z}$ direction. This alignment translates into an anisotropic behavior of the properties of the foam (i.e., the thermal conductivity in the Z-direction is 3-4 times that of the $\mathrm{X}$ - or $\mathrm{Y}$-direction). Work is under way to improve the manufacturing process in order to eliminate/minimize the anisotropic behavior of the foam.

Four capsules, each with three foam samples plus a silicon carbide ( $\mathrm{SiC})$ temperature monitor, were irradiated in the High Flux Isotope Reactor (HFIR) at ORNL. Two capsules were used for the in-plane samples, and the other two were used for the out-of-plane samples. One in-plane and one out-of-plane capsule received an irradiation dose of 2.6 displacements per atom (dpa); ${ }^{*}$ while the other in-plane and outof-plane capsule received an irradiation dose of $0.3 \mathrm{dpa} .{ }^{*}$ The location of the capsules within the hydraulic tube was such that the variation of the neutron flux was less than $15 \%$ from capsule to capsule.

Observation of irradiated samples under a scanning electron microscope (SEM) showed no apparent changes or damage, that is, samples conserved their structural integrity during irradiation. Thermal conductivity measurements and annealing studies of irradiated samples showed that thermal conductivity decreased as the irradiation dose increased. This effect is consistent with typical results for graphite samples. Annealing of irradiated foam samples to $1000^{\circ} \mathrm{C}$ and $1200^{\circ} \mathrm{C}$ lead to recovery of their thermal conductivity. This annealing process would be an integral part of the normal operation of the reactor in response to power demands.

At the beginning of the project, a commercial vendor for the material was not available. However, since then, the material has been licensed to a commercial firm, and a commercial product is now available. It has been shown that the commercially available material is superior in quality and thermal properties to that initially produced at ORNL. It is expected that the commercial product will exhibit higher thermal properties in the reactor than that used for this project.

\footnotetext{
*2.6 dpa $=1.8 \times 10^{25} \mathrm{n} / \mathrm{m}^{2}(\mathrm{E}>0.1 \mathrm{MeV})$. $0.3 \mathrm{dpa}=0.21 \times 10^{25} \mathrm{n} / \mathrm{m}^{2}(\mathrm{E}>0.1 \mathrm{MeV})$.
} 


\section{THERMAL AND REACTOR SIMULATION}

A series of 1-D and 3-D computations were performed to assess the temperature distributions for candidate reactor configurations. Following a series of computations examining several cooling approaches, it was decided for the reference design to use a solid-core geometry with cooling at the core/reflector boundary by means of a circulating gas, driving a Brayton power conversion system.

Computations indicate that for the target $500-\mathrm{kW}(\mathrm{t}$ ) solid core design (without coolant passage holes), cooling at the external boundary of the reflector is not desirable. For equal power generation levels, it would result in much higher internal temperatures without appreciable benefits. It was also clear that cooling at the top and/or bottom circular surfaces had little impact on the peak temperatures inside the reactor because the thermal conductivity in the axial direction is significantly lower than in the radial direction.

Although cooling by means of longitudinal coolant passages is clearly better from the thermal point of view, it adds considerable complexity to this conceptual design.

\section{POWER CONVERSION}

The reference thermal power conversion system consists of the heat transfer geometry surrounding the nuclear core cladding and the closed Brayton cycle components that convert the thermal power generated by the reactor into electrical power. Heat transfer fins are necessary to increase the effective heat transfer area of the core clad surrounding the nuclear-fueled region. The fins will be made of the same material, a superalloy steel as the core clad, and the clad surrounding the reflector will serve as an outer shroud to contain the cooling flow.

The working fluid of the recuperated closed Brayton cycle system chosen is a mixture of helium and xenon having a molecular weight of $40(\mathrm{HeXe} 40)$. If pure helium were chosen as the working fluid, the relatively high thermal conductivity would result in the recuperator having a minimal necessary heat transfer area as compared to other gases, and thus minimize the overall volume envelope of the system. However, pure helium also has a high specific heat that would limit the temperature change and thus pressure ratio across a stage. This stage pressure ratio limit would increase the number of turbine and compressor stages and result in complicated turbomachinery. Thus, a compromise is necessary between the small recuperator and complicated turbomachinery for pure helium and the larger recuperator with simple turbomachinery of HeXe40. Closed Brayton cycle turbomachines have been successfully designed and tested for space applications using HeXe40 in the electrical power range of interest $[\sim 100 \mathrm{~kW}(\mathrm{e})]$. So, the $\mathrm{HeXe} 40$ turbomachinery design was chosen. Because the working fluid is clean and inert, relatively long full-power operating intervals of a decade can be expected.

Because of core/clad interface temperature limitations, the turbine inlet temperature has been specified as $900 \mathrm{~K}$. Because a terrestrial location is postulated for this reactor concept, a compressor inlet temperature of $310 \mathrm{~K}$ is specified. The ultimate heat sinks of water, forced convection air, and natural convection air were analyzed. While water would result in the smallest heat-rejection heat exchanger and perhaps a lower compressor inlet temperature, the presence of water vapor near the active core during an upset transient is a nuclear criticality consideration. A natural convection heat sink design would require an air chimney and have a large heat rejection heat exchanger. Thus, for simplicity, the forced convection air design was chosen as the ultimate heat sink.

Because a $95 \%$ effective recuperator is sized here, the pressure ratio across the compressor that results in the optimum cycle efficiency is 1.65 . Using this pressure ratio with the appropriate cycle parameters results in a cycle thermal efficiency of $28.2 \%$ with a HeXe40 mass flow of $6.28 \mathrm{~kg} / \mathrm{s}$. Thus, for the proposed core thermal power of $500 \mathrm{~kW}, 150 \mathrm{~kW}$ of shaft power is available. With a generator efficiency of $95 \%$, the electrical power resulting from this design is projected to be $141 \mathrm{~kW}$. 


\section{CONCLUSIONS AND FOLLOW-ON RESEARCH}

The results from this initial investigation indicate that the newly developed graphite foam can be effectively integrated into a conceptual design for a reactor to take advantage of its enhanced thermal properties. While these properties are degraded upon irradiation, annealing of irradiated foam samples lead to recovery of the thermal conductivity. In principle, there are a number of potential applications for the reactor concept and potential for coupling it to other power conversion technologies (e.g., thermoelectric, thermionic, etc.). For the purposes of developing a reference design, a Brayton cycle was selected.

There are five major areas for which additional research is required to further investigate the viability of this concept.

1. Evaluate the manufacturing processes of the graphite foam that have been improved since the inception of this project to evaluate the extent to which the anisotropic properties of the original foam have been reduced or eliminated.

2. Conduct further irradiation experiments to establish a broader baseline data for thermal properties of the foam. This is particularly needed because the graphite foam is now being produced commercially with apparently improved properties.

3. Identify the appropriate research and testing needed to determine the method (s) for loading the fuel into the graphite foam.

4. Conduct research on advanced matrix manufacturing of materials with tunable thermal, mechanical, neutronic, and environmental resistance properties at high temperatures, such as electron-beam vapor deposition of rhenium and iridium on graphitized foam.

5. Perform nuclear data evaluations that include confirmation of the critical mass and values of the temperature coefficient as well as evaluations for uranium, carbon, oxygen, and cadmium isotopes for the epithermal and fast energy ranges.

In addition to these research areas, a preliminary cost analysis should be performed to understand the key cost drivers and where design options might offer potential cost reductions. 


\section{INTRODUCTION}

The Solid State Reactor (SSR) is an advanced reactor concept that takes advantage of Oak Ridge National Laboratory's (ORNL's) recently developed materials that enhance heat transfer characteristics and provide high-temperature mechanical properties to provide an inherently safe, self-regulating source of heat with an extended reactor core lifetime. The concept achieves operational simplicity via demand-driven heat generation without the need of moving a control mechanism and a primary system working fluid. The reactor design concept is inherently safe, proliferation resistant, and ideal as a long-term, reliable source of power for harsh, remote, and/or inaccessible environments.

One of the principal design goals for the SSR is to provides power on an as-needed basis and shut down automatically when there is no demand. This is accomplished by designing the reactor to have a negative temperature coefficient. As the heat extraction is decreased (power demand is reduced), the reactor temperature will increase causing an increase in parasitic neutron absorption in the fuel due to the Doppler effect. The power level of the reactor will then drop to the level where the thermal heat production balances the thermal heat removal.

The reactor core is to be made of ORNL's high-conductivity porous graphite foam. This highconductivity graphite foam, developed and produced at ORNL, is the candidate material for the core as the basic heat source. Neutron moderation will primarily take place in the reflector, yielding an energy spectrum peaked in the epithermal regime. The low density of the foam will result in a low carbonuranium ratio. This is the key to attain a zero burn-up reactivity swing over long time periods. Irradiation studies at ORNL's High Flux Isotope Reactor (HFIR) facility were conducted to determine the effects of neutron flux on the thermal properties of the graphite foam as a function of neutron dose.

The fuel is to be loaded into the foam's pores, thus minimizing the thermal path length between the fuel and the heat sink. The reactor will be sealed and will include a reflector that surrounds the core fully, consisting of a radial module (ring) and two axial modules (discs) - the core is subcritical without the reflector.

This work was funded by the U.S. Department of Energy's (DOE's) Nuclear Energy Research Initiative (NERI) program (Project No. 99-064) from August 1999 through September 30, 2002. This report documents the results of research efforts to support the development of the preconceptual design.

\subsection{PRINCIPAL AREAS OF RESEARCH}

During the course of the project, research and development (R\&D) activities focused on the first three areas noted below for the first 2 years; then as a particular application was identified that established certain design considerations and objectives, the fourth area was included:

- establishing the design and safety-related basis via neutronic and reactor control assessments with the graphite foam as heat transfer medium;

- evaluating the thermal performance of the graphite foam for heat removal, reactor stability, reactor operations, and overall core thermal characteristics;

- characterizing the physical properties of the graphite foam under normal and irradiated conditions to determine any effects on structure, dimensional stability, thermal conductivity, and thermal expansion; and

- developing a power conversion system design to match the reactor operating parameters.

A small physical model was constructed, as well, using the graphite foam and electric heaters coupled with a computer model to benchmark codes, heat transfer. and overall material performance.

This project specifically addressed the NERI program nuclear technology goals for conducting research that addressed areas of (1) reactors with higher performance and efficiency, (2) low-output reactors, and (3) advanced nuclear fuel. 


\subsection{PRECONCEPTUAL DESIGN FEATURES}

The principal objectives of the project were to develop a reactor concept with a target power level of $500 \mathrm{~kW}(\mathrm{t})$ that is naturally load following, inherently safe, optimized via neutronic studies to achieve nearzero reactivity change with burnup, and proliferation resistant. The general application targeted for this concept was for supplying power for remote/harsh environments and a design that was easily deployable. Figure 1.1 presents a simplified illustration of the concept.

The reactor core consists of a right circular cylinder of graphite foam impregnated with uranium carbide. The radius of the cylinder is $75 \mathrm{~cm}$. The cylinder is divided into two zones-a central unpoisoned region having a radius of approximately $13 \mathrm{~cm}$ and an outer annular region in which the foam is impregnated with cadmium at a density of $86 \mathrm{mg} / \mathrm{cm}^{3}$. The $\mathrm{C} / 235 \mathrm{U}$ ratio is 39 . The uranium (20\% enriched uranium; critical mass of about $4 \mathrm{MTU}$ ) exists as $\mathrm{UC}_{2}$. During normal operation, the cadmium is relatively innocuous (the reactor has a fast spectrum). However, should there be ingress of water to the core, the cadmium acts as an effective neutron poison, causing the reactor to be subcritical. The temperature coefficient of the fueled-foam is expected to be between -0.2 and $-0.3 \mathrm{pcm} / \mathrm{K}$.

The core is surrounded by a graphite reflector (i.e., normal graphite, not graphite foam). Uraniumimpregnated foam would be encased in a "superalloy" steel. The reflector/clad interface temperature is expected to be limited to $900 \mathrm{~K}$. The reflector thickness (considering reactor weight, size, and cost of fuel) is approximately $30 \mathrm{~cm}$. Shutdown/startup of the reactor would be achieved by control elements in the radial reflector, outside the core clad.

At nominal operation, the $500 \mathrm{~kW}$ of power generated in the reactor core is transferred to a stream of $\mathrm{He}-\mathrm{Xe}$ gas circulating through the 1-cm-wide finned channel between the core and the reflector. The cooling gas enters the reactor from the bottom at $654 \mathrm{~K}$ and exits from the top at $900 \mathrm{~K}$.

The reference thermal power conversion system consists of the heat transfer geometry surrounding the nuclear core cladding and the closed Brayton cycle components that convert the thermal power generated by the reactor into electrical power. Heat transfer fins are necessary to increase the effective heat transfer area of the core clad surrounding the nuclear-fueled region. The fins will be made of the same material, a superalloy steel as the core clad, and the clad surrounding the reflector will serve as an outer shroud to

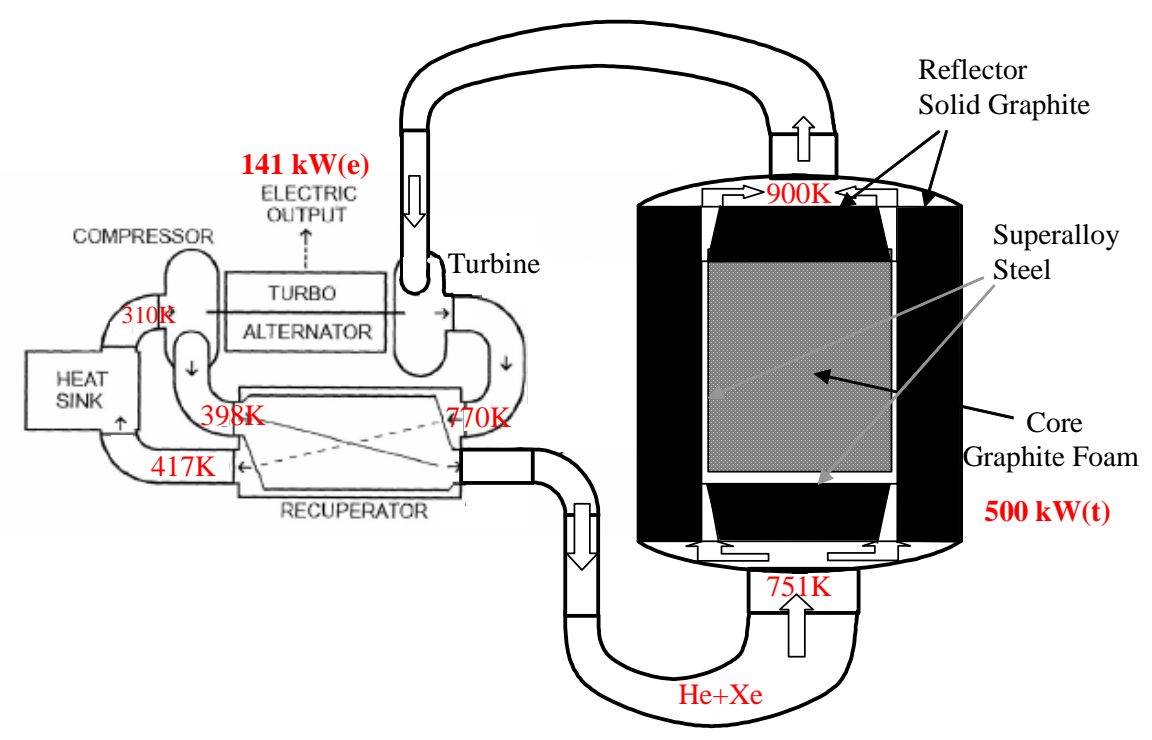

Fig. 1.1. Diagram of SSR. 
contain the cooling flow. Based on optimization studies, the fin geometry is as follows: fin height of $10 \mathrm{~mm}$, fin width of $5 \mathrm{~mm}$, and fin spacing of $10 \mathrm{~mm}$. Using this cooling geometry, the working fluid pressure drop in the finned area is less than $1 \%$. The working fluid of the recuperated closed Brayton cycle system chosen is a mixture of helium and xenon having a molecular weight of 40 (HeXe40).

Because of core/clad interface temperature limitations, the turbine inlet temperature has been established as $900 \mathrm{~K}$. Because a terrestrial location is postulated for this reactor concept, a compressor inlet temperature of $310 \mathrm{~K}$ is specified. For simplicity, a forced convection air design was chosen as the ultimate heat sink. The electrical power conversion efficiency for this system, given $500 \mathrm{~kW}(\mathrm{t})$, is $28.2 \%$.

\subsection{ABOUT THIS REPORT}

Sections 1 and 2 of this report summarize the principal areas of $R \& D$ and analysis that were performed and highlight design objectives and preconceptual design features for the SSR. Discussed in Sect. 3 are the principal technical issues that were to be researched and addressed based upon the design objectives. Addressing these technical issues required having a viable design that effectively made use of the graphite foam. Section 4 presents the accompanying results of the $R \& D$ and analysis efforts for the aforementioned four areas-reactor design, neutronics, and control; thermal performance; graphite foam characterization; and power conversion system design. Section 5 describes the preconceptual design of the SSR at a macroscopic view on a systems level basis. Section 6 identifies the additional research recommended to further develop this advanced reactor concept. 


\section{DESIGN APPROACH AND OBJECTIVES}

When the original idea of utilizing the graphite foam as a basis for developing an advanced reactor concept was conceived, it was envisioned that a suite of reactor configurations and power levels could be developed for several different applications. The initial focus was looking at the reactor as a heat source that was scalable, independent of any heat removal/power conversion process. These applications included conventional power generation, isotope production and destruction (actinides), and hydrogen production.

Having conducted the initial research on the graphite foam and having performed the scoping parametric analyses from neutronics and thermal-hydraulic perspectives, it was necessary to focus on a particular application that would (1) demonstrate the viability of the overall concept and (2) require a reasonably structured design analysis process that would synthesize those important parameters that influence the concept the most as part of a feasible, working reactor system.

The overall concept of the utilizing the heat transfer characteristics of the graphite foam makes it particularly attractive as a long-term, reliable source of electric power for harsh and/or remote environments - terrestrial or space. Thus, the reference design selected for demonstrating the concept and developing a preconceptual design was a small modular reactor at a design thermal power rating of $500 \mathrm{~kW}$ to supply electric power and was deployable in a harsh and/or remote environment.

Section 2.1 briefly presents the design philosophy employed to guide the design analysis process, while Sect. 2.2 discusses the key design objective that were established.

\subsection{DESIGN APPROACH}

Any design activity involves an iterative process given the relationships and dependencies of any number of the involved parameters. For reactors, the heat generation rate from the fission process and heat removal rates are key to identifying the limiting design criteria for the reactor. The overall integration of important reactor parameters is schematically depicted in Fig. 2.1.

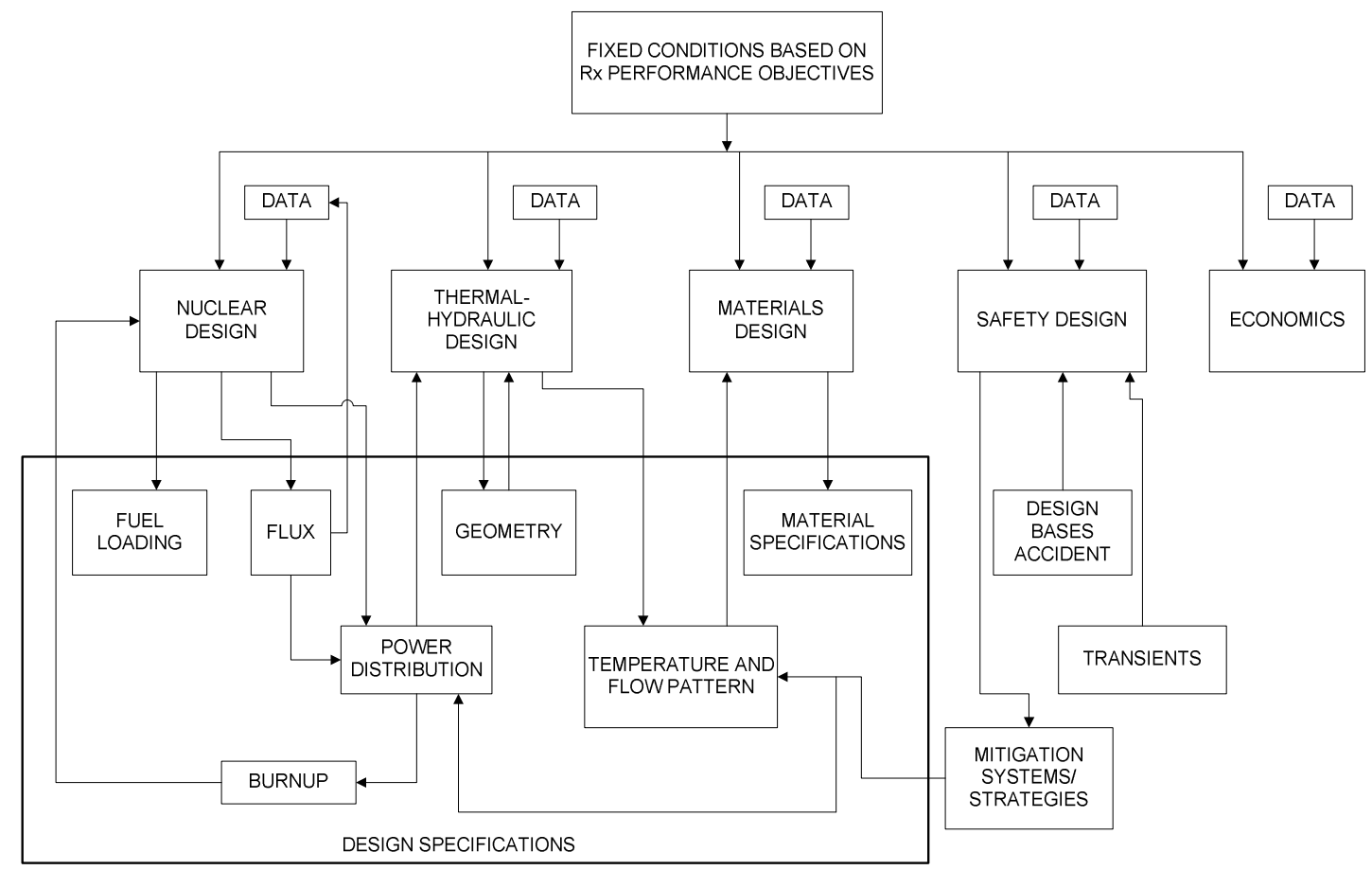

Fig. 2.1. Integration of nuclear design, thermal-hydraulic design, and materials design. Source: Adapted from Nuclear Power Plant Design Analysis, Alexander Sesonshe, TID-26241, 1973. 
Five primary analytical areas are shown in Fig. 2.1, including nuclear design, thermal-hydraulic design, materials design, safety design, and economics. The particular design specifications are included within the "boxed" portion of the figure and are ultimately determined by performing analyses in all of the analytical areas. For this project, no economics analyses were performed. Such analyses should be performed as part of any follow-on research.

\subsection{DESIGN CRITERIA FOR SSR}

The generalized process used to develop the SSR design criteria is presented in Fig. 2.2. The technical approach for this process was to essentially "start at the end." Specific application of this process for the SSR is illustrated by the stepwise approach noted in Fig. 2.2, starting at the right side of the figure with the "End State" of developing a new reactor concept using the new graphite foam working through development of reactor performance objectives and conducting the design syntheses of the five analytical areas noted in Sect. 2.1 and Fig. 2.1, and then identifying needed testing, tools, and data.

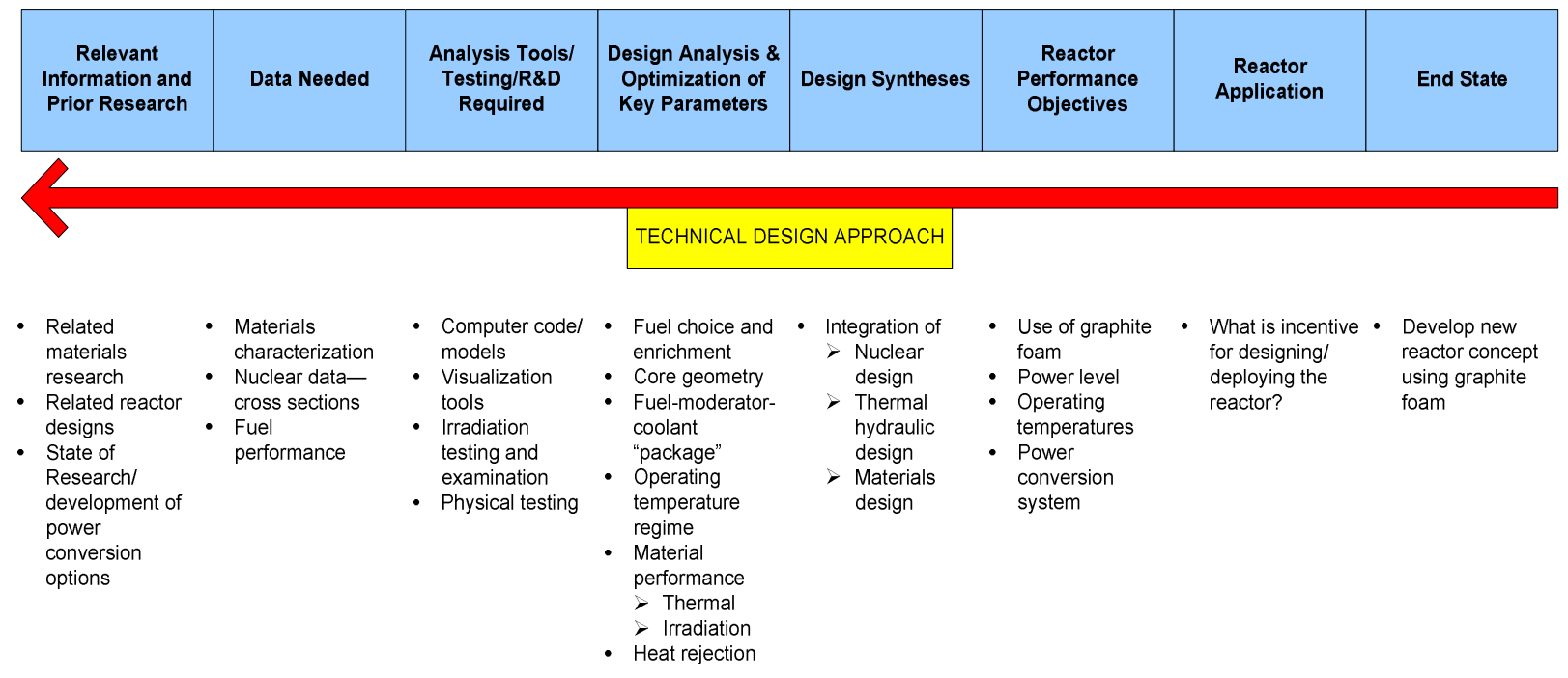

Fig. 2.2. General process used to develop the SSR design criteria. 


\section{TECHNICAL ISSUES TO BE ADDRESSED BASED UPON DESIGN OBJECTIVES}

\subsection{NEUTRONICS/REACTOR CONTROL ISSUES}

Neutronics analyses can be grouped into two categories - design basis and safety related. Achieving one goal of this study-determining if a configuration exists in which the reactor power is self-limiting (negative temperature coefficient) for all anticipated transients-actually fits in both categories. A second goal-maximizing the lifetime of the reactor core (maximize the fuel cycle length) for the design basis power level of $500 \mathrm{~kW}$ - would be classified as determining the design basis.

To accomplish these goals, parametric studies of enrichment, moderator-to-fuel ratio, operating temperature, and fuel density must be conducted. Multiplication factors, critical radii, migration lengths, neutron lifetimes, delayed neutron fraction, and reflector savings must all be calculated. Coefficients of reactivity must be calculated and shown to be negative or acceptably small. Critical masses must be computed. Reactor lifetime must be estimated. Shutdown reactivity requirements must be determined. If the reactor cannot be shown to be self-limiting, then a reactor control system must be designed. Adequate shielding must be provided not only for the operating condition but also for disassembly and removal of the reactor from the site at which it has been deployed.

Because the reactor is intended to be deployable, the size and mass of the system must be kept to a minimum and must be consistent with currently available cargo capacity of planes, ships, or trucks. The requirement that the system be transportable introduces various potential accident scenarios for which the reactor must be shown to be safe. Parametric studies must be performed to bound these conditions and show that the system is controllable in all anticipated conditions.

\subsection{GRAPHITE FOAM PERFORMANCE}

The graphite foam's performance is central to this design concept. Characterizing the foam both in terms of structural and physical properties is required. Examining the effects on structure, dimensional stability, thermal conductivity, thermal expansion, and strength under irradiation is equally important.

Samples of the graphite foam were irradiated in ORNL's HFIR to evaluate irradiation-induced structural and dimensional changes in the foam to

- develop a microstructural model of the graphite foam,

- examine the displacement damage in the graphite,

- examine the irradiation-induced volume changes in the graphite foam, and

- investigate the dimensional changes on the foam structure itself.

In understanding the irradiation-induced changes in thermal properties, it was necessary to

- compare thermal properties (thermal conductivity) of preirradiated graphite foam with that of nucleargrade graphite,

- determine the thermal properties of the irradiated graphite, and

- compare the thermal properties of commercially available graphite foam with those of the experimentally produced foam to understand effects from manufacturing processes.

\subsection{GRAPHITE AND FUEL}

Many issues are to be addressed regarding the graphite foam and fuel in the reactor. First, it has been determined that the maximum uranium loading in the foam would only fill $80 \%$ of the initially void space. 
Because the reactor core will be highly undermoderated (to achieve a high conversion ratio), the possible ingress of any moderation into the core must be considered as a part of the prototypic design process.

The high-thermal conductivity graphite foam matrix reactor approach requires a source of uranium that is compatible with the graphite foam at the processing and operating temperatures of the reactor. It also requires a particular ratio of carbon to ${ }^{235} \mathrm{U}$ for nucleonics purposes. These will be discussed in later sections.

In addition, the method of filling the foam with the fuel itself will need to be addressed. Many methods of filling the foam with fuel were examined. These range from the ability to impregnate the foams with gelcasting, sol-gel, and chemical vapor infiltration (CVI). For example, initially, it was assumed that miniature fuel kernels could be infiltrated into the foam with a sol-gel or gel-casting technique. This was simulated with submillimeter stainless steel beads as shown in Fig. 3.1. Unfortunately, it was shown that this process yielded a nonuniform filling of the foam, which was unacceptable. Further work showed that this process would be very difficult on pieces more than 1 in. thick, thereby ruling out this method for impregnation of the foam. Other methods such as CVI, reaction conversion, and melt impregnation have been explored and seem to be the most promising. However, these techniques have not been proven and need further study to optimize the process to attain the desired fuel loading.

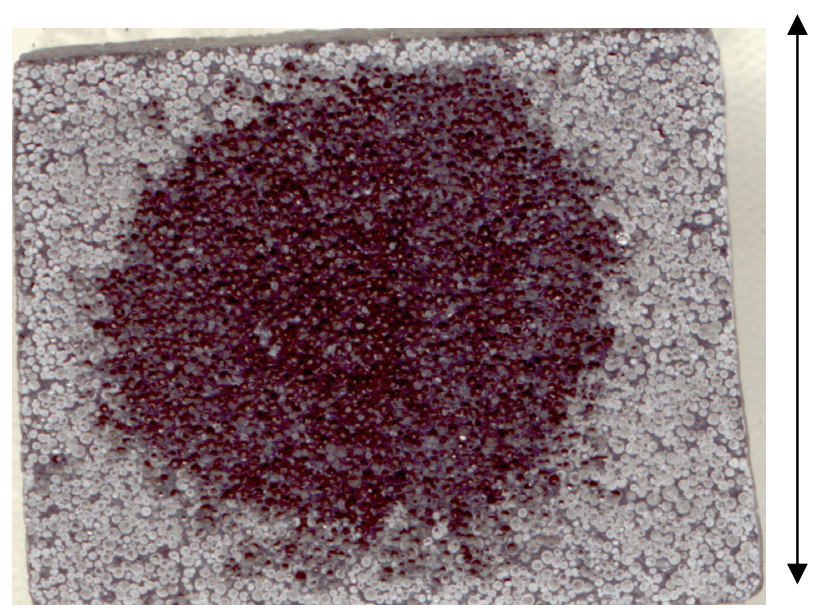

$1 \mathrm{in.}$

Fig. 3.1(a). Gel-cast stainless steel powder impregnated into carbon foam.

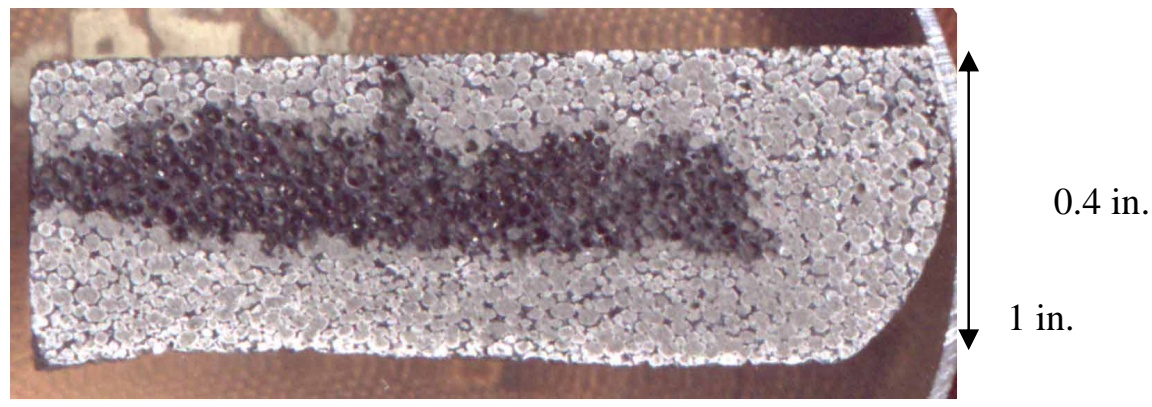

Fig. 3.1(b). Gel-cast stainless steel powder impregnated into carbon foam.

\subsection{MATERIALS-OPERATIONAL LIMITS}

The core consists of graphitized carbon foam with $20 \%$ enriched uranium fuel deposited onto the internal surfaces of the foam's pores. This results in a very short heat flow path from the fuel to the 
graphitized foam. Consequently, the temperature of the fuel will be close to that of the graphitized foam. Because graphite maintains its structural strength above $3000 \mathrm{~K}$ [with melting point (MP) above $3900 \mathrm{~K}$ ] and carbide materials exhibit high MP temperatures with high-thermal conductivity, operating temperatures as high as $2200 \mathrm{~K}$ could be considered acceptable for the SSR. Uranium reacts with carbon to form $\mathrm{UC}_{2}$ and $\mathrm{U}_{2} \mathrm{C}_{3}$ that are stable to temperatures in the $2200 \mathrm{~K}$ range.

Graphitized carbon foam exposed to air starts to oxidize above $600 \mathrm{~K}$. The surfaces with potential exposure to air need to be protected or maintained at temperature below $600 \mathrm{~K}$.

Although it is expected that the fuel deposited in the foam's pores will plug the interconnecting passages effectively sealing the pores, cladding will be used to enhance the isolation between the core's internal and external environments at all times. A thin clad made of a high-temperature metal will seal all of the core boundary surfaces, top and bottom circles, outer cylinder, and pass-through holes, if present. This will prevent surface exposure and ingress of external elements such as air, water, helium, and xenon gases. It will also prevent the release of internally generated fission products. Appendix A contains tables of MPs of ultra high-temperature materials. Some will undoubtedly be good cladding/containment candidates. $\mathrm{ZrC}$ (with MP of $3800 \mathrm{~K}$ ) and rhenium alloys seem best for the present design.

Rhenium is a high-temperature material with properties well suited for coating graphite foam. Rhenium has high strength at high temperatures - above $3300 \mathrm{~K}$ - high toughness and wear resistance, high ductilitym, and high-impact resistance. In addition, rhenium is insensitive to embrittlement; is stable in $\mathrm{H}_{2}, \mathrm{~N}_{2}$, and $\mathrm{H}_{2} \mathrm{O}$ environments; and has a low $\mathrm{H}_{2}$ diffusion rate.

Electron-beam physical vapor deposition (EB-PVD) of rhenium on graphite has been demonstrated at The Pennsylvania State University. ${ }^{1}$ With EB-PVD technology, two or more materials can be co-evaporated or deposited in layers to form functionally tailored coatings with improved properties and performance. Because rhenium is compatible not only with carbon but with platinum, palladium, rhodium, ruthenium, osmium, and iridium, it follows that EB-PVD technology can produce coatings with improved rhenium properties. For instance, deposition by electron-beam co-evaporation of rhenium with iridium will most likely provide high-temperature oxidation resistance. (Note that, presently, high-temperature, $2500 \mathrm{~K}$, oxidation resistance is commercially achieved by vapor deposition of 50 - to $250-\mu \mathrm{m}$-thick iridium films on rhenium. $^{2}$

The Munich fission fragment accelerator ${ }^{3}$ uses uranium carbide distributed homogeneously in a porous graphite matrix surrounded by a rhenium container. During operation, the target is maintained at temperatures above $2273 \mathrm{~K}$. The rhenium container provides mechanical support, prevents the uranium and fission fragments from escaping through the periphery of the graphite matrix, and prevents excessive sublimation of graphite. The target of the PIAFE project in Grenoble's Laue-Langevin Institute (ILL) reactor is of similar construction. ${ }^{4}$

Although the main application focus of this project has been for a reactor with 500-kW thermal output and cooling at $945 \mathrm{~K}$ at the core/reflector boundary, we are confident that designs tailored to processes requiring much higher output temperatures are feasible. High temperatures can be achieved when the peak-to-average ratios are minimized as is the case when the heat is extracted uniformly across the core volume by means of pass-through channels. These channels could be sealed with a thin layer of high-temperature material such as a rhenium/iridium composite.

\subsection{POWER CONVERSION CYCLE ISSUES}

\subsubsection{Introduction}

Passive or active power conversion devices can be used to convert the heat generated by the nuclear core into electricity. Passive systems, such as thermoelectric or thermophotovoltaic, are solid state and have no moving components. The lack of moving components can lead to high reliability, but these devices presently have thermal power conversion efficiencies less than $10 \% .^{5}$ Active systems convert thermal power first into shaft power and then into electrical power. Active systems typically have thermal 
efficiencies greater than $25 \%$ and possibly much higher if heat is added at a high temperature and rejected at a low temperature. Active systems are being considered for space power, ${ }^{6}$ where reliable operation during a decade of full power is a mission requirement.

These active systems are usually based on thermodynamic cycles, such as Rankine, Stirling, or Brayton. The relative merits of these thermodynamic cycles and others are described by Theiss et al. ${ }^{5}$ Mason ${ }^{6}$ presents the relative weights of these cycles as a function of electrical power level. Although the application considered by Mason ${ }^{6}$ was deep space electrical power production where a relatively high heat rejection temperature is necessary, the objective of maximizing the electrical output per unit mass is very appropriate for this power conversion system design. For these cycles, most of the components (rotating machinery, heat exchangers, etc.) will not be much different between the terrestrial and deep space applications, except for the ultimate heat sink. The heat sink design for a deep space application would be a flat-plate radiator operating at a relatively high temperature $(\sim 900 \mathrm{~K})$, and the design for a terrestrial application heat sink would be a gas-to-gas heat exchanger operating at a much lower operating temperature $(\sim 300 \mathrm{~K})$. Because the terrestrial heat rejection heat exchanger would probably weigh less than a deep space radiator, Mason's conclusion would likely be valid for a terrestrial thermal power conversion system. Thus, for the electrical power range of interest here [ 100 kW(e)], a closed Brayton cycle is chosen for thermal to electrical power generation.

The design of a thermal power conversion system will have two subcomponents- the heat removal method from the nuclear core, and the closed Brayton cycle machinery design. The work performed and reported here was focused on achieving a maximal overall cycle thermodynamic efficiency.

To keep the core heat transfer design straightforward, simple fins made of stainless steel were placed around the active nuclear core. The actual fin length, width, and pitch (i.e., distance between fins) will be optimized for maximal heat transfer at a minimal parasitic pressure drop. The best location of the cooling fins is between the core and the reflector due to a carbon/clad interface material compatibility concern. These fin parameters will affect the neutron leakage out the ends and the core temperature profile. The fin parameters will also affect the performance of the closed Brayton power conversion cycle because the parasitic pressure drop through the finned section will penalize the cycle efficiency.

To design a closed Brayton cycle and calculate an overall system thermal efficiency, certain cycle performance parameters must be specified. As might be expected, trade-offs result. The first is the choice of working fluid. Helium is both chemically inert and transparent to neutrons; thus helium would be a likely candidate. Also, because the thermal conductivity of helium is relatively high, smaller heat exchangers would thus result. The high specific heat of helium, however, might result in more complicated turbomachinery because the enthalpy change for any given stage must be limited, which limits the temperature change, which in turn limits the pressure change across any given stage. This more complicated turbomachinery does present a challenge using helium, and another inert gas or mixture of inert gases should be investigated, albeit these other inert gases result in larger heat exchangers. The closed Brayton cycle turbomachinery components currently being considered by the National Aeronautics and Space Administration (NASA) for deep space power electrical generation applications in the power range of interest here use a mixture of helium and xenon with a molecular weight of 40 (HeXe40).

The next parameters of importance are the compressor inlet temperature and the turbine inlet temperature. The compressor inlet temperature is dependent on the ultimate heat sink for the rejected heat from the cycle. A compressor inlet temperature of $310 \mathrm{~K}$ is chosen for now. This temperature can readily be achieved if water or forced convection air is chosen as the heat sink. For this closed Brayton cycle, the ultimate heat sink heat exchanger is called the precooler. If a natural convection system using air is used as the ultimate heat sink, the compressor inlet temperature will be a function of the chimney height and air inlet temperature, among other parameters. Thus, a natural convection precooler design is dependent on plant layout and will not be considered here. Because moisture ingress to the active core region will insert positive reactivity, a water precooler will also not be considered here, Thus, only a forced convection air precooler will be designed. Because a material compatibility concern between the carbon foam and stainless steel limits the interface temperature, the turbine inlet temperature is limited to $900 \mathrm{~K}$. If the 
materials compatibility issue can be overcome in some fashion and this $900 \mathrm{~K}$ limitation for helium turbine inlet temperature can be increased, the resulting thermodynamic cycle efficiency will be improved.

The next parameters chosen for the Brayton cycle components of this concept are the allowable pressure drops. The allowable fractional pressure drops are parasitic to the power output and are thus directly taxed to the gross turbine output. The NASA designs for deep space applications use a 5\% total pressure drop $(\Delta \mathrm{P} / \mathrm{P})$ for all the cycle components, and this number will be used here. The allocations for the individual components are somewhat arbitrary, so a $1 \% \Delta \mathrm{P} / \mathrm{P}$ is chosen for the core, $3 \%$ for the recuperator, and $1 \%$ for the precooler. This allowable system pressure drop is somewhat optimistic but reasonably achievable in hardware.

The recuperator is an important component in the closed Brayton cycle because it takes heat from the turbine exit at low pressure and adds it to the high-pressure flow between the compressor and the core. This component allows the core to add a lesser amount of heat to the flow at a higher temperature and thus increase overall thermal efficiency. The recuperator parameter of interest is the effectiveness, which is a measure of the actual heat transferred to the maximum possible heat that could be transferred. A low value of effectiveness will decrease cycle thermal efficiency but have a small physical size. A high value of effectiveness will increase cycle efficiency at the expense of a larger physical size. An appropriate value balancing the cycle efficiency and the physical size is $95 \%$.

The final parameters chosen for the cycle design are the polytropic stage efficiencies of the turbine and compressor. Also somewhat optimistic but reasonably achievable, values for actual turbomachinery efficiencies are $85 \%$ for the compressor and $90 \%$ for the turbine.

\section{REFERENCES}

1. J. Singh and D. E. Wolfe, "Net-Shape Rhenium Fabrication by EB-PVD," Advanced Materials \& Processes AM\&P, 160(4), April 2002.

2. http://www.ultramet.com/rhenium.htm.

3. "High Temperature Furnace for Fission Target Investigation," http://www.bl.physik.unimuenchen.de/bl_rep/jb1997/p100.ps.

4. J. A. Lettry, "Exotic Ion-Beams, Targets and Sources," CERN, Geneva, Switzerland, http://arxiv.org/PS_cache/physics/pdf/0009/0009036.pdf.

5. T. J. Theiss et al., Comparison of Prime Suitable for USMC Expeditionary Power Sources, ORNL/TM-2000/116, 2000.

6. L. S. Mason, "Power Technology Options for Nuclear Electric Propulsion," Proceedings of the 2002 IECEC, Paper 20159, 2002. 


\section{RESEARCH RESULTS}

\subsection{REACTOR PHYSICS DESIGN STUDIES}

Several computational methods were used to conduct parametric design studies for the SSR. These included the SCALE ${ }^{1}$ system, with multiplication factors and critical dimensions computed with the onedimensional (1-D), discrete ordinates program, XSDRNPM or the Monte Carlo programs, KENO-Va and KENO-VI (all three a part of the SCALE system). Reactivity coefficients, shutdown rod worths, and few group cross sections for heat transfer calculations were computed with HELIOS ${ }^{2,3}$ (version 1.6), a twodimensional (2-D), collision probability theory-based program. The MCNP4 Monte Carlo program was coupled to a thermal analysis program documented in Sect. 4.3. The SCALE calculations were performed with either 44 or 238 group cross-sections libraries with data derived from ENDF/B-V. ${ }^{5}$ HELIOS and MCNP calculations were performed with libraries based on ENDF/B-VI. ${ }^{6}$

\subsubsection{Review of Results Presented in FY 2000 and FY 2001 Reports}

Extensive physics studies were conducted by F. C. Difilippo during the first 2 years of this project. These are documented in previous quarterly reports 7,8 and in a paper presented to the American Nuclear Society. ${ }^{9}$ A summary of the design studies is presented in Table 4.1. All of the core configurations in Table 4.1 were right circular cylinders. All calculations were performed with the HELIOS computer program.

Table 4.1 reveals that for small values of $\mathrm{C} /{ }^{235} \mathrm{U}$, it is possible to build small reactor cores (relative to commercial power reactors) with essentially zero reactivity swings (conversion ratio of 1.0 or nearly so). It was found that the presence of a graphite reflector significantly reduced critical mass, but that the reflector size (thickness) must be limited. A large reflector would significantly moderate neutrons at the outer edge of the reactor core, reducing the ETA value of the fuel (number of neutrons emitted per neutron absorbed in the fuel) and, consequently, leading to a requirement of low enrichment and unrealistically high values for uranium density. A small reflector $(15$ to $30 \mathrm{~cm})$ was shown to affect criticality rather than burnup (i.e., its purpose being to reflect neutrons to the core with only minimal degradation in neutron energy, thereby maintaining a high conversion ratio. The data in Table 4.1 show that it is possible to build cores with zero reactivity swing using values of $\mathrm{C} / 235 \mathrm{U}$ between 20 and 50.9

Temperature coefficients were calculated for these designs and shown to be negative. Thermal transients were simulated, and the response of the system was shown to be faster than other gas-cooled reactor concepts based on normal graphite. Doppler coefficients were shown to be negative over the entire range of exposure from fresh fuel to a burnup of $40 \mathrm{GWd} / \mathrm{MT}$ and over the temperature range of 300 to 1200 K. Small reactivity transients $(20 \%$ cent insertion of reactivity; boundary temperature change of $100 \mathrm{~K}$ ) were simulated and rapidly damped oscillations observed.

\subsubsection{Limitations Due to Fuel Fabrication Procedures}

Studies described in the previous section had been based on the assumption that the voids in the graphite foam could be filled with uranium metal. Materials investigations conducted showed that such a production process was not feasible. Previous works at ORNL studied possible methods of impregnating foam with uranium and are discussed below.

The source of uranium for the SSR must be compatible with the graphite foam at the processing and operating temperatures of the reactor. Table 4.2 shows the $\mathrm{C} / \mathrm{U}$ ratios that are obtainable using several different approaches to incorporating uranium in the graphite foam. For stoichiometric $\mathrm{UC}_{2}$ and $\mathrm{U}_{2} \mathrm{C}_{3}$, the only uranium carbides that are stable in contact with graphite at $1500^{\circ} \mathrm{C}$, the $\mathrm{C} / 235 \mathrm{U}$ ratios range from a low of $7.5\left(\mathrm{U}_{2} \mathrm{C}_{3} @ 20 \%\right.$ enrichment) to a high of 16.7 ( $\mathrm{UC}_{2} @ 12 \%$ enrichment). The lowest $\mathrm{C} / \mathrm{U}$ ratios 
Table 4.1. Design parameters for near-zero burnup reactivity swing*

\begin{tabular}{|c|c|c|c|c|c|c|c|c|c|c|}
\hline Case & $\mathrm{C}^{2} / 235 \mathrm{U}$ & $\begin{array}{c}\text { Enrichmen } \\
\text { (at. \%) }\end{array}$ & \multicolumn{2}{|c|}{$\begin{array}{c}\text { Uranium } \\
\text { density } \\
\left(\mathrm{g} / \mathrm{cm}^{3}\right)\end{array}$} & \multicolumn{2}{|c|}{$\begin{array}{l}\text { Reflector } \\
\text { thickness } \\
\qquad(\mathrm{cm})^{a}\end{array}$} & $\begin{array}{c}\left\langle\mathbf{E}_{\mathbf{c}}\right\rangle \\
(\mathbf{k e V})^{b}\end{array}$ & $\begin{array}{c}\left\langle\mathbf{E}_{\mathbf{r}}\right\rangle \\
(\mathbf{k e V})^{b}\end{array}$ & $\begin{array}{c}k_{\text {eff at }} \\
0 \mathrm{GWd} / \mathrm{t}\end{array}$ & $\begin{array}{c}k_{\text {eff }} \text { at } \\
40 \mathrm{GWd} / \mathrm{t}\end{array}$ \\
\hline 1 & 5 & 11.0 & \multicolumn{2}{|c|}{$18.0^{c}$} & \multicolumn{2}{|c|}{20} & 107 & 1.04 & .994 & 0.989 \\
\hline 2 & 5 & 13.9 & \multicolumn{2}{|c|}{14.24} & \multicolumn{2}{|c|}{5} & 241 & 140 & 0.999 & 0.985 \\
\hline 3 & 7 & 9.0 & \multicolumn{2}{|c|}{15.7} & \multicolumn{2}{|c|}{35} & 68.2 & 0.185 & 0.999 & 1.004 \\
\hline 4 & 7 & 9.9 & \multicolumn{2}{|c|}{14.3} & \multicolumn{2}{|c|}{25} & 89.7 & 0.571 & 1.004 & 1.012 \\
\hline 5 & 10 & 9.0 & \multicolumn{2}{|c|}{11.0} & \multicolumn{2}{|c|}{35} & 64.0 & 0.193 & 1.009 & 1.011 \\
\hline 6 & 20 & 9.0 & \multicolumn{2}{|c|}{5.5} & \multicolumn{2}{|c|}{30} & 58.0 & 0.300 & 1.005 & 1.006 \\
\hline 7 & 50 & 8.4 & \multicolumn{2}{|c|}{2.36} & \multicolumn{2}{|c|}{20} & 55.3 & 2.13 & 1.002 & 0.999 \\
\hline 8 & 50 & 8.4 & \multicolumn{2}{|c|}{2.36} & & ) & 60.2 & - & 0.992 & 0.991 \\
\hline Case & $\begin{array}{c}\text { Core } \\
\text { volume } \\
\left(\mathbf{m}^{3}\right)\end{array}$ & $\begin{array}{c}\text { Reactor } \\
\text { volume } \\
\left(\mathbf{m}^{3}\right)\end{array}$ & $\begin{array}{l}\text { Mass of } \\
\text { uranium } \\
\text { (t) }\end{array}$ & & \multicolumn{3}{|c|}{$\begin{array}{l}\text { Density } \\
\text { fission } \\
\text { gases per } \\
\text { unit energy } \\
\text { (g/L GWd) }\end{array}$} & $\begin{array}{l}\text { Damage in } \\
\text { foam per } \\
\text { unit energy } \\
(\mathrm{dpa} / \mathrm{GWd})^{d}\end{array}$ & $\begin{array}{c}\text { Energy } \\
\text { produced } \\
\text { at } \\
\mathbf{4 0} \mathbf{G W d} / \mathbf{t} \\
(\mathbf{G W d})^{\boldsymbol{e}}\end{array}$ & $\begin{array}{c}\text { Core } \\
\text { diameter } \\
(\mathbf{m})\end{array}$ \\
\hline 1 & 0.101 & 0.584 & 1.827 & & .72 & 1.28 & & 1.77 & 73 & 0.518 \\
\hline 2 & 0.140 & 0.229 & 1.996 & & .22 & 0.92 & & 1.62 & 80 & 0.578 \\
\hline 3 & 0.219 & 1.947 & 3.438 & & 55 & 0.5 & & 0.971 & 138 & 0.671 \\
\hline 4 & 0.217 & 1.200 & 3.104 & & 92 & 0.55 & & 1.06 & 124 & 0.669 \\
\hline 5 & 0.455 & 2.834 & 5.003 & & 37 & 0.28 & & 0.623 & 201 & 0.856 \\
\hline 6 & 2.848 & 7.662 & 15.670 & & .47 & 0.04 & & 0.199 & 628 & 1.577 \\
\hline 7 & 141.260 & 173.501 & 333.172 & & 90 & 0.00 & & 0.00618 & 13.323 & 5.796 \\
\hline 8 & 209.857 & 209.857 & 494.961 & & 89 & 0.00 & & 0.00428 & 19.791 & 6.582 \\
\hline
\end{tabular}

*Constant carbon density corresponding to the graphite foam, $0.5 \mathrm{~g} / \mathrm{cm}^{3}$.

${ }^{a}$ Graphite density 1.74 .

$b_{\text {Average neutron energy in core and reflector. }}$

${ }^{c}$ Note that for this uranium density, it is not possible to have a carbon density of 0.5 .

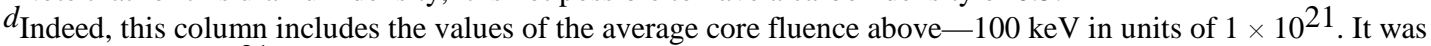
assumed then that $1 \times 10^{21}$ fluence produces $1 \mathrm{dpa}$ in the foam.

${ }^{e}$ A pure neutronics results without consideration any material degradation.

Table 4.2. $\mathrm{C} / \mathrm{U}$ ratios for graphite foams with various uranium compounds filling the void space in the foam

\begin{tabular}{|c|c|c|c|}
\hline Filler material & $\begin{array}{c}\mathrm{C} / \mathrm{U} \\
(\text { atom/atom) }\end{array}$ & $\begin{array}{c}\mathrm{C} / \mathbf{2 3 5}^{\mathrm{U}} @ \\
12 \% \text { enriched } \\
\text { (atom/atom) }\end{array}$ & $\begin{array}{c}\mathrm{C} / 235 \mathrm{U} @ \\
20 \% \text { enriched } \\
\text { (atom/atom) }\end{array}$ \\
\hline Pure $\mathrm{UC}_{2}$ (no graphite) & 2 to 1 & 16.7 & 10 \\
\hline Pure $\mathbf{U}_{2} \mathbf{C}_{3}$ (no graphite) & 1.5 to 1 & 12.5 & 7.5 \\
\hline $\begin{array}{l}\text { Uranium metal (pure, completely } \\
\text { filling pore space) }\end{array}$ & 0.781 to 1 & 6.5 & 3.9 \\
\hline $\begin{array}{l}\mathrm{UC}_{2} \text { (pure, completely filling pore } \\
\text { space) }\end{array}$ & 3.27 to 1 & 27.25 & 16.35 \\
\hline $\begin{array}{l}\mathrm{UC}_{2} \text { (derived from } \mathrm{UO}_{2} \text { and carbor } \\
\text { powders-60\% filling of pore } \\
\text { space by } \mathrm{UO}_{2} / \text { carbon precursor) }\end{array}$ & 6.58 to 1 & 54.8 & 32.9 \\
\hline
\end{tabular}


were achieved assuming that all of the pore space in the foam could be filled with uranium metal (3.9 for $20 \%$ enrichment), presumably incorporated by infiltrating the foam with liquid uranium. The highest ratios were observed for $\mathrm{UC}_{2}$, assumed to be derived from the carbothermal reduction of $\mathrm{UO}_{2}$ (32.9 for $20 \%$ enrichment, 54.8 for $12 \%$ enrichment).

Unfortunately, molten uranium is highly aggressive toward graphite. In research conducted for the AVLIS program (http://www.nrc.gov/reading-rm/doc-collections/cfr/part110/part110-appg.html), ${ }^{3}$ researchers demonstrated that the only materials that were resistant to molten uranium were tantalum and graphite coated with yttrium oxide or other rare-earth oxides. Neither of these materials is a good candidate for coating the interior walls of the graphite foam. Therefore, any process that depends on using molten uranium in contact with the foam is not likely to be successful. Infiltrating the foam with uranium would simply result in converting the graphite in the foam to $\mathrm{UC}_{2}$, which would defeat the reason for using the foam to begin with (i.e., its high-thermal conductivity).

The use of $\mathrm{UC}_{2}$ or $\mathrm{U}_{2} \mathrm{C}_{3}$ as the source of uranium seems the most likely route. There are several approaches one might take to produce a graphite foam containing one or the other of these materials. One could simply infiltrate the foam with a fluid suspension of particles in a solvent. Typically, one can achieve upwards of 50 to $60 \mathrm{vol} \%$ solids in a suspension and still have it be flowable. Assuming the lower number, $50 \mathrm{vol} \%$, one could incorporate $37.5 \mathrm{vol} \% \mathrm{U}_{2} \mathrm{C}_{3}$ or $\mathrm{UC}_{2}$ in the foam. One real problem with this approach is that fine-particle-size uranium carbides are pyrophoric, and, therefore, safe production processes are difficult to achieve.

$\mathrm{UC}_{2}$ has a melting point of 2720-2770 K, significantly higher than the decomposition temperature of $\mathrm{U}_{2} \mathrm{C}_{3}-2045 \mathrm{~K}$. Furthermore, thermal properties of $\mathrm{UC}_{2}$ are much better known that those of $\mathrm{U}_{2} \mathrm{C}_{3}$.

The reference approach for the SSR project is to infiltrate the foam in the vapor state using CVI. Using that approach, one might achieve as much as $75 \%$ filling of the pore space before the surface sealed off. This would allow one to incorporate about $56 \mathrm{vol} \%$ carbide into the foam. Another route to incorporating uranium as uranium carbide is the carbothermal reduction of uranium oxide by carbon. This will result in at most about $30 \mathrm{vol} \% \mathrm{UC}_{2}$ in the foam.

The reference fuel for the SSR was assumed to have a volume-averaged carbon density of $0.55 \mathrm{~g} / \mathrm{cm}^{3}$ ( $25 \%$ of a unit volume of fuel is filled with graphite from the foam). The fraction of a unit volume that is available for fuel is $75 \%$. Of that volume, $60 \%$ can be filled with $\mathrm{UC}_{2}$. These characteristics yield a $\mathrm{C} / \mathrm{U}$ ratio of 7.86 . The average core density is $2.595 \mathrm{~g} / \mathrm{cm}^{3}$. The average uranium density is $1.857 \mathrm{~g} / \mathrm{cm}^{3}$. The average carbon density (including both the carbon in the graphite foam and the carbon associated with the uranium) is $0.738 \mathrm{~g} / \mathrm{cm}^{3}$.

\subsubsection{Selection of Moderator-to-Fuel Ratio and Uranium Enrichment}

The maximum possible uranium density (the reference fuel noted previously) was found to be less than the densities assumed in Sect. 4.1.1. To achieve a $\mathrm{C} / 235 \mathrm{U}$ ratio of 50 , an enrichment of $11 \%$ would be required rather than the value of 8.4 reported in Table 4.1. To achieve a $\mathrm{C} / 235 \mathrm{U}$ ratio of 20 , an enrichment of $27 \%$ would be required rather than the value of 9.0 reported in Table 4.1. Note that Table 4.1 shows that the mass of uranium required for a $\mathrm{C} / 235 \mathrm{U}$ ratio of 50 is 21 times greater than the amount required at a $\mathrm{C} /{ }^{235} \mathrm{U}$ ratio of 20 . An economic assessment of the cost of these two fuels revealed that the cost of fuel for the lower $\mathrm{C} / 235 \mathrm{U}$ ratio was more than a factor of 10 less than that for the higher ratio. Furthermore, the significant increase in core mass and thus an increase in transportation costs for moving the reactor from the production to deployment site seemed to make it apparent that the $\mathrm{C} / 235 \mathrm{U}$ ratio should be kept to the minimum possible value. Because it is the policy of the United States that fuel for reactors deployed outside the borders of the United States have an enrichment no greater than $20 \mathrm{wt} \%{ }^{235} \mathrm{U}$, the value of $20 \%$ enrichment at the reference fuel uranium density would provide the lowest possible $\mathrm{C} / 235 \mathrm{U}$ ratio. The assumption of $20 \%$ enriched uranium leads to a $\mathrm{C} / 235 \mathrm{U}$ ratio of 39.28 (based on an assumed density for $\mathrm{UC}_{2}$ of $\left.13.63 \mathrm{~g} / \mathrm{cm}^{3}\right)$. 


\subsubsection{Reflector Savings and Choice of Reflector}

Cases 7 (with) and 8 (without) in Table 4.1 show that the use of a reflector provides for a significant reduction in critical mass with consequent economic savings. Following the establishment of the reference fuel composition (Sects. 4.1.3 and 4.1.4), another study, similar to that reported in Table 4.1, was conducted to determine the optimal reflector thickness for the reference fuel.

A series of calculations were performed with the XSDRNPM module of the SCALE system to determine the variation of critical mass as a function of reflector thickness. The objective of the study was to minimize reactor volume and mass - reactor being defined as both the fueled region (core) and the reflector. A spherical, two region model was prepared [core region with near reference fuel $\left(C /{ }^{235} \mathrm{U}=33\right.$, $20 \%$ enriched uranium) and reflector region composed of graphite], and critical radius searches for selected reflector thicknesses were performed. The results of the study are shown in Figs. 4.1 and 4.2.

Figure 4.1 shows that while critical mass monotonically decreases with reflector thickness, reactor volume is minimized at a reflector thickness of $30 \mathrm{~cm}$. Because the core region has a density similar to the density of graphite $\left(2.595 \mathrm{~g} / \mathrm{cm}^{3}\right.$ for the fueled core vs $2.2 \mathrm{~g} / \mathrm{cm}^{3}$ for graphite), it is not surprising that the minimum in reactor mass also occurs at nearly the same reflector thickness as the minimum in reflector volume.

Though these studies were an obvious extension of the work presented in Sect. 4.1.1, shield studies, described subsequently in this report, led to the consideration of reflectors other than graphite. As noted previously, the purpose of the reflector for the SSR is to return neutrons to the core with little thermalization of the neutron flux. Once shielding considerations were examined, it was realized that a "high-Z" (i.e., higher atomic number) reflector might be desirable.

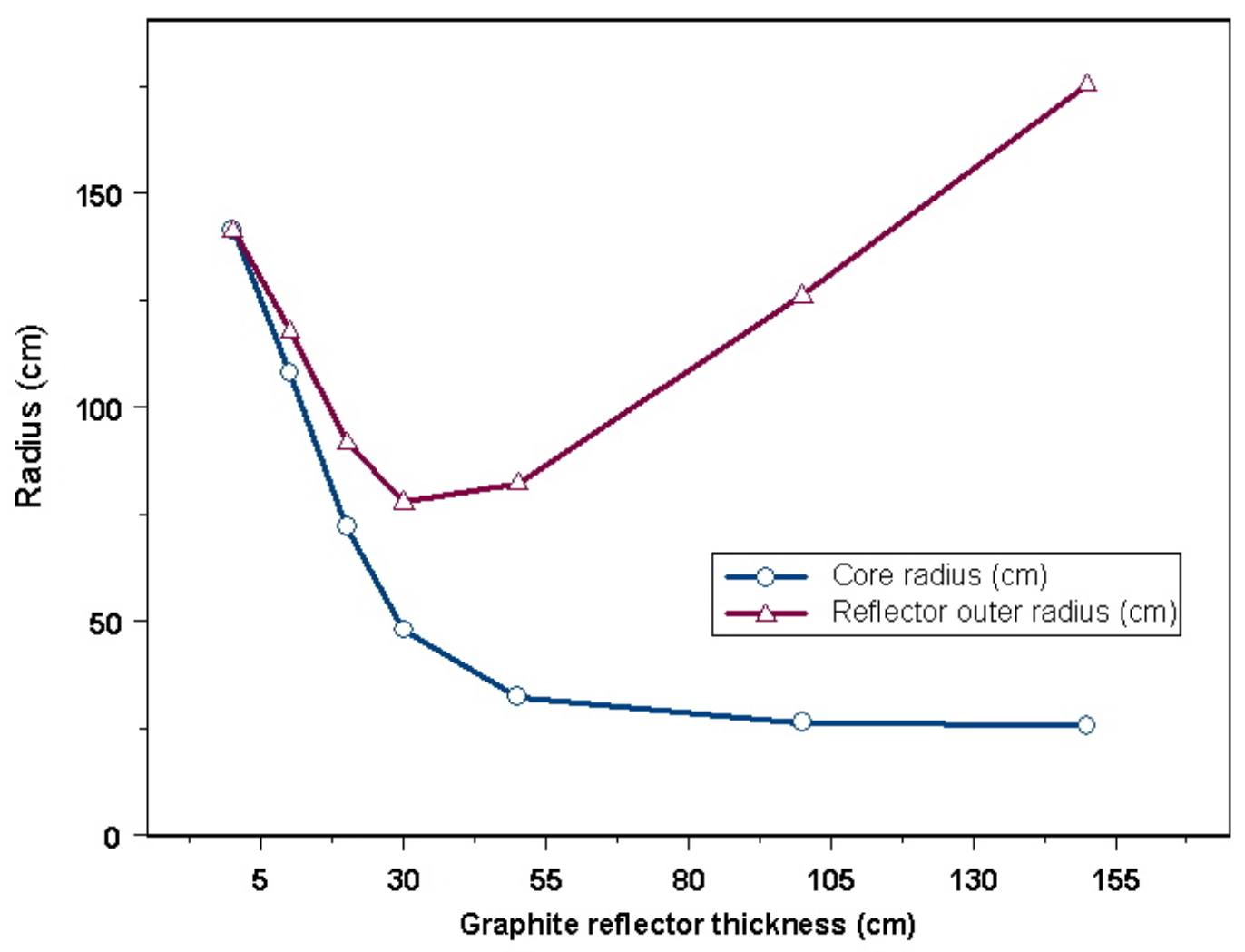

Fig. 4.1. Impact of reflector thickness on reactor volume. 


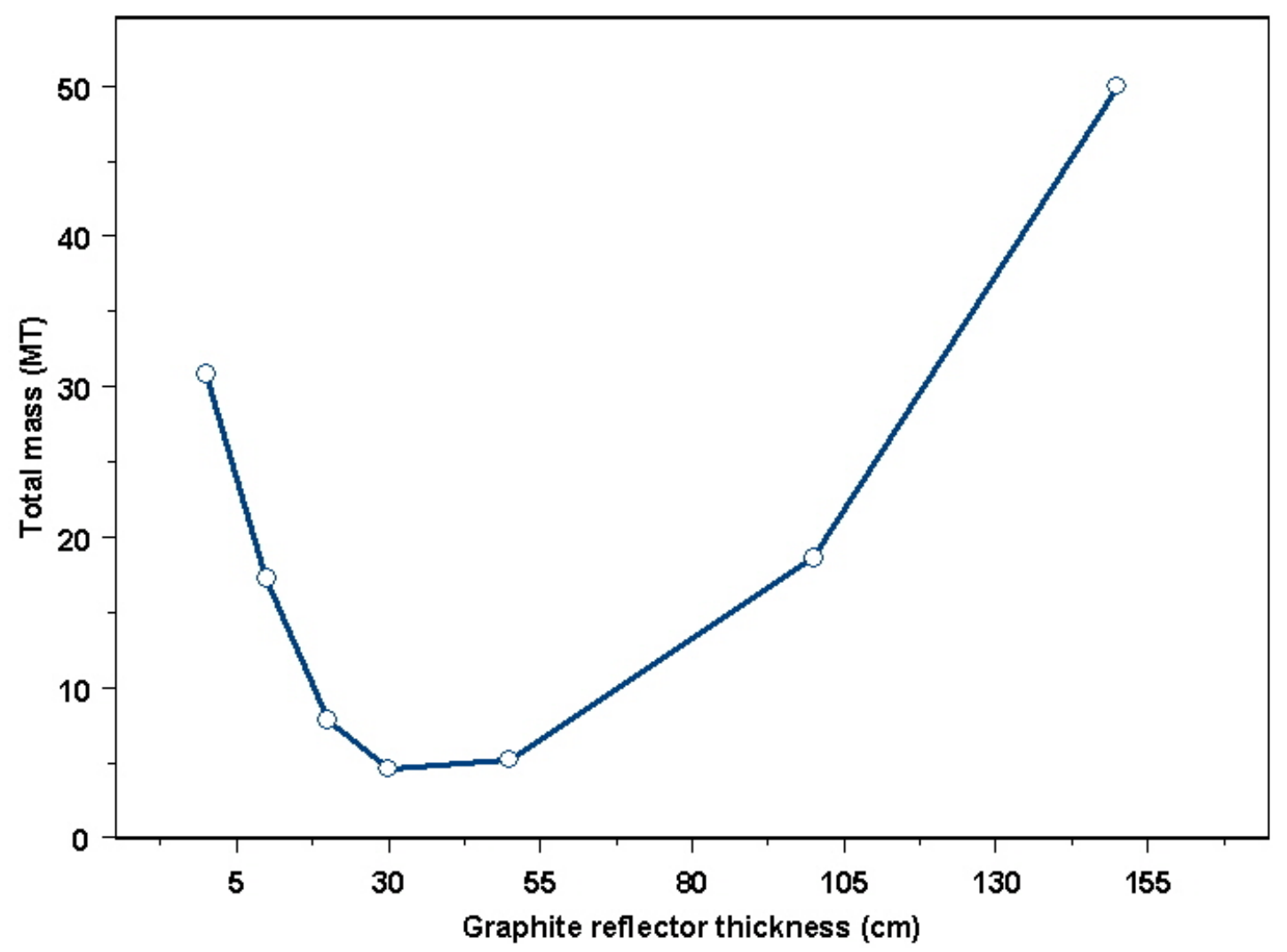

Fig. 4.2. Reactor mass for various critical configurations.

For certain liquid-metal fast reactor designs, where an objective is to minimize thermalization of neutrons, steel reflectors are employed. Steels such as stainless steel 304 are well characterized for reactor applications and are relatively inexpensive as compared to other structural materials.

The computational model used to produce the data shown in Figs. 4.1 and 4.2 was modified to substitute a stainless steel reflector for the graphite. The model was also modified to include a two-region core (to be described in a later section), and critical radius as a function of reflector thickness was computed. The results of the study are shown in Figs. 4.3 and 4.4. For comparable reflector thicknesses, reactor volumes and masses were lower for graphite reflectors than for steel.

Though one conclusion of the early studies was that a low-moderation ratio was needed to maintain a high-conversion ratio, some degree of moderation in the reflector is needed to enhance core reactivity. Consequently the choice of reflector must be a "low-Z" material. Because liquid hydrogenous reflectors will be shown in subsequent sections to be excluded for safety reasons, the obvious (meaning having been used in other reactor applications) solid candidate materials would be beryllium and graphite. Cost and fabrication expense leads immediately to the selection of graphite as a reflector material, and a reference design thickness of $30 \mathrm{~cm}$ was adopted.

\subsubsection{Consideration of Balance-of-Plant Lifetime and Design Basis Power}

In the first 2 years of study, it was assumed that the SSR would generate electricity through a "passive" system (i.e., the use of a thermoelectric material). As such, the lifetime of the balance of plant would be limited only by radiation damage to the thermoelectric material and could potentially reach 


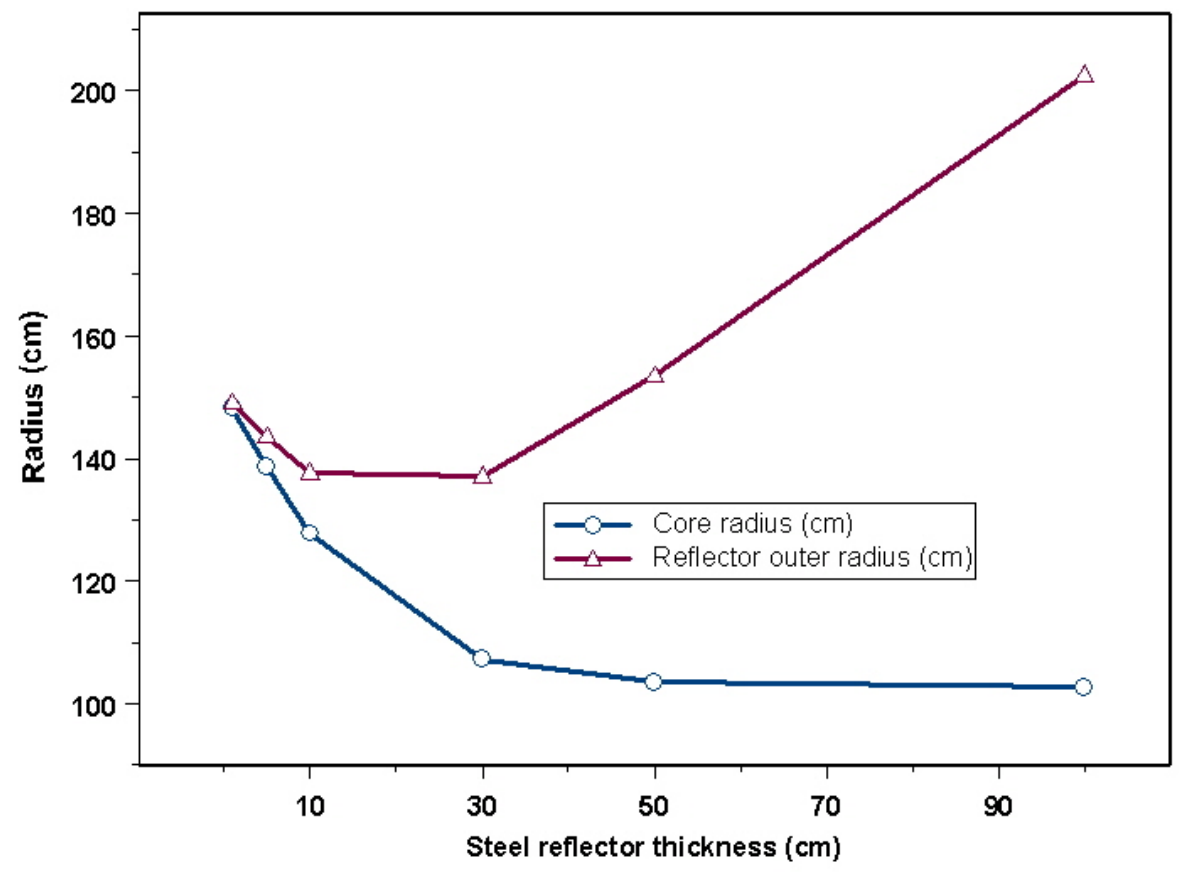

Fig. 4.3. Critical configurations with steel reflectors.

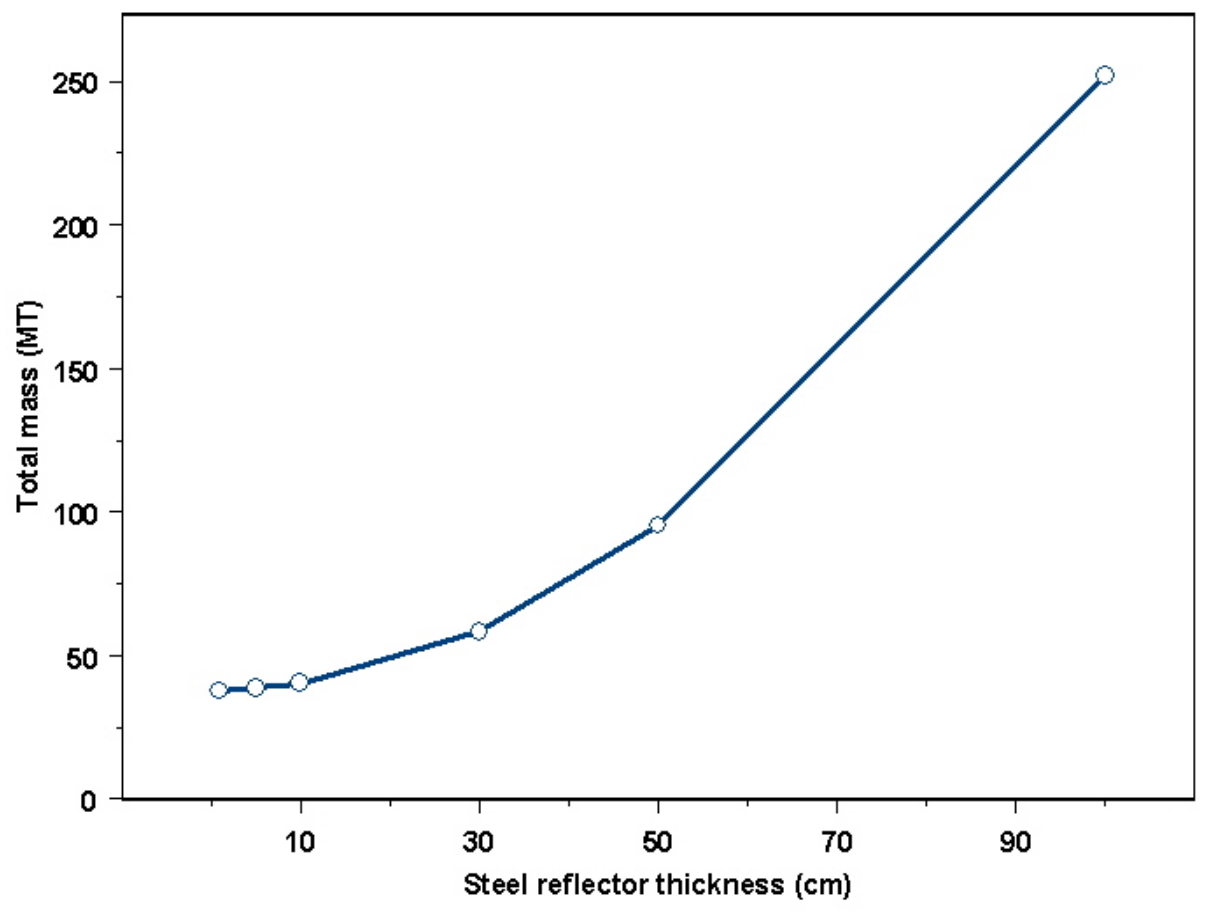

Fig. 4.4. Reactor mass for various steel reflectors. 
decades or more. The studies documented in Sect. 4.1.1 had, as a criterion, maximizing the lifetime of the core. A high-conversion ratio was needed to have long reactor lifetimes and consequently large energy production. Following an evaluation of the efficiency of thermoelectric systems and "waste" heat rejection requirements, a decision was made in calendar year 2002 to switch to an "active" balance-of-plant configuration-coolant loop, turbine, generator system, etc. The lifetimes of such systems, discussed elsewhere in this report, are estimated at 10 years.

Given that the design basis "thermal power" of the SSR is $500 \mathrm{~kW}$, the quantity of energy to be generated over the expected lifetime of the plant (10 years) would be about $2 \mathrm{GWd}$. This value is drastically lower than any of the cases presented in Table 4.1. The quantity of heavy metal corresponding to the minimum reactor mass shown in Fig. 4.2 is approximately 0.9 MT (safety considerations to be discussed in a later section will lead to an increase in heavy metal mass) leading to a maximum burnup of the fuel of about $2.3 \mathrm{GWd} / \mathrm{MT}$, also considerably less than values shown in Table 4.1. The quantity of $235 \mathrm{U}$ that will be consumed during 10 years of operation will be about $2 \mathrm{~kg}$; the initial loading in the model used to generate Fig. 4.2 being $180 \mathrm{~kg}$ (about $1 \%$ of the initial ${ }^{235} \mathrm{U}$ is consumed, whereas a typical light-water reactor (LWR) fuel assembly has approximately $70 \%$ of its initial ${ }^{235} \mathrm{U}$ consumed during irradiation).

With an "active" balance of plant, while there is a need for "zero reactivity swing" so that the reactor does not need to be refueled, the zero swing can be accomplished by a low power density relative to fuel density and consequent low consumption of fuel (low fuel utilization) relative to the initial amount needed to obtain criticality. The conversion ratio becomes almost unimportant. Nevertheless, one arrives at the same reactor design parameters as were the result of the studies in Table 4.1 because systems that have a high conversion ratio for $20 \%$ enriched uranium fuel generally have large critical masses, and the ratio of fuel consumed to fuel loaded is small (a finding related to the concept of doubling time for breeder reactors).

While one could find a $\mathrm{C} / 235 \mathrm{U}$ ratio that would yield a minimum critical mass, a reactor based on such a design would have a consumption-to-initial-loading ratio that would be much higher than the SSR design, thus higher beginning-of-life reactivity and a need for control rods. In subsequent sections, it will be shown that the SSR fuel design leads to a reactor configuration where only shutdown, not control rods, are needed. It is noted though, that the reference fuel, if irradiated to a burnup of $40 \mathrm{GWd} / \mathrm{MT}$, would experience a loss in reactivity of approximately 0.08 (about $\$ 12$ ) from the fresh fuel condition. There is degradation in the conversion ratio from the cases presented in Table 4.1.

\subsubsection{Selection of Clad and Limitations Due to Clad}

Because the uranium that will be impregnated into the foam will not be "clad" or coated (as is the case for microsphere-based gas-cooled reactor fuels), fission products will be released directly into the foam matrix. To prevent these fission products from migrating to the coolant and subsequently to the balance-of-plant and perhaps to the environment, the reactor core must be clad. In fact, the core would likely be doubly clad to provide an acceptably small risk of breach.

The behaviors of zirconium and its various alloys are well known in the range of temperatures experienced in LWRs (up to $400^{\circ} \mathrm{C}$ ). Operation at higher temperatures is complicated by annealing and recrystallization, which occurs at $550-600^{\circ} \mathrm{C}$. It is also complicated by the $\alpha-\beta$ transition, which occurs at $865^{\circ} \mathrm{C}$ in unalloyed zirconium and at slightly higher or lower temperatures in the various alloys of interest (Zircaloy-2, Zircaloy-4, Zirlo, M5, E-110, and E-635).

Stainless steel cladding was utilized in some of the early vintage pressurized-water reactors. It was replaced not due to performance deficiencies but rather due to the lower thermal cross section of the various zirconium alloys. Various low- and high-alloy steels have been investigated to support liquid-metal reactor deployment. The operating temperatures of interest for liquid-metal reactor use range up to $600^{\circ} \mathrm{C}$. However, according to the American Society of Mechanical Engineers (ASME) Code, the 
time-dependence of mechanical properties must be considered for these alloys in the proposed temperature range (above $500^{\circ} \mathrm{C}$ ).

Similar high-alloy steels have been investigated for advanced gas reactor applications in which the peak operating temperatures reach $900^{\circ} \mathrm{C}$. Only four have undergone the extensive qualification testing (alloy 800, alloy 800 RK, Hastelloy-WR, and alloy 617). Many others have been investigated to lesser extents. These alloys were investigated, not for cladding but for structural materials and components. Their behavior in the core region may or may not be adequate.

Above $900^{\circ} \mathrm{C}$, only refractory metals, such as tantalum and tungsten, retain sufficient mechanical strength to serve the required function. Cost and fabricability must be addressed if these refractory metals are required. Experience under $900^{\circ} \mathrm{C}$ or greater temperature operating conditions is limited at best, and extensive qualification testing would be required to prove the code case.

Another option for high-temperature retention of fission products is coating with either $\mathrm{SiC}, \mathrm{NbC}$, or $\mathrm{ZrC}$. Of these, only $\mathrm{SiC}$ has been utilized to a great extent. $\mathrm{ZrC}$ is probably the best choice for the current application, but extensive work would be required to optimize the coating process to ensure even coating of large components. Most of the experience with these coatings has been with much smaller substratecoated particles on the order of 500- $\mu \mathrm{m}$ diameter. More recently, chemical vapor deposition processes have been utilized to produce macroscopic components, and this experience is much more similar to the proposed application.

To minimize the require development program associated with the SSR, the use of a high-alloy steel for a core jacket was selected. There were two consequences of selecting this clad material on the reactor design. First, the selection of clad determines the temperature at the core/clad boundary and thus sets certain balance-of-plant design criteria. Second, given that the SSR concept is based on a monolithic right circular cylinder, a system to "shut down" the reactor should be located external to the core to maximize the temperature of the coolant at the exit from the reactor.

\subsubsection{Validation with Applicable Critical Experiments}

From the discussion in the previous section, it is apparent that the dimensions of the reactor core (the fueled region) should be very close to the "just critical" configuration of the system. Due to biases in the nuclear data and approximations in the computational methods, a calculated k-effective for a "just critical" configuration may well be quite different from 1.0. A computational "bias" is established by comparing a configuration experimentally determined to be critical (a benchmark) with the value of k-effective determined from a computational model. For an experimental configuration to be judged an applicable benchmark, the materials, geometric configuration, and neutron energy spectra should be similar to that of the system under evaluation. For the SSR, these criteria are $20 \%$ enriched uranium as fuel, graphite moderator and reflector, and a neutron energy spectra corresponding to a $\mathrm{C} /{ }^{235} \mathrm{U}$ ratio of approximately 40 .

The region-averaged neutron energy spectra and fission rate spectra for a graphite-reflected sphere of the reference fuel is shown in Fig. 4.5. The energy of the average lethargy group for fissions (a spectral index that has been shown to be robust across libraries of different energy group structures) is $10.7 \mathrm{keV}$.

A review of critical experiments tabulated in Ref. 10 revealed only two experiments that might serve as benchmarks for the SSR. One experiment, designated IEU-MET-FAST-004, was composed of a graphite-reflected metal sphere composed of $36 \%$ enriched uranium metal. The second "experiment" was actually a set of four critical configurations, designated IEU-SOL-THERM-001. These were configurations of $20.9 \%$ enriched uranyl sulphate solution in a steel vessel reflected by graphite. Multiplication factors and spectral indices were calculated for all of these configurations and are presented subsequently. Detailed descriptions of the experimental configurations are contained in Ref. 10. 


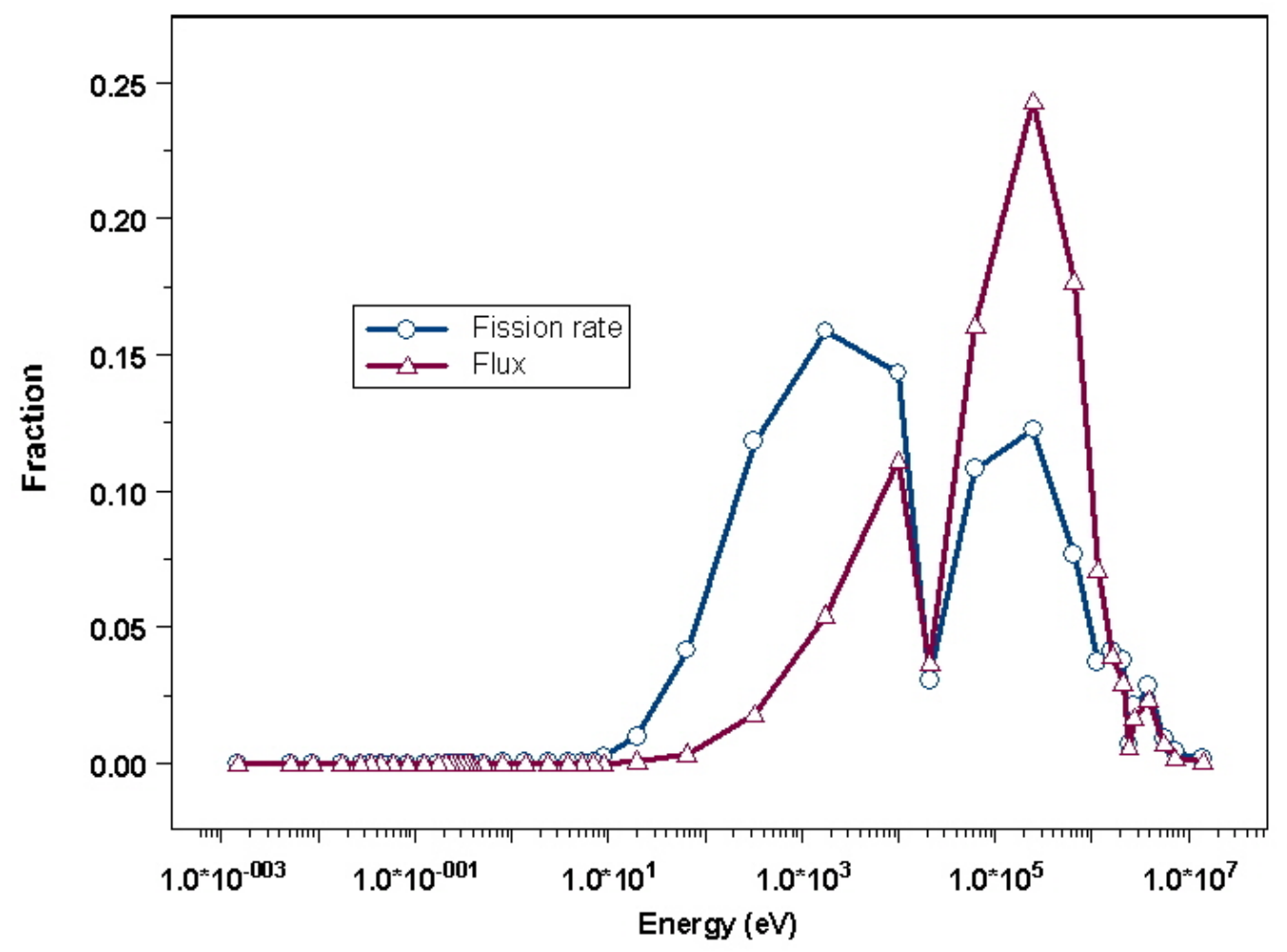

Fig. 4.5. Spectral indices for reference fuel.

\subsubsection{Graphite-reflected spherical assembly of uranium metal}

Criticality measurements of a graphite-reflected assembly of uranium (36\% enriched) were performed under Russian sponsorship in September 1977. Figure 4.6 shows a schematic sectional view of the assembly in the critical facility.

The assembly was composed of two separate units. The upper unit, comprising two hemispherical layers of uranium (with inner and outer radii of $12.25 \mathrm{~cm}$ and $14.0 \mathrm{~cm}$, respectively) and one hemispherical graphite layer (with inner and outer radii of $14.0 \mathrm{~cm}$ and $17.2 \mathrm{~cm}$, respectively) was laid on a steel diaphragm $0.4 \mathrm{~cm}$ thick. The lower (movable) unit incorporated the remainder of the parts. All hemispherical shells of uranium had cylindrical pole holes $2.2 \mathrm{~cm}$ in diameter. During measurements, these holes were plugged with specialized stoppers of core material.

The upper hemispherical layer of graphite had a cylindrical pole hole $6.2 \mathrm{~cm}$ in diameter that was plugged with a stopper of graphite. The graphite reflector was a single spherical layer with an outer radius of $17.2 \mathrm{~cm}$.

The fissile material used in the test assembly was uranium metal with density ranging from 18.4 to $18.8 \mathrm{~g} / \mathrm{cm}^{3}$. The proportion between the most abundant uranium nuclides in the core layers, ${ }^{235} \mathrm{U}$ and ${ }^{238} \mathrm{U}$, was approximately $36.7 \%$ and $63.3 \%$, respectively. The percentage of ${ }^{235} \mathrm{U}$ isotope in the core parts was known with $0.28 \%$ of relative error, and the core pieces were all weighed to an accuracy of $0.01 \%$ or better.

Graphite used as reflecting material in the assembly had the average density of $1.55 \mathrm{~g} / \mathrm{cm}^{3}$. Chemical analysis of the graphite used in this assembly was not performed. Reflector parts were weighed to an accuracy of $0.35 \%$. 


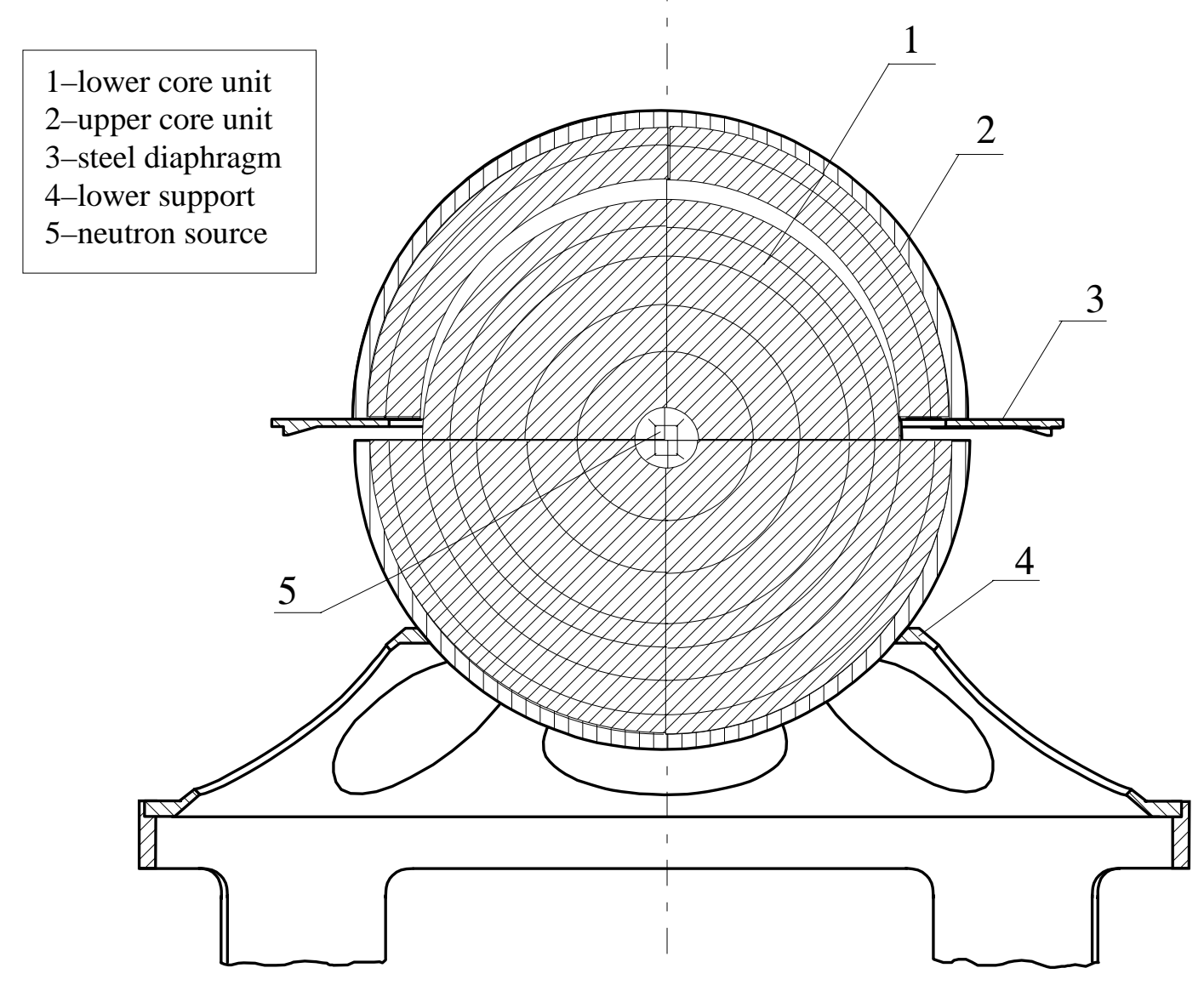

Fig. 4.6. Sectional view of the uranium metal assembly.

The calculated value of k-effective was $1.00920 \pm 0.00108$ (KENO-V.a, 238 groups, ENDF/B-V). The energy of the average lethargy group for fission was $665 \mathrm{keV}$, a considerably faster system than the reference fuel for the SSR.

\subsubsection{Graphite-reflected hemicylinder of uranyl sulphate}

The purpose of these experiments, performed at the Russian Research Center "Kurchatov Institute" in 1980-1981, was to investigate nuclear safety issues for a special-purpose compact reactor with an aqueous solution of uranyl sulphate $\left(\mathrm{UO}_{2} \mathrm{SO}_{4}\right)$ enriched in ${ }^{235} \mathrm{U}$ to $20.9 \%$ and a graphite reflector. Four configurations of critical assemblies with different concentrations of uranium in the solution were involved in this work.

Schematics of the critical assembly with the main structures of the facility are presented in Figs. 4.7, 4.8 , and 4.9, which also give all the necessary dimensions of the experimental configuration.

The core vessel was a welded steel cylinder with a hemispherical bottom and a lid, the latter penetrated by vertically arranged steel pipes that form leak-tight channels. Core vessels of two wall thicknesses were used, $0.5 \mathrm{~cm}$ and $0.3 \mathrm{~cm}$.

An aqueous solution of uranyl sulphate was placed in the steel vessel. The inner diameter of $30.5 \mathrm{~mm}$ is the same for vessels of both wall thicknesses. Three benchmark experiment configurations have the vessel wall thickness of $0.5 \mathrm{~cm}$, and one configuration has the vessel wall thickness of $0.3 \mathrm{~cm}$. The vessel is recessed into the graphite reflector to a depth of $65.6 \mathrm{~cm}$ from the reflector top (Fig. 4.7). 


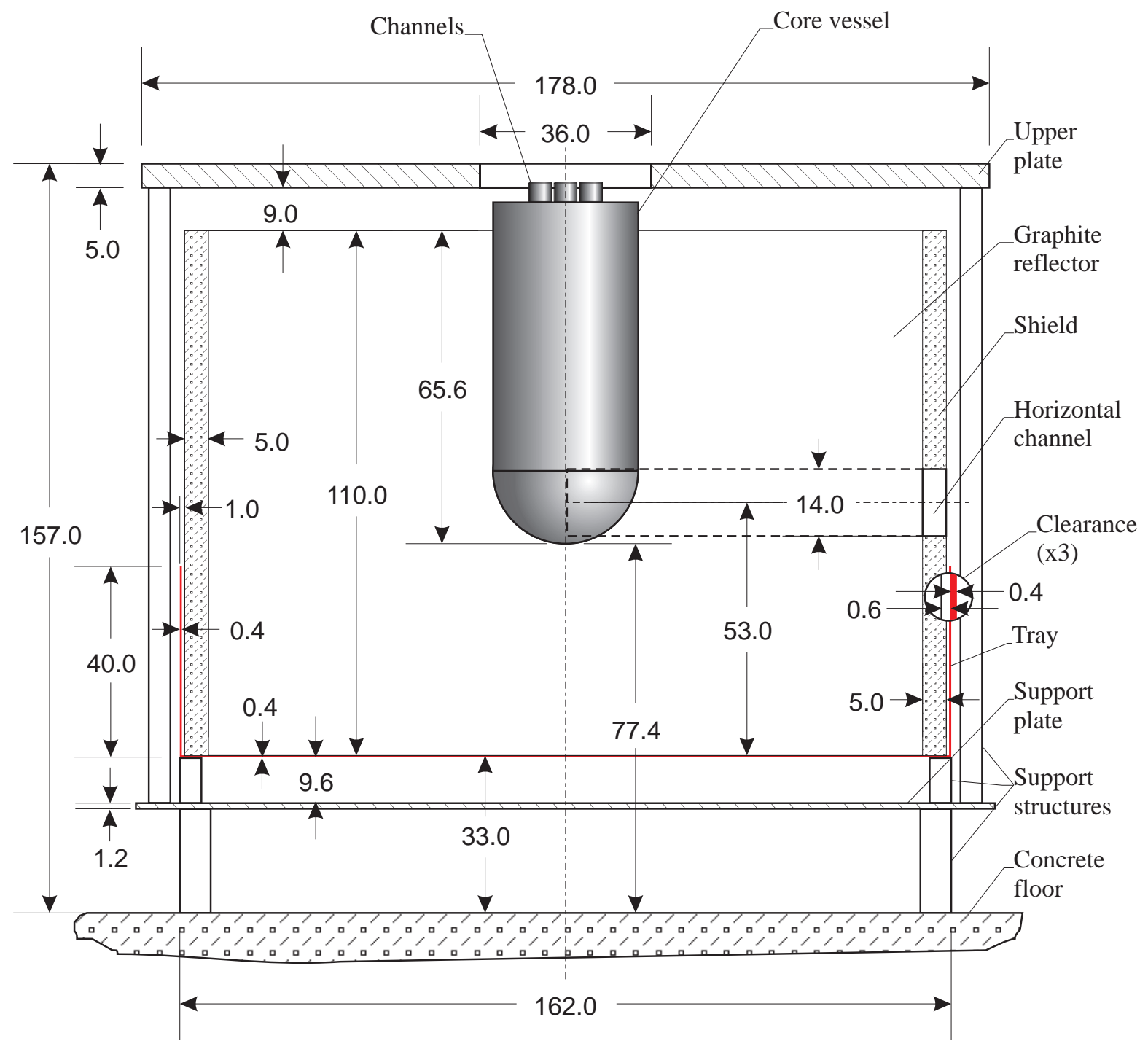

Fig. 4.7. Longitudinal section of the critical assembly with structural elements of the facility (dimensions given in $\mathbf{c m}$ ). 


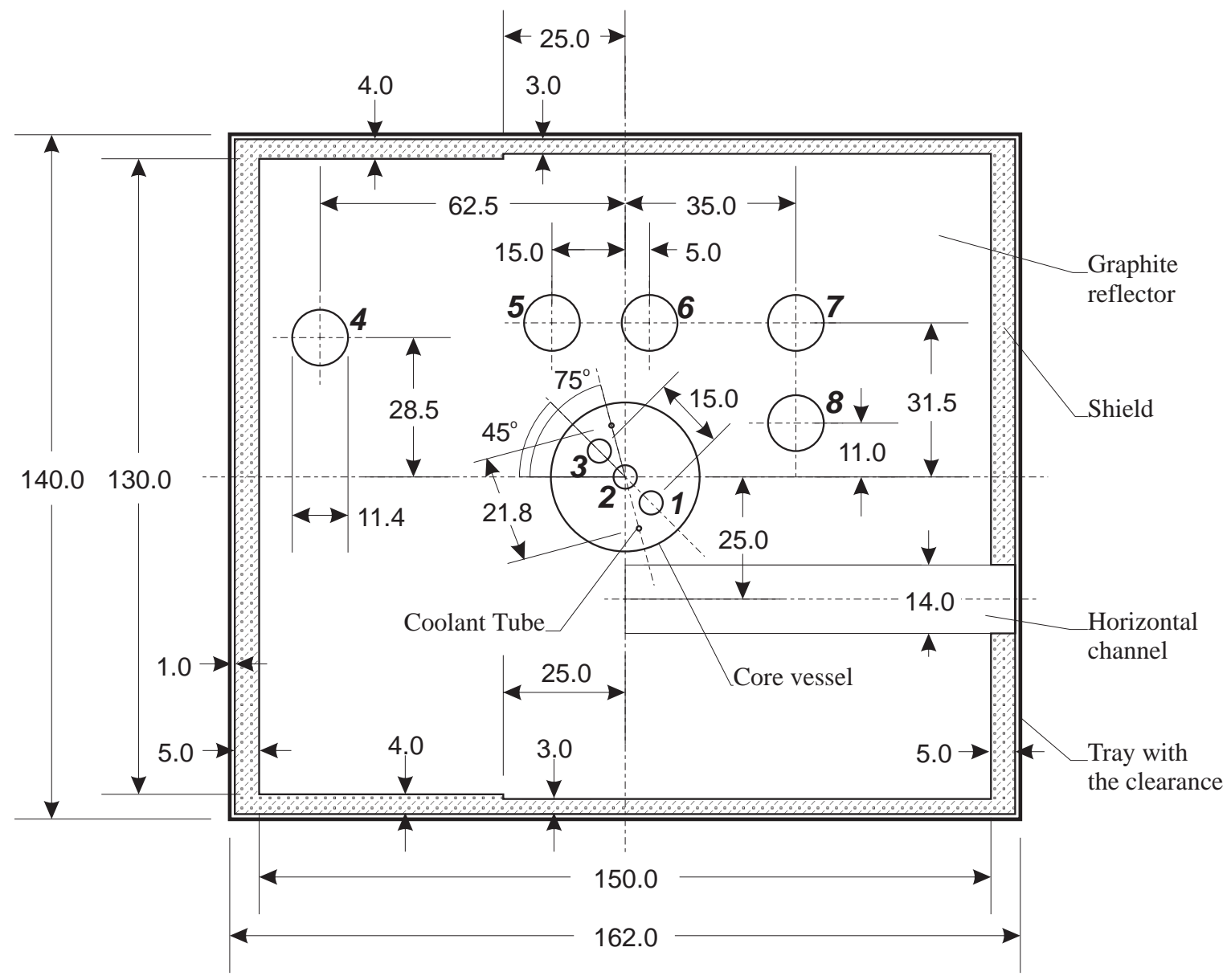

Fig. 4.8. Cross section of the critical assembly showing the arrangement of channels (dimensions given in $\mathbf{c m}$ ). 


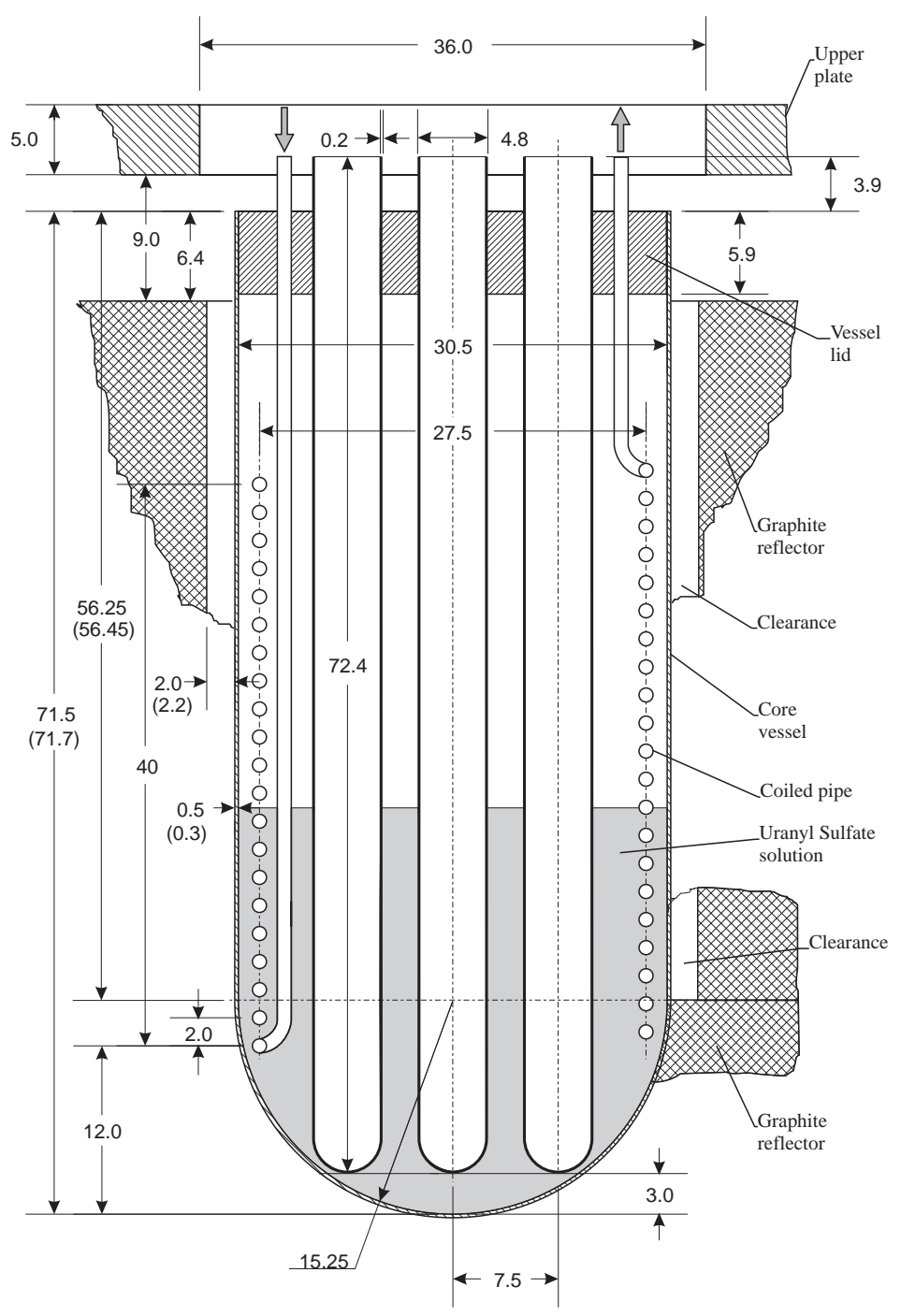

Fig. 4.9. Longitudinal section of the assembly core (dimensions given in $\mathrm{cm}$ ).

The core vessel was surrounded with a graphite reflector. In its external shape, the graphite reflector with the shield is represented by a rectangular parallelepiped. The side surface of the graphite reflector is surrounded by a shield of borated polyethylene. On top of the reflector is a steel plate.

Critical configurations differed in uranium concentration in the aqueous solution of uranyl sulphate, and in thickness of the core vessel wall. The critical condition was determined through addition of a portion of the uranyl sulphate solution to the assembly core. The uncertainty in determining the critical condition in reactivity units is $\pm 0.001 \$$ (at $\beta_{\text {eff }}=0.008$ ).

Due to the shape of the experimental vessel and the orientation of the penetrations in the solution vessel and in the reflector, the KENO-VI program from the SCALE system was used to model the four critical configurations. Calculated multiplication factors and spectral indices are provided in Table 4.3. The calculated k-effective values are unusually low as compared to the previously discussed uranium metal sphere but are in reasonable agreement with values reported by the experimenters (average calculated k-effective of 0.9794). 
Table 4.3. Calculated physics parameters for uranyl sulfate critical experiments

\begin{tabular}{ccc}
\hline $\begin{array}{c}\text { Critical } \\
\text { experiment } \\
\text { No. }\end{array}$ & $\begin{array}{c}\text { Calculated k-effective } \\
\text { (KENO-VI, 238 group x-sects, } \\
\text { ENDF/B-V) }\end{array}$ & $\begin{array}{c}\text { Spectral index } \\
\left.\text { (EALF }^{a} \text { in } \mathbf{~ e V}\right)\end{array}$ \\
\hline $\mathbf{1}$ & $0.97981 \pm 0.00113$ & 0.0485 \\
$\mathbf{2}$ & $0.96933 \pm 0.00107$ & 0.0606 \\
$\mathbf{3}$ & $0.96824 \pm 0.00121$ & 0.0599 \\
$\mathbf{4}$ & $0.96253 \pm 0.00129$ & 0.0762 \\
Average & $0.97048 \pm 0.00058$ & 0.0613 \\
\hline
\end{tabular}

${ }^{a} \mathrm{EALF}=$ energy of the average lethargy group for fission.

\subsubsection{Derived, critical k-effective for reference fuel}

Spectral indices for the best available, evaluated critical experiment data $(665 \mathrm{keV}$ and $0.06 \mathrm{eV})$ are significantly different than the expected conditions for the SSR $(10 \mathrm{keV})$. These being the best available data, using linear interpretation between the experiments, a critical k-effective for the reference fuel is calculated to be 0.971 . Because of the limited applicable data, in the studies reported subsequently, a calculated k-effective of 1.000 was assumed to be critical. Consequently, the proposed reactor radius and height are possibly too large. Clearly a development plan for this project should include a series of critical experiment measurements, especially in light of the poor experiment/calculation agreement for the uranyl sulfate experiments.

\subsubsection{Method of Shutdown}

A design goal of the SSR was that it would be self-regulating with regard to power excursions (negative temperature coefficient) and thus not require control rods during reactor operation. Nevertheless, some type of shutdown mechanism must be present in the system to keep the reactor subcritical prior to reaching the deployment site and also to allow for shutdown of the reactor prior to depletion of its fuel inventory.

In prismatic high-temperature gas-cooled reactor designs, the inlet coolant temperature was approximately $600 \mathrm{~K}$, and the outlet temperature was approximately $1000 \mathrm{~K}$. The control rod drive normally sat in the cold inlet helium, and the control rod itself was actively cooled by a flow of helium under normal conditions. Because of the porous nature of the graphite foam, if a similar configuration were employed for shutdown rods for the SSR, fission gas release to the shutdown rod drive would be a normal mode of operation. If shutdown rod channels were employed internal to the reactor core to prevent fission gas release, then the cladding material for these channels must be able to withstand the operating temperature of the core and be robust to any transient conditions. Such a configuration would require that the maximum operating temperature at the internal shutdown rod locations be no more than approximately $1000 \mathrm{~K}$. This limitation would significantly reduce the temperature at the core clad/coolant interface to a value well below $1000 \mathrm{~K}$ (the design basis set by materials considerations), and the thermal efficiency would be unacceptably low. Consequently, the SSR was designed with shutdown rods located in the reflector region, external to the core clad.

A rotating control rod design similar to that proposed for various space reactor concepts was adopted. The control drum in question was a rotating cylinder of graphite with a boron carbide insert along a $120^{\circ}$ section of the exterior face of the control drum (see Fig. 4.10). The drum could be rotated so that the poison face would be adjacent to the core-equivalent to shutdown rod insertion-or away from the core-shutdown rod withdrawn. The configuration was assumed to be similar to that developed for the space reactors' program and having a history that extends as far back as the construction of the PARKA critical assembly at Los Alamos National Laboratory. ${ }^{11}$ 


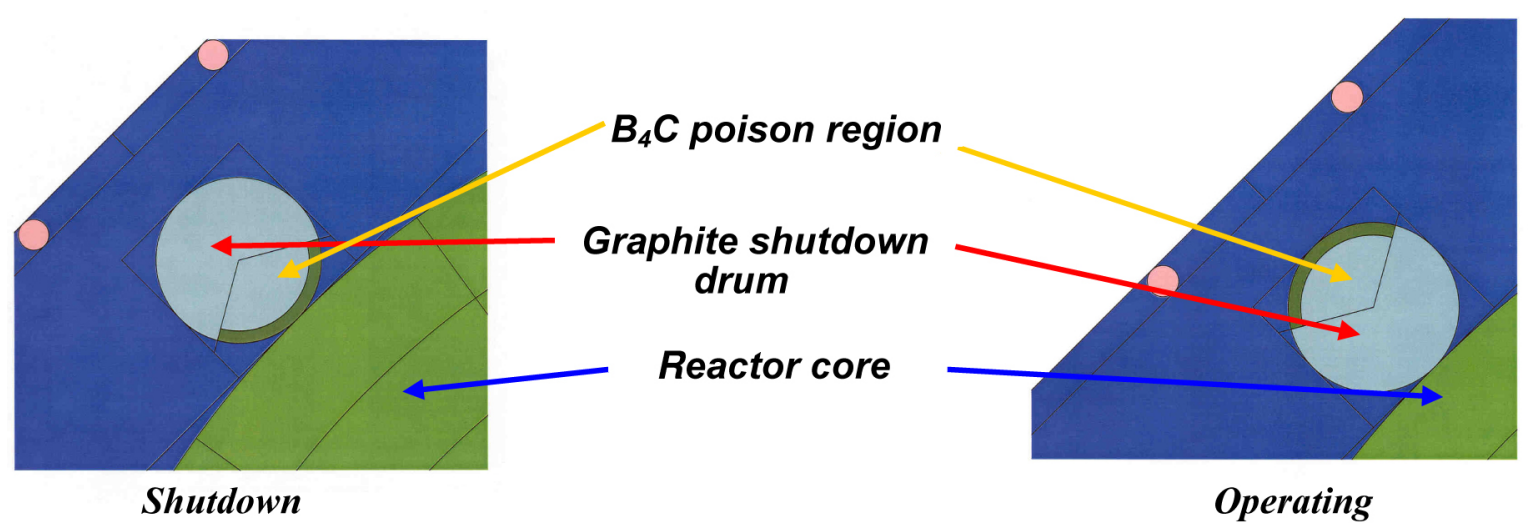

Fig. 4.10. Rotating control drum design for thermoelectric configuration.

No attempt was made to optimize the thickness of the boron carbide region of the control drum. In various space reactor studies, a poison "slab" thickness of $0.8 \mathrm{~cm}$ was adopted. The diameter of the drum was set equal to the thickness of the graphite reflector $(30 \mathrm{~cm})$ so that the operating configuration would correspond to the poison region being effectively removed from the reactor. The reference design was configured to place the maximum number of shutdown rods around the reactor core. This criterion results in the number of control rods being 18.

\subsubsection{Consequence of Water Ingress Accident}

During the operation of the Fort St. Vrain gas-cooled reactor, an incident occurred in which a large quantity of water leaked from a water-cooled bearing to a coolant loop and ultimately to the reactor core. While it is not certain that the SSR would employ a similar circulation system, the possibility of a transportation accident leading to water immersion of the SSR or the possibility of water vapor ingress to the core coolant are safety-related scenarios that should be considered in the design of the reactor.

As noted in Sect. 4.1.2, in the reference fuel, $30 \mathrm{vol} \%$ of the fuel region is void and, therefore, potentially available to be occupied by water in the event of an accident. A simulation was conducted in which this void region was filled with water and modeled using the computer model used to generate the results shown in Fig. 4.1 (SCALE/XSDRNPM, 44 energy groups, ENDF/B-V). The critical radius of the fueled region for a configuration with a 30-cm graphite reflector decreases from $50 \mathrm{~cm}$ (with no water, the value in Fig. 4.1) to $8.74 \mathrm{~cm}$. The various critical configurations shown in Table 4.1 would all be superprompt critical if flooded with water.

Studies were conducted to design a cylindrical core configuration with control rod penetrations in the fueled region, such that the distance between rods would be less than the water-flooded critical diameter. However, such a configuration would require that the penetrations for control rods be lined with a clad to prevent fission product migration (presumably the same material as used for the core coolant interface). The resulting limitations on core/clad interface temperature led to the conclusion that the thermal efficiency of such a system would be unacceptably low.

The solution to the consideration of water ingress was to add a neutron poison to the fuel/carbon mixture to be deposited to the foam. When water-flooded, the neutron spectra in the critical system is highly thermalized (EALF - the spectral index mentioned previously - is reduced from $10 \mathrm{keV}$ for the dry system to $0.27 \mathrm{eV}$ for the flooded system). Thus, a search was conducted for a neutron poison that would be very effective in a thermal spectrum but relatively innocuous in a fast spectrum.

Boron, hafnium, and cadmium were all considered as candidate neutron poisons (mixtures of poisons were not considered). In no case could a poison be found in which a system was simultaneously critical when unflooded yet subcritical (k-effective $=0.95)$ when flooded. Nevertheless, cadmium, with a sharp 
reduction in absorption cross section at approximately $0.5 \mathrm{eV}$ and remaining low at energies above this value, was observed to be the most promising candidate (see Fig. 4.11).

A configuration that satisfies the critical dry/subcritical flooded criteria can be found by creating a two-zone reactor core. The central zone is composed of unpoisoned, uranium-loaded graphite foam having a diameter corresponding to that of a bare cylinder with an effective multiplication factor of 0.95 (13 cm for the reference fuel). The outer, second zone is composed of cadmium-poisoned, uranium-loaded graphite foam with a cadmium loading that gives an infinite multiplication factor of 0.95 (reference fuel but with slight reduction in uranium content to provide room for cadmium).

Figure 4.12 shows the results of computational studies to identify the reference cadmium concentration. Infinite multiplication factors were calculated for a cadmium-poisoned reference fuel using XSDRNPM (44 group, ENDF/B-V cross sections). A second set of calculations, also shown in Fig. 4.12, were conducted with SCALE/KENO to determine the impact on the target cadmium concentration of having a graphite reflector (30-cm thick) surrounding the cadmium-poisoned region. Assuming that a k-effective value of 0.95 represents an acceptably safe level, a cadmium concentration of $0.08642 \mathrm{~g} / \mathrm{cm}^{3}$ ( 0.01 of the cadmium metal density) was determined to be needed.

The outer radius of the cadmium-poisoned zone is set by the criteria of operating for 10 years at a power level of $500 \mathrm{~kW}$. Note that the reactor must be critical at operating temperature-nominally $1000 \mathrm{~K}$ - and "dry" yet be subcritical when flooded at room temperature-300 K. Calculations with SCALE/KENO-V.a (238-group, ENDF/B-V cross sections) showed that an outer radius of the poisoned zone of $75 \mathrm{~cm}$ was required. Under the assumption that a right, circular cylinder yields the minimum critical mass in cylindrical geometry, a height of $150 \mathrm{~cm}$ was determined.

A cross section view of the reactor core and reflector is shown in Fig. 4.13. Note that the coolant gap would actually be occupied by fins spaced on a $1-\mathrm{cm}$ pitch rather than the broad spacing implied in Fig. 4.13. An axial profile showing an "exploded" view of the control element design is shown in Fig. 4.14.

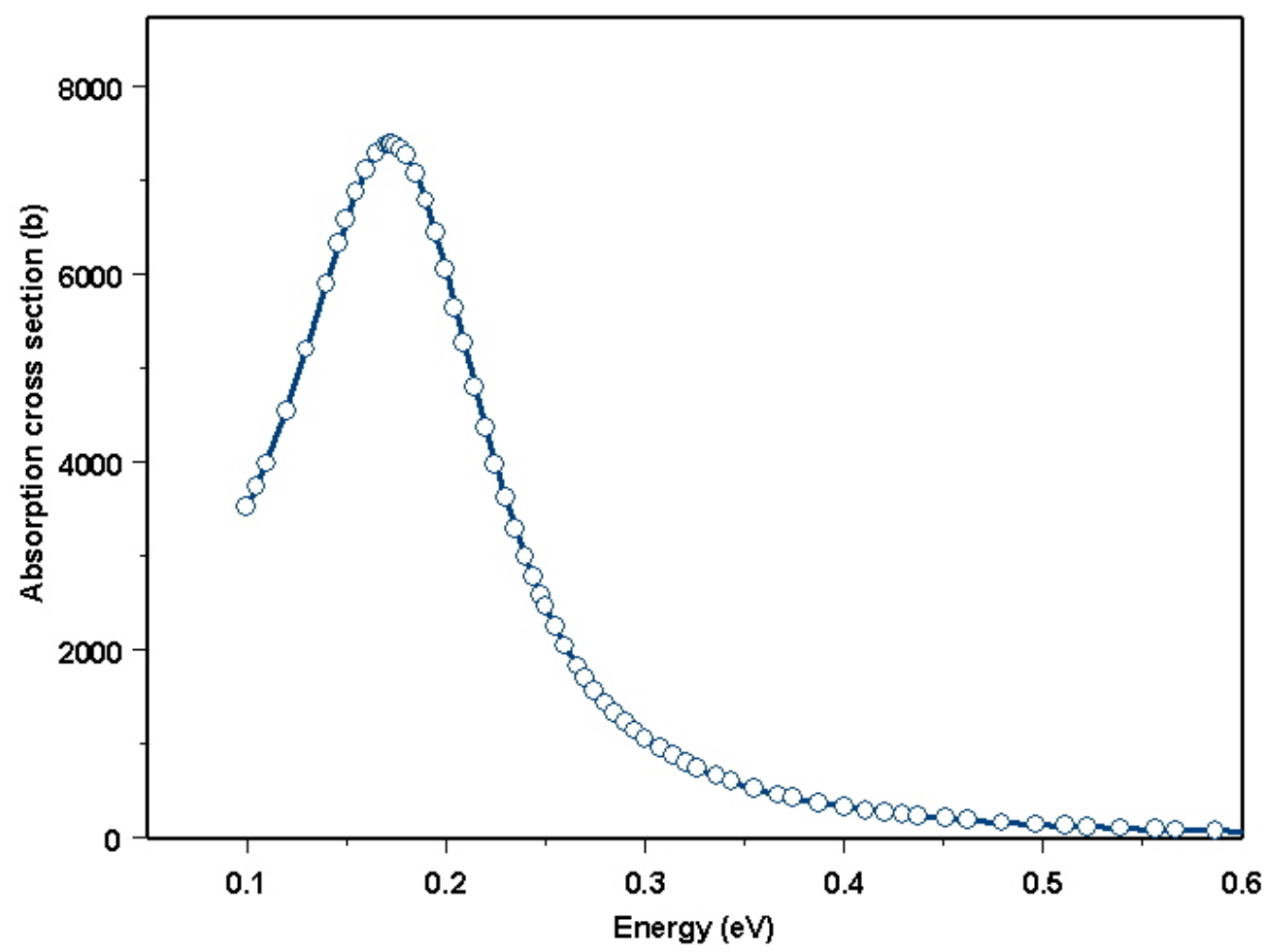

Fig. 4.11. Absorption cross section for cadmium at "so-called" cadmium cutoff. 


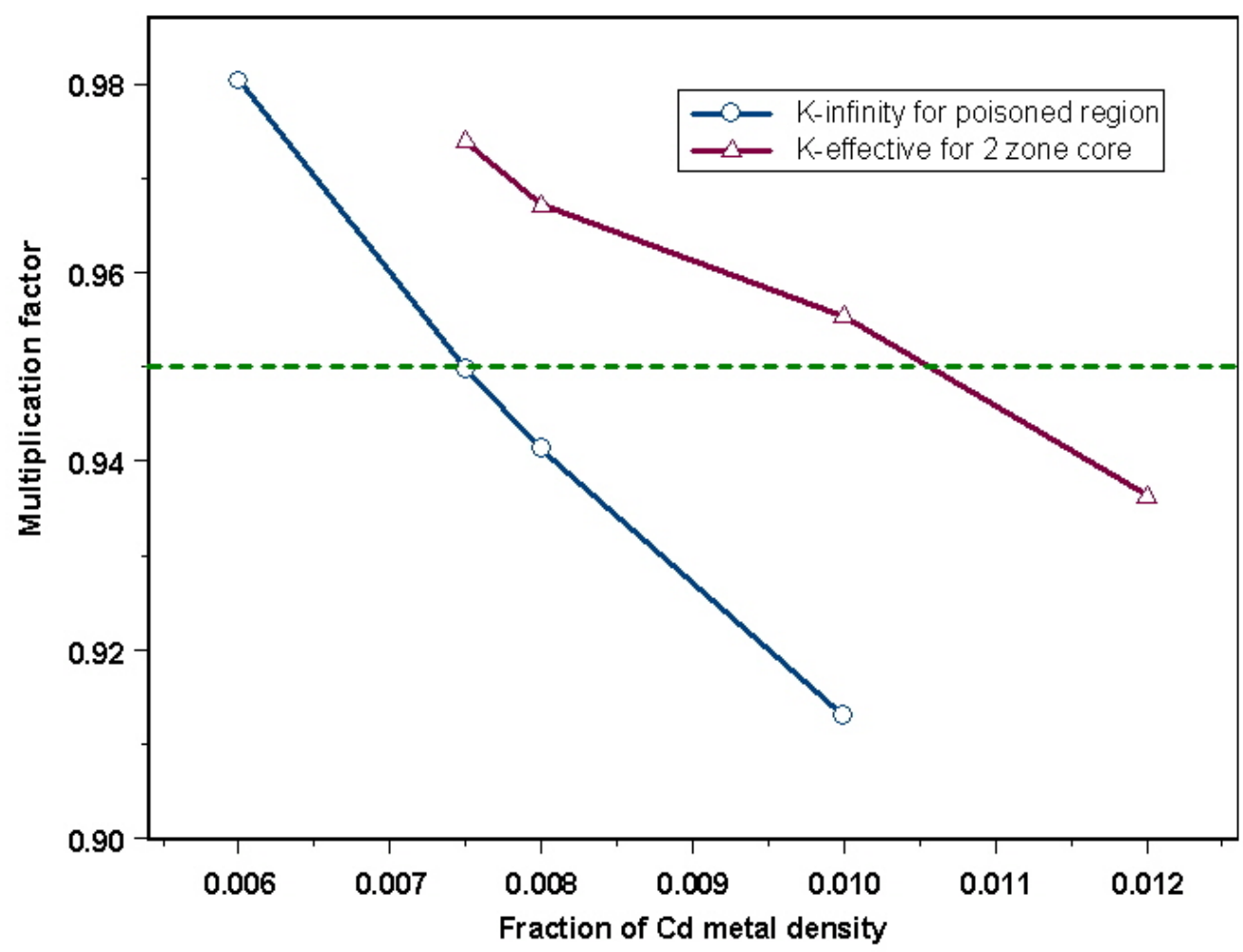

Fig. 4.12. Effect of cadmium on flooded, fueled foam.

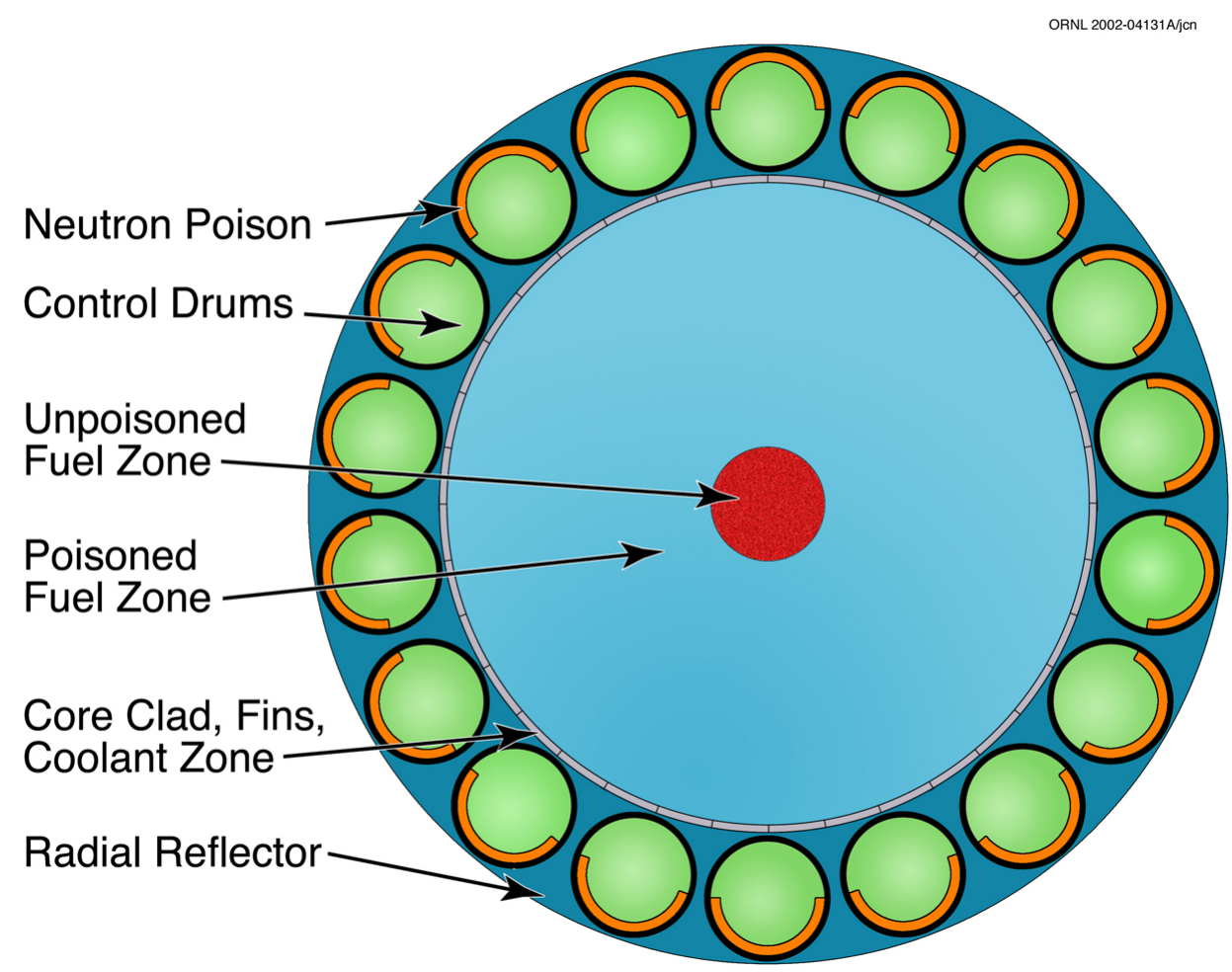

Fig. 4.13. Cross section view of SSR core and reflector. 


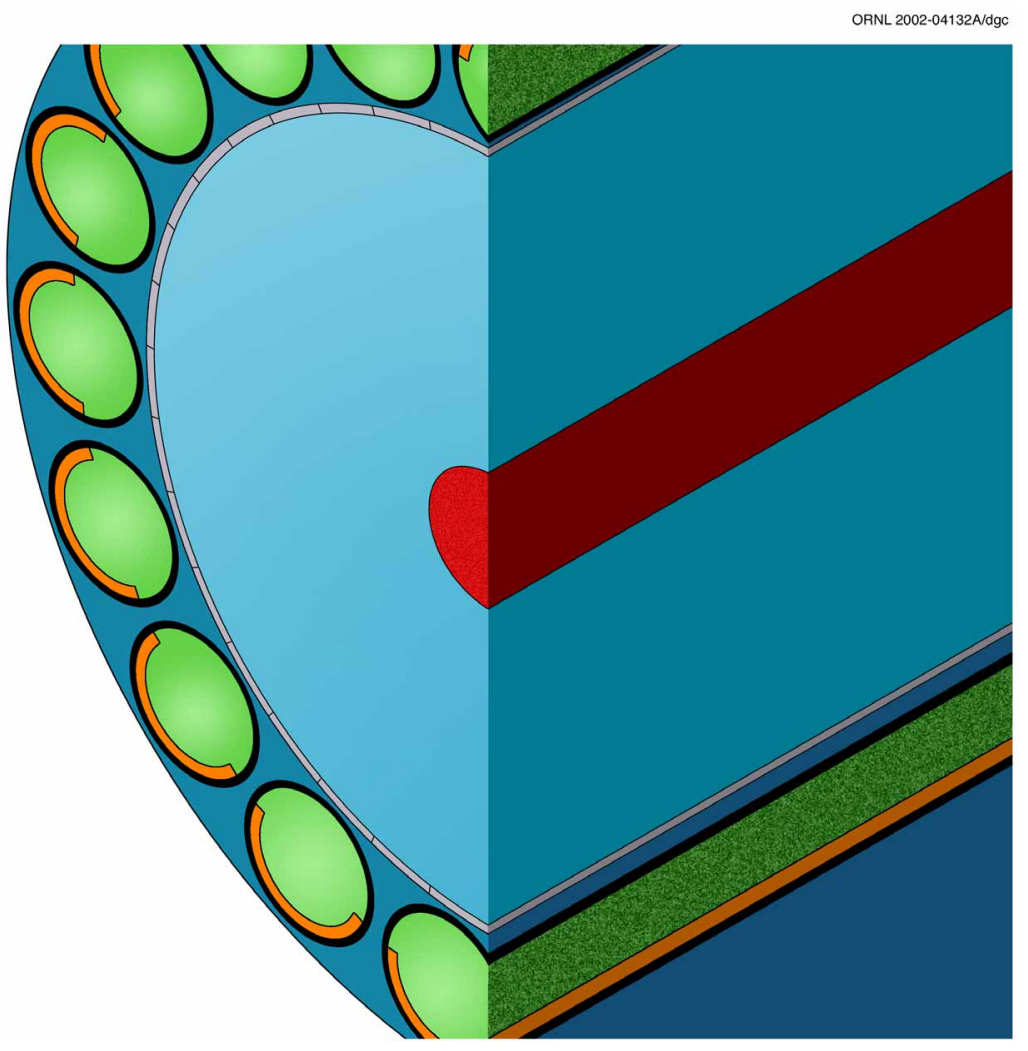

Fig. 4.14. Vertical profile of SSR core.

\subsubsection{Consequence of Water Vapor in Coolant During Operation at Full Power}

During normal operation of the reactor (fuel temperature of approximately $1000 \mathrm{~K}$ ), it is clearly impossible to have liquid water present. Nevertheless, water vapor could inadvertently enter the coolant through some structural failure in the system. Lacking knowledge as to credible values of water vapor content, a parametric study was conducted to determine the concentration of water in the "void" region of the graphite foam that would yield maximum reactivity.

A KENO-V.a (44-group) model corresponding to Fig. 4.14 (without shutdown rods) was prepared using the reference fuel. An outer radius for the poisoned region of $70 \mathrm{~cm}$ was assumed (rather than the final design value of $75 \mathrm{~cm}$ ), but this is not believed to affect the determination of the optimal water concentration. Results of the calculations are displayed in Fig. 4.15 for two reactor temperatures-shutdown $(300 \mathrm{~K})$ and operating $(1200 \mathrm{~K}$ for the unpoisoned region, $1000 \mathrm{~K}$ for the poisoned region, and $900 \mathrm{~K}$ for the coolant and reflector). The optimum volume percent for water vapor at reactor operating temperature is $5 \%$ (meaning that $1 / 6$ of the void region filled with water molecules). The room temperature optimal value is slightly higher $-6 \%$.

The spectral index (EALF) for the operating temperature "soggy" condition (5 vol \% water) is $1 \mathrm{keV}$. This is lower than for the nominal, dry configuration $(10 \mathrm{keV})$ but still indicates a fast spectrum in the system. A computational study was conducted (XSDRNPM, 44 groups) to determine the cadmium concentration required to keep the system subcritical at "soggy" operating conditions. The needed cadmium concentration $\left(0.691 \mathrm{~g} / \mathrm{cm}^{3}\right)$ was eight times greater than that found for the "full water immersion" condition described in the previous section. Unfortunately, the nominal, dry condition was also subcritical at this concentration of cadmium. As the closeness of the spectral indices indicates, because the spectra in the two systems are similar, introducing sufficient negative reactivity to keep one system subcritical also keeps the second system subcritical, albeit by a lesser degree. 


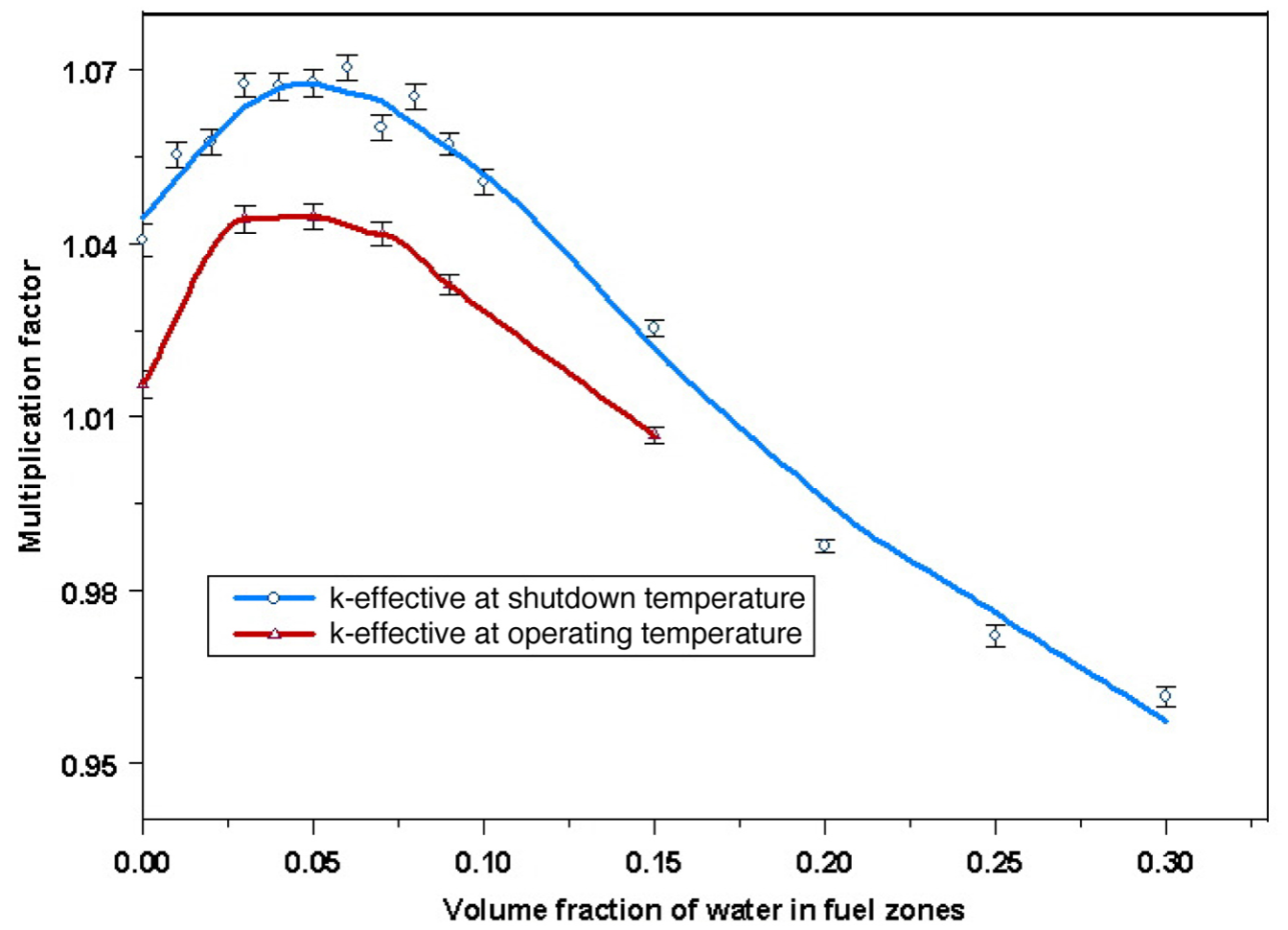

Fig. 4.15. Reactivity effect of water ingress to reference fuel.

Overcoming the excess reactivity due to optimal water content is the criterion that must be met by the shutdown rods with allowance for a "stuck rod" condition. From Fig. 4.15, the amount of excess reactivity that must be compensated by the shutdown rods is 0.03 (approximately $\$ 4$ ). To determine if the 18 shutdown rods sufficiently compensated for this level of reactivity, a HELIOS model, shown in Fig. 4.16

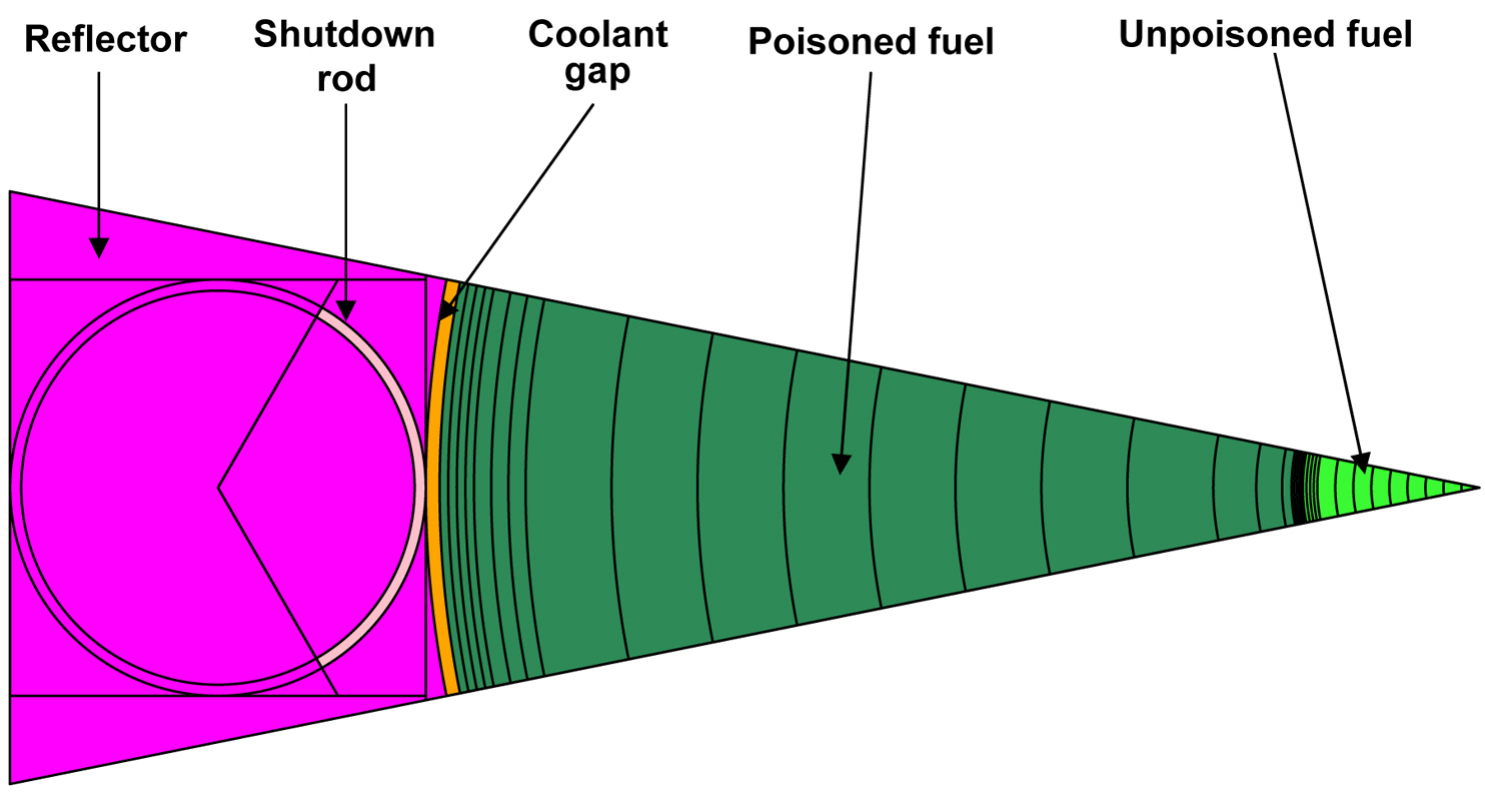

Fig. 4.16. HELIOS model of a segment of the SSR showing shutdown rod "out." 
was prepared. The figure shown is a "pie-shaped" segment of the configuration shown in Fig. 4.17—an axial profile showing an "exploded" view of the control element design. The radial "faces"—sides of the arc-have reflected boundary conditions, and the outer face of the reflector had a black (void) boundary condition. The "within-region" line segments reflect the radial mesh in the calculation and have no physical meaning. "Rod out" and "rod in" calculations were performed. To achieve a banked rod worth of greater than $0.03(\$ 5)$, it was necessary to set the $\mathrm{B}_{4} \mathrm{C}$ thickness in each shutdown rod to $1.6 \mathrm{~cm}$. This level of reactivity, while barely sufficient, could be increased by modifications in poison dimensions or materials. Furthermore, it is not certain that the most reactive water ingress configuration $(6 \mathrm{vol} \%)$ is a credible condition.

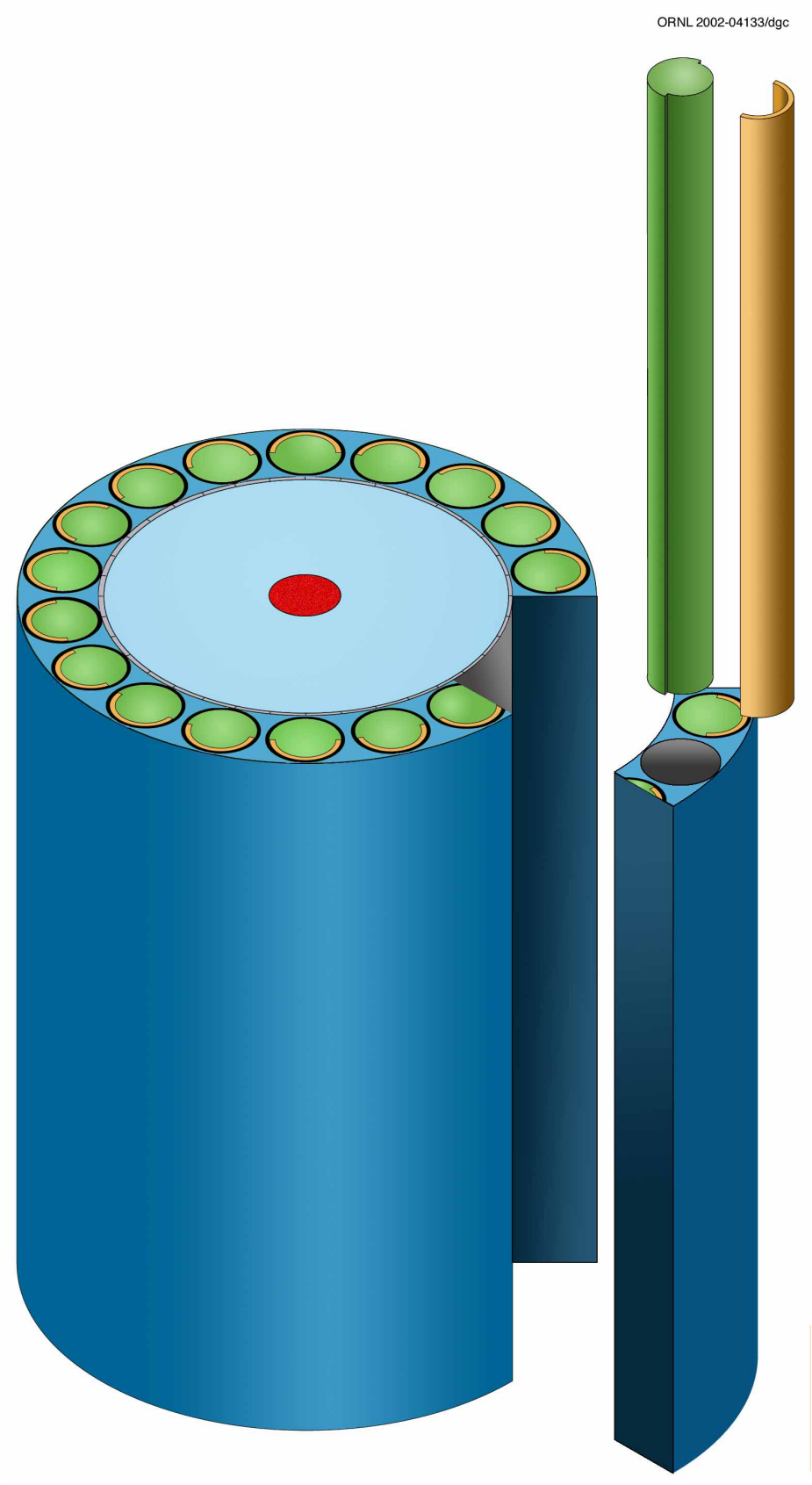

Fig. 4.17. Axial view of SSR core and reflector showing shutdown rod construction. 


\subsubsection{Operational Cycle}

Later in Sect. 4, the following heat transfer system parameters are derived. The coolant mixture is $28.3 \%$ xenon and $71.7 \%$ helium by volume (coolant designation is HeXe40, where 40 represents the molecular weight).

With this coolant, the core thermal conductance is estimated to be $10.2 \mathrm{~kW} / \mathrm{K}$ with a very low pressure drop $(0.6 \%)$ for the following parameters:

- fin material-stainless steel,

- fin width-5 mm,

- fin spacing-10 $\mathrm{mm}$, and

- fin height $-10 \mathrm{~mm}$.

The core clad/graphite temperature is estimated to be $949 \mathrm{~K}$ for the $500-\mathrm{kWh}(\mathrm{t})$ core thermal power.

Ten years of operation at $500 \mathrm{~kW}$ yields an energy output of $1.826 \mathrm{MWd}$. The heavy metal mass of the fueled regions is $4.59 \mathrm{MT}$, yielding a core average burnup at end-of-life of $398 \mathrm{MWd}$ /MT.

The HELIOS model in Fig. 4.16 was used to estimate the reactivity change due to this level of burnup. A reactivity loss of 0.00065 (about 10 cents) was calculated. The model was also used to generate few group cross sections for use in the coupled neutrons/thermal analysis program described elsewhere in this report.

\subsection{MATERIALS-GRAPHITE FOAM}

\subsubsection{Graphite Foam Samples for Irradiation Studies}

The graphite foam utilized in this project was produced using a process developed at ORNL in the Carbon Materials Technology group (J. W. Clett, Process for Making Carbon Foam, U.S.A., U.S. Patent $6,033,506,2000$ ). This manufacturing process induces a preferred alignment of the ligaments of the foam in the $\mathrm{Z}$ direction (see Fig. 4.18). This alignment translates into an anisotropic behavior of the properties of the foam (i.e., the thermal conductivity in the Z-direction is 3-4 times that of the $\mathrm{X}$ - or Y-direction). To evaluate the effect of this texture, samples in both orientations [out-of-plane (OP) and in-plane (IP)] were utilized in this study.

Cylindrical samples of graphite foam were machined from a block of graphite foam produced at ORNL from an AR mesophase pitch and graphitized at $2800^{\circ} \mathrm{C}$. A total of 38 cylindrical samples (19 IP and 19 OP) of approximately 6-mm diameter by $10-\mathrm{mm}$ length were prepared for this study.

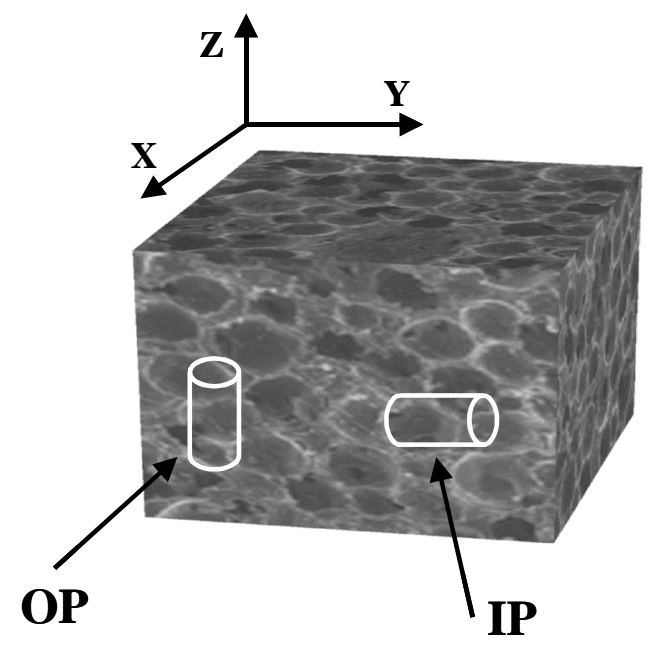

Fig. 4.18. Orientation of machined samples within the block of carbon foam. 


\subsubsection{Capsule layouts}

Initial plans were to load each irradiation capsule with five foam samples; however, due to the size of the capsules, only three foam samples, plus a chemical vapor deposition (CVD) SiC temperature monitor, fit in each capsule. Two of the capsules were used for the IP samples, and the other two were used for the OP samples; a total of 12 foam samples were irradiated at ORNL's HFIR. Table 4.4 lists the content of each capsule and the neutron irradiation dose received by each capsule. The location of the capsules within the hydraulic tube (see Fig. 4.19, position 3-4) was such that the variation of the neutron flux was less than $15 \%$ from capsule to capsule. The planned irradiation temperature was $600^{\circ} \mathrm{C}$; however, the actual irradiation temperature was considerably higher (as explained in the next section).

Table 4.4. Capsule content and neutron irradiation dose

\begin{tabular}{cllcc}
\hline Capsule & \multicolumn{1}{c}{ Foam samples $\boldsymbol{a}$} & Monitor & $\begin{array}{c}\text { Dose } \\
(\mathbf{d p a})\end{array}$ & $\begin{array}{c}\text { Planned irradiation } \\
\text { temperature } \\
\left({ }^{\circ} \mathbf{C}\right)\end{array}$ \\
\hline NERI-1 & IP-1, IP-3, IP-4 & CVD SiC TM 600 & 2.6 & 600 \\
NERI-2 & OP-2, OP-3, OP-9 & CVD SiC TM 601 & 2.6 & 600 \\
NERI-3 & IP-7, IP-14, IP-15 & CVD SiC TM 602 & 0.3 & 600 \\
NERI-4 & OP-15, OP-16, OP-17 & CVD SiC TM 603 & 0.3 & 600 \\
\hline
\end{tabular}

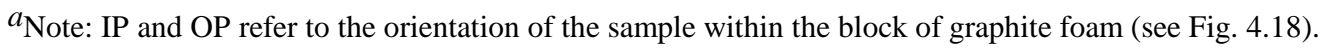

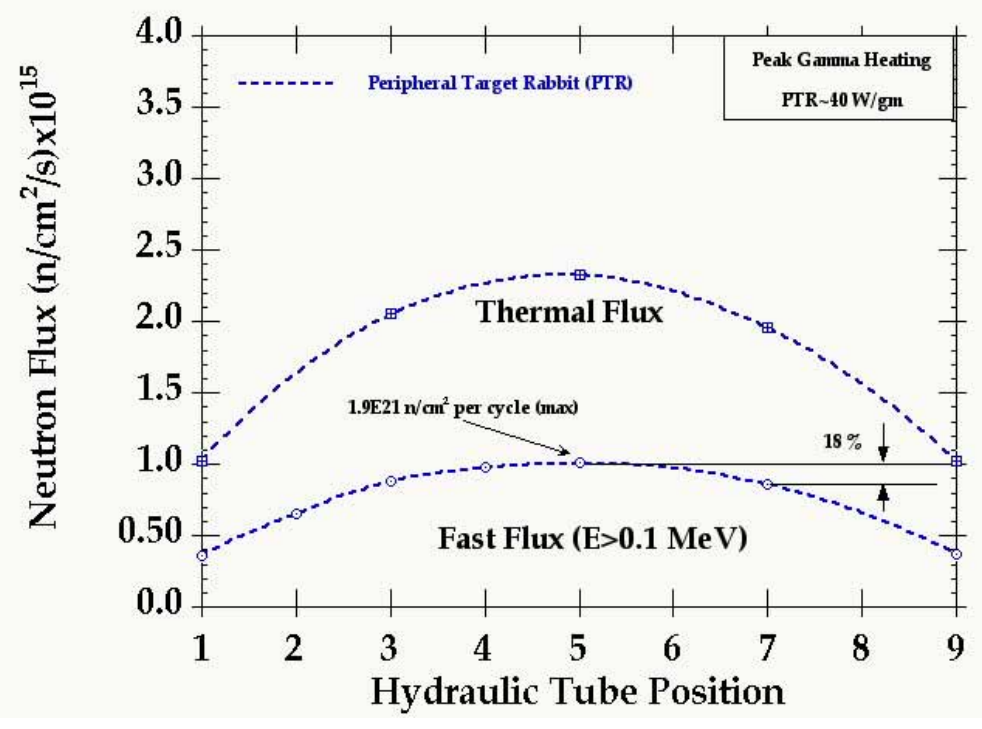

Fig. 4.19. Neutron flux vs hydraulic tube position.

\subsubsection{Analysis of temperature monitor}

To determine the ultimate irradiation temperature, an isochronal annealing method was followed. ${ }^{12}$ The temperature monitor was first sliced into three pieces to reduce its thickness (because of the low thermal conductivity of $\mathrm{SiC}$, a thinner sample is required to perform the measurements). The thermal diffusivity of the sample was measured at $200^{\circ} \mathrm{C}$ and taken as the reference value. The sample was then heated to temperatures between $400^{\circ} \mathrm{C}$ and $600^{\circ} \mathrm{C}$ in $50^{\circ} \mathrm{C}$ intervals. After each temperature increment, the sample was cooled down to $200^{\circ} \mathrm{C}$, and its thermal diffusivity was measured. A similar procedure was repeated for temperatures from $610^{\circ} \mathrm{C}$ up to $890^{\circ} \mathrm{C}$ but in $20^{\circ} \mathrm{C}$ intervals. The values of thermal diffusivity 
at $200^{\circ} \mathrm{C}$ after each annealing temperature are plotted in Fig. 4.20. The annealing temperature, after which the thermal diffusivity starts to increase (recover), indicates the actual irradiation temperature of the capsules.

From Fig. 4.20 it was determined that the actual irradiation temperature of the temperature monitors was $770^{\circ} \mathrm{C} \pm 25^{\circ} \mathrm{C}$. With the type of capsules utilized for this project (vanadium holder), a temperature difference of about $30^{\circ} \mathrm{C}$ between the temperature monitor and the graphite foam is expected. Therefore, we can state that the irradiation temperature of the graphite foam was $740^{\circ} \mathrm{C} \pm 25^{\circ} \mathrm{C}$. This temperature is significantly higher than the anticipated irradiation temperature of $600^{\circ} \mathrm{C}$.

\section{Temperature Monitor - TM 602}

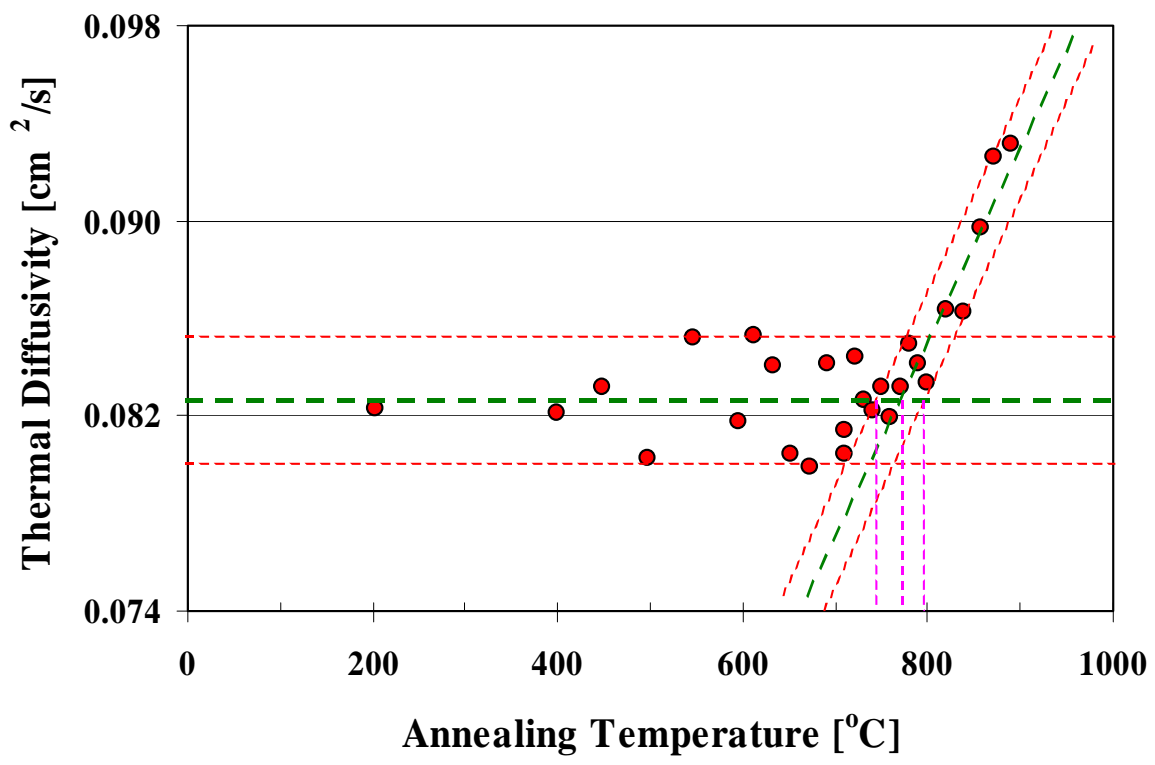

Fig. 4.20. Results from the swing test for an $\mathrm{SiC}$ monitor to determine actual irradiation temperature of graphite foam samples.

\subsubsection{Irradiation-induced structural and dimensional changes in graphite foam}

4.2.1.3.1 Experimental results. Postirradiation examination of the graphite foam samples discussed in Sect. 4.2.1 included dimensional changes, microstructural examination, and thermal conductivity. Here we discuss the effect of neutron irradiation on the dimensions of the graphite foam samples. Figure 4.21 reflects the volume change of the irradiation samples as a function of neutron dose expressed as displacements per atom (i.e., the average number of times each carbon atom is displaced from its equilibrium lattice position). The volume change was determined from the pre- and postirradiation specimen dimensions.

As indicated by the data in Fig. 4.21, the volume change behavior is dominated by a rapid swelling of the graphite foam at relatively low doses, followed by a turnaround to shrinkage. The data indicate that a shrinkage continues into net volume shrinkage (i.e., $\Delta \mathrm{V} / \mathrm{V}=0$, at $\sim 3 \mathrm{dpa}$ ). The dimensional changes are reported in Fig. 4.22. Similarly, the dimensional change (as represented by the change in specimen length) is dominated by initial low dose $(\varphi)$ expansion, followed by a turnaround to shrinkage. Significant anisotropy in the neutron irradiation-induced dimensional change is seen in Fig. 4.22, with the OP-type specimens reaching $\Delta \mathrm{l} / \Delta \varphi=0$ (turnaround) at smaller length changes than the IP-type specimens, and the return to original length $(\Delta \mathrm{l} / \mathrm{l}=0)$ occurring at lower dose for the OP specimens. While these observations are based on very limited data, it is evident that a reversal from growth to shrinkage occurs in graphite 


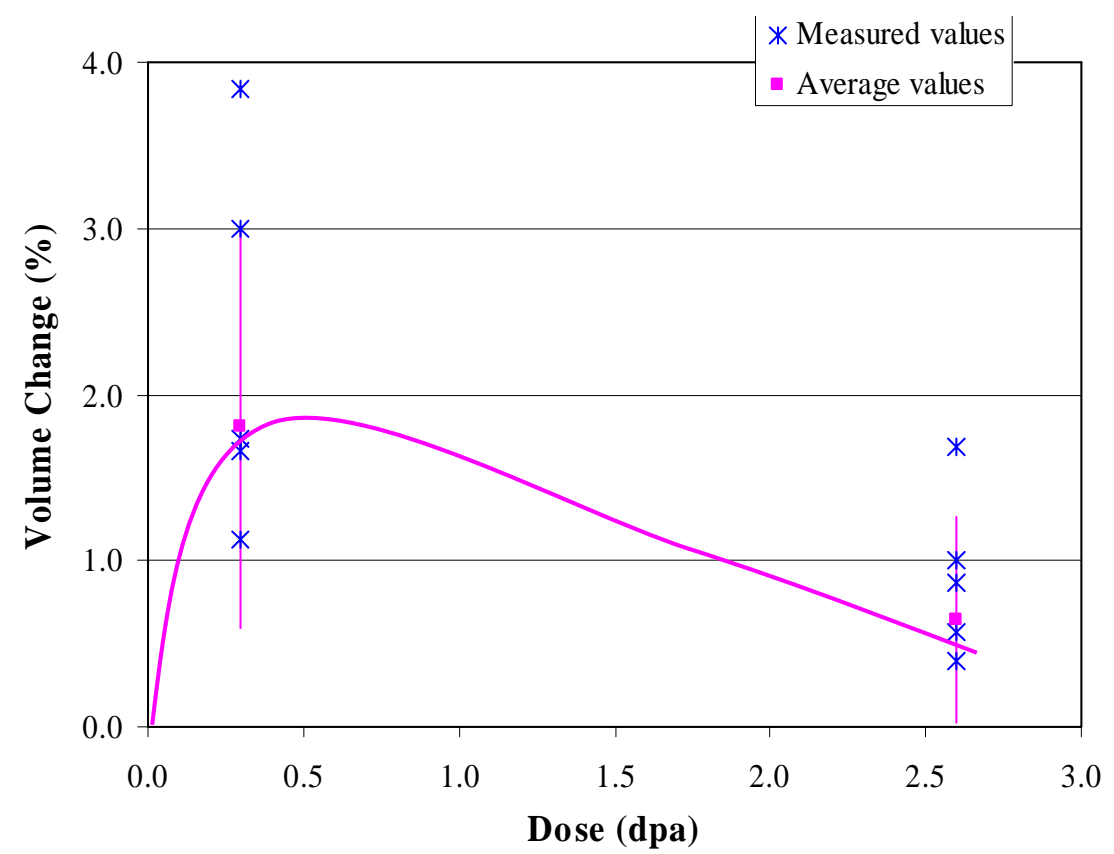

Fig. 4.21. Volume changes $(\Delta \mathrm{V} / \mathrm{V})$ as a function of irradiation dose for graphite foam samples.

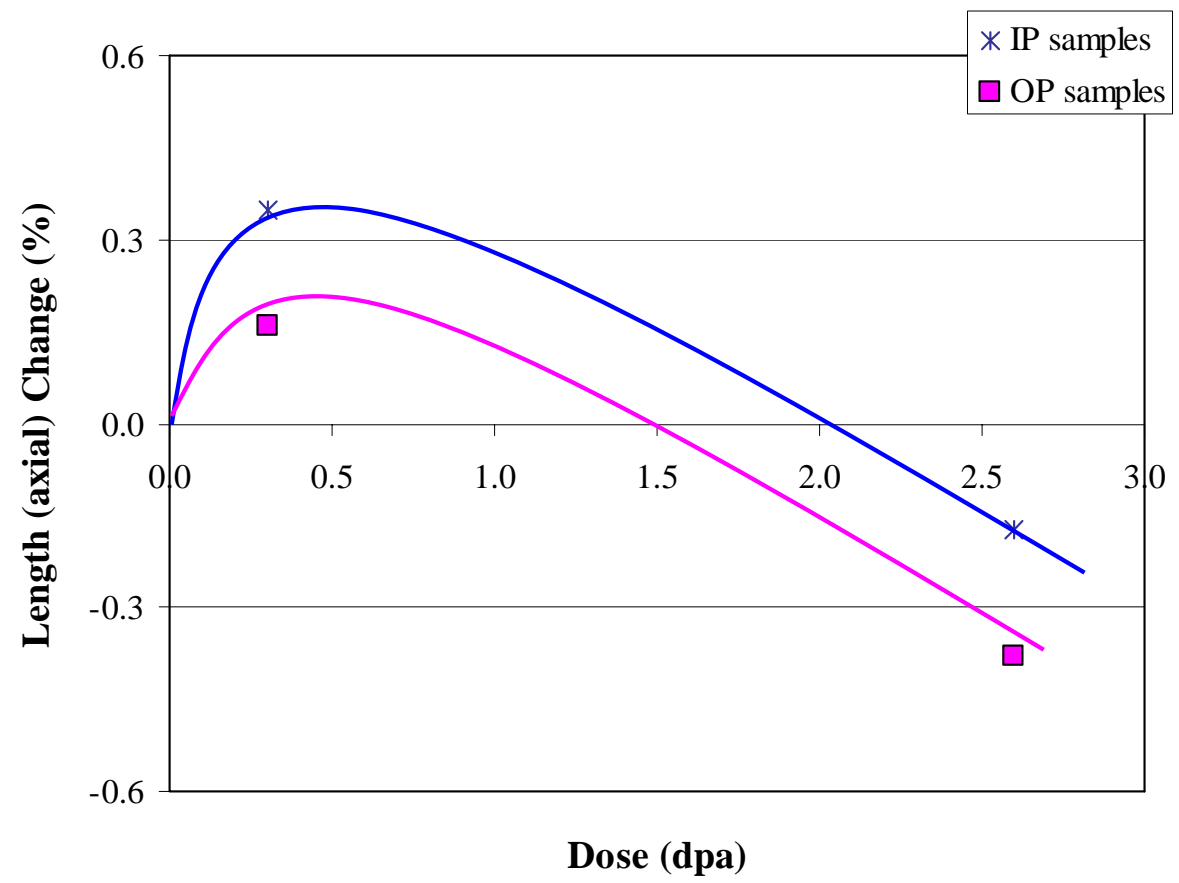

Fig. 4.22. Dimensional changes $(\Delta \mathrm{l} / \mathrm{l})$ as a function of irradiation dose for graphite foam samples.

foam at the temperature of this irradiation study. Here we develop a simple microstructural model of graphite foam and, by coupling this model to the known single crystal and polycrystalline irradiation behavior of graphite, postulate a mechanism by which the irradiation-induced volume and dimensional changes in graphite foam may be explained.

4.2.1.3.2 A simple microstructural model of graphite foams. SEM micrographs of graphite foam are presented in Fig. 4.23. During manufacture of the foam, the expansion of evolving pyrolysis gases 


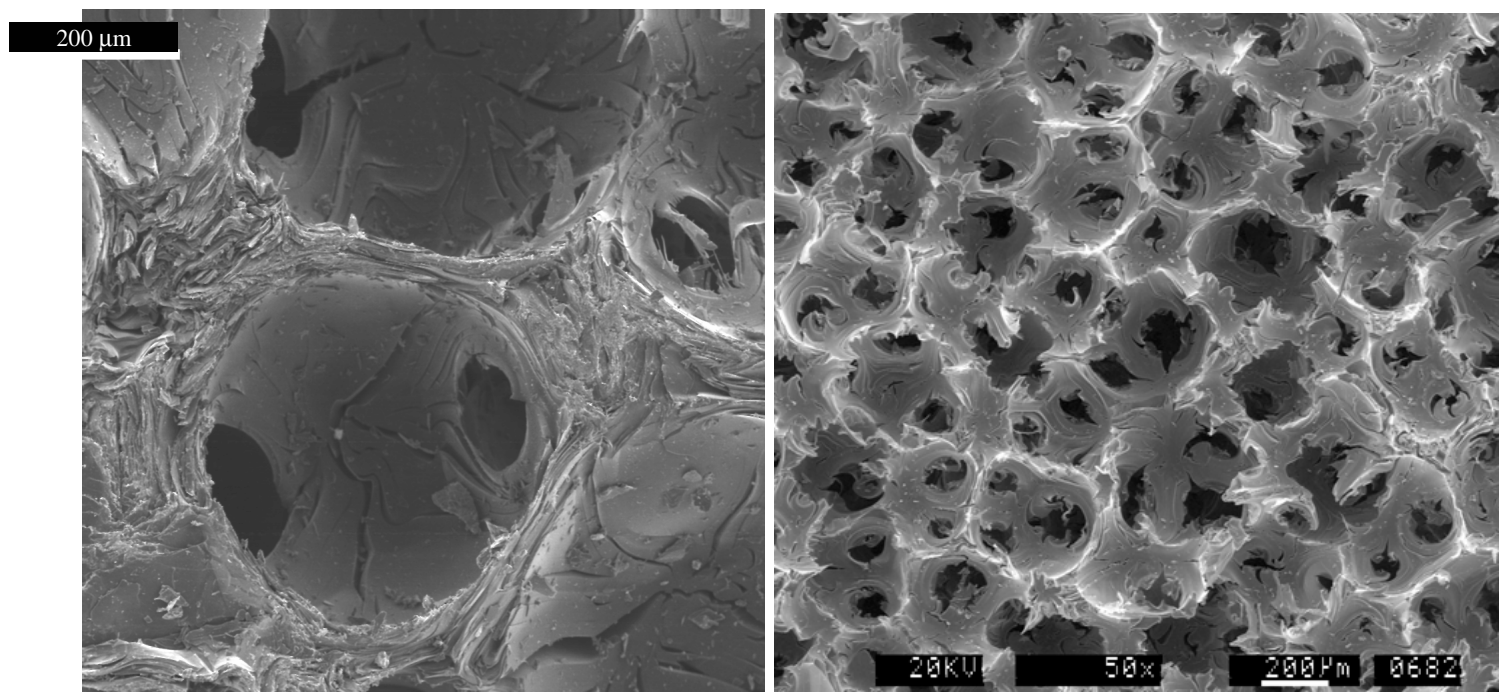

Fig. 4.23. SEM images of the graphite foam.

results in the stretching of the carbonaceous mesophase. Therefore, during graphitization the walls of the foam cells develop strong graphitic basal plane orientation, with the crystallographic $<c>$-direction being preferentially aligned tangentially to the bubble circumference. These regions of the foam microstructure (termed ligaments) are isochromatic when observed on an optical microscope under polarized lights, as indicated in Fig. 4.24. The regions where the ligaments merge can be seen in Fig. 4.24 to be composed of small crystals forming a polycrystalline zone, as indicated by the small-domain structure observed in Fig. 4.24.

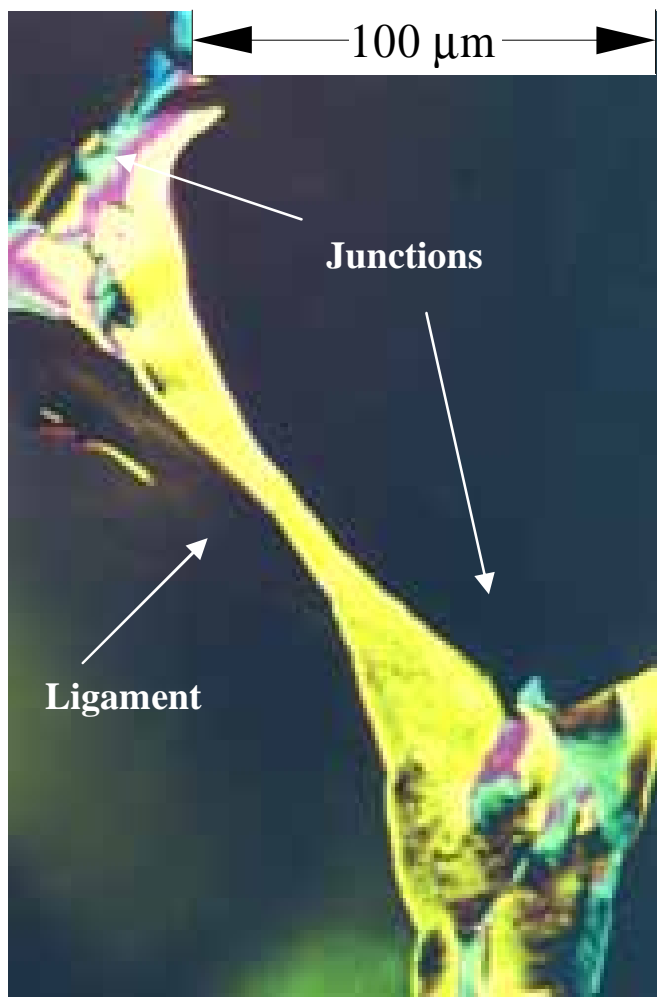

Fig. 4.24. Cross-polarized light image of graphite foam ligament and junction. 
Based on the microstructure revealed by optical microscopy, the following microstructural model is proposed. The graphite foam is postulated to be comprised of well-aligned graphite walls or ligaments surrounding and encapsulating the bubbles. Within the bubble walls or ligaments, the graphite layers are assumed to be aligned as the skins of an onion. The crystallographic <a>-direction is contained within the "onion skin," whereas the crystallographic <c>-direction is perpendicular to the "onion skins." Where the ligaments merge at adjacent bubbles, regions of polycrystalline graphite exist with small randomly oriented crystallites. These features are depicted schematically in Fig. 4.25. In polycrystalline graphites, fine microcracks are known to form parallel to the crystal basal planes during cooling from graphitization. The formation of the cracks accommodates thermal strains arising at the crystal boundaries due to the mismatch of coefficients of thermal expansion (CTEs) in the graphite single crystal (CTE is large and positive in the $\langle\mathrm{c}\rangle$-direction and small and negative in the $\langle\mathrm{a}\rangle$-direction). It is postulated that thermally induced, aligned microcracks such as these are prevalent in the polycrystalline regions of the foam (Fig. 4.24). Moreover, because the ligaments are considered to essentially be stretched single crystals and thus would not be expected to experience the thermal mismatch strain, it is assumed that they are effectively free of basal plane microcracks.

Polycrystalline regions exist where the ligaments coalesce. Within these regions the crystallites are randomly orientated, and aligned microcracks exist between the basal planes. Such cracks are absent from the ligament regions, which are assumed to be essentially stretched single graphite crystals.

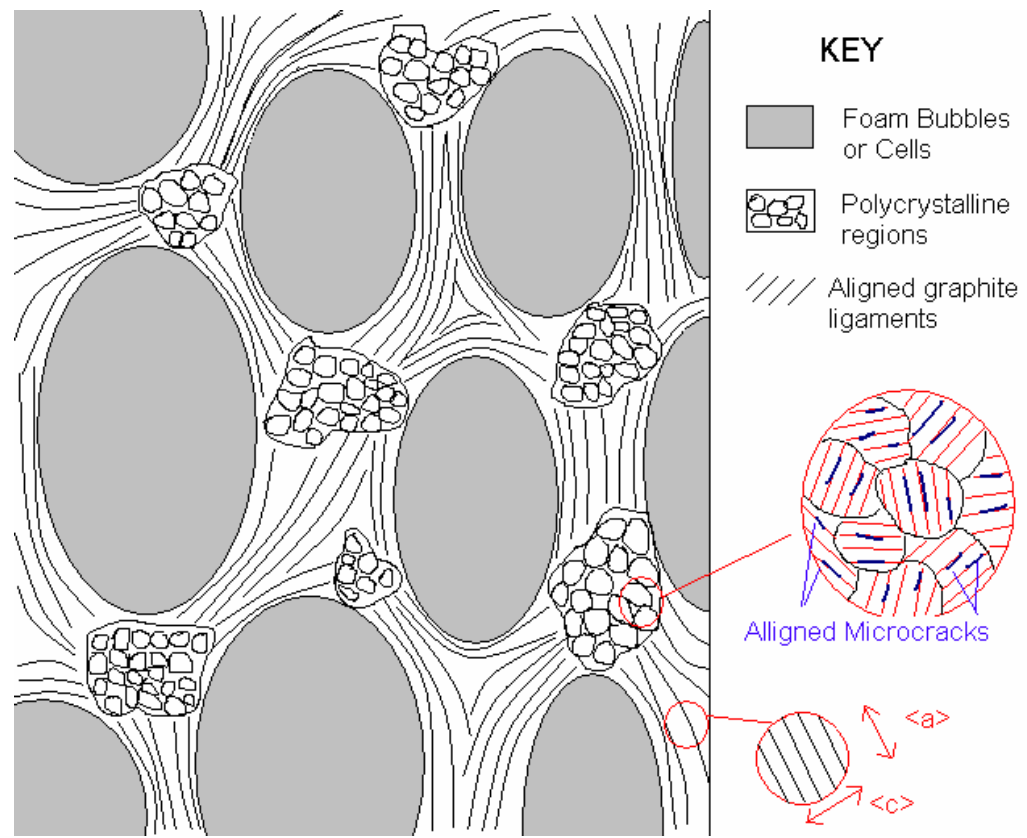

Fig. 4.25. A schematic 2-D representation of the postulated microstructural model of graphite foam.

4.2.1.3.3 Displacement damage in the graphite single crystal. Figure 4.26 illustrates the displacement mechanism of the graphite single crystal and the associated dimensional changes. Impinging fast neutrons cause the displacement of carbon atoms from their equilibrium lattice positions into interstitial locations between the graphite basal planes, leaving a vacancy in the basal plane. These interstitial carbon atoms are mobile at room temperature and migrate between the graphite layer planes, where they may be annihilated by combination with basal plane vacancies or may coalesce with other displaced carbon atoms to form clusters and eventually new graphite planes. This results in an expansion of the crystal in the $\langle\mathrm{c}\rangle$-direction (Fig. 4.26). The basal plane vacancies are mobile above $300^{\circ} \mathrm{C}$ and can coalesce, causing shrinkage parallel to the basal planes (<a>-direction). In polycrystalline graphite, aligned 


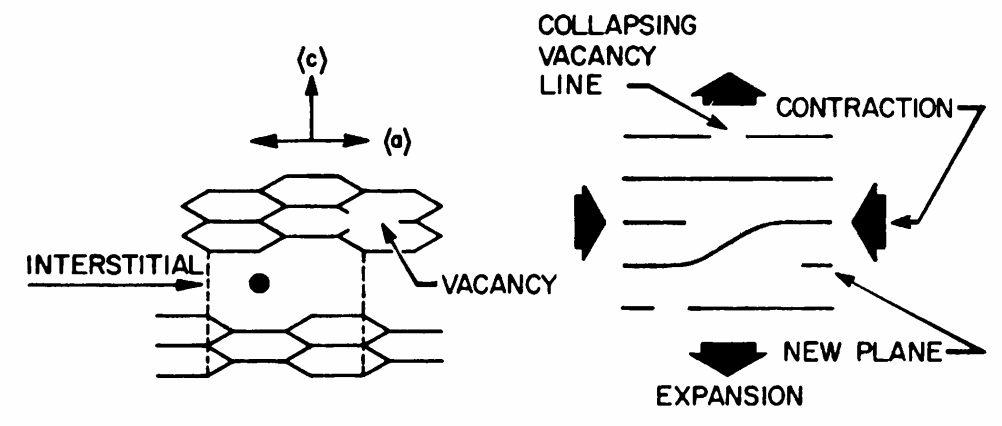

Fig. 4.26. Radiation damage in graphite showing the induced crystal dimensional strains.

microcracks existing between the basal planes may initially accommodate the $\langle\mathrm{c}\rangle$-axis growth. Therefore, the low-dose behavior of polycrystalline graphite is dominated by the <a>-direction shrinkage. Upon further irradiation the mismatch of crystal strains arising from $\langle a\rangle$-axis shrinkage and $\langle\mathrm{c}\rangle$-axis growth causes the generation of crack and voids, causing the polycrystalline material to "turn around" from shrinkage to volumetric swelling.

Combining the simple microstructural model described here and the explanation of single and polycrystalline graphites irradiation behavior, we may attempt to explain the irradiation-induced volume and dimensional changes of graphite foam reported in Figs. 4.21 and 4.22.

4.2.1.3.4 Irradiation-induced volume changes in graphite foam. When graphite foam is initially irradiated, $\langle\mathrm{c}\rangle$-axis growth occurs in the foam ligaments and within the polycrystalline regions of the foam. The absence of accommodating porosity in the ligaments causes the bubble walls to expand as depicted in Fig. 4.27 and contract in the perpendicular direction due to $<a>$ shrinkage. In contrast, the $<c>$-axis growth in the polycrystalline regions is accommodated by aligned microcracks between the layer planes. The polycrystalline regions, therefore, initially undergo volume shrinkage (Fig. 4.27) due to $<\mathrm{a}>$-axis contraction.

The expansion of the ligaments (pore walls) will cause the formation of cracks and voids in the structure of the graphite foam, thus accommodating and relaxing the internal strains but causing a rapid increase in specimen volume (reduction in density).

Two distinct types of cracks may be postulated in the graphite foam. The bonds between graphene sheets in graphite are Van der Waals type bonds and are orders of magnitude weaker than the in-plane

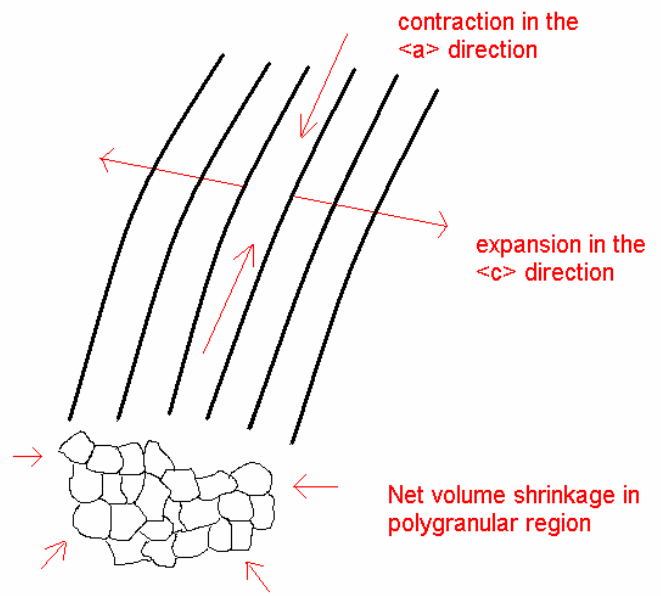

Fig. 4.27. Schematic representation of initial strain in graphite foam. 
covalent bonds. Therefore, strains within the graphite crystal lattice will cause cracks to develop between the grapheme layers (Fig. 4.28). Here we designate these as type I cracks. At the junctions between the ligaments and polycrystalline regions, a second type of crack may be postulated. The polycrystalline regions will initially exhibit shrinkage; thus, at the boundaries with ligaments (Fig. 4.28) both tensile and shear strains (from the polycrystalline shrinkage and the ligament growth, respectively) will cause fracture and separation of the boundary, creating voids. Here we designate these as type II cracks. The absence of accommodating $<\mathrm{a}>$-axis porosity in the ligaments (between the onion skins) in the unirradiated foam will thus create rapid pore generation in the graphite foam, and a concomitant increase in volume. Some direct evidence for the formation of type I and II cracks may be found in the SEM micrographs of irradiated graphite foam samples in Figs. 4.29 and 4.30.

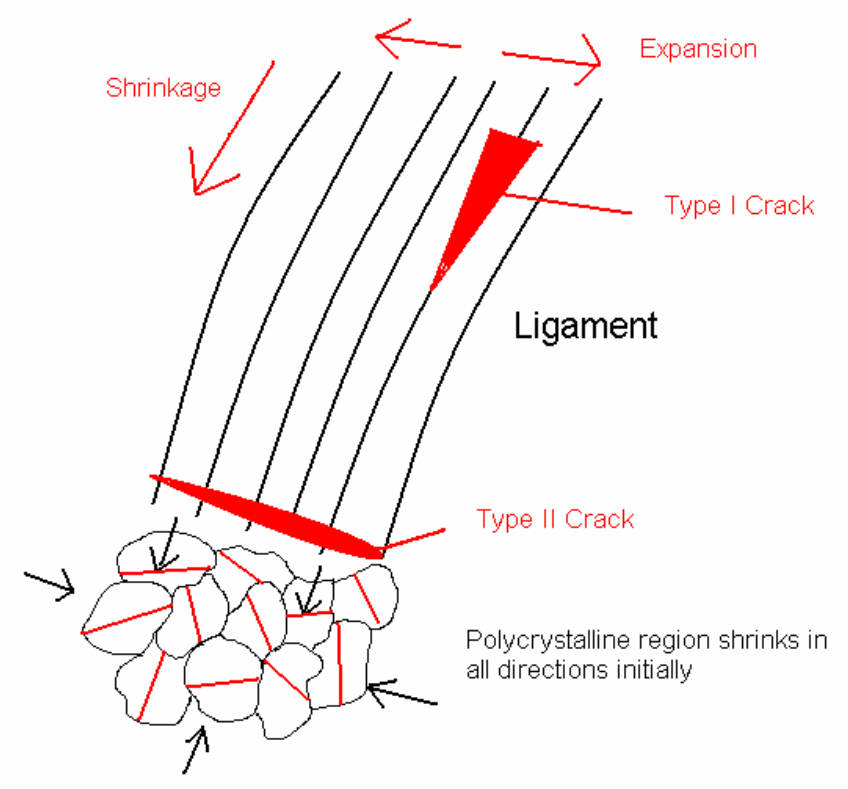

Fig. 4.28. The formations of type I and II cracks.
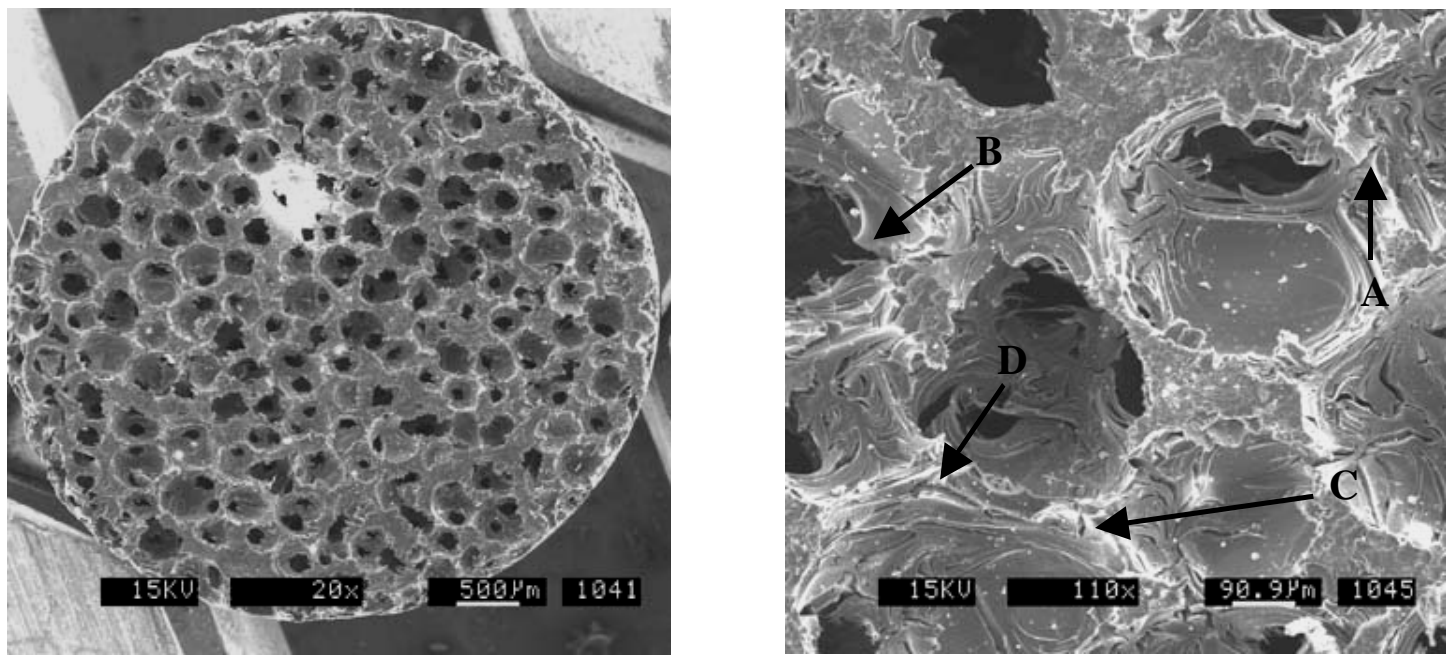

Fig. 4.29. SEM photographs of sample OP-17, $0.3 \mathrm{dpa}$. 

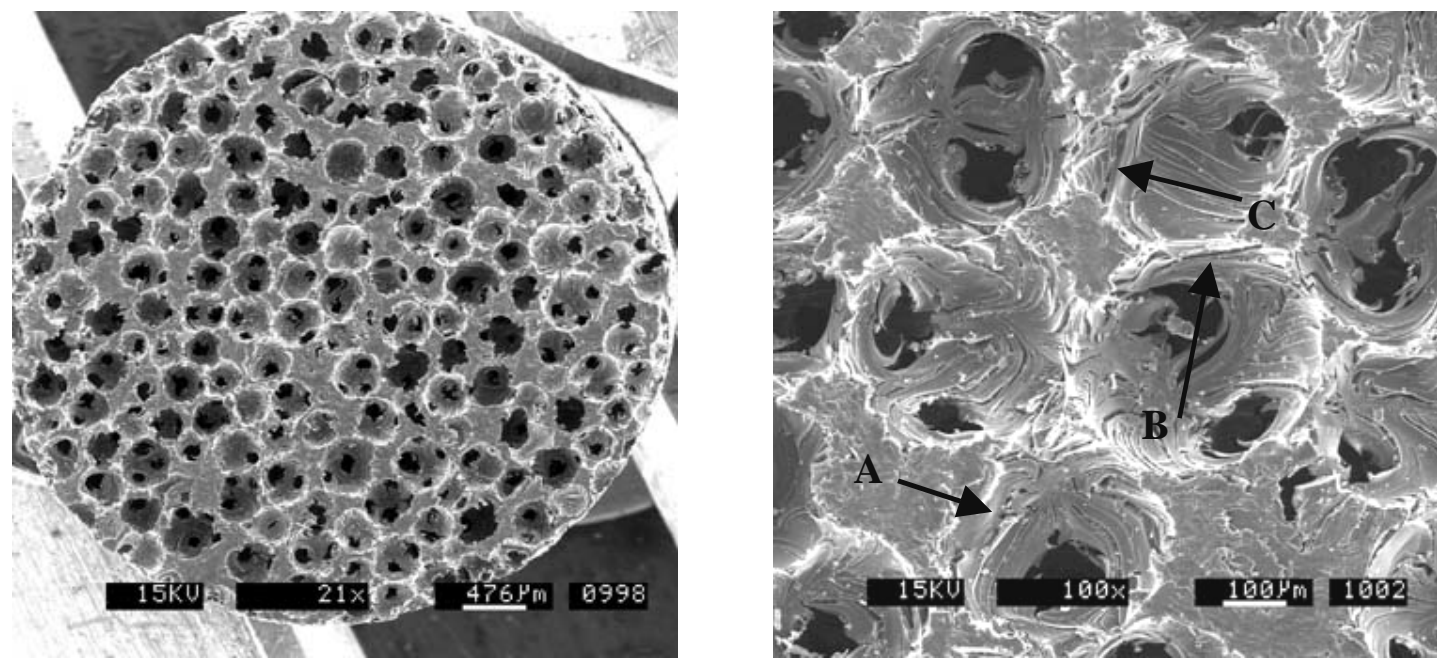

Fig. 4.30. SEM photographs of sample OP-9, 2.6 dpa.

We have postulated that low-dose irradiations cause the creation of new porosity within the graphite structure in much the same way as volume swelling is seen in polygrannular graphite. However, graphite foam differs markedly from polygrannular graphite in several ways, but most significantly in its density. Polygrannular graphites typically exhibit bulk densities in the range $1.75-1.85 \mathrm{~g} / \mathrm{cm}^{3}$ (i.e., less than $30 \%$ porosity). Graphite foam, however, has a bulk density of $\sim 0.5 \mathrm{~g} / \mathrm{cm}^{3}$ or a porosity level of greater than $75 \%$. In the graphite foam the majority of this porosity is in the form of interconnected bubbles creating the open cell structure. To explain the graphite foams volume turnaround to shrinkage at higher doses (Fig. 4.21), we must take account of possible interactions between the graphite and the bubbles it surrounds.

Here we postulate that with increasing neutron dose, the ligaments (cell walls) surrounding the bubbles begin to collapse inward. This inward collapse is driven by the ligament "thickening" and shrinkage in the <a>-direction previously postulated and is facilitated by the type II cracks in the foam (Fig. 4.31). The formation of type I and II cracks will continue to occur within the graphite foam structure;

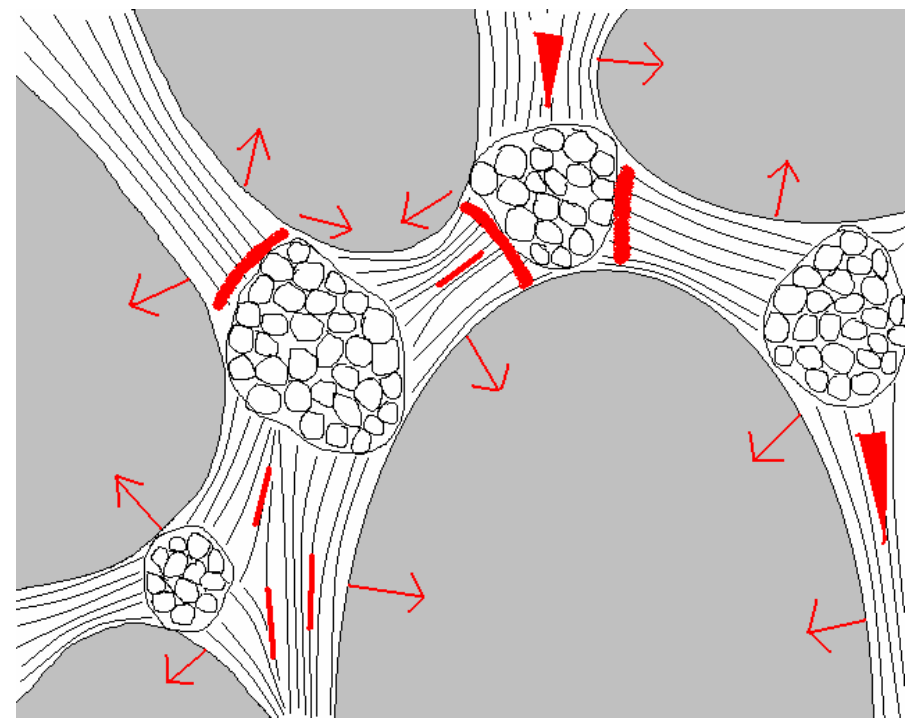

Fig. 4.31. An illustration of the graphite cell collapsing around a bubble in the graphite foam, driven by ligament thickening and contraction (type I cracking) and facilitated by type II cracks. 
but, as the neutron dose increases, the entire graphite network collapses around the bubbles causing a contraction of the cells and a turnaround from volume swelling due to pore generation alone to net volume shrinkage.

Because the postulated mechanisms of volume shrinkage via bubble collapse requires the formation of structural defects and cracks, it is apparent that the foam cannot continue to contract (or implode) upon itself indefinitely but rather will begin, at some as yet unknown neutron dose, to disintegrate. Prior to disintegration the graphite foam might be expected to exhibit another reversal into volume swelling, just as polygrannular graphite would behave. The need for higher dose irradiations is thus indicated.

4.2.1.3.5 Graphite foam dimensional changes and the effect of texture. As discussed previously, and shown in Fig. 4.18, the irradiation samples have significant preferred structural orientation resulting from the manufacturing process. The foam bubbles are elliptical in cross sections in one plane and circular in cross sections in the perpendicular plane (i.e., the bubbles are egg-shaped). The OP samples exhibit bubbles whose major axes are aligned parallel to the sample length. The IP samples have the bubbles' major axis perpendicular to the specimen length.

On initial irradiation we have postulated that the formation of internal voids is due to the mismatch of intercrystallographic strains. Thus, the length of the specimens would be expected to initially grow as the sample volume swells. The data in Fig. 4.22 confirm this; however, the initial rate of expansion is apparently greater in the IP specimens. This may be explained by considering the microstructural model in Fig. 4.25. The initial dimensional growth rate along the direction one-half to the bubble major axis will be influenced by the shrinkage of the polycrystalline region at the north and south poles of the bubbles and the $<\mathrm{a}>$-direction contraction in the ligaments, whereas the dimensional growth rate in the bubble east-west direction will be influenced by the polycrystallite shrinkage and the $\langle c\rangle$-axis swelling (thickening) of the ligaments. The OP specimens with the preferred alignment of the pores one-half to the specimen length should thus exhibit a dimensional change rate less than the IP specimens. With increasing neutron dose, the specimen dimensions turn around to shrinkage as the bubbles begin to collapse inward in the manner previously described. The data reported here suggest that turnaround occurs at smaller length changes for the OP specimen, presumably because of the slower initial rate of growth.

4.2.1.3.6 Summary. We have presently explained the experimentally observed irradiation-induced dimensional and volume changes in graphite foam via the known graphite single-crystal and polycrystallite behavior and a simple microstructural model of graphite foam. The observed volume changes in graphite foam are opposite to those observed in polygrannular graphites (i.e., growth followed by shrinkage in foam and shrinkage reversal to growth for polygrannular graphites). However, the same pore-generation mechanism is applied to the foam's initial shrinkage as is used to account for the turnaround in polygrannular graphites volume change behavior. The inverse nature of the foams behavior compared to graphite is attributed to the huge differences in the densities and, hence, porosities of the two graphite's materials. The volume change and dimensional behavior of the irradiated graphite foam is summarized in Fig. 4.32.

- Stage I: Void formation causes swelling and growth.

- Stage II: Onset of bubble collapse and slow dominance over void-formation-driven growth.

- Stage III: Void formation continues, but bubble collapse dominates and causes the bubbles to contract (inward) and the graphite foam to shrink dimensionally and volumetrically (i.e., densification).

\subsubsection{Irradiation-induced thermal property changes in graphite foam}

4.2.1.4.1 Thermal properties of preirradiated graphite foam and nuclear-grade graphite. The thermal diffusivity of nonirradiated samples with densities similar to those of irradiated samples was measured. Figure 4.33 shows average values of thermal conductivity for OP and IP samples. Data were collected only at lower temperatures $(100<\mathrm{T}<473 \mathrm{~K})$ because of problems with the high-temperature detector of the Anter system. Significant variation between thermal conductivity values of individual 


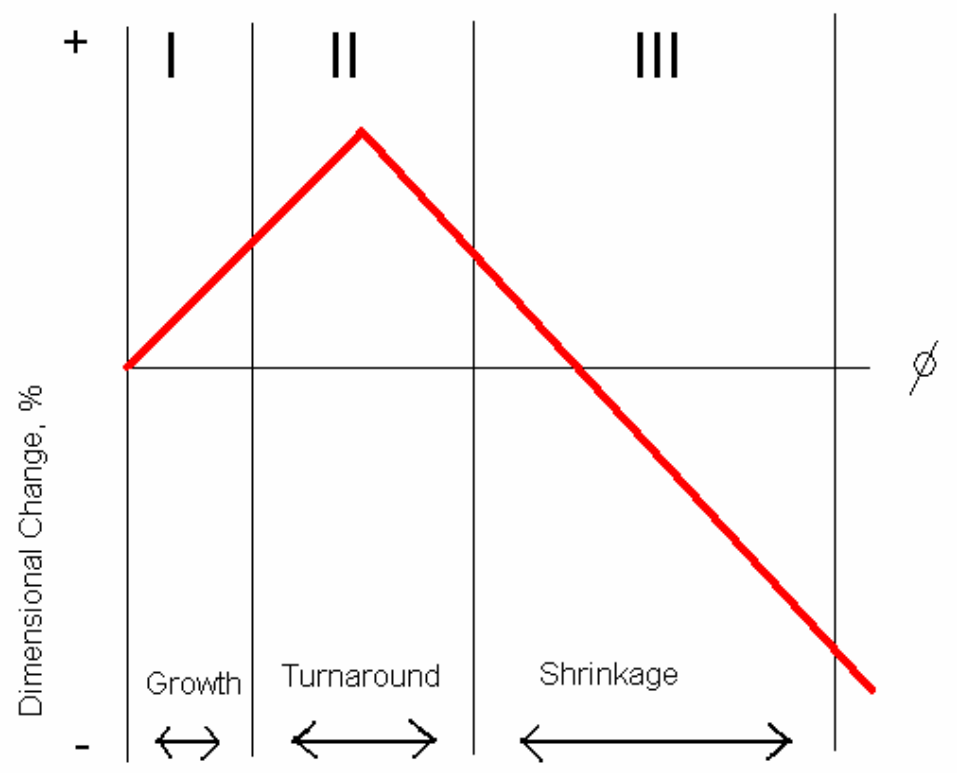

Fig. 4.32. Summary of the postulated explanation for the experimentally observed dimensional/volume changes in graphite foam after neutron irradiation.

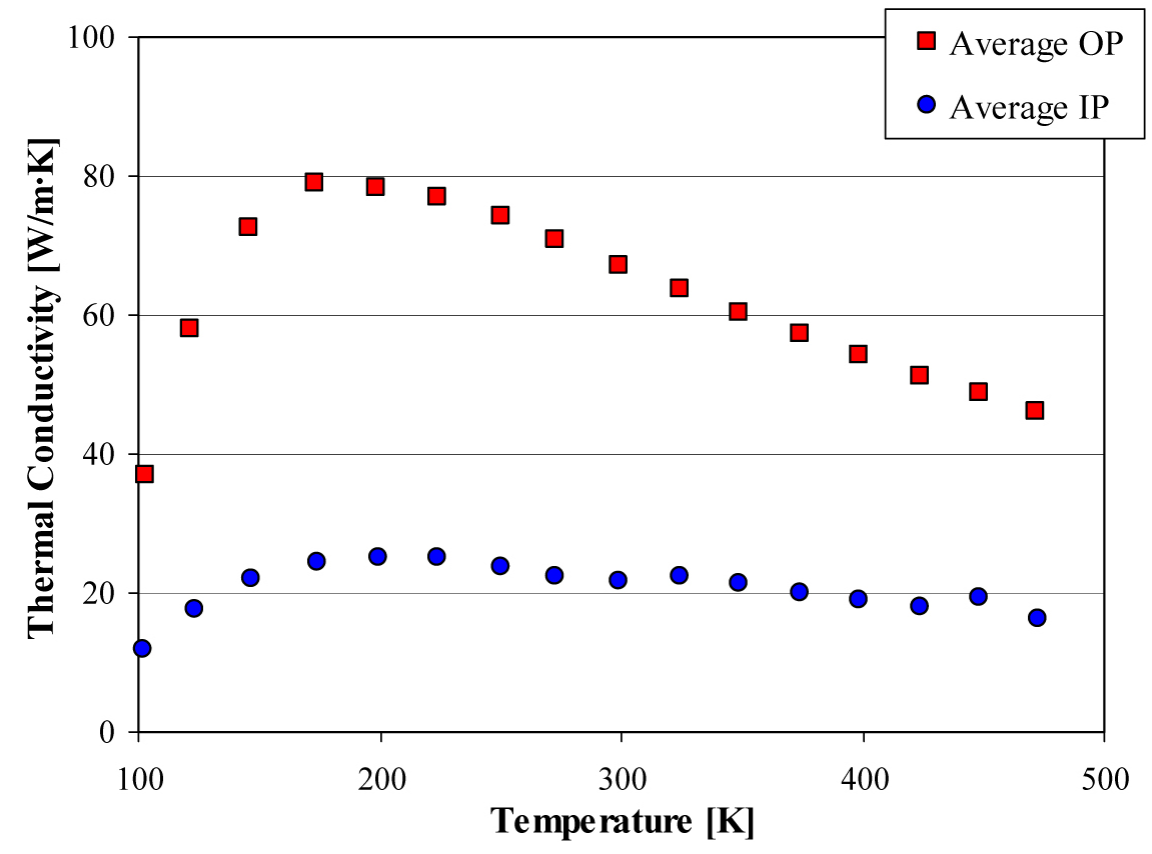

Fig. 4.33. Average values of thermal conductivity, as a function of temperature, for nonirradiated IP and OP samples. 
samples was observed; we think this was primarily due to limitations in applying the thermal flash technique for porous materials and samples of small dimensions (test samples are 6-mm-diam by 10-mmlong, and average pore size is $\sim 250-300 \mu \mathrm{m}$ ). The anisotropic nature of the properties of graphite foam is also evidenced in this figure, with higher thermal conductivity values in the Z-direction than in the $\mathrm{X}-\mathrm{Y}$ direction.

As expected, the behavior of the thermal conductivity of graphite foam with temperature is similar to that of graphite; that is, thermal conductivity decreases as temperature increases. With increasing temperature, the dominant phonon interaction becomes phonon-phonon scattering (Umklapp processes) and, thus, the observed reduction of thermal conductivity with increasing temperature. The temperature dependence of thermal conductivity for nuclear-grade graphite H 451 is shown, for reference, in Fig. 4.34.

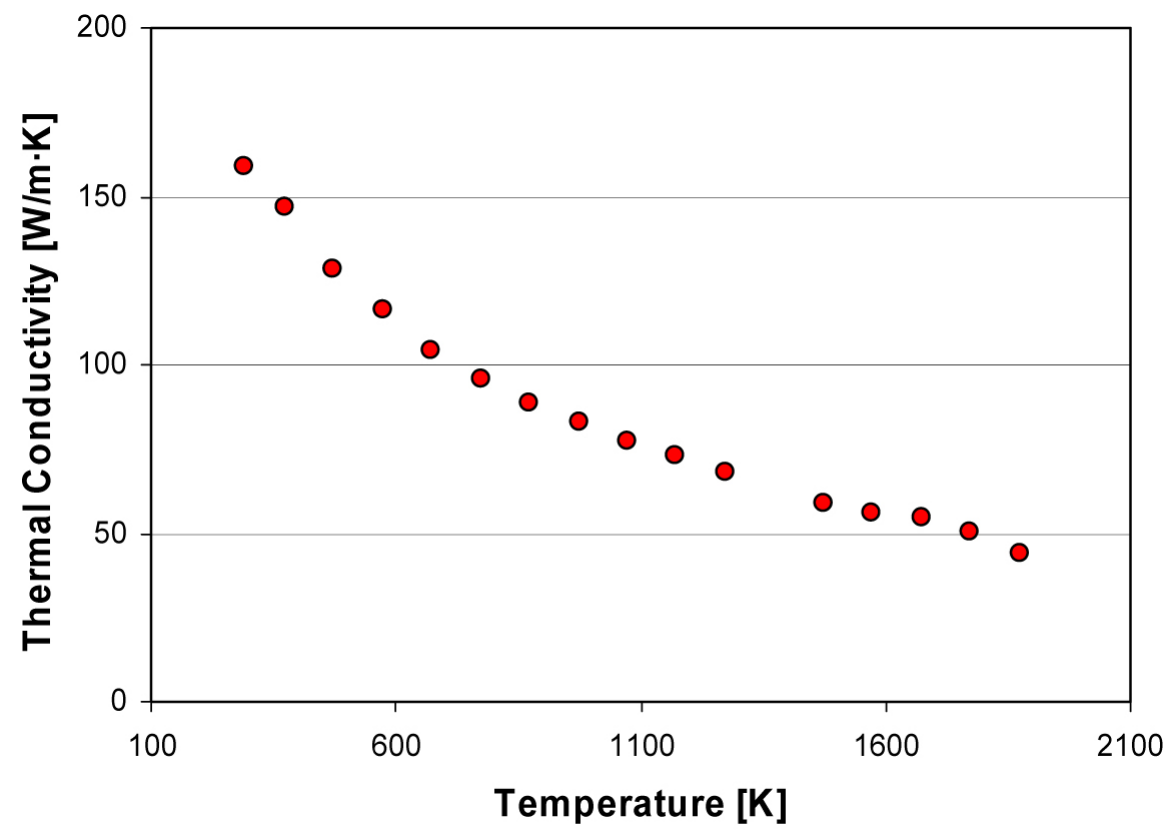

Fig. 4.34. Temperature dependence of thermal conductivity for nuclear-grade graphite $\mathbf{H} 451$.

4.2.1.4.2 Thermal properties of irradiated graphite foam. Because of budget and time limitations, combined with equipment difficulties, only two irradiated samples were evaluated for thermal properties after irradiation; annealing studies were also conducted in these samples. The selected samples were OP-9 and OP-17, irradiated to $2.6 \mathrm{dpa}$ and $0.3 \mathrm{dpa}$, respectively.

The lower curves of Figs. 4.35 and 4.36 show the temperature dependence of the graphite foam thermal conductivity after irradiation. At the irradiation temperature $\left(\sim 740^{\circ} \mathrm{C}\right)$, the room temperature thermal conductivity decreased from an average of $\sim 70 \mathrm{~W} / \mathrm{m} \cdot \mathrm{K}$ (Fig. 4.33 ) to $\sim 30 \mathrm{~W} / \mathrm{m} \cdot \mathrm{K}$ for a dose of $0.3 \mathrm{dpa}$ and to $\sim 15 \mathrm{~W} / \mathrm{m} \cdot \mathrm{K}$ for a dose of $2.6 \mathrm{dpa}$. Some fraction of the irradiation-induced damage was annealed from the material by heating it above its irradiation temperature $\left(1000^{\circ} \mathrm{C}\right)$. The annealing effect may be seen in the "cooling" curves of Figs. 4.35 and 4.36. More substantial recovery of thermal conductivity can be expected as the annealing temperature is increased, as observed in the curves for after annealing to $1200^{\circ} \mathrm{C}$.

The mechanism of thermal conductivity and the degradation of thermal conductivity of graphite materials have been extensively reviewed. ${ }^{13-18}$ The increase of thermal resistance due to irradiation damage has been ascribed to the formation of the following: (1) submicroscopic interstitial clusters containing $4 \pm 2$ carbon atoms; (2) vacant lattice sites, existing as singles, pairs, or small groups; and 


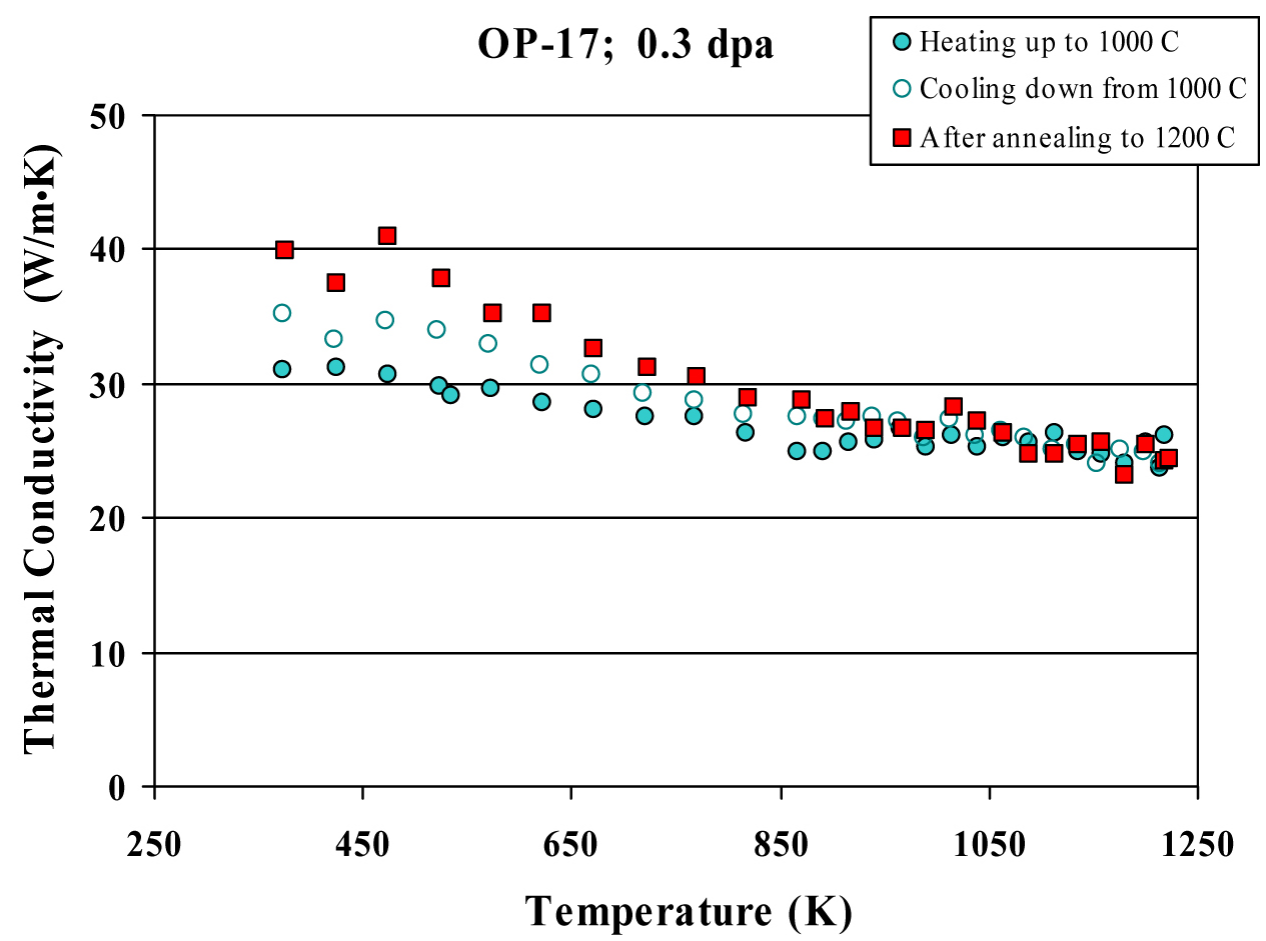

Fig. 4.35. Thermal conductivity measurements of samples OP-17 after irradiation and after annealing to $1000^{\circ} \mathrm{C}$ and $1200^{\circ} \mathrm{C}$.

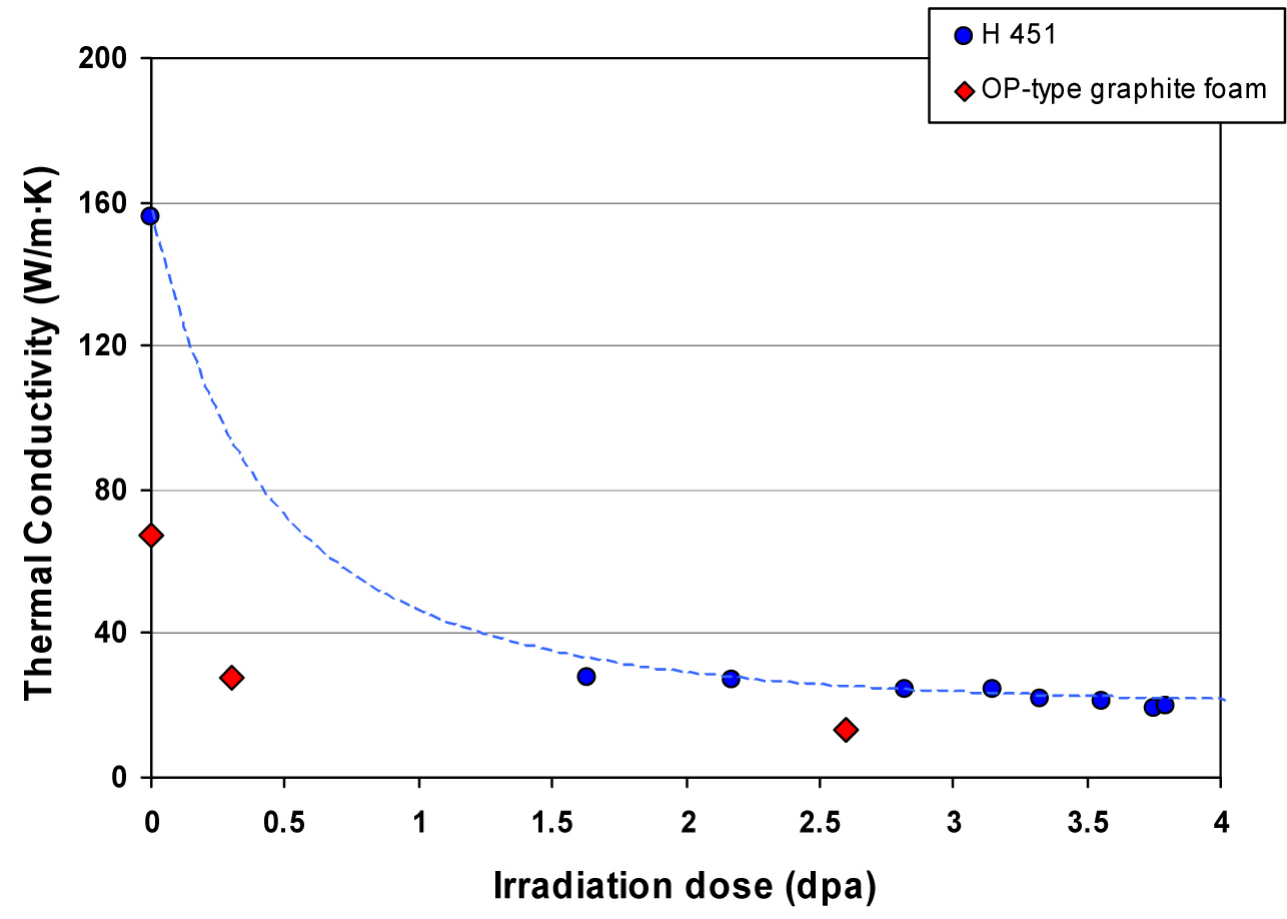

Fig. 4.36. Thermal conductivity measurements of samples OP-9 after irradiation and after annealing to $1000^{\circ} \mathrm{C}$ and $1200^{\circ} \mathrm{C}$. 
(3) vacancy loops, which exist in the basal plane of the graphite crystal and are too small to have collapsed parallel to the hexagonal axis. ${ }^{14}$

For graphite materials, the reduction in thermal conductivity due to irradiation damage is temperature and dose sensitive. At any irradiation temperature, the decreasing thermal conductivity will reach a "saturation" limit. This limit is not exceeded until the graphite undergoes gross structural changes at high fluences caused by pore generation and cracking. The saturated thermal conductivity will be attained more rapidly and will be at lower conductivity level at lower temperatures.

Thermal conductivity measurements and annealing studies of irradiated samples showed that thermal conductivity decreased as the irradiation dose increased. This effect is consistent with typical results for graphite as shown in Fig. 4.37, where the variation of room-temperature thermal conductivity as a function of irradiation dose is shown for graphite foam samples and for nuclear-grade graphite H 451 .

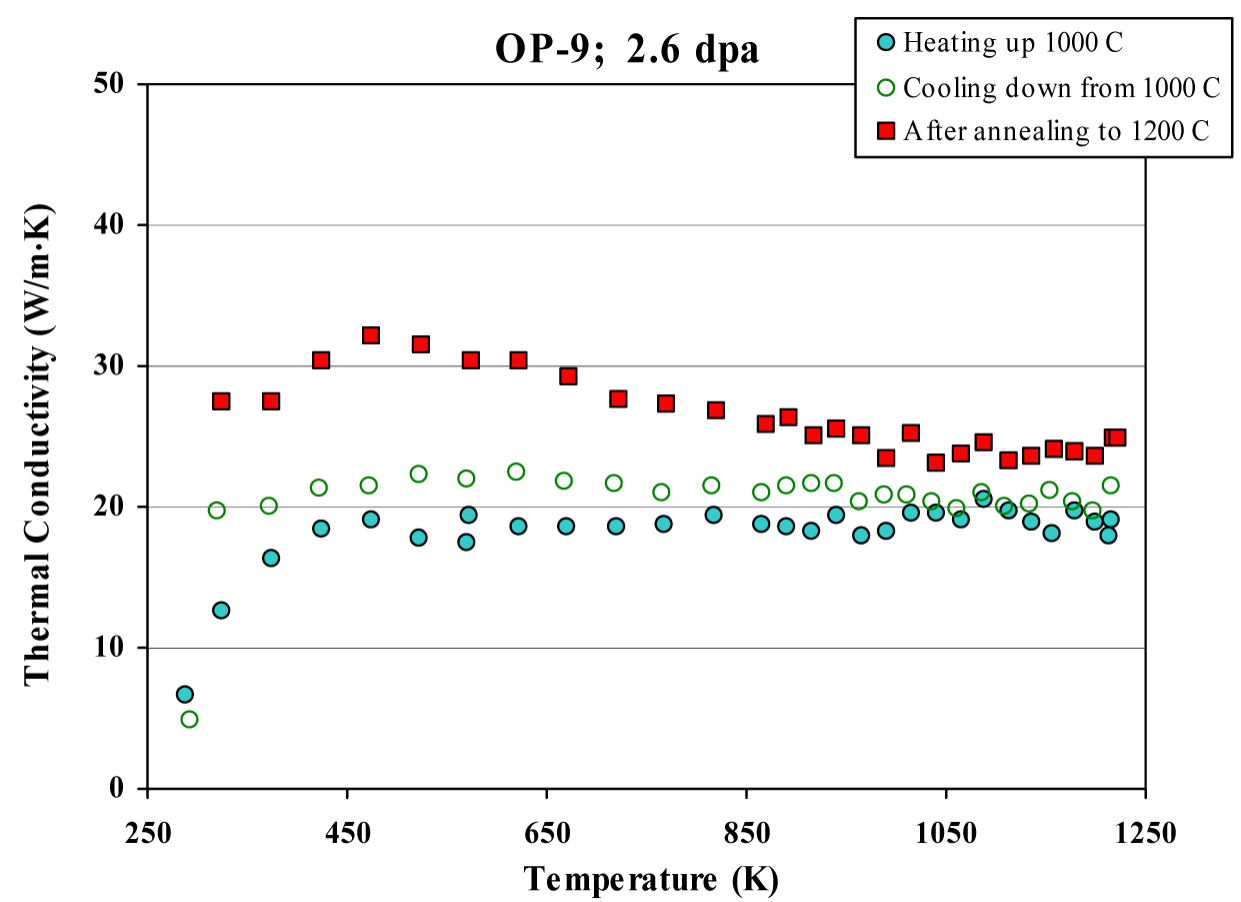

Fig. 4.37. Room temperature conductivity vs irradiation dose for (1) nuclear-grade graphite $\mathrm{H} 451$ and (2) graphite foam (OP-type samples).

4.2.1.4.3 Thermal properties of commercially available graphite foam and comparison to experimental graphite foam. The samples utilized for the irradiation studies in this project were machined from a billet of foam produced a couple of years ago, and they were not carefully characterized. There exists a need to perform a more detailed and extensive study on foam irradiation utilizing the improved and more homogeneous foam produced recently and making sure that samples are fully characterized prior to irradiation.

To get an idea of how much the foam production process has improved the properties of the foam samples, the thermal conductivity of samples from commercially available graphite foam produced by Poco was measured. Samples were cut in the same direction as that of samples OP in this project (see Fig. 4.18). The results were compared to those previously obtained for foam samples cut from the billet of foam utilized for the irradiation studies on this project. The results are plotted in Fig. 4.38. Table 4.5 lists the density values for all samples. 


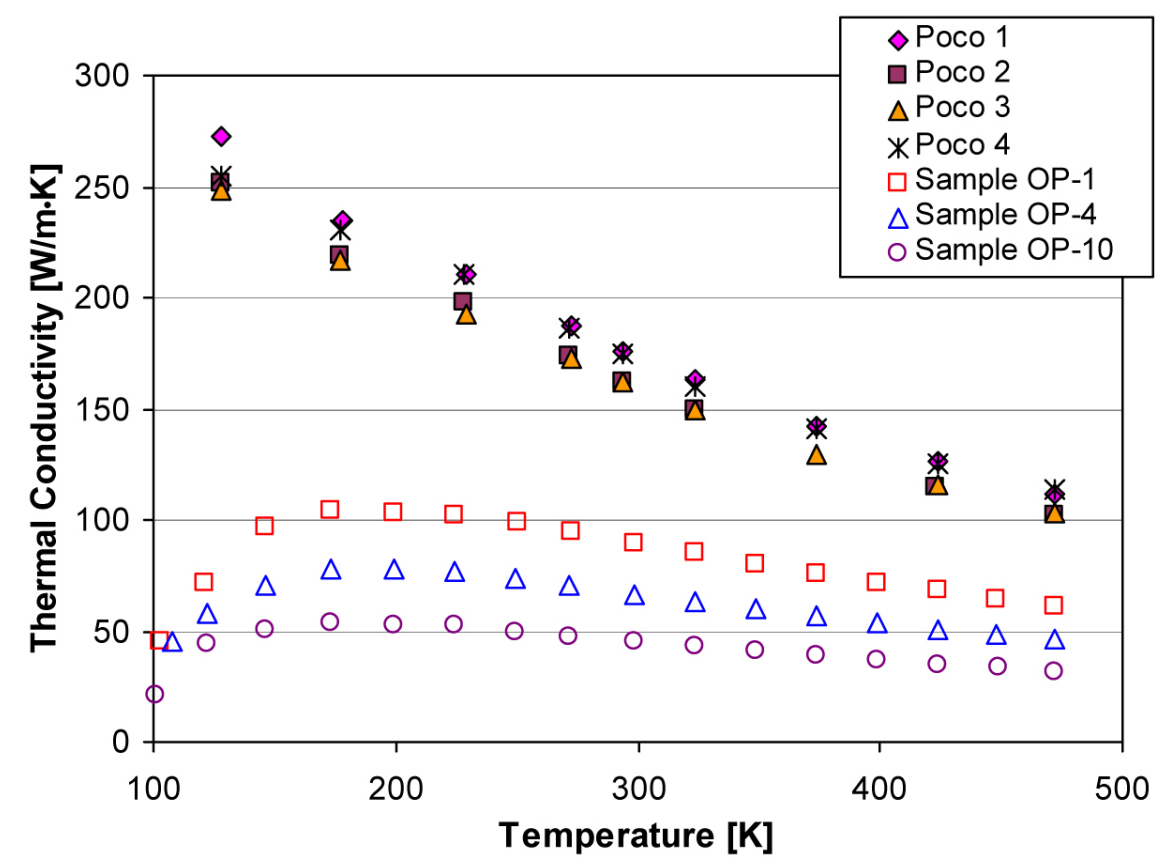

Fig. 4.38. Thermal conductivity of commercially available graphite foam (Poco ${ }^{\circledR}$ foam) compared with the thermal conductivity of foam originally produced for this project (nonirradiated samples OP-1, OP-4, and OP-10).

Table 4.5. Density of graphite foam samples

\begin{tabular}{cc||cc}
\hline \multicolumn{2}{c||}{ Original graphite foam } & \multicolumn{2}{c}{ Commercial Poco ${ }^{\circledR}$ foam } \\
\hline Sample & $\begin{array}{c}\text { Density } \\
\left(\mathbf{g} / \mathbf{c m}^{\mathbf{3}}\right)\end{array}$ & Sample & $\begin{array}{c}\text { Density } \\
\left(\mathbf{g} / \mathbf{c m}^{\mathbf{3}}\right)\end{array}$ \\
\hline OP-1 & 0.509 & Poco-1 & 0.701 \\
OP-4 & 0.431 & Poco-2 & 0.677 \\
OP-10 & 0.513 & Poco-3 & 0.671 \\
\hline
\end{tabular}

From Fig. 4.38 it is observed that commercial graphite foam exhibits considerably higher density and thermal conductivity values than the graphite foam utilized for the irradiation studies of this project. It is, therefore, anticipated that irradiated samples made from this material would exhibit higher thermal conductivities than the samples used in this study. Hence, the data generated in this study are a good conservative estimate of the thermal properties of commercial foams under irradiation conditions.

Also note that the thermal conductivity of the pristine samples does not peak in the temperature range tested. This is only typical of highly ordered or pristine graphite with very high thermal conductivity.

\subsubsection{Conclusions}

It has been shown that the foams' thermal properties decrease with both temperature and radiation dose. However, it has also been shown that the foam will recover a significant portion of that decrease due to radiation damage with proper annealing. This annealing step would be an integral part of the operation of the reactor during normal shutdown or powerdown. This behavior of reduced properties is not unique to the graphite foam. This same trend is found with highly ordered pyrolitic graphite. A significant amount of knowledge of this material and its behavior under irradiation has been gained; however, the need for further work on irradiation effects is clearly indicated. 
At the beginning of the project, a commercial vendor for the material was not available. However, since commencement of the project, the material has been licensed to Poco Graphite, Inc., and a commercial product is now available. It has been shown that the commercially available material is superior in quality and thermal properties than that initially produced at ORNL. It is anticipated that the results gained here will translate directly to the $\mathrm{POCO}^{\circledR}$ material and, therefore, it is expected that the commercial product will exhibit higher thermal properties in the reactor than that used for this project.

The current manufacturing process for graphite foams induces a preferred alignment of the ligaments of the foam in the $\mathrm{Z}$ direction. This alignment translates into an anisotropic behavior of the properties of the foam (i.e., the thermal conductivity in the Z-direction is 3-4 times that of the $\mathrm{X}$ - or Y-direction). Work has been directed toward improving the manufacturing process to eliminate/minimize the anisotropic behavior of the foam. Additionally, techniques have been developed to speed up the characterization process of foam properties. Some of the work performed includes:

1. Heat treatment of the precursor material (mesophase pitch) to eliminate some of the volatile material and increase the melting temperature. Several of the heat-treated mesophases have produced foam with very homogeneous densities across the mold. The anisotropy ratio of some of the properties has been reduced significantly (down to 1.6 , compared to 3-4 previously).

2. Extrusion techniques are being evaluated as an alternative production method. It has been proven that foam can be produced using extrusion techniques; however additional work is required to determine the appropriate conditions to produce foam that is comparable to the foam currently produced with a batch process.

\subsection{THERMAL PERFORMANCE/SIMULATION}

\subsubsection{Study of the Temperature Field}

Calculations of the temperature fields for the target reactor power of $500 \mathrm{~kW}$ of thermal energy were performed to scope the differences between cooling at the reactor core boundary and cooling at the external boundary of the reflector. These scoping calculations were performed for the preliminary core size of 100-cm-diam by 100-cm-long cylinder with a 15-cm-thick reflector on all surfaces. Two computational approaches were used to model the reactor-a simplified infinite-cylinder 1-D model and a detailed 3-D finite element.

The 1-D computations used a Bessel's $\mathrm{J}_{0}$-shaped power generation with a 1.245 axial peaking factor inside the reactor core with zero power generation in the reflector using temperature-dependent thermal conductivities on both core and reflector. The 3-D finite-element computations used a cosine-shaped power generation distribution in the axial direction and the same Bessel's $\mathrm{J}_{0}$-shaped in the radial direction inside the reactor core and zero power generation in the reflector with temperature-dependent thermal conductivities in the core six times smaller in the axial direction than in the radial direction. The temperature at the cooling boundaries was assumed to vary linearly from $703 \mathrm{~K}$ at the bottom to $945 \mathrm{~K}$ at the top.

Appendix $\mathrm{C}$ documents the mathematical representation of the power generation shapes and the directional and temperature dependence of the thermal conductivity. As shown below, the results of the 1-D piecewise computations compare well with the computationally expensive 3-D models.

\subsubsection{Solid core and reflector-results of 1-D infinite cylinder computations}

The two curves shown in Fig. 4.39, correspond to the temperature distribution at the midreactor plane (1.245 axial peaking factor) for cooling at the reflector's external surface and for cooling at the core/ reflector internal boundary. In both cases, the external temperature was taken to be $918 \mathrm{~K}$. Note that the peak temperature is $862 \mathrm{~K}$ higher (a doubling of temperature increment) for cooling from the outside surface of the reflector. 


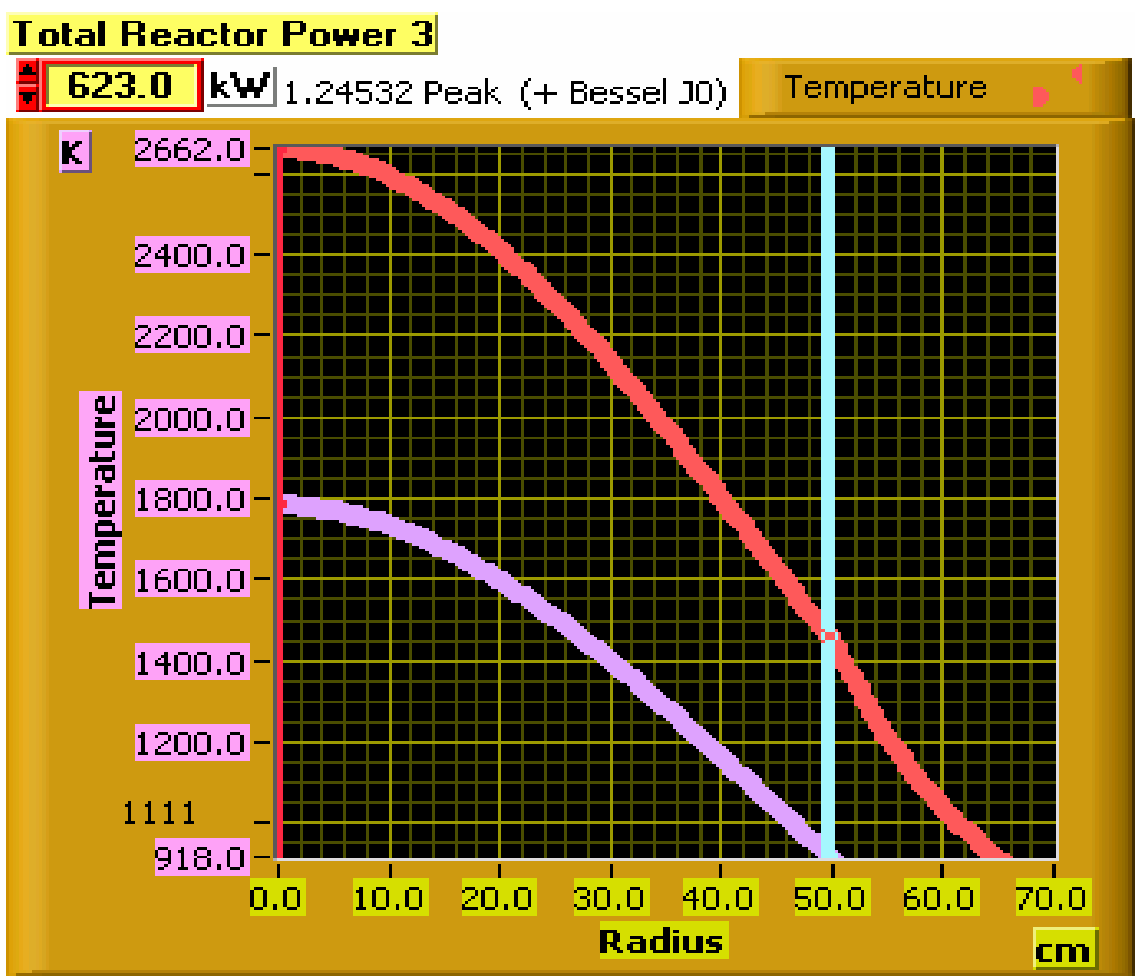

Fig. 4.39. Radial temperature distributions at midheight point for cooling: $(a)$ at the outside reflector boundary (upper curve) and (b) at the core/reflector internal boundary (lower curve).

4.3.1.1.1 Results of the 3-D finite element computations. For comparison, three cases were computed using the finite-element code ANSYS:

- Case 1a-Cooling only at the core's cylindrical boundary [Figs. 4.40( $a$ and $b)$ ]: the reflector needs not to be included.

- Case $1 \boldsymbol{b}$ - Cooling at all of the core boundaries (including top and bottom surfaces of the cylindrical core) (Fig. 4.41): the reflector needs not to be included.

- Case 2-Cooling at all of the reflector's external boundaries (including top and bottom) [Figs. 4.42 $(a$ and $b)$ ].

Note that in all cases, the thermal conductivities are temperature dependent, and in the core the thermal conductivity is six times smaller in the axial direction than in the radial direction, the inlet and outlet temperature were taken to be $730 \mathrm{~K}$ and $918 \mathrm{~K}$, and all noncooled surfaces were considered to be perfectly insulated (i.e., with zero heat flux).

4.3.1.1.2 Comparison of the 1-D and 3-D results. From Figs. 4.40(b) and 4.39, we see that for cooling at the core's cylindrical boundary, the peak temperatures for the 3-D (1841 K) and 1-D (1800 K) computations differ only about $2 \%(41 \mathrm{~K})$.

The peak temperature of Figs. 4.42(b) and 4.39 cannot be compared directly because the 3-D computation cooling was at all of the reflector's boundary, but the 1-D cooling took place only at the reflector's cylindrical boundary. Nevertheless, their peak temperatures of $2564 \mathrm{~K}$ for the 3-D case with extra cooling and $2662 \mathrm{~K}$ for the 1-D computation differ only about $4 \%(-98 \mathrm{~K})$.

In view of the small difference in the estimation of peak temperatures, we decided to use the least costly 1-D modeling approach for subsequent assessments of maximum temperatures in the reactor. The final computations were then performed using a coupled neutron and thermal computation. 
Case 1a-Cooling only at the core's cylindrical boundary

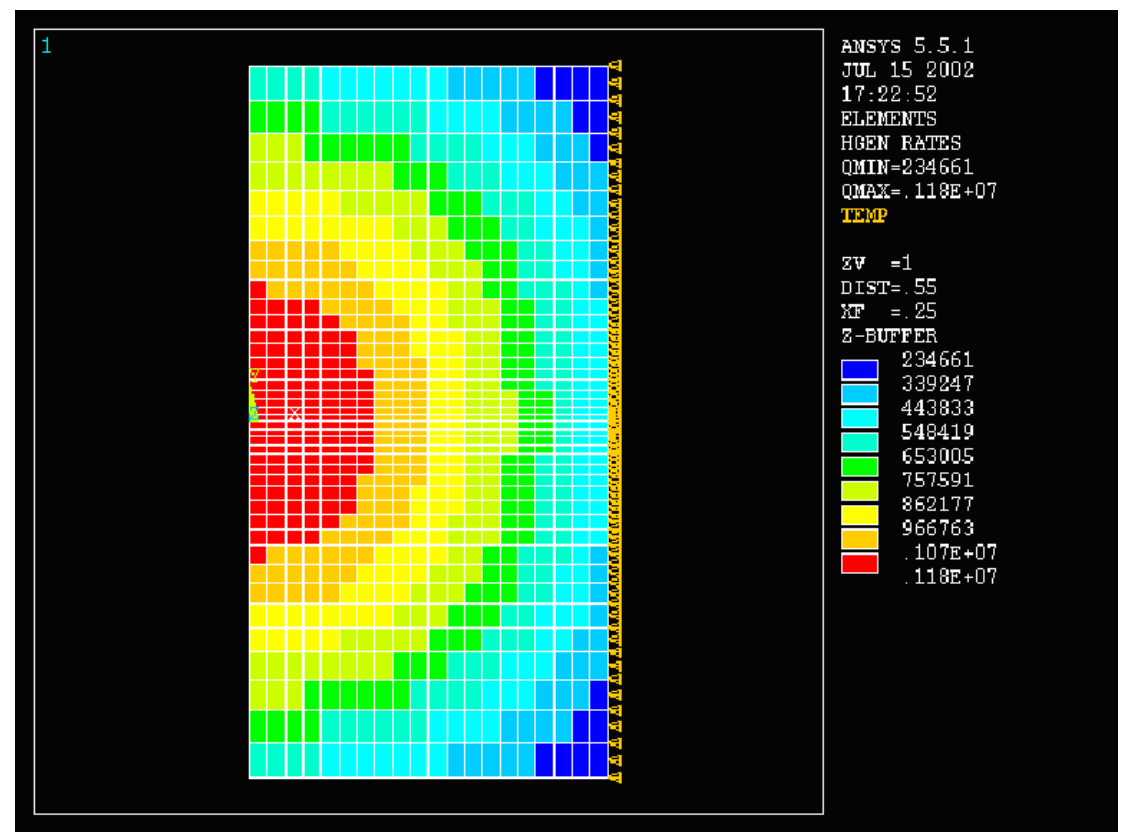

Fig. 4.40(a). Power generation density for $500 \mathrm{~kW}$ (reflector not included).

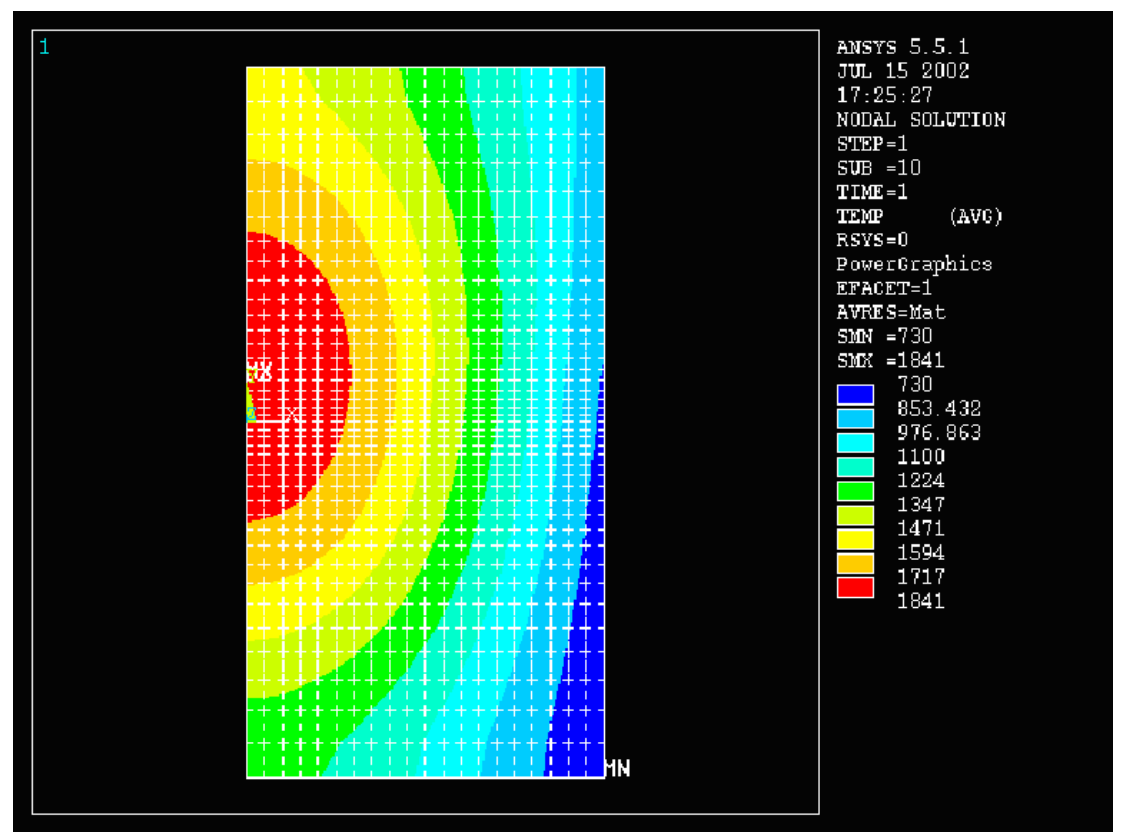

Fig. $4.40(b)$. Temperature distribution for $500 \mathrm{~kW}$ with cooling only at the core's cylindrical boundary (reflector not included). 
Case $1 b$-Cooling at all of the core boundaries (including top and bottom surfaces)

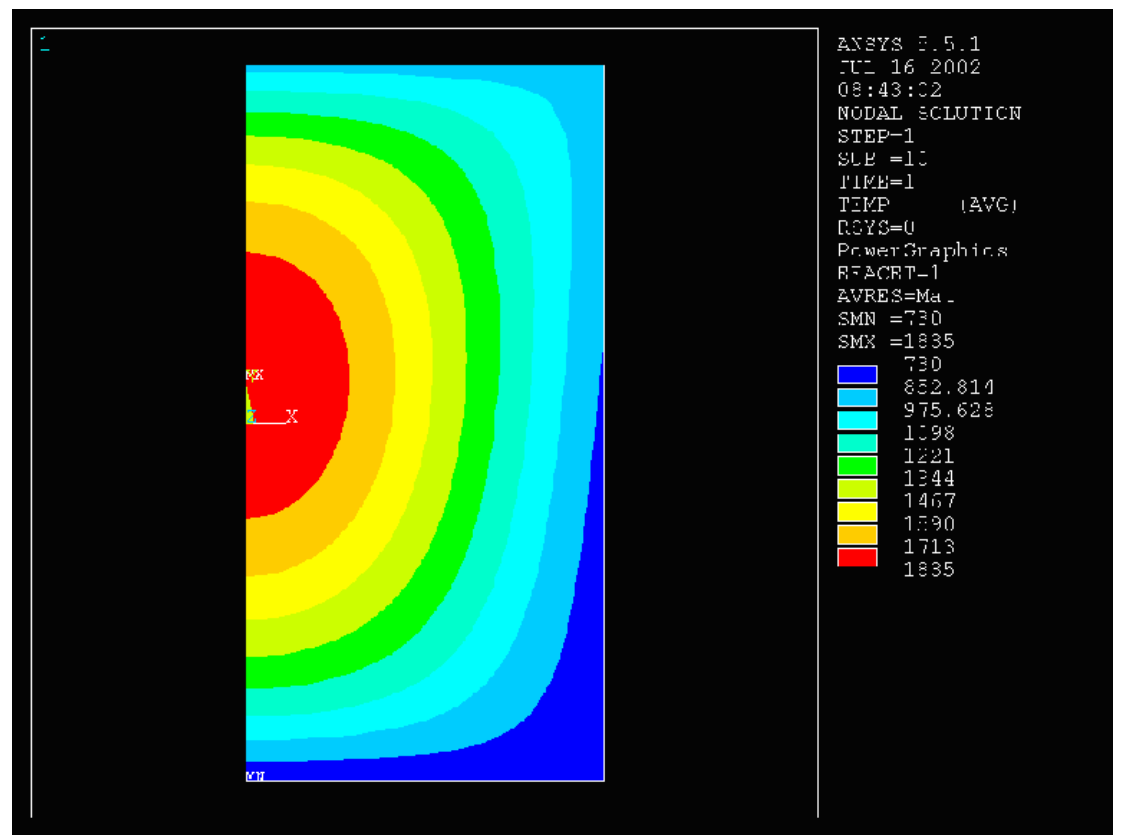

Fig. 4.41. Temperature distribution for $500 \mathrm{~kW}$ with cooling at all of the core's boundaries (reflector not included).

Case 2-Cooling at all of the reflector's external boundaries (including top and bottom surfaces)

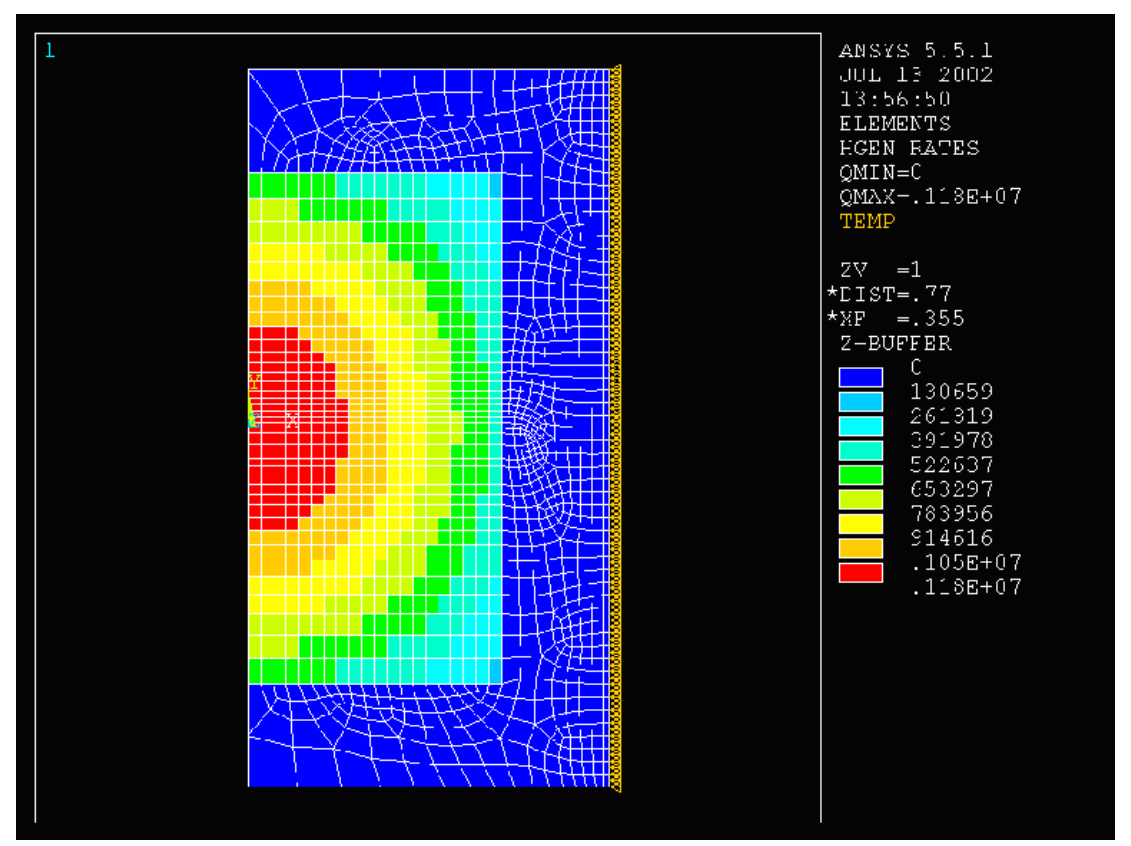

Fig. 4.42(a). Power generation density distribution for $500 \mathrm{~kW}$ with no power generation in the reflector . 


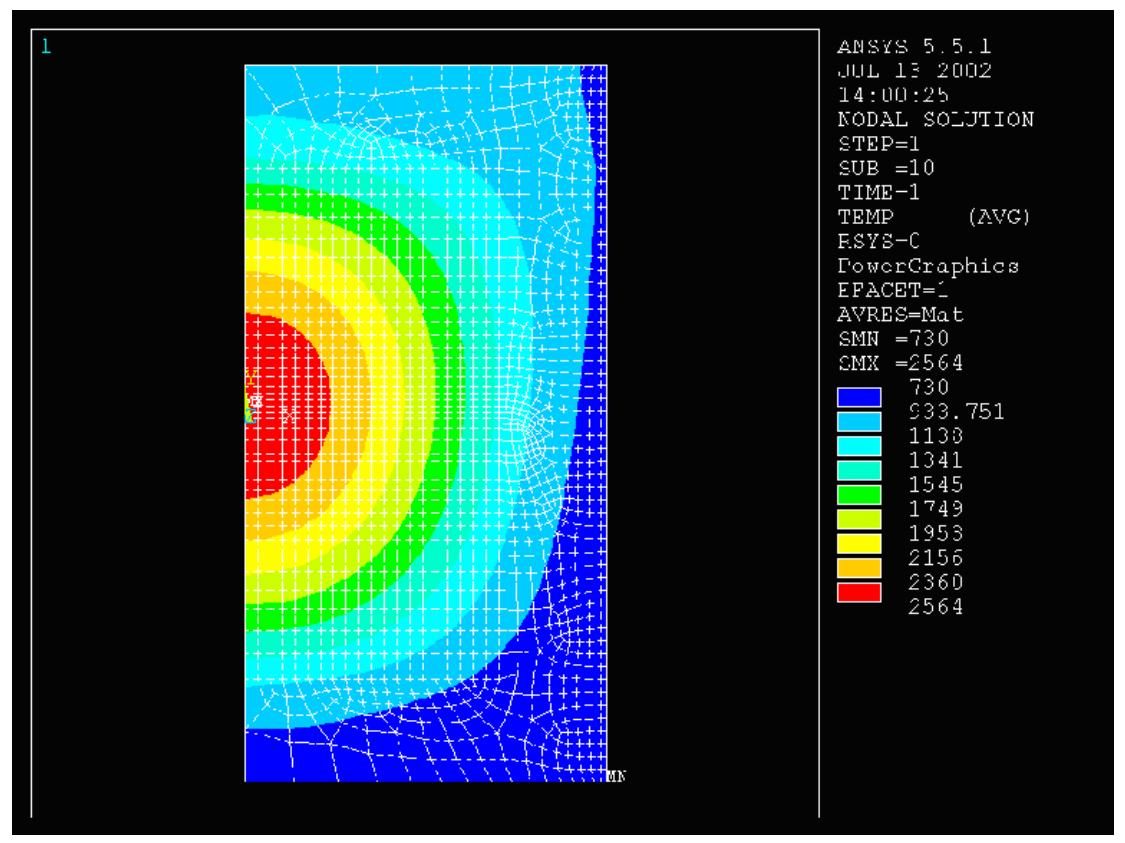

Fig. 4.42(b). Temperature distribution for $500 \mathrm{~kW}$ with cooling at all of the reflector's outside boundaries.

Comparing the peak temperatures between the 3-D cases with cooling, $1835 \mathrm{~K}$ in Fig. 4.41, and not cooling, $1851 \mathrm{~K}$ in Fig. 4.40(b), at the upper and lower circular surfaces, we can conclude that additional cooling through the upper and lower surfaces of the cylinders does not produce significantly lower peak temperatures-a $6 \mathrm{~K}$ difference in this study. This is a consequence of the much lower thermal conductivity used for the foam in the axial than in the radial direction. In the actual core, the presence of the fuel filling the foam pores will increase the heat conductivity and reduce the anisotropy, thus, enhancing the value of cooling at the top and bottom surfaces.

\subsubsection{Core with axial passages—results of 1-D infinite cylinder computations}

The 1-D and 3-D computations were performed for alternative ways to remove the heat from the reactor core. The most promising approach is that of using longitudinal holes passing through the core to remove heat by means of a fluid, gas, or molten metal flowing through them or by means of heat pipes inserted in them.

These computations were made for the 500-kW 1-m using the same power distributions and thermal conductivities as in Appendix B but with 33 holes traversing in the core as in Fig. 4.43.

The four rings of eight channels each, plus one in the center of the reactor, were placed centered on rings bound by 7.18-, 22.24-, 31.8-, 40.56-, and 50-cm radii. This configuration results in equal power production in each channel's neighborhood.

The peak temperature estimated for this configuration by the 1-D thermal simulator was $1006 \mathrm{~K}$ for cooling at $900 \mathrm{~K}$. The results obtained with the 3-D code for cooling at $900 \mathrm{~K}$ are shown below in Figs. 4.44(a)-4.44(d).

Figure 4.44(a) shows the power density for $500-\mathrm{kW}$ power generation and the 3-D mesh used. The resulting temperature field is shown in three dimensions in Fig. 4.44(b). A two-dimension cut of the temperature field of Fig. 4.44( $a$ and $b)$ is shown in Fig. 4.44(c). 


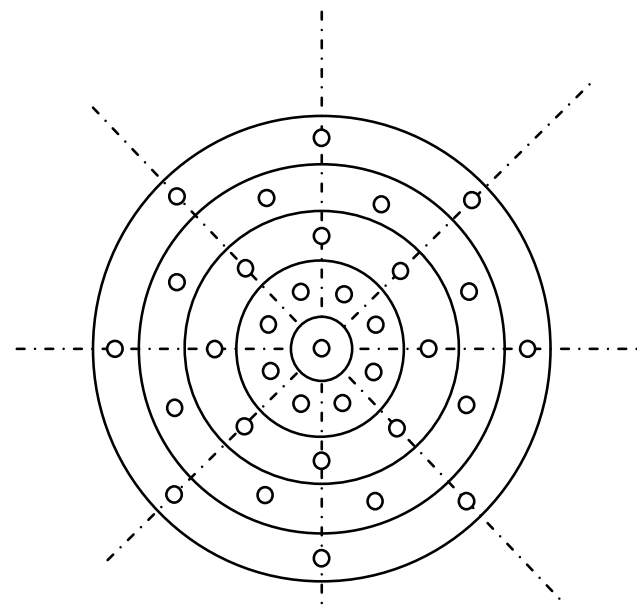

Fig. 4.43. Schematic, not to scale, of the placement of 33 heat pipes in a 4-ring configuration. The hole diameters are $1.6 \mathrm{~cm}$, and the core's outside diameter is $100 \mathrm{~cm}$.

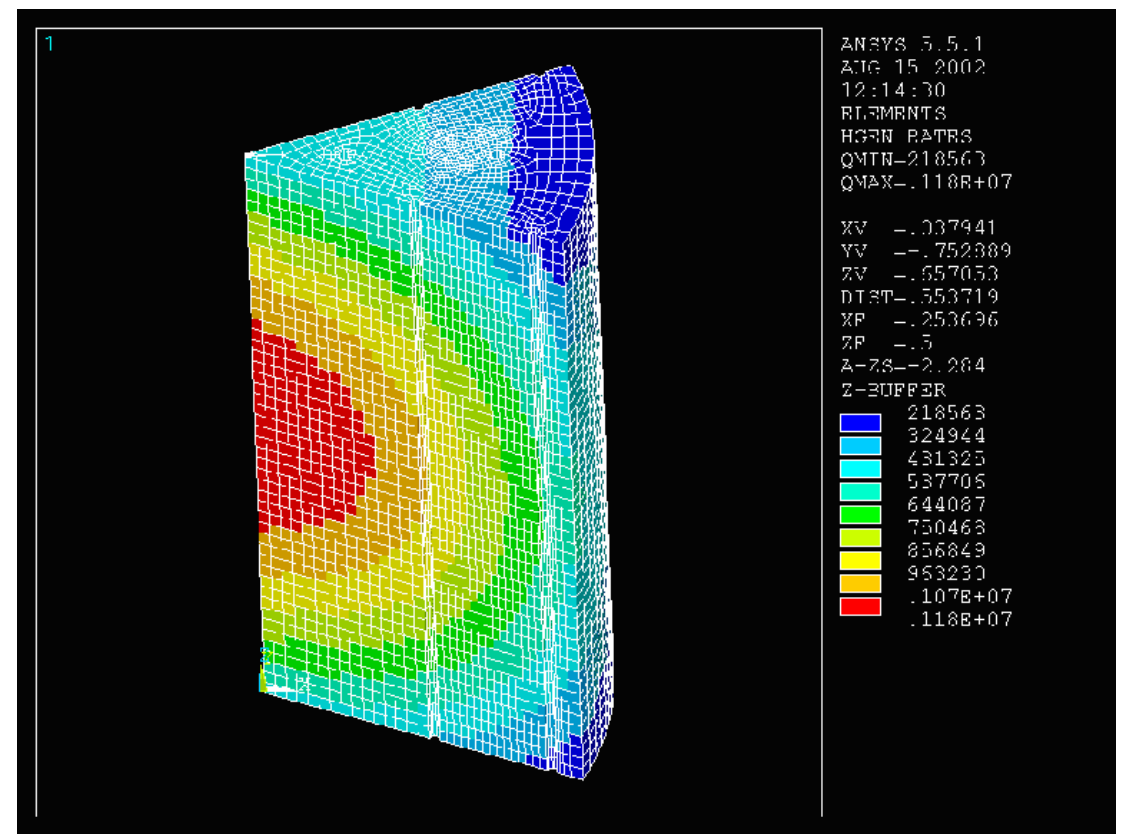

Fig. 4.44(a). Power generation density and cooling channels grip for $500 \mathrm{~kW}$. Distribution is shaped axially like a cosine and radially as a Bessel $\mathrm{J}_{0}$ (reflector not included). 


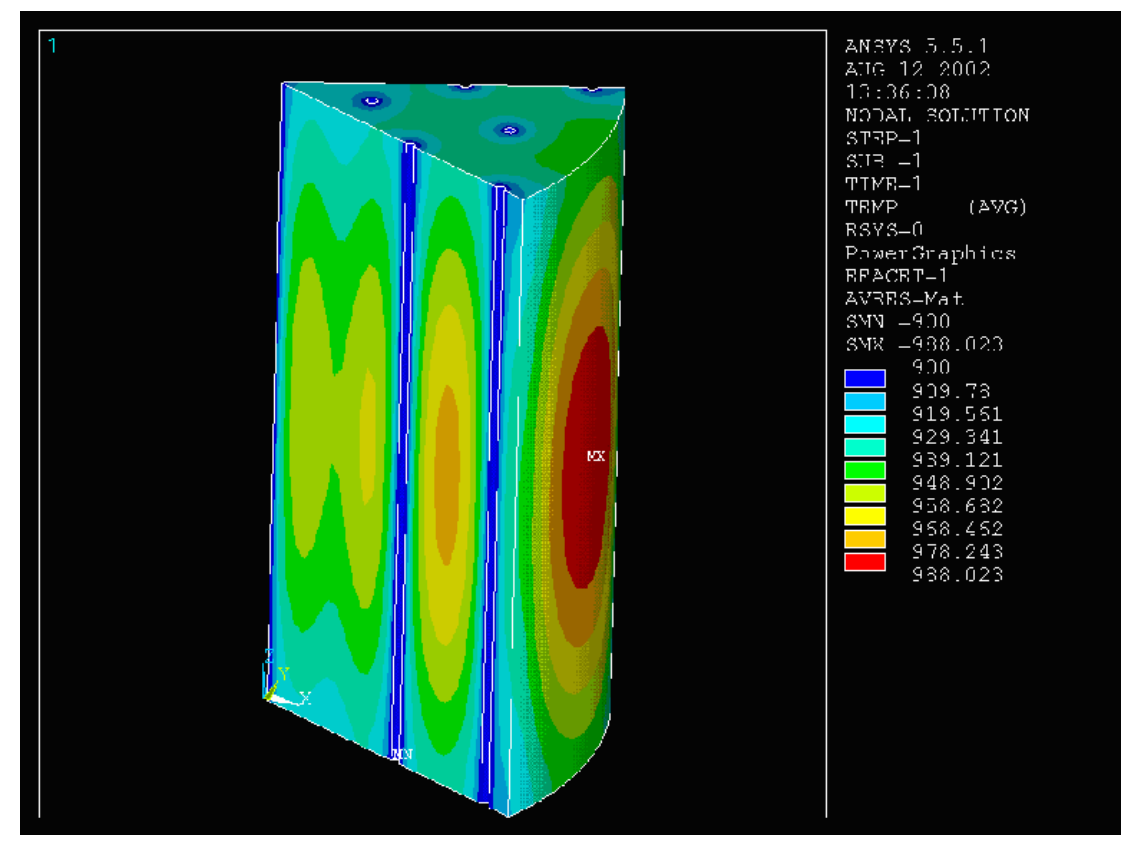

Fig. 4.44(b). Temperature distribution with cooling only through the core's channels. Uniform $900 \mathrm{~K}$ temperature occurs along the cooling channels and perfectly insulated everywhere else (reflector not included).

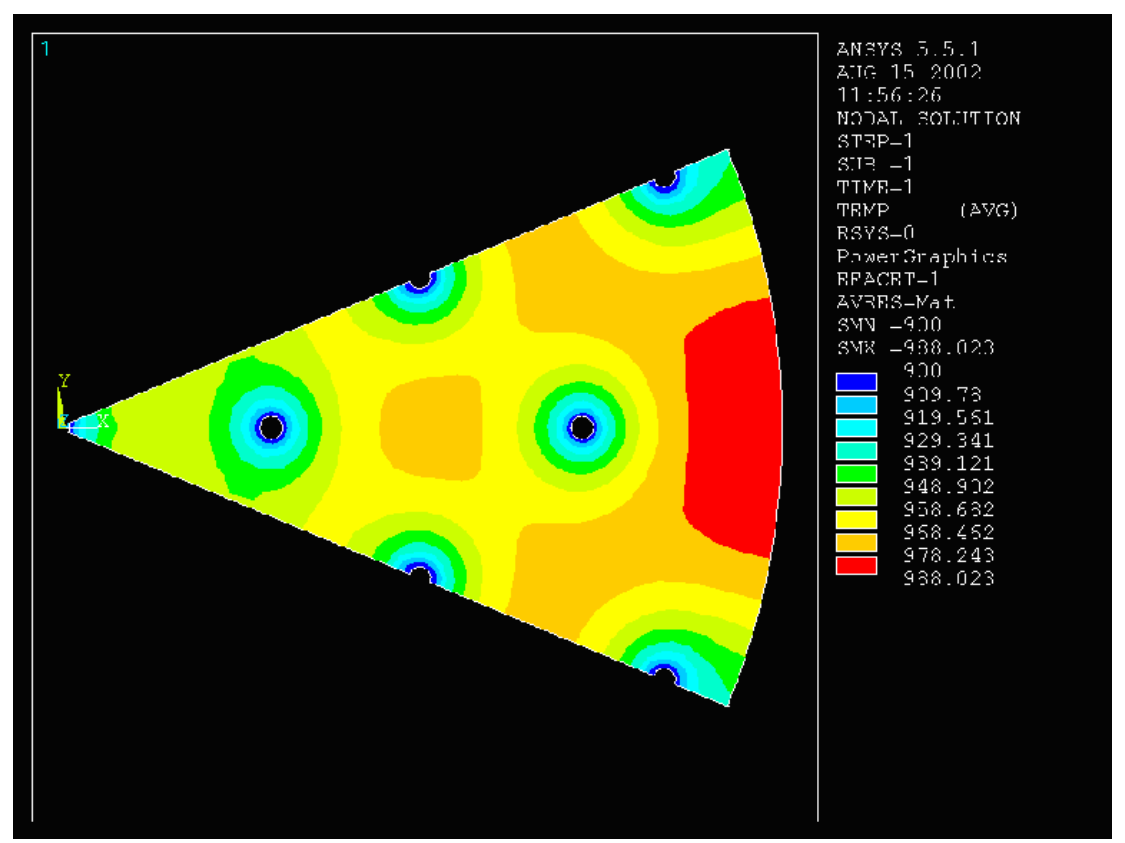

Fig. 4.44(c). Midplane cut showing the temperature distribution with cooling only through the core's channels (reflector not included). Peak temperature is at the core boundary because of the longer heat-path for the same power. 


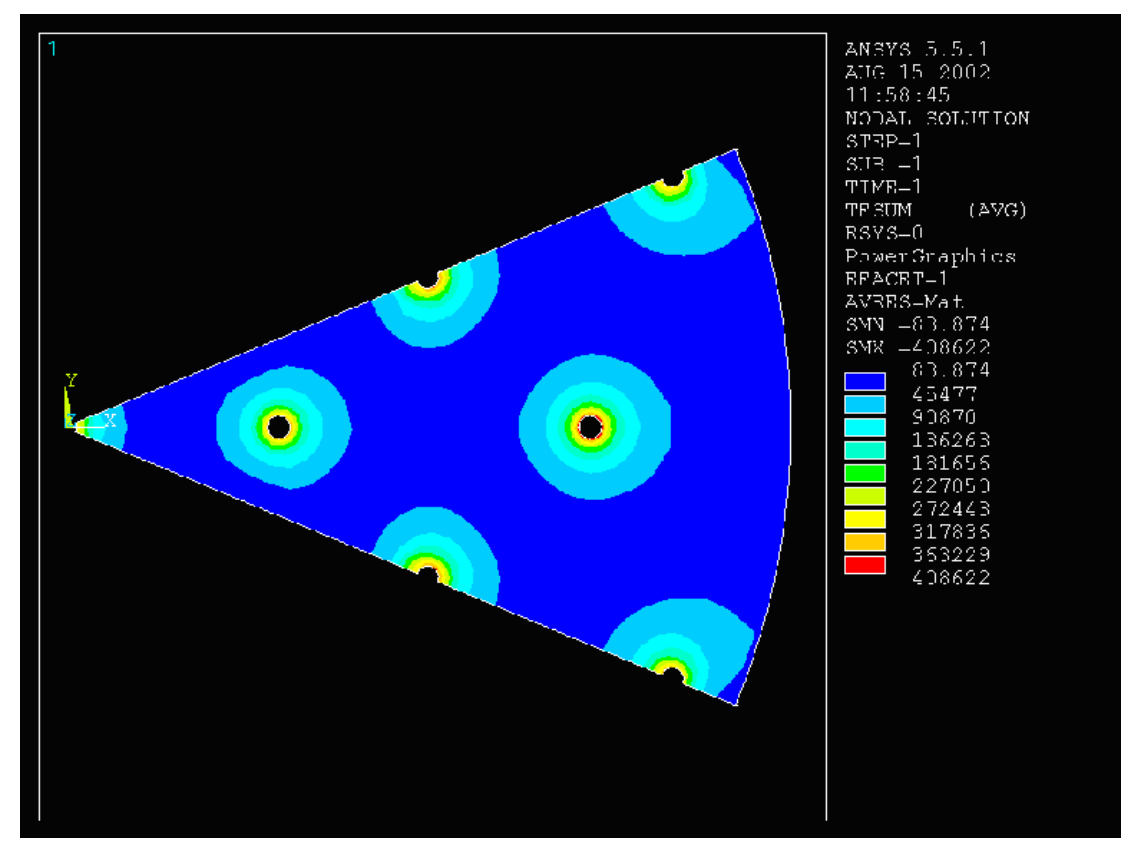

Fig. 4.44(d). Midplane cut showing the heat flux distribution with cooling only through the core's channels (reflector not included).

The peak temperature computed occurs at the core boundary slightly above the midheight plane and has a value of $988 \mathrm{~K}$. That is, the peak temperature is $88 \mathrm{~K}$ higher than that at the cooling channels. This compares well with the $106 \mathrm{~K}$ computed by the 1-D code.

Figure 4.44(d) shows the heat fluxes at the midplane. Note that the outer, top, and bottom boundaries of the core are treated as if they were perfectly insulated. Also note that the heat fluxes are very similar around each hole, thus, indicating that similar amounts of power are being extracted in each of them.

\subsubsection{Conclusions of preliminary temperature fields assessment}

The set of Figs. 4.44( $a-d)$ confirm that removal of heat from the core by means of longitudinal passthrough holes results in flatter temperature distributions inside the reactor core. This design will thus enable removal of the energy generated at substantially higher temperatures and, alternatively, will allow the production of more power for the same temperature constraints.

For the solid core design without holes, Fig. 4.39 shows that cooling at the external boundary of the reflector is not desirable because, for equal power generation levels, it would result in much higher internal temperatures without appreciable benefits. It was also clear from Figs. 4.41 and $4.40(b)$ that cooling at the top and/or bottom circular surfaces had little impact on the peak temperatures inside the reactor, because the thermal conductivity in the axial direction is significantly lower than in the radial direction.

Although cooling by means of longitudinal pass-through holes is clearly better from the thermal point of view, it adds complexity; consequently, it was decided for the prototype design to use a solid core geometry with cooling at the core/reflector boundary by means of a circulating gas driving a Brayton power conversion system. As discussed in Sect. 4.1.9, safety considerations related to impact on reactivity by water ingress resulted in an increase of $50 \%$ in the core dimensions. Also the choosing of stainless steel as cladding material for this system limited the core's temperature at the coolant gas exit to a maximum of $945 \mathrm{~K}$. 


\subsection{POWER CONVERSION}

\subsubsection{Introduction}

As given in Sect. 3.3, the power conversion technical issues are core heat transfer design, choice of Brayton cycle working fluid, turbine and compressor inlet temperatures, allowable pressure drops, working fluid compressor discharge pressure and system pressure ratio, recuperator effectiveness, and turbomachine polytropic efficiencies. Many of these parameters have an effect on the others, so the best approach to design the system components is to postulate reasonable parameters, calculate overall cycle efficiency, calculate component designs that will support the chosen postulated parameters, then check all parameters for consistency. A good place to start is the overall cycle heat balance, because the parameter of interest is the overall cycle thermal efficiency.

\subsubsection{Overall Cycle Thermal Performance}

Staudt ${ }^{19}$ derives the following relationship for the overall cycle thermal power conversion efficiency:

$$
\eta_{t h}=\frac{E \cdot T^{*}-C}{T^{*}(1-\varepsilon(1-E))-(1+C)(1-\varepsilon)},
$$

where $T^{*}$ represents the ratio of turbine inlet temperature to compressor inlet temperature, $\varepsilon$ represents the recuperator effectiveness (the ratio of actual heat transferred to the ideal maximal heat transferred in the recuperator), $E$ represents the work done by the expander or turbine, and $C$ represents the work consumed by the compressor. Staudt ${ }^{19}$ related $E$ and $C$ to the pressure ratio $P^{*}$ across the compressor by the following relationship:

$$
\begin{gathered}
C=P^{* \frac{R}{\eta_{c} C_{p}}}-1, \\
E=1-\left[\left(1-\sum \frac{\Delta P}{P}\right) P *\right]^{-\left(\frac{\eta_{t} R}{C_{p}}\right)},
\end{gathered}
$$

where $\eta_{\mathrm{c}}$ and $\eta_{\mathrm{t}}$ are the compressor and turbine polytropic efficiencies. Note that the total of the fractional pressure drops is taxed to the turbine, regardless of where the parasitic loss occurs. Thus, there is some freedom in designing the cycle components for pressure drop as long as the total is the same.

Because the cycle temperature ratio $T^{*}$ has been prescribed by the nuclear core and ambient conditions, $T^{*}$ is fixed at a constant value. Also, the compressor and turbine polytropic efficiencies are fixed at values that are reasonably achieved with existing turbomachine designs. There are two degrees of freedom left to choose - the compressor pressure ratio $P^{*}$ and the working fluid that determines the property values of $R$ and $C p$. Because any pressure ratio can be designed for any specific compressor, but the working fluid is fixed, the next design choice is that for the working fluid.

Of the existing designs for closed Brayton cycle turbomachinery, machines larger than $1 \mathrm{MW}$ usually use pure helium as the working fluid, and machines on the order of $100 \mathrm{~kW}$ use a mixture of inert gases. Because the turbomachine of interest falls in the lower power range, a mixture of helium and xenon with a molecular weight of $40(\mathrm{HeXe} 40)$ will be used as the working fluid. 
Because no turbine or compressor can be completely efficient, Wilson and Kora Kianitis ${ }^{20}$ derives a polytropic efficiency defined as the actual differential energy change divided by the isentropic differential energy change that occurs over an infinitesimal pressure change in the device stage. Frequently, a total or adiabatic efficiency is given for a particular turbomachine, but this adiabatic efficiency is a function of the given pressure ratio. Proper diligence must be used to state and use the appropriate turbomachine efficiency definition. The use of the polytropic efficiency is easier when doing the cycle efficiency calculations proposed here. According to current turbomachine designs ${ }^{21,22}$ in the power range of interest here, a compressor polytropic efficiency of $85 \%$ and turbine polytropic efficiency of $90 \%$ are reasonably achievable in hardware and will be used in this study.

One parameter of choice is the recuperator effectiveness. Effectiveness is defined as the actual heat transferred divided by the maximal possible heat transferred with an infinite area heat exchanger. As might be expected, the higher the effectiveness, the higher the resultant cycle thermal efficiency. The disadvantage of a higher effectiveness is that the heat transfer area and volume, as well as pressure drop, increase as the effectiveness increases. Because recuperators with a high effectiveness of $95 \%$ are currently reasonably achievable in hardware, this parameter will be used in this study.

The remaining parameter is the compressor ratio $P^{*}$. The pressure ratio is a design parameter for the compressor component so it can be varied for optimum overall cycle thermal efficiency.

The expression for cycle thermal efficiency can now be calculated by varying the pressure ratio. Other curves representing the thermal efficiency as a function of pressure ratio for different recuperator effectiveness were also calculated. The results are shown in Fig. 4.45.

From inspection of Fig. 4.45, the optimum cycle thermal efficiency is $28.2 \%$, occurring at a pressure ratio of 1.65 for a recuperator effectiveness of $95 \%$. It is clear from Fig. 4.45 that the higher the effectiveness, the higher the cycle thermal efficiency. Also, note that the maximal efficiency occurs at a lower pressure ratio as the effectiveness increases. The cycle heat balance showing the temperatures throughout the cycle are shown in Fig. 4.46.

Now that the overall cycle configuration has been determined, the individual parameters need to be checked for consistency with good design practice and effect on the other cycle parameters of interest.

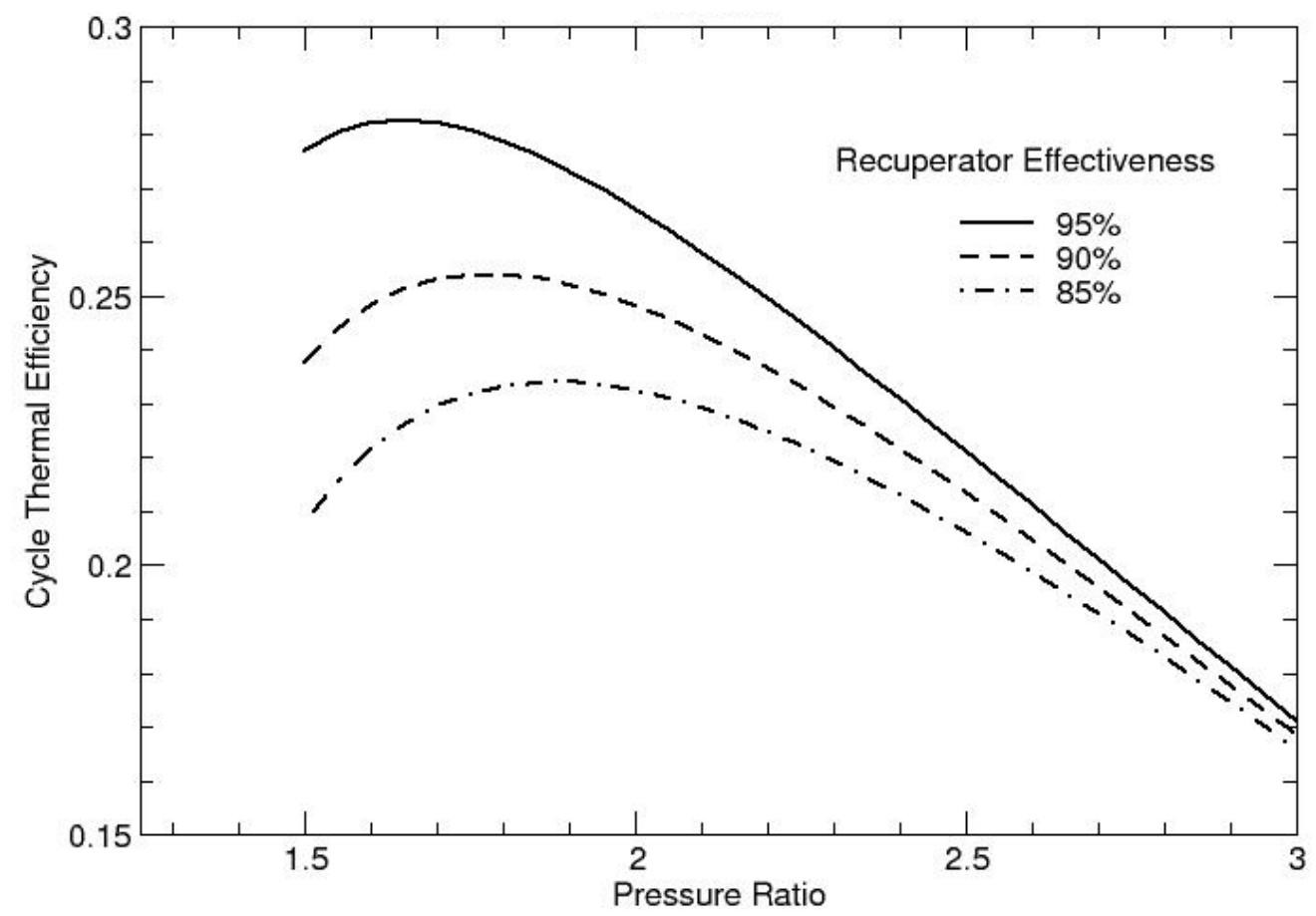

Fig. 4.45. Cycle thermal efficiency. 


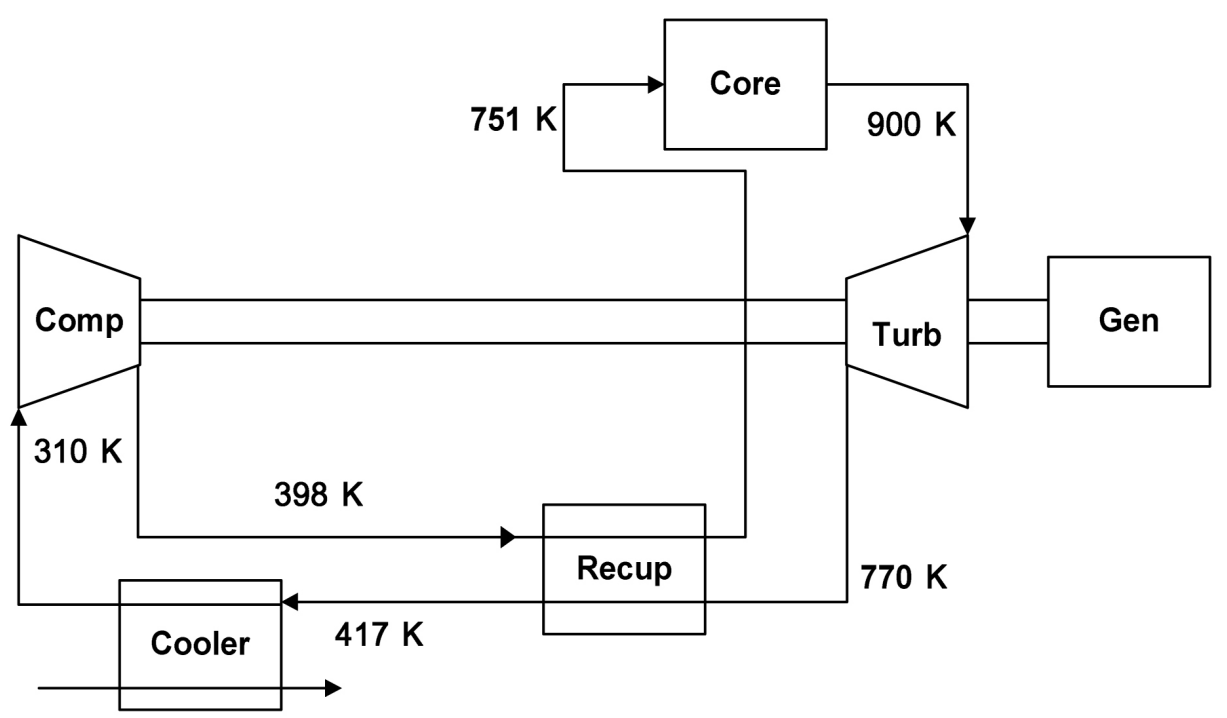

Fig. 4.46. Cycle heat balance.

\subsubsection{Recuperator Design}

The recuperator is designed using the techniques and extended heat transfer surface configurations found in Kays and London. ${ }^{23}$ This particular design technique is an industry standard and is derived from fundamental heat transfer considerations. Design detail taken by measuring an existing high-effectiveness recuperator for large Brayton cycle turbomachines was used here. A typical counterflow design appears in Fig. 4.47. Counterflow is typically used in high-performance heat exchange equipment, where the two fluids flow in opposite directions in their respective flow passages. This counterflow arrangement is usually thermodynamically efficient.

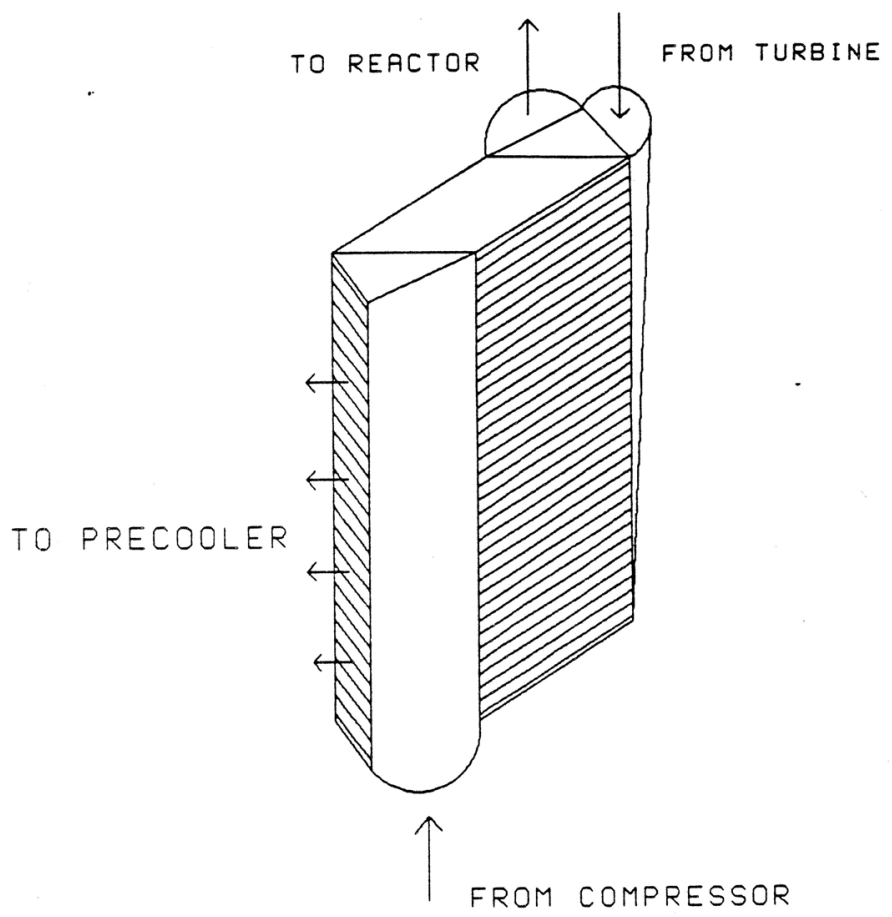

Fig. 4.47. Typical counterflow recuperator design. 
There are two good reasons to chose the mixture of inert gases HeXe40 used in this study: to decrease the number of stages in the turbomachine and to minimize the size of the heat exchangers. For the heat exchangers, helium would result in the smallest recuperator because of the relatively high thermal conductivity. Unfortunately, the resultant turbomachine would have a large number of stages because of the high specific heat. Mixing the inert gases helium and xenon to a molecular weight of 40 results in a turbomachine that is comparable in size to an argon turbomachine, but without penalizing the recuperator size to the same extent as using argon with the relatively low value of thermal conductivity. The recuperator is usually the largest component of a closed Brayton cycle. The mixture of inert gases results in a very much decreased Prandtl number of the mixture (0.2) as compared to any of the pure inert noble gases (0.7). The reasons for this decreased Prandtl number are described by Pierce ${ }^{24}$ and Giacobbe. ${ }^{25}$ The heat transfer correlation also developed by Pierce is used here.

Up to now, only the pressure ratio need be specified for the cycle efficiency determination. To size the recuperator, the actual operating pressure must also be specified. Because the cycle efficiency is not affected, the system maximum pressure can be varied to suit other design objectives, such as space and weight. Thus, the compressor discharge pressure was used as a parameter for the recuperator sizing, and the results are shown in Fig. 4.48. Figure 4.48, which begins the calculations with a compressor discharge pressure of $0.3 \mathrm{MPa}$, shows a quick decrease in total volume and flow length as the pressure is increased to $1 \mathrm{MPa}$, a slower rate of decrease as the compressor discharge pressure is increased from 1 to $2 \mathrm{MPa}$, and then a very slight decrease as the pressure increases beyond $2 \mathrm{MPa}$. Because building a recuperator to operate at high pressure can be more involved with thicker walls and sturdier joints, choosing the compressor discharge pressure to be $1.5 \mathrm{MPa}$ is a good choice here in the absence of stringent size and weight design limitations. If a very small recuperator and other heat exchanger components are necessary to meet stringent limitations, the operating pressure can be increased.

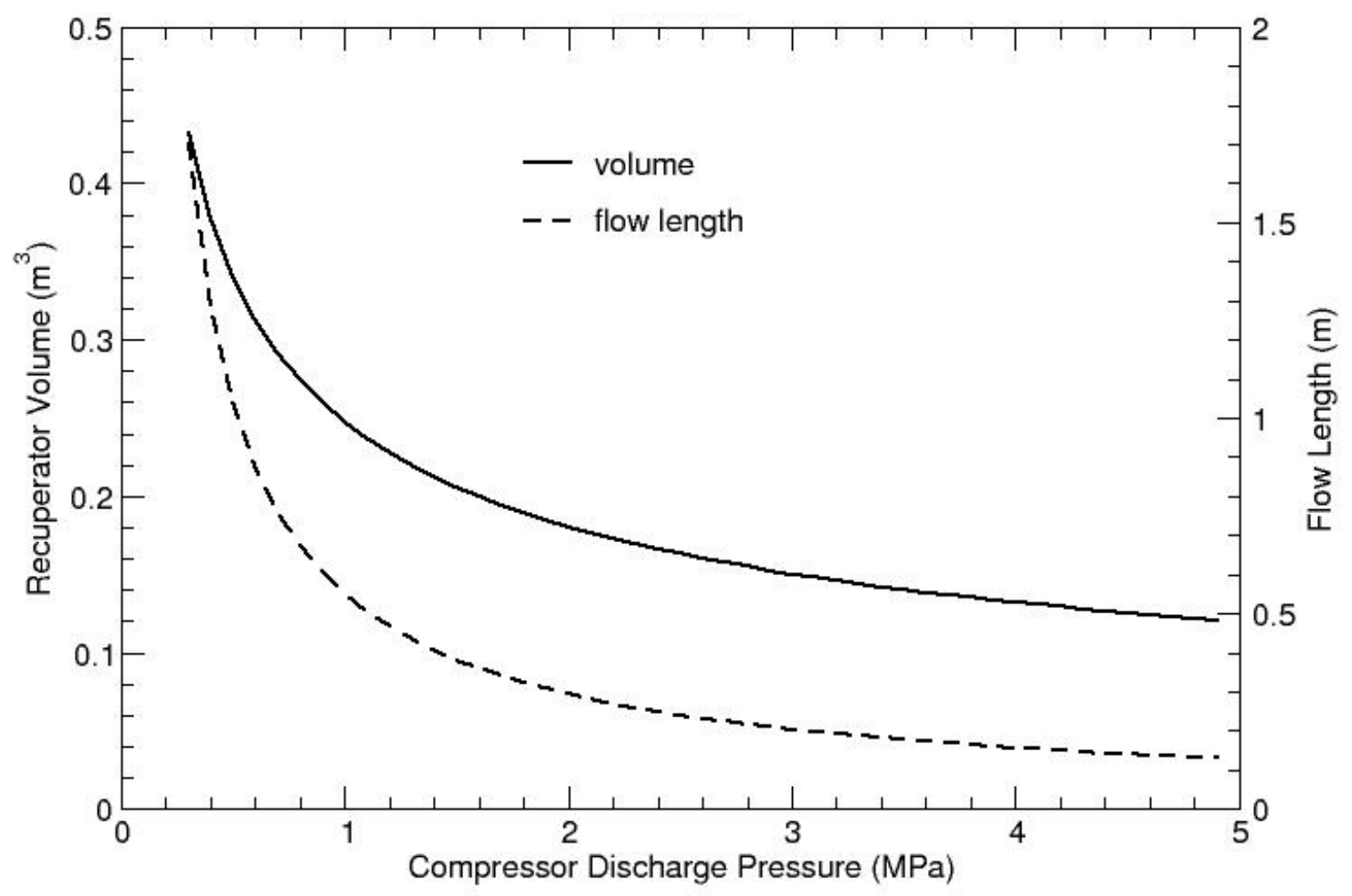

Fig. 4.48. Recuperator dimensions for a $3 \%$ pressure drop. 
Thus, the choice of compressor discharge pressure of $1 \mathrm{MPa}$ results in a recuperator having $95 \%$ effectiveness and a total parasitic pressure drop of $3 \%$, having a volume of $0.21 \mathrm{~m}^{3}$ and a flow length of $0.35 \mathrm{~m}$.

\subsubsection{Active Core Heat Transfer Surface Design}

Because the design philosophy behind this concept is its simplicity, a simple heat exchanger surface design is desirable. A simple design is the one proposed by London ${ }^{26}$ to cool a $25-\mathrm{kW}$ microwave power tube. This analysis was revisited and updated by Bar-Cohen and Jelinek ${ }^{27}$ and was adapted for use here with the conditions and working fluid of interest. While the original intent of this London analysis was to find an optimal surface for a very specific application, the fundamentals of the simple heat transfer surface are quite appropriate for this NERI application. No extensive optimization is presented here, and certainly not to the level of detail by London for the power tube, but sufficient for the scope of the proposed concept.

The basic geometry of this London analysis is shown in Fig. 4.49, where the heat transfer surface can be described as a series of fins in an annulus that separates two walls. The basic geometry of an active core length of $1.5 \mathrm{~m}$ and a right circular cylinder diameter of $1.5 \mathrm{~m}$ were used to set the inside dimensions of the finned channel surface. Then the fin width and height were specified, which leaves the fin spacing, or alternatively the number of fins in the annulus, as a parameter. The choice of fin width and height are somewhat arbitrary but can be determined with some guidelines. For example, the higher a fin is in this particular geometry, the lower is the parasitic pressure drop. But increasing the fin height does not increase the heat transfer proportionally. Thus there is a trade-off between pressure drop and heat transfer due to the fin height. Also, a thin fin may be desirable to increase heat transfer but at the cost of structural weakness.

Based on numerous calculations with various fin height and thickness parameters, a height of $10 \mathrm{~mm}$ and a fin width of $5 \mathrm{~mm}$ appeared to be the best compromise between pressure drop and heat transfer. The remaining parameter of fin spacing or total number of fins in the annulus remains to be determined. This parameter was varied over an appropriate range of values, and the calculated results for resultant thermal conductance and fractional pressure drop are presented in Fig. 4.50. The thermal conductance represents the heat load dissipated by the finned annulus per degree of temperature difference between the fin root and the fluid at the inner diameter.

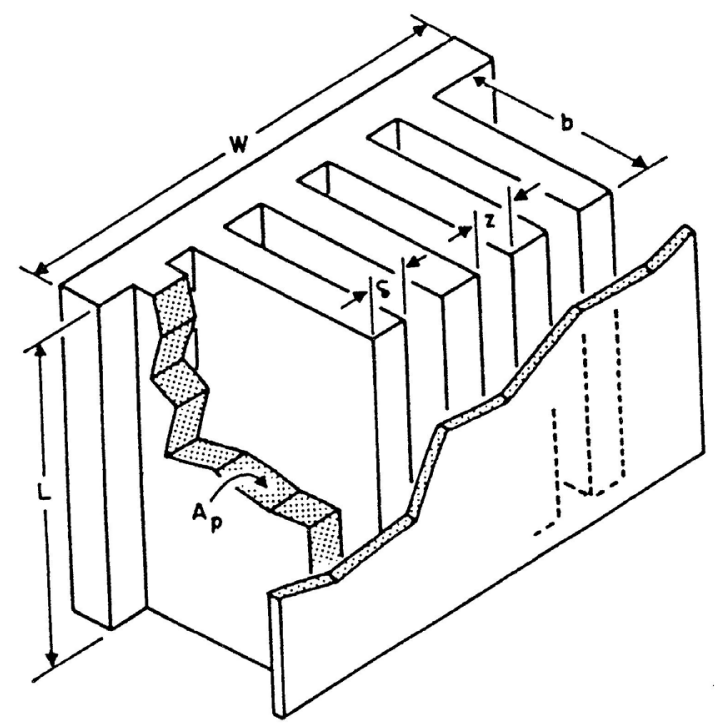

Fig. 4.49. Finned annulus heat transfer geometry. 


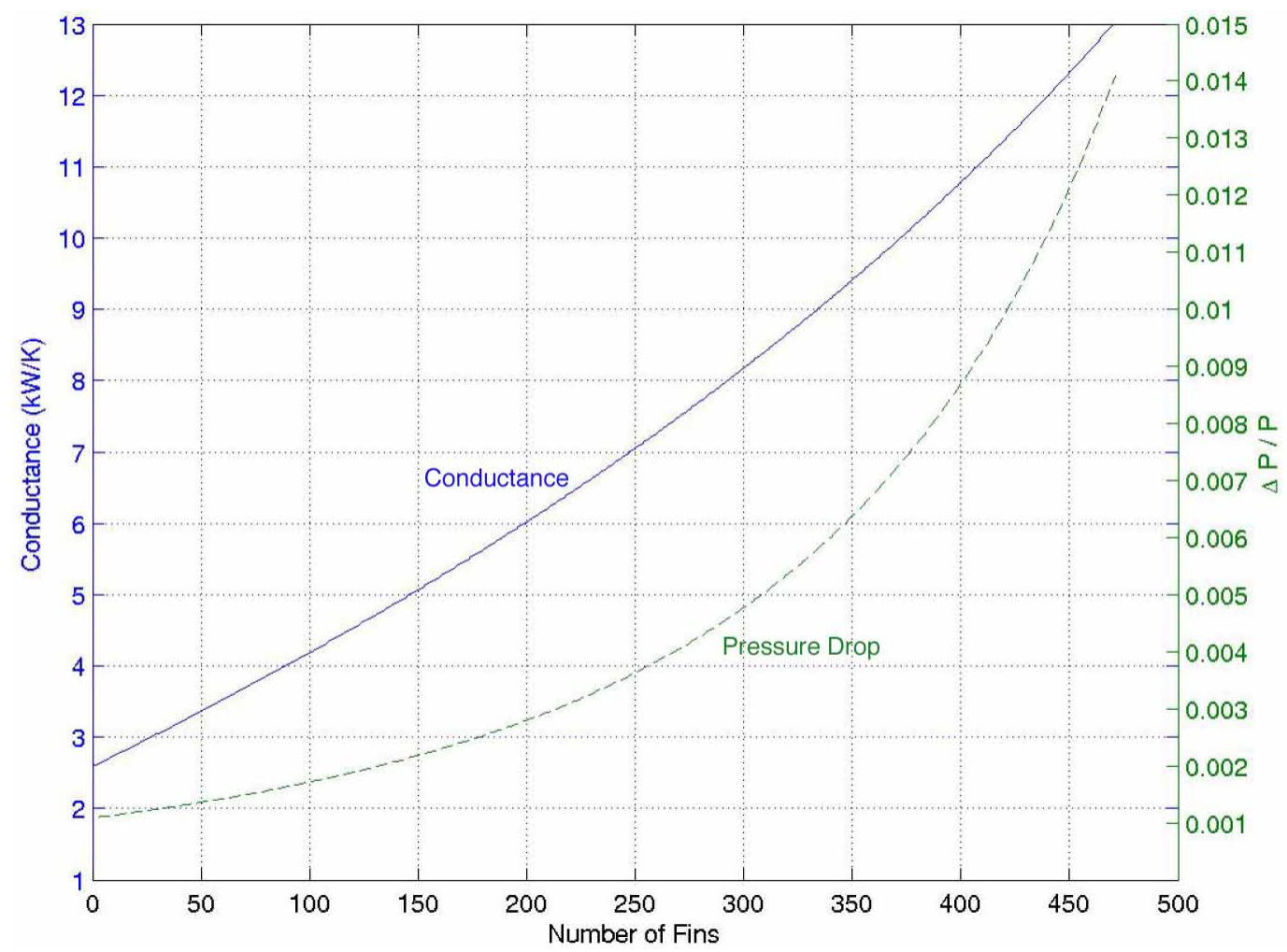

Fig. 4.50. Core fin geometry effects on pressure drop and thermal conductance.

From inspection of Fig. 4.50, the thermal conductance (solid line) increases as the number of fins increases but at the cost of an increasing pressure drop (dotted line). As stated previously, a low parasitic pressure drop will increase overall cycle thermal efficiency. A pressure drop of $1 \%$ was budgeted arbitrarily for the core heat transfer surface, which results in a thermal conductance of $11.3 \mathrm{~kW} / \mathrm{K}$ for a fin count of 420 (fin spacing of $6 \mathrm{~mm}$ ) as shown on Fig. 4.50. Thus for a core power level of $500 \mathrm{~kW}$, the metal temperature at the fin root would be $44 \mathrm{~K}$ higher than the working fluid. If a lower pressure drop is considered to potentially improve the overall cycle thermal efficiency, the core temperatures would increase to accommodate the lower thermal conductance of the heat removal finned annulus.

\subsubsection{Precooler Design}

As for the recuperator, the precooler is designed using the techniques and extended heat transfer surface configurations found in Kays and London. ${ }^{23}$ The extended surface performance detail presented in the Kays and London appendix may be somewhat dated. More recent surfaces are most likely being used by manufacturers, but the design detail necessary to size the precooler as well as the recuperator is also most likely proprietary. For the scope of this concept, the extended surface detail given in the appendix of Kays and London is sufficient.

A compact extended surface used in automotive radiators was chosen (Kays and London surface 1/8-13.95) for the air side, and the previously extended surface chosen for the recuperator was chosen for the HeXe40 working fluid. A counterflow arrangement was also chosen to be similar in design to the recuperator. The previously budgeted $1 \%$ parasitic pressure drop for the working fluid was used. For the recuperator, the mass flow of both sides of the heat exchanger is identically the same. In comparison to the recuperator, however, the precooler air side flow rate, and, thus, the resultant pressure drop and temperature rise of the air side can be varied to suit other design conditions. These other design conditions include the air-side face area and flow length. A small precooler is obviously desirable, but a short flow 
length requires an increase in mass flow to increase the heat transferred from the shorter flow path. A faster flow of air will have a higher pressure drop and require a larger power air handler ("blower"). Note that the heat load from the working fluid must be met, and however the geometry is varied, the pressure drop limitation of $1 \%$ on the working fluid side must be met.

With the design limit of $1 \% \mathrm{HeXe} 40$ working fluid pressure drop and the appropriate heat load and temperatures calculated for the cycle efficiency determined earlier, the heat exchanger sizing algorithm was exercised with a varying air mass flow rate to determine the dimensions of the precooler and the resultant pressure drop. The face area and face velocity as a function of air mass flow rate is shown in Fig. 4.51, and the flow length and pressure drop as a function of air mass flow rate is shown in Fig. 4.52.

From inspection of Figs. 4.51 and 4.52, an air mass flow rate of $4 \mathrm{~kg} / \mathrm{s}$ appears to be a good compromise between minimizing the pressure drop and minimizing the size of the precooler. For a mass flow rate of $4 \mathrm{~kg} / \mathrm{s}$, the calculated face area is $0.9 \mathrm{~m}^{2}$, and the flow length is $0.3 \mathrm{~m}$. The volume is thus $0.27 \mathrm{~m}^{3}$. The air face velocity is $3 \mathrm{~m} / \mathrm{s}$, which is a reasonable number to size an air supply duct and blower, but the pressure drop is $1 \mathrm{kPa}$, which might require a blower more powerful than typically found in air moving equipment used in building heating and cooling applications. A blower with sufficient power is probably available with this capability, but a lower pressure drop might be advisable. However, a lower pressure drop would result in a very much larger face area and flow length and, thus, volume. In the absence of stipulated size limitations or air handling equipment specifications, this design of a precooler is presented as just one potential heat exchanger using ambient air as the heat sink.

\subsubsection{Turbomachinery Considerations}

Some recent effort concerning the use of closed Brayton cycle power conversion system applicable to space electricity generation has appeared in the technical literature. ${ }^{21,22}$ Because these efforts are directly applicable to the power range, working fluid, and other parameters of interest here, no turbomachine sizing or rating calculations were specifically performed in this scoping calculation. Calculating appropriate turbomachine design details, such as stage velocities, blade angles, and blade height, were beyond the limited resources available, and frankly are not justified for the scope of this investigation. These published works are sufficient to show that a turbomachine can be designed and built to operate as needed for this concept. One design detail that must be addressed for this concept is the rotational speed of the shaft that connects the turbomachine with the electrical generator.

For efficient stage design of radial flow turbomachines, the stage diameter decreases as the pressure ratio decreases, and the most efficient rotational speed increases. For the highly recuperated turbomachine postulated here, a pressure ratio less than two results in the highest cycle thermal efficiency as shown on Fig. 4.45. For the recent turbomachines presented by Foti et al. ${ }^{21}$ and Hansen, ${ }^{22}$ however, the design pressure ratios were slightly higher at 2.2. This higher pressure ratio is thought to result from the shaft speed limitation of $60,000 \mathrm{rpm}$ caused by present generator speed limitations in the subject power range. If a stage having a diameter is operated at a lower speed than optimal, the polytropic stage efficiency degrades. Thus the trade-off of polytropic stage efficiency and overall system cycle thermal efficiency vs speed must be calculated. This particular parameter calculation was beyond the limited resources available here because it requires a high level of stage design detail. 


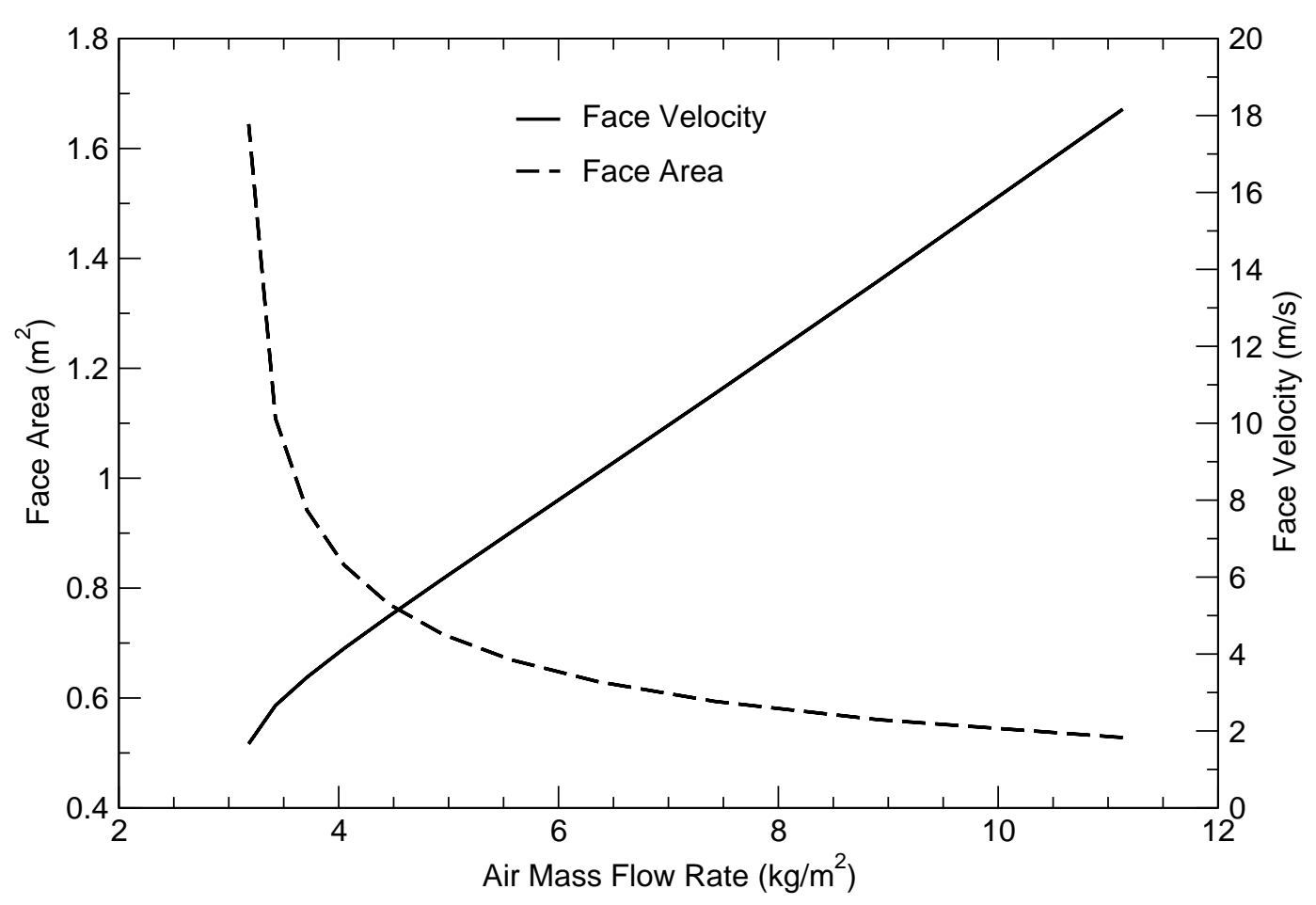

Fig. 4.51. Face area and face velocity as a function of air mass flow rate.

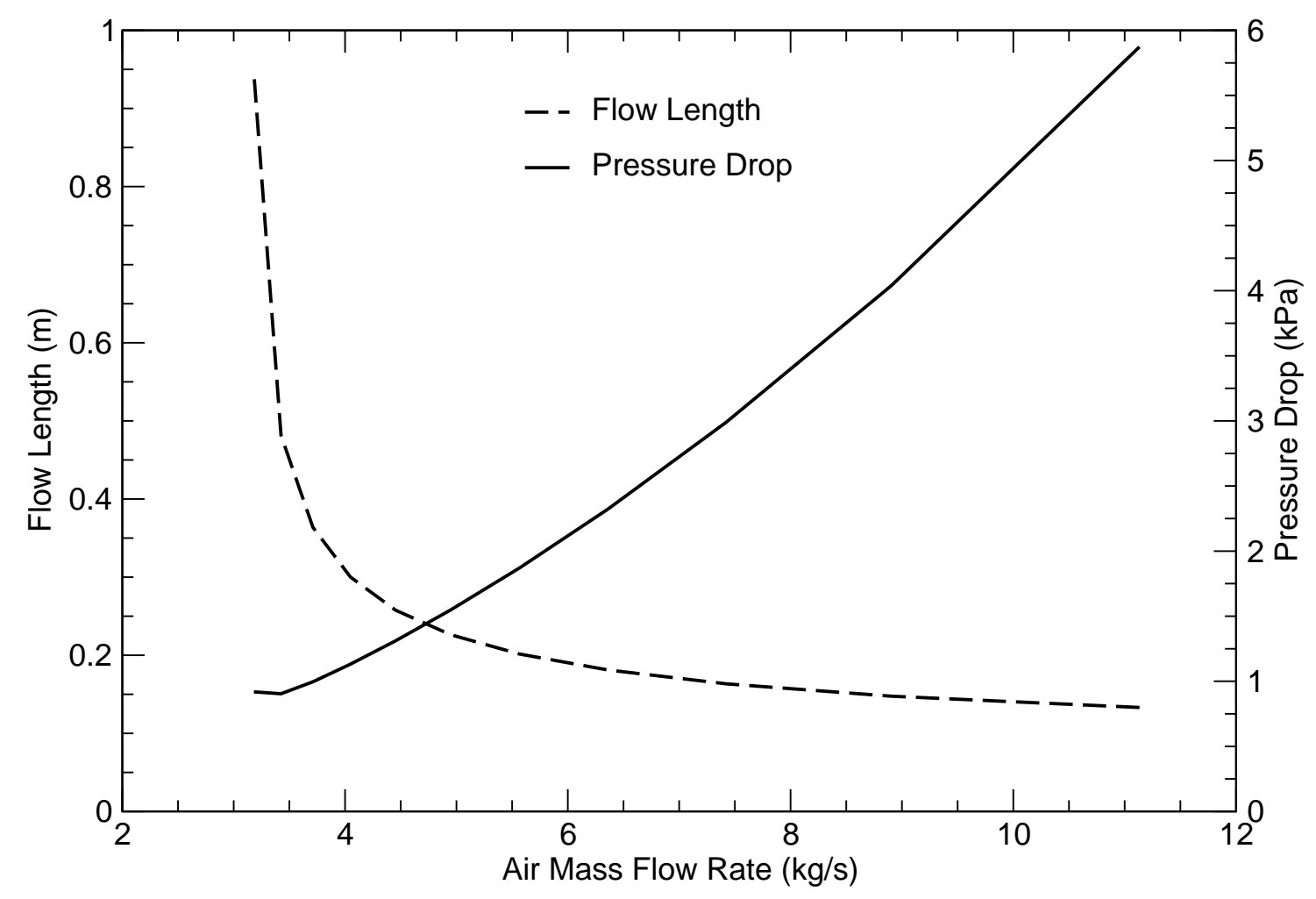

Fig. 4.52. Precooler pressure drop and flow length as a function of air mass flow rate. 


\subsection{PHYSICAL MODEL MOCKUP}

To illustrate the passive operation of the core, a physical model of the SSR concept was built using graphite foam and electrical heat sources. The mockup consists of a 12-cm-diam by 16-cm-high cylinder of graphite foam with an electrically heated rod inserted in a hole drilled in the central axis. A thermistor (an electronic component whose electrical resistance decreases as temperature increases) placed near the outer edge of the cylinder provides temperature feedback to the power electronics driving the heating rod. As a result, the heating rod delivers less power as the temperature increases and shuts off at a preestablished standby temperature $\left(70^{\circ} \mathrm{C}\right)$. A cooling fan is used to vary the amount of power removed from the graphite block. Following is a photo of this model. Its dimensions are approximately scaled 1/10 of the base reactor core. The protective transparent plastic enclosure and attached cooling fan are not shown in the picture.

The power electronics caused the heating rod to deliver more power as the temperature decreased but less power as the temperature increased, reaching zero power generation at a preestablished temperature $\left(70^{\circ} \mathrm{C}\right)$.

The model, enclosed in a transparent plastic box with a fan attached, was used to demonstrate the load following and hot-standby properties of the SSR (Fig. 4.53).

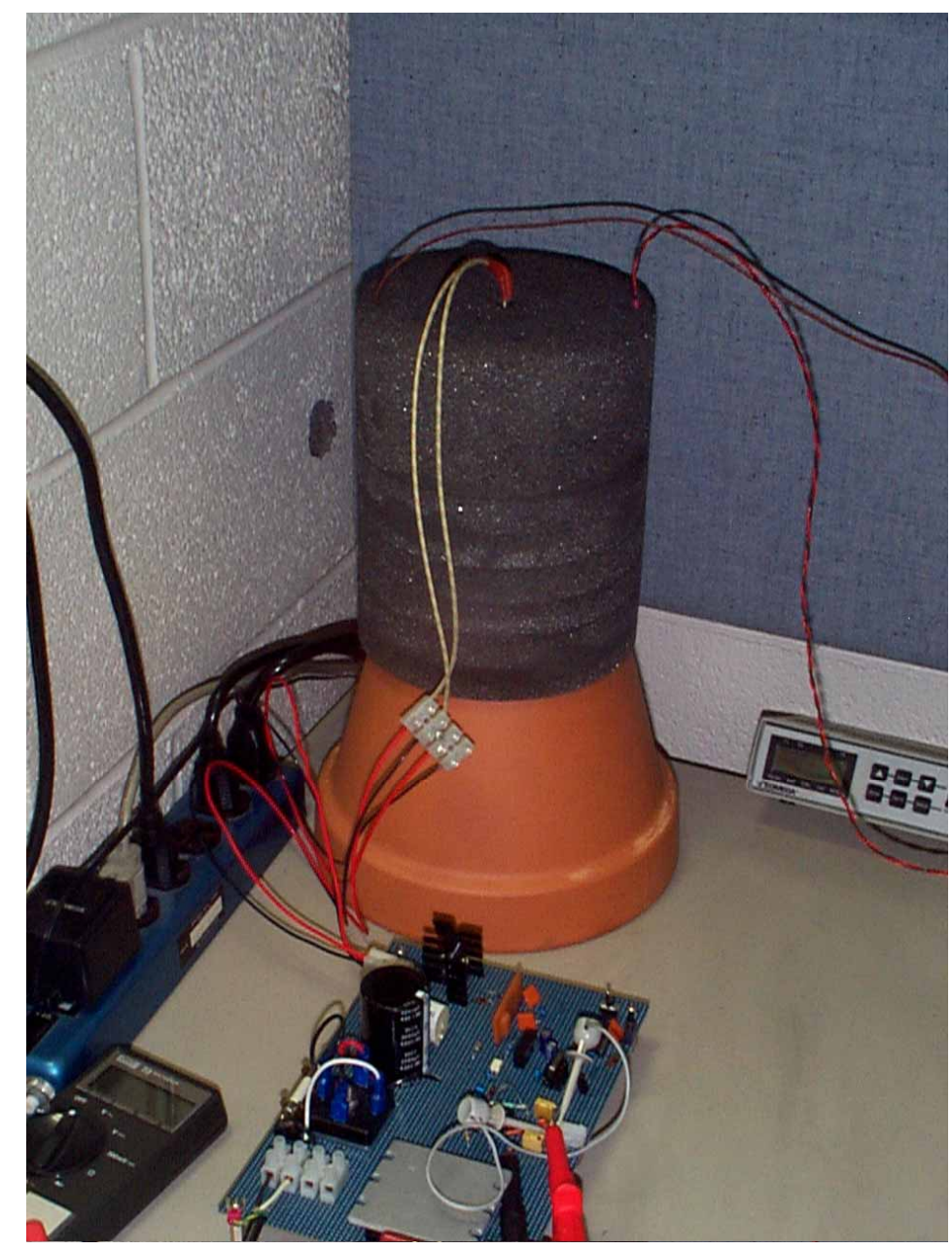

Fig. 4.53. Physical mockup of the SSR core without enclosures and cooling fan. 


\section{REFERENCES}

1. SCALE-A Modular Code System for Performing Standardized Computer Analyses for Licensing Evaluation, NUREG/CR-0200, Rev. 5 (ORNL/NUREG/CSD-2/R5), Vol. 1-4, Oak Ridge National Laboratory, March 1997.

2. J. J. Casal et al., "HELIOS: Geometric Capability of a New Fuel-Assembly Diagram," p 10.2 1-1 in Proceedings of the International Topical Meeting on Advances in Mathematics, Computations, and Reactor Physics, April 28-May 2, 1991, Pittsburgh, PA.

3. Scandpower, Inc., HELIOS Documentation, FMS-The Scandpower Fuel Management System, December 15, 1995.

4. J. F. Briesmeister, Ed., MCNP-A General Monte Carlo N-Particle Transport Code, Version 4C, LA-13709-M, April 2000.

5. R. K. Kinsey, Ed., ENDF-102, Data Formats and Procedures for the Evaluated Nuclear Data File, ENDF, BNL-NCS-50496 (ENDF-102), 2nd ed. (ENDF/B-V), Brookhaven National Laboratory, October 1979.

6. P. F. Rose and C. L. Dunford, Eds., ENDF-102, Data Formats and Procedures for the Evaluated Nuclear Data File, ENDF-6, BNL-NCS-44945, Brookhaven National Laboratory, July 1990.

7. Quarterly Report for September-December, 2000.

8. Quarterly Report for January-March, 2001.

9. F. C. Difilippo, "Design Parameters for Graphite-Reflected Graphite-Foam-U Cores with Zero Burnup Reactivity Swing," Trans. Am. Nucl. Soc., 245-6 (June 2001).

10. International Handbook of Evaluated Criticality Safety Benchmark Experiments, Nuclear Energy Agency, NEA/NSC/DOC(95)03, September 1999.

11. R. T. Primm III, Justification and Planning for a Proposed Series of Damp Mixed-Oxide Critical Experiments, ORNL/TM-9675, August 1985.

12. L. L. Snead, A. M. Williams, and A. L. Qualls, "Revisiting the use of SiC as a postirradiation temperature monitor," Effects of radiation on materials, ASTM STP 1447, M. L. Grossbeck, ed., ASTM International, West Conshohocken, Pennsylvania, 2003.

13. B. T. Kelly and R. Taylor, "The thermal properties of graphite," in Chemistry and Physics of Carbon, P. L. Walker and P. A. Thrower, eds., Vol. 10, pp. 1-140, Dekker, New York, 1973.

14. R. Taylor, B. T. Kelly, and K. E. Gilchrist, "The thermal conductivity of fast neutron irradiated graphite," J. Phys. Chem. Solids, 30, 2251-2267 (1969).

15. J. E. Brocklehurst and B. T. Kelly, "Analysis of the dimensional changes and structural changes in polycrystalline graphite under fast neutron irradiation," Carbon, 31(1), 155-178 (1993).

16. J. E. Brocklehurst and B. T. Kelly, "The dimensional changes of highly-oriented pyrolytic graphite irradiated with fast neutrons at $430^{\circ} \mathrm{C}$ and $600^{\circ} \mathrm{C}$," Carbon, 31(1), 179-183 (1993).

17. B. T. Kelly and T. D. Burchell, "Structure-related property changes in polycrystalline graphite under neutron irradiation," Carbon, 32(3), 499-505 (1994).

18. T. D. Burchell, "Radiation effects in graphite and carbon-based materials," MRS Bulletin, 22(2), 29-35 (1997).

19. R. L. Staundt, Ph.D. dissertation, The Massachusetts Institute of Technology, Cambridge, MA, 1987.

20. D. Wilson and T. Korakianitis, The Design of High-Efficiency Turbomachinery and Gas Turbines, 2nd Edition, Prentice Hall, 1998.

21. J. Foti, D. Halsey, and T. Bauch, "Applicability of Aircraft Brayton Power Technologies to Future Space Power Conversion Systems," in Proceedings of the 2002 IECEC, Paper 20158, 2002.

22. J. L. Hansen, Conceptual Design Study of a Closed Brayton Cycle Turbogenerator for a Space Power Thermal-to-Electric Conversion System, EDR 90258, Allison Advanced Development Company report to NASA/Marshall Space Flight Center, 2002.

23. W. Kays and L. London, Compact Heat Exchanger Design, 1984. 
24. B. L. Pierce, "The Influence of Recent Heat Transfer Data on Gas Mixtures $\left(\mathrm{He}-\mathrm{Ar}_{2} \mathrm{H}_{2}-\mathrm{CO}_{2}\right)$ on Closed Cycle Gas Turbines," Journal of Engineering for Power, 103, 114-117 (1982).

25. F. W. Giacobbe, "Heat Transfer Capability of Elected Binary Gaseous Mixtures Relative to Helium and Hydrogen," Applied Thermal Engineering, 18, 199-206 (1998).

26. A. L. London, “Air-Coolers for High Power Vacuum Tubes,” Trans. IRE, ED-1, pp. 9-26 (1954).

27. A. Bar-Cohen and M. Jelinek, "Optimization of Longitudinal Finned Arrays-London's $25 \mathrm{~kW}$ Power-Tube Revisited," in Compact Heat Exchangers-A Festschrift for A. L. London, Shah, Kraus, and Metzger, Eds., Hemisphere, New York, pp. 105-120, 1990. 


\section{REACTOR DESCRIPTION}

\subsection{CORE DESCRIPTION AND DIMENSIONS}

Design studies for the reactor core configuration are discussed in Sect. 4.1. A summary of reactor parameters is presented in Table 5.1.

Table 5.1. Characteristics of nuclear energizer module

\begin{tabular}{|c|c|c|}
\hline \multirow[t]{13}{*}{ Core geometry } & Configuration & Right circular cylinder \\
\hline & Number of fuel zones in core & 2 , radial \\
\hline & Outer radius of inner fuel zone (unpoisoned) & $13.0 \mathrm{~cm}$ \\
\hline & Outer radius of outer fuel zone (poisoned) & $75.0 \mathrm{~cm}$ \\
\hline & Height of core & $150 \mathrm{~cm}$ \\
\hline & Thickness of core clad & About $1 \mathrm{~cm}$ \\
\hline & Thickness of reflector & $30 \mathrm{~cm}$, radial and axial \\
\hline & Type of shutdown control & $\begin{array}{l}\text { Rotating rods, poison material on } \\
\text { portion of external surface; } \\
\text { rods external to core }\end{array}$ \\
\hline & Number of shutdown rods & 18 \\
\hline & Location of shutdown rods & $\begin{array}{l}\text { Reflector, adjacent to inner } \\
\text { radius, equal azimuthal spacing }\end{array}$ \\
\hline & Shutdown rod diameter & $30.0 \mathrm{~cm}$ \\
\hline & $\begin{array}{l}\text { Thickness of poison material on shutdown } \\
\text { rod }\end{array}$ & $1.6 \mathrm{~cm}$ \\
\hline & $\begin{array}{l}\text { Angle subtended by poison region on } \\
\text { shutdown rod }\end{array}$ & $120^{\circ}$ \\
\hline \multirow[t]{15}{*}{ Materials } & Density of graphite in foam & $0.5 \mathrm{~g} / \mathrm{cm}^{3}$ \\
\hline & Uranium enrichment & $20 \mathrm{wt} \%{ }^{235} \mathrm{U}$ \\
\hline & Chemical form of uranium & $\mathrm{UC}_{2}$ \\
\hline & Neutron poison in outer fuel zone & $\mathrm{CdCO}_{3}$ \\
\hline & Density of $\mathrm{CdCO}_{3}$ in outer fuel zone & $0.1326 \mathrm{~g} / \mathrm{cm}^{3}$ \\
\hline & $\mathrm{C} / 235 \mathrm{U}$ ratio for inner zone & 39.28 \\
\hline & $\mathrm{C} / 235 \mathrm{U}$ ratio for outer zone & 41.97 \\
\hline & Clad & Hastelloy or other "superalloy" \\
\hline & Clad density & Depends on choice of clad \\
\hline & Coolant & $\mathrm{He} / \mathrm{Xe}$ \\
\hline & Coolant density & $9 \mathrm{~kg} / \mathrm{m}^{3}$ \\
\hline & $\mathrm{He} / \mathrm{Xe}$ ratio (by volume) & $28.2 \% \mathrm{Xe} / 71.8 \% \mathrm{He}$ \\
\hline & Reflector material & Graphite \\
\hline & Reflector density & $2.30 \mathrm{~g} / \mathrm{cm}^{3}$ \\
\hline & $\begin{array}{l}\text { Volume fraction of graphite in inner and } \\
\text { outer zone fuel }\end{array}$ & 0.25 \\
\hline
\end{tabular}


Table 5.1 (continued)

\begin{tabular}{|c|c|c|}
\hline & $\begin{array}{l}\text { Volume fraction of void in inner and outer } \\
\text { fuel }\end{array}$ & 0.30 \\
\hline & Volume fraction of $\mathrm{UC}_{2}$ in inner fuel zone & 0.45 \\
\hline & Volume fraction of $\mathrm{UC}_{2}$ in outer fuel zone & 0.42 \\
\hline & $\begin{array}{l}\text { Volume fraction of } \mathrm{CdCO}_{3} \text { in outer fuel } \\
\text { zone }\end{array}$ & 0.03 \\
\hline & Poison material on shutdown rod & ${ }^{10} \mathrm{~B}_{4} \mathrm{C}$ \\
\hline & Nonpoison constituent of shutdown rod & Graphite \\
\hline & Weight of inner fuel zone & $207 \mathrm{~kg}$ \\
\hline & Weight of uranium in inner fuel zone & $148 \mathrm{~kg}$ \\
\hline & Weight of outer fuel zone & $6304 \mathrm{~kg}$ \\
\hline & Weight of uranium in outer fuel zone & $4442 \mathrm{~kg}$ \\
\hline & Weight of core and reflector & $9091 \mathrm{~kg}$ \\
\hline Reactor Control & Isothermal temperature coefficient & Negative (see Fig. 5.3) \\
\hline & Delayed neutron fraction & 0.00765 \\
\hline & Neutron lifetime & $8.361\left(10^{-5}\right) \mathrm{s}$ \\
\hline & Reactivity loss per year of operation & $<1$ cent \\
\hline & Shutdown rod materials & $\mathrm{B}_{4} \mathrm{C}$ on a graphite cylinder \\
\hline & Single shutdown rod worth & 25 cents \\
\hline & Total shutdown worth & $\$ 4.57$ \\
\hline Thermal & Fission power & $500 \mathrm{~kW}$ \\
\hline characteristics & Net electric power & $100 \mathrm{~kW}$ \\
\hline & Coolant inlet temperature & $654 \mathrm{~K}$ \\
\hline & Coolant outlet temperature & $900 \mathrm{~K}$ \\
\hline & Peak temperature in core & $1460 \mathrm{~K}$ \\
\hline & Core average temperature & $\sim 1200 \mathrm{~K}$ \\
\hline & Core thermal conductance & $10.2 \mathrm{~kW} / \mathrm{K}$ \\
\hline & Pressure drop across core $(\%)$ & 0.6 \\
\hline & Temperature at core/clad interface & $949 \mathrm{~K}$ \\
\hline & Fin material & Stainless steel \\
\hline & Fin width & $5 \mathrm{~mm}$ \\
\hline & Fin height & $10 \mathrm{~mm}$ \\
\hline & Fin pitch & $10 \mathrm{~mm}$ \\
\hline $\begin{array}{l}\text { Balance of plant } \\
\text { characteristics }\end{array}$ & Compressor discharge pressure & $1.48 \mathrm{MPa}$ \\
\hline
\end{tabular}

The radial power profile at the axial center of the reactor is shown in Fig. 5.1. The HELIOS calculation is taken as the reference value, and cross sections for the reactor simulator (described elsewhere in this report) were derived from that calculation. The SCALE/XSDRNPM calculation was performed as a quality assurance check on the HELIOS calculation. The SCALE code system and associated cross section 


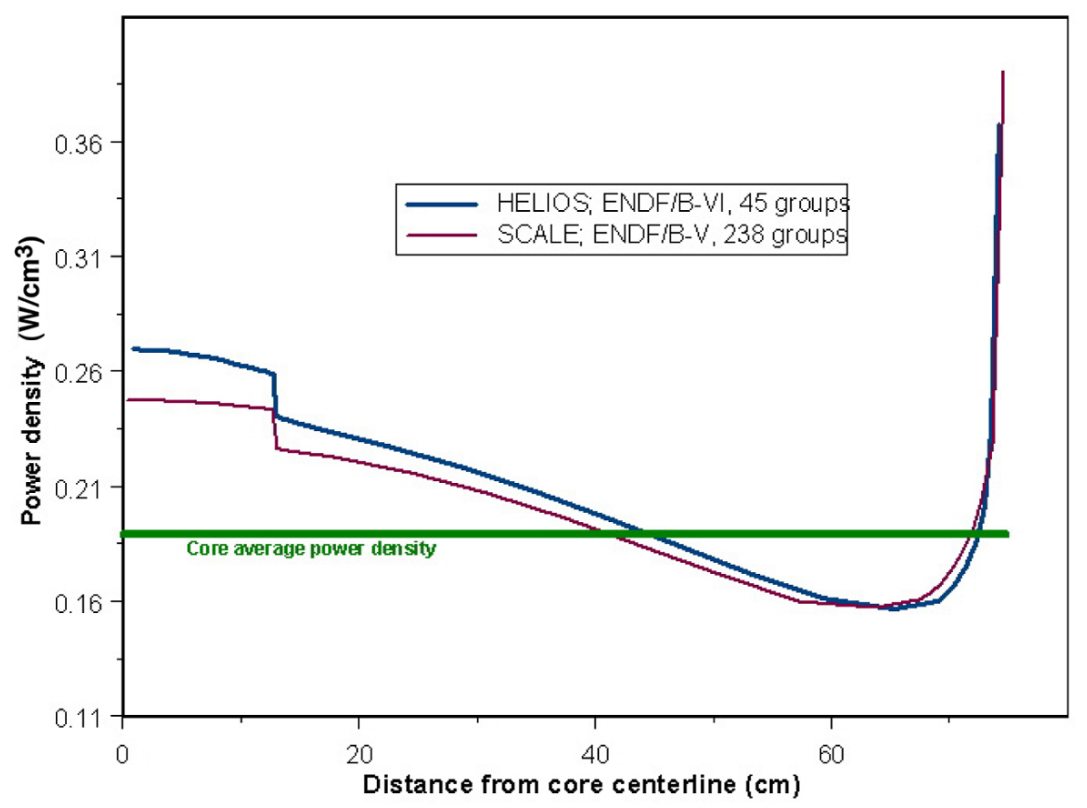

Fig. 5.1. Radial power distribution for SSR.

data libraries are independent of the HELIOS methodology. The level of agreement was judged acceptable for the purposes of this study.

Four group fluxes, derived during the cross section library production process for the reactor simulator, are shown in Fig. 5.2.

\subsubsection{Reflector}

The optimization of the graphite reflector thickness is described in Sect. 4.1. The material selection is based on cost, weight, and neutronic property considerations. An important aspect of the SSR reflector is

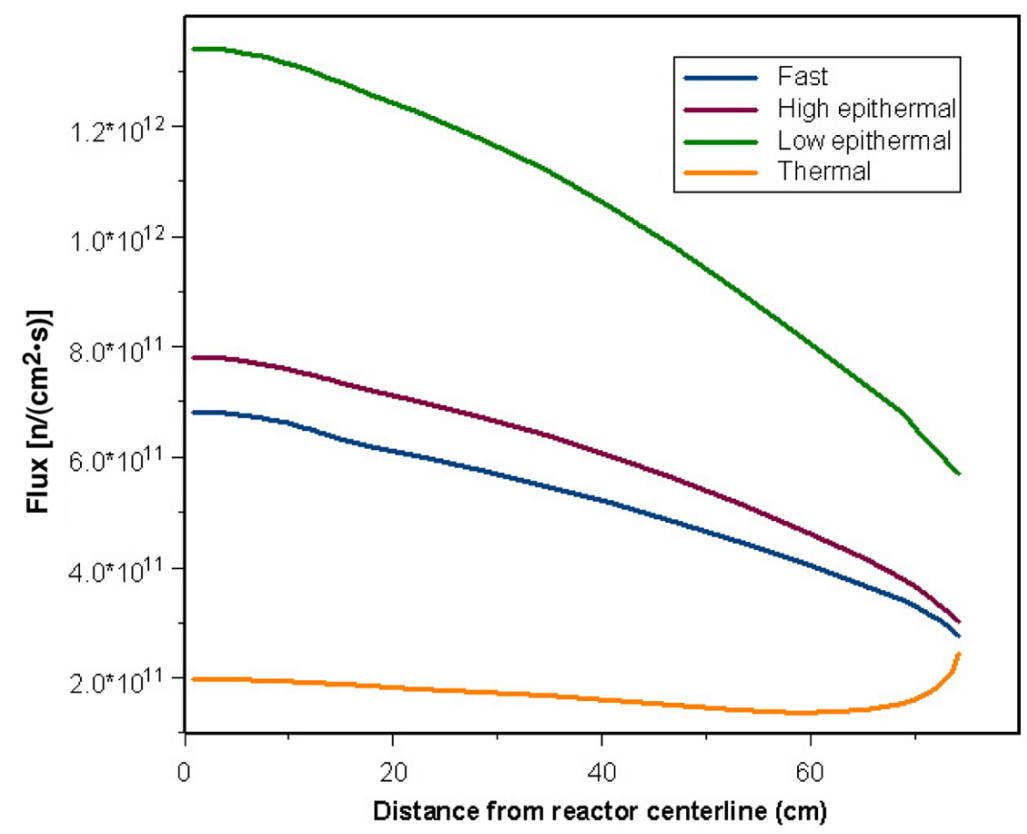

Fig. 5.2. Flux profile from HELIOS calculation. 
that a significant fraction of the reflector is contained in the rotating shutdown rods. While rods of similar geometric configuration have been constructed, the use of graphite as a structural material would be a change from previous designs.

\subsection{FUEL SYSTEM}

\subsubsection{Fuel Stability Over Reactor Lifetime}

As described in Sect. 4.2.1.1, unfueled samples of the graphite foam were irradiated in the HFIR at a neutron flux level on the order of $10^{15}$ neutrons $/\left(\mathrm{cm}^{2} \cdot \mathrm{s}\right)$. From Fig. 5.2, the flux in the SSR is on the order of $2 \times 10^{12}$. So a single cycle of $25 \mathrm{~d}$ in the HFIR would correspond to a fluence of $12,400 \mathrm{~d}$ or 34 years for the SSR - far beyond the design lifetime of 10 years. An examination of fueled specimens would be the next logical step in a fuel qualification procedure, but the cost of such an experiment exceeded funds available for this project.

\subsubsection{Reactor Control}

Because of the very small loss in reactivity per year of operation, the reactor is designed with minimal excess reactivity. The 18 control elements are much more than needed for shutdown at nominal conditions, and "stuck rod" considerations are of no consequence for the nominal condition. The number of control elements is set by the consideration of credible abnormal conditions such as flooding of the reactor core with water. The current design appears to be adequately subcritical even in the condition of water flooding. The magnitude and credibility of uniformly distributed water vapor at a concentration that would lead to positive reactivity greater than found in the water flooding case would have to be assessed in a succeeding study and would have to be coordinated with fuel-in-foam fabrication studies.

The isothermal temperature coefficient calculated with the HELIOS model described in Sect. 4 is shown in Fig. 5.3. While small in magnitude at high temperatures, the value appears to approach an asymptote at temperatures approximately corresponding to the expected peak temperature in the core.

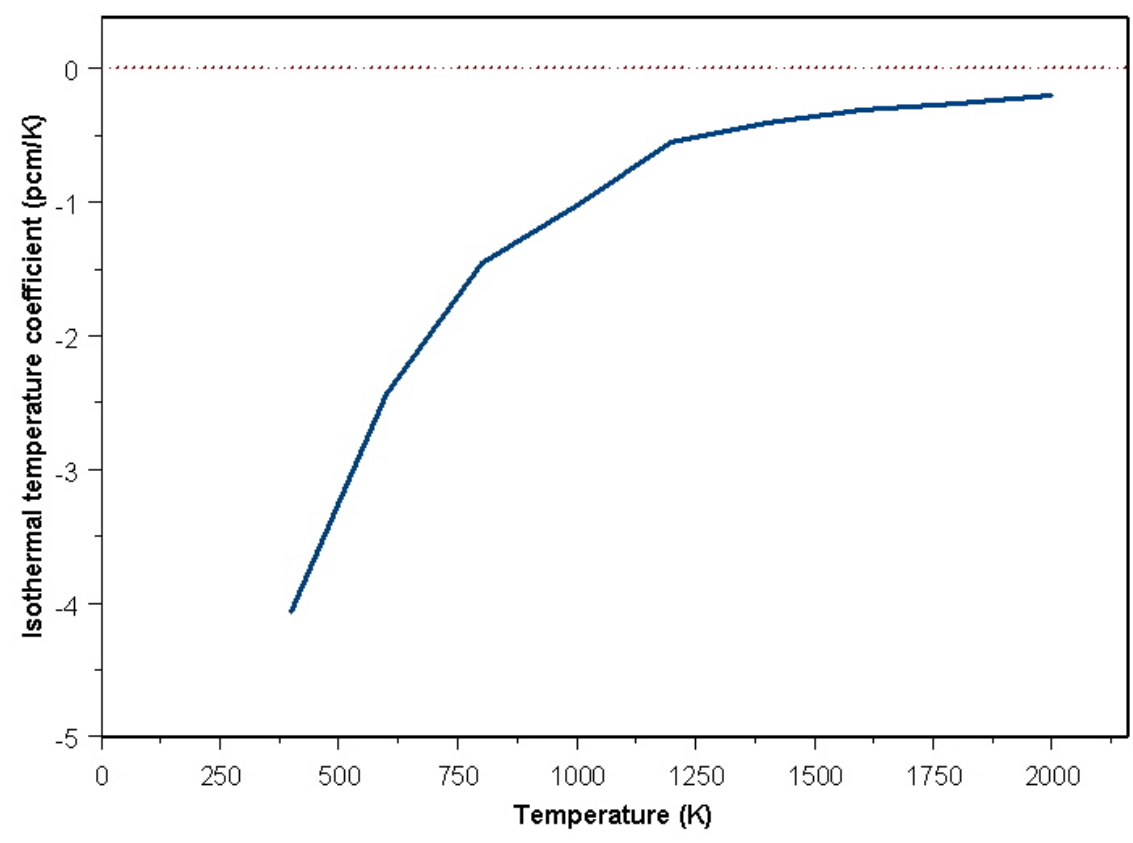

Fig. 5.3. Temperature coefficient for SSR. 


\subsubsection{Fission Product Containment}

Principal gaseous products from fission and radioactive decay are xenon, krypton, and helium. Using the SCALE/ORIGEN program, the whole core inventories of these elements after 10 years of operation were estimated to be $217 \mathrm{~g}$ of xenon, $24 \mathrm{~g}$ of krypton, and $1 \mathrm{mg}$ of helium. A considerable amount of these elements would be expected to be entrained in the foam. Consequently, a core clad breach due to pressurization is not credible, and consequences of clad rupture would be relatively insignificant as compared to a commercial power reactor.

Table 5.2 shows the $\mathrm{C} / \mathrm{U}$ ratios that are obtainable using several different approaches to incorporating uranium in the graphite foam. For stoichiometric $\mathrm{UC}_{2}$ and $\mathrm{U}_{2} \mathrm{C}_{3}$, the only uranium carbides that are stable in contact with graphite at $1500^{\circ} \mathrm{C}$, the $\mathrm{C} /{ }^{235} \mathrm{U}$ ratios range from a low of $7.5\left(\mathrm{U}_{2} \mathrm{C}_{3}\right.$ @ $20 \%$ enrichment) to a high of 16.7 ( $\mathrm{UC}_{2} @ 12 \%$ enrichment). The lowest $\mathrm{C} / \mathrm{U}$ ratios were achieved assuming that all of the pore space in the foam could be filled with uranium metal (3.9 for $20 \%$ enrichment), presumably incorporated by infiltrating the foam with liquid uranium. The highest ratios were observed for $\mathrm{UC}_{2}$ assumed to be derived from the carbothermal reduction of $\mathrm{UO}_{2}$ (32.9 for $20 \%$ enrichment, 54.8 for $12 \%$ enrichment).

Unfortunately, molten uranium is highly aggressive toward graphite. In research conducted for the AVLIS program (http://www.nrc.gov/reading-rm/doc-collections/cfr/part110/part110-appg.html), researchers demonstrated that the only materials that were resistant to molten uranium were tantalum and graphite coated with yttrium oxide or other rare-earth oxides. Neither of these materials is a good candidate for coating the interior walls of the graphite foam. Therefore, any process that depends on using molten uranium in contact with the foam is not likely to be successful. Infiltrating the foam with uranium would simply result in converting the graphite in the foam to $\mathrm{UC}_{2}$, which would defeat the reason for using the foam to begin with (i.e., its high thermal conductivity).

The use of $\mathrm{UC}_{2}$ or $\mathrm{U}_{2} \mathrm{C}_{3}$ as the source of uranium seems the most likely route. There are several approaches one might take to produce graphite foam containing one or the other of these materials. One could simply infiltrate the foam with a fluid suspension of particles in a solvent. Typically, one can achieve upward of 50 to $60 \mathrm{vol} \%$ solids in a suspension and still have it be flowable. Assuming the lower number, $50 \mathrm{vol} \%$, one could incorporate $37.5 \mathrm{vol} \% \mathrm{U}_{2} \mathrm{C}_{3}$ or $\mathrm{UC}_{2}$ in the foam. One real problem with this approach is that fine-particle-size uranium carbides are pyrophoric, and, therefore, they are difficult to work with. Another approach would be to infiltrate the foam in the vapor state using CVI. Using that approach, one might achieve as much as $75 \%$ filling of the pore space before the surface sealed off. This would allow one to incorporate about $56 \mathrm{vol} \%$ carbide into the foam. Another route to incorporating uranium as uranium carbide is the carbothermal reduction of uranium oxide by carbon. This will result in at most about $30 \mathrm{vol} \% \mathrm{UC}_{2}$ in the foam. Which of the described methods is acceptable for this application will depend largely on the required volumetric concentration of ${ }^{235} \mathrm{U}$ and on the required $\mathrm{C} /{ }^{235} \mathrm{U}$ ratio.

Table 5.2. $\mathrm{C} / \mathrm{U}$ ratios for graphite foams with various uranium compounds filling the void space in the foam

\begin{tabular}{|c|c|c|c|}
\hline Filler & $\begin{array}{c}\mathrm{C} / \mathrm{U} \\
\text { (atom/atom) }\end{array}$ & $\begin{array}{c}\mathrm{C} / 235 \mathrm{U} @ \\
\text { 12\% enriched } \\
\text { (atom/atom) }\end{array}$ & $\begin{array}{c}\mathrm{C} /{ }^{235} \mathrm{U} @ \\
20 \% \text { enriched } \\
\text { (atom/atom) }\end{array}$ \\
\hline Pure $\mathrm{UC}_{2}$ (or graphite) & 2 to 1 & 16.7 & 10 \\
\hline Pure $\mathrm{U}_{2} \mathrm{C}_{3}$ & 1.5 to 1 & 12.5 & 7.5 \\
\hline Uranium metal & 0.781 to 1 & 6.5 & 3.9 \\
\hline $\begin{array}{l}\mathrm{UC}_{2} \text { (pure, completely filling pore } \\
\text { space) }\end{array}$ & 3.27 to 1 & 27.25 & 16.35 \\
\hline $\begin{array}{l}\mathrm{UC}_{2} \text { (derived from } \mathrm{UO}_{2} \text { and carbon } \\
\text { powders- } 60 \% \text { filling of pore } \\
\text { space by } \mathrm{UO}_{2} / \text { carbon precursor) }\end{array}$ & 6.58 to 1 & 54.8 & 32.9 \\
\hline
\end{tabular}




\subsection{REACTOR MATERIALS}

\subsubsection{Graphite Foam Description and Characteristics}

A relatively simple technique for fabricating graphite foams has been developed and patented at ORNL (U.S. patents 6,033,506, 6,037,032, 6,261,485, 6,287,375, 6,344,159, 6,387,343, 6,398,994, $6,399,199)$. This technique produces an open-celled graphitic foam with extremely high-bulk thermal conductivity (up to $180 \mathrm{~W} / \mathrm{m} \cdot \mathrm{K}$ ) (see Fig. 5.4). The cell walls are made of oriented graphitic planes, more aligned than high-performance carbon fibers. Moreover, because of the graphite foam's inherently low density, the material exhibits a specific thermal conductivity (thermal conductivity divided by density) more than 5 times greater than aluminum and 7 times greater than copper at room temperature. The open porosity yields a relatively large specific surface area $\left(>20 \mathrm{~m}^{2} / \mathrm{g}\right)$, significantly improving heat transfer to a working fluid and leading to extremely efficient and lightweight heat exchangers. In fact, a finned heat sink made from graphitic foam can be up to 3 times more efficient than an aluminum heat sink, yet at 1/5 the weight (effectively 5 times more efficient per gram of heat sink). Currently, a finned heat sink has been cooling a Pentium 133-MHz chip for 3 years with no problems experienced.

Recently, many aerospace applications have identified improved thermal management as a leading research objective. Many heat sinks and heat exchangers are bulky and require large areas to dump generated heat to the environment. The use of graphite foams as an alternative to current designs is very attractive from the standpoint of reducing weight and volume, while improving heat transfer efficiencies.One of the most impressive and unique features of the graphite foam is its ability to absorb acoustic energy. Preliminary measurements of the absorption performance were made in a low amplitude impedance tube. These results indicated that its performance was on par with or better than conventional acoustic foam (see Fig. 5.5).

\subsubsection{Reactor Container Material}

As mentioned in Sect. 3.2, a thin layer of rhenium/iridium alloy will be ideal to protect the core and reflector from oxidation as well as external and internal contaminants at high temperature. This would require a development program to investigate the thickness needed for the degree of sealing desired, the bond strength with the graphitized foam, radiation effects, and the mechanical resistance to internal pressure buildup.

Nevertheless, as indicated in Sect. 4.1.6, stainless steel was the material chosen for the conceptual design.

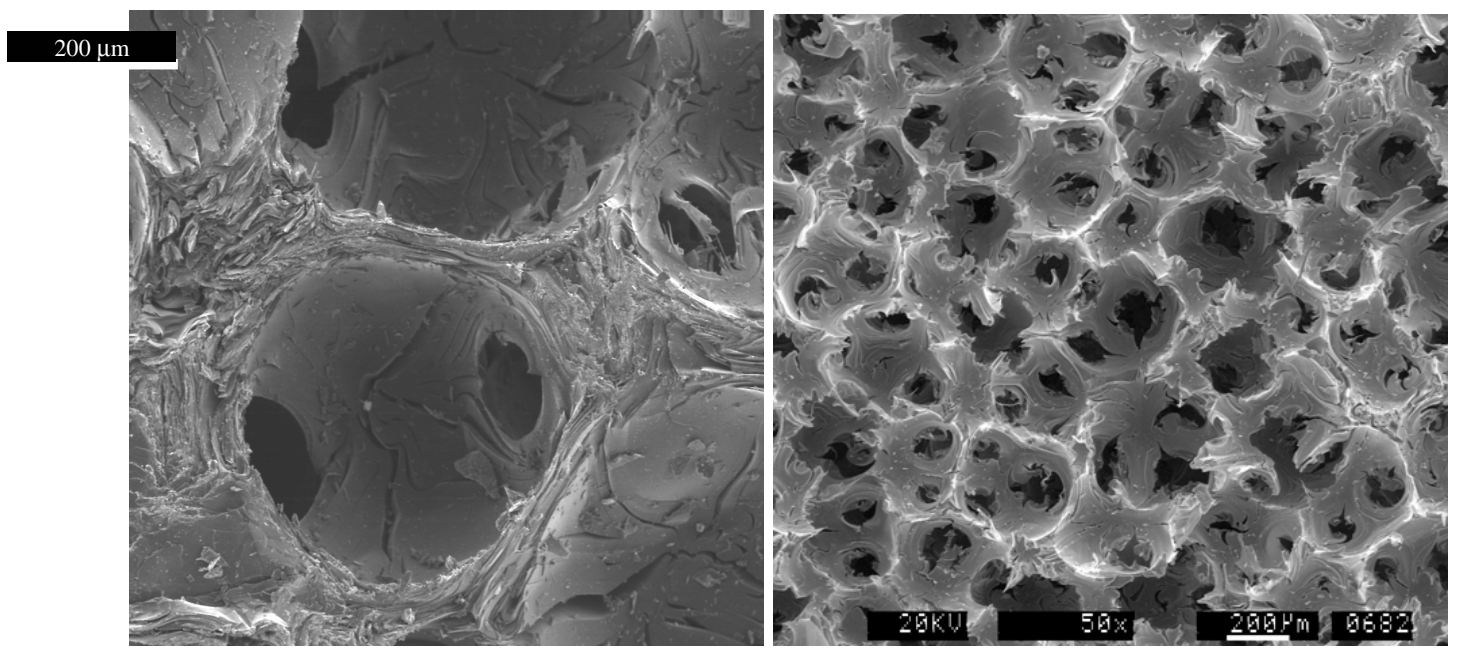

Fig. 5.4. SEM images of the graphite foam. 


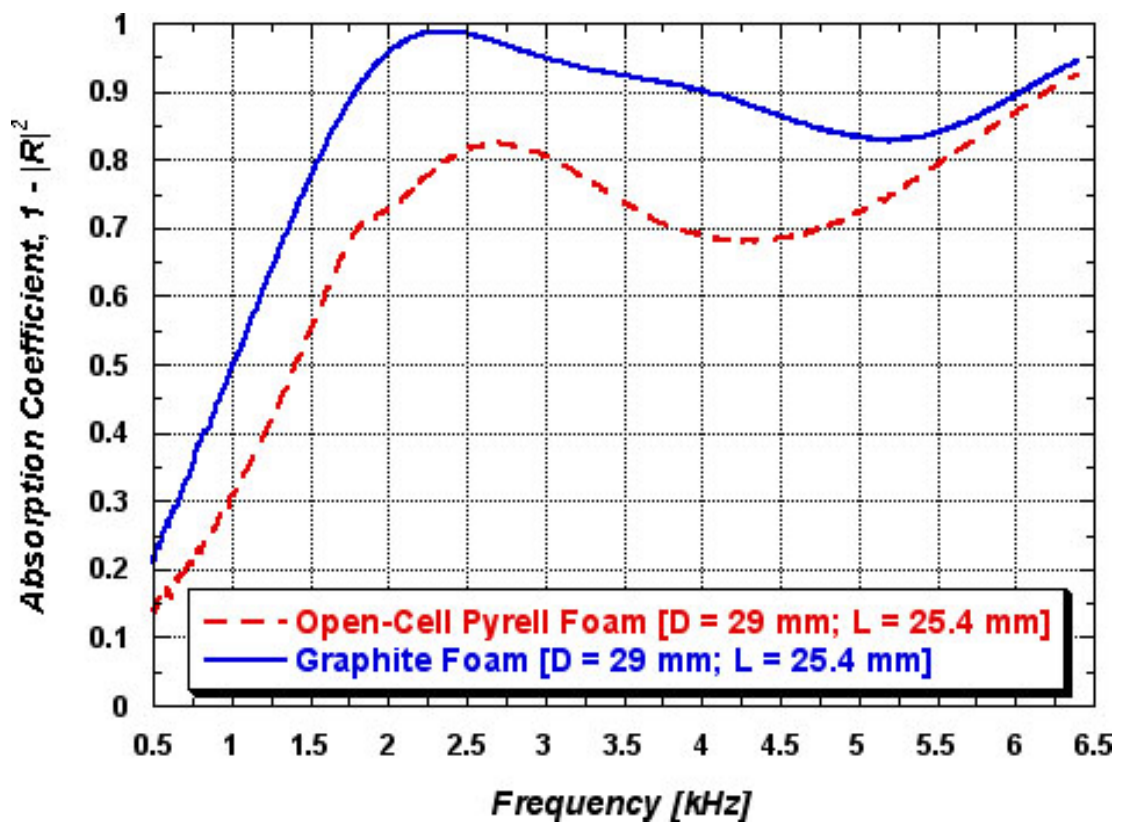

Fig. 5.5. Acoustic behavior of the graphite foam compared with Pyrell foam used in anechoic chambers.

\subsubsection{Shielding Considerations}

The 1-D discrete ordinates model (XSDRNPM), used for the power density profile calculation shown in Fig. 5.1, was used to calculate the dose rate at the outside surface of the graphite reflector. The calculation was performed with the SCALE 27 neutron-18 gamma group library (ENDF/B-V). The dose rates were calculated at the axial midplane and $1 \mathrm{~cm}$ above the outside surface of the reflector. The neutron dose rate, as calculated with the American National Standards Institute (ANSI) standard flux-to-dose-rate factors, was $5200 \mathrm{rem} / \mathrm{h}$, and the gamma dose rate (ANSI standard) was $250 \mathrm{rem} / \mathrm{h}$. The gamma dose rate should be regarded as a minimum estimate. Software and data library developers are uncertain as to whether the prompt fission gammas were accurately represented in the calculation.

These dose rates are for the normal operating condition of the reactor $(500 \mathrm{~kW})$. Shielding materials and configurations would depend on the deployment scenario for the reactor.

Some lanthanides, such as gadolinium $(48,800 \mathrm{~b})$, europium $(4,570 \mathrm{~b})$, or samarium $(5,600 \mathrm{~b})$, have neutron absorption cross sections that are higher than boron $(760 \mathrm{~b})$ or even ${ }^{10} \mathrm{~B}(3,800 \mathrm{~b})$, which makes materials containing lanthanide elements potentially attractive neutron absorbers. Additionally, whereas isotopic separation increases the cost of ${ }^{10} \mathrm{~B}$ to several $\$ 1000 / \mathrm{kg}$, the increased industrial usage of these rare-earth elements has reduced their cost to the $\$ 25$ to $\$ 40 / \mathrm{kg}$ range.

A thin coat of gadolinium in the interior of the outside surfaces will be enough to block neutrons. Gamma ray shielding will require classical shielding.

\subsection{THERMAL ANALYSIS/HEAT REMOVAL FOR THE CONCEPTUAL DESIGN}

The final conceptual design consists of a core of $75-\mathrm{cm}$ radius and $150-\mathrm{cm}$ height with a $30-\mathrm{cm}$-thick reflector separated by a $1-\mathrm{cm}$-thick cooling channel. At nominal operation, the $500 \mathrm{~kW}$ of power generated in the reactor core is transferred to a stream of $\mathrm{He}-\mathrm{Xe}$ gas circulating through the 1-cm-wide finned channel between the core and the reflector. The cooling gas enters the reactor from the bottom at $751 \mathrm{~K}$ and exits from the top at $900 \mathrm{~K}$. The temperature at the core surface is expected to be of the order of $45 \mathrm{~K}$ higher than the cooling gas. The reflector is presumed to be thermally insulated externally; that is, during normal operation, the heat losses through the outer surfaces can be considered to be negligible. 


\subsubsection{Preliminary Core Temperature Profiles}

Figure 5.6 shows the temperature profiles at three axial planes-bottom, center, and top-computed with the 1-D model with heat removal at the core-reflector boundary.

Power peaking factors of $0.54,1.245$, and 0.54 (i.e., $270 \mathrm{~kW}, 623 \mathrm{~kW}$, and $270 \mathrm{~kW}$ thermal) and heat sink boundary temperatures of $703 \mathrm{~K}, 824 \mathrm{~K}$, and $945 \mathrm{~K}$ were used to describe the bottom, middle, and top planes, respectively.

From the curves in Fig. 5.6, we see that the peak temperatures at the center of the bottom, middle, and top planes are $889 \mathrm{~K}, 1368 \mathrm{~K}$, and $1117 \mathrm{~K}$, respectively.

Figure 5.7 shows the power flows per unit area as a function of radial position at the same three elevations. The respective values at the core boundary are $3.8 \mathrm{~W} / \mathrm{cm}^{2}, 8.8 \mathrm{~W} / \mathrm{cm}^{2}$, and $3.8 \mathrm{~W} / \mathrm{cm}^{2}$.

Figure 5.8 shows the thermal conductivities of the core's foam as a function of radial position at the same three elevations. The minimum values occur at the core centerline because that is where the temperatures peak and are $75.2 \mathrm{~W} / \mathrm{m} / \mathrm{K}, 54.4 \mathrm{~W} / \mathrm{m} / \mathrm{K}$, and $60.8 \mathrm{~W} / \mathrm{m} / \mathrm{K}$, respectively.

The temperatures thus computed constituted a first approximation from which the range of temperatures for nuclear data generation was determined.

\subsubsection{Core Temperature and Power Generation Profiles}

The final temperature fields were computed with a multiregion, multigroup coupled neutronic/ thermohydraulic simulator developed for this purpose. This simulator takes as input temperature-dependent multigroup neutronic parameters - collapsed from detailed computations by specialized computer codesand temperature-dependent thermal conductivities for the core and reflector materials. The simulator implements in a 2-D geometry an iterative inner-outer difference-scheme to solve the multigroup multiregion diffusion equation coupled to the heat transfer equations.

The solution of the neutronic equations yields the power generation distribution and the neutron multiplication factor. The solution of the heat transfer equations yields the corresponding temperature

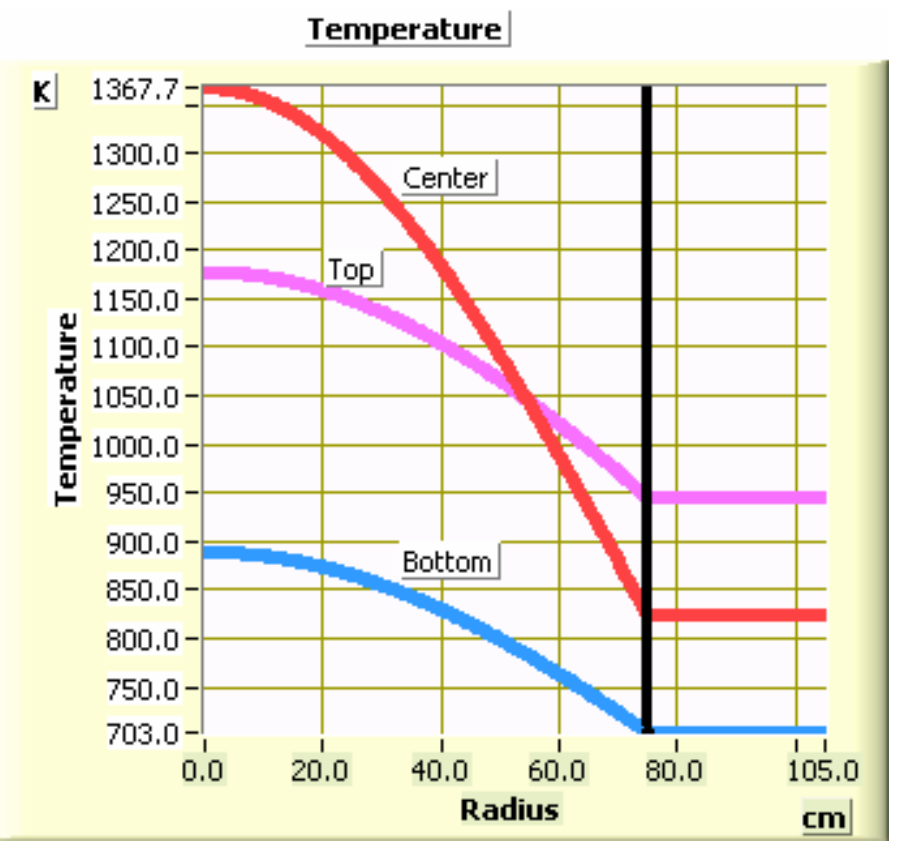

Fig. 5.6. 1-D calculation of radial temperature distributions at the bottom, middle, and top planes for the $500-\mathrm{kW}$ reactor core. 


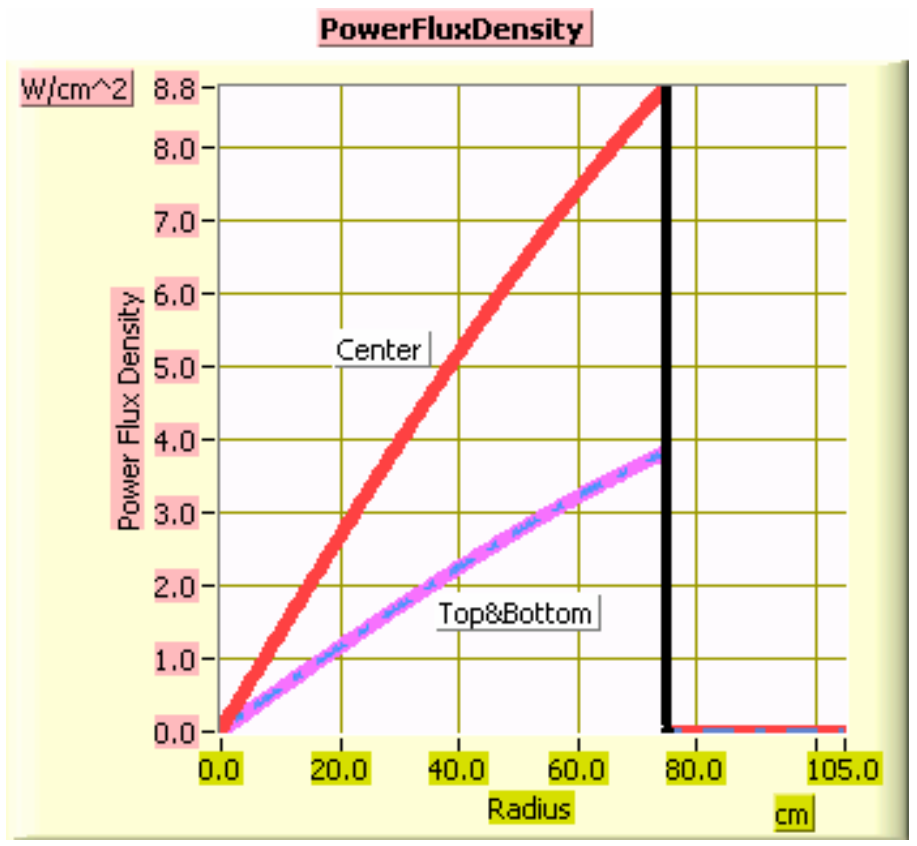

Fig. 5.7. 1-D calculation of radial distributions of power flow at the bottom, middle, and top planes for the $500-\mathrm{kW}$ reactor core.

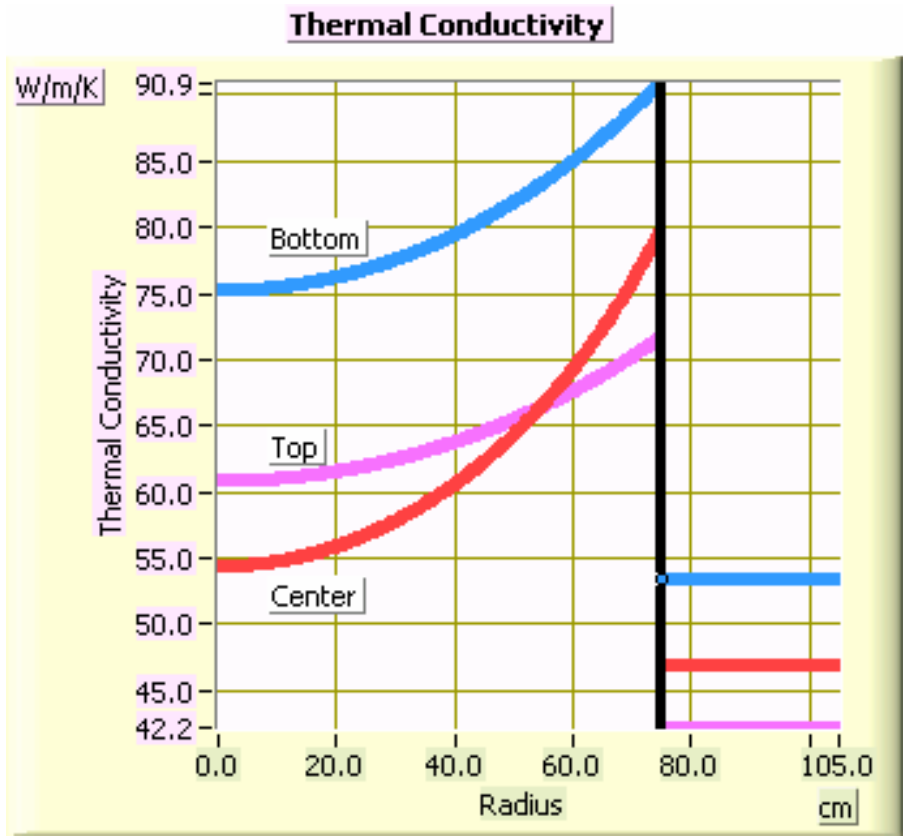

Fig. 5.8. 1-D calculation of radial distribution of thermal conductivity at the bottom, middle, and top planes for the 500-kW reactor core. 
distribution. Local changes in temperature affect the neutron cross sections and, thus, the heat sources that, in turn, produce new temperature distributions.

Neutronic computations were performed by interpolating the set of four energy groups' cross sections for $300 \mathrm{~K}, 900 \mathrm{~K}, 1500 \mathrm{~K}$, and $2100 \mathrm{~K}$ averaged over four material regions: three regions to describe the reactor core and one for the reflector. The neutronic parameters and their temperature dependence for each material region and energy group are shown graphically in Appendix B.

Figure 5.9 shows the neutron fluxes along a diameter in the center of the reactor for the base-case of $500 \mathrm{~kW}$ power with $930 \mathrm{~K}$ heat sink. The computation uses nodes representing squares of $1 \mathrm{~cm}^{2}$ in area. The neutron flux is shown in the figures scaled to produce a unit fission in the core. The multiplication factor computed for the base case is $k_{\text {eff }}=1.00008527$. This value is taken as reference to determine reactivity coefficients and to find the self-regulating operating map. The dominant neutron energy group inside the core is the epithermal. Moderation in the reflector causes the thermal neutron flux to peak. As shown in Fig. 5.3, neutrons return to the core from the reflector with thermal energies, thus causing a significant increase in power generation near the reflector's boundary. Figure 5.3 also shows discontinuities in power generation density near the center and near the reflector. The discontinuity in the center is real, and it is due to the different cross sections of the fuel type used in a central 14-cm-radius region. The discontinuity at the $13-\mathrm{cm}$ ring from the periphery of the core is a computational artifact resulting from cross-section averaging in the core regions.

Table 5.3 shows core-averaged and peak temperature values, neutron multiplication factor, and relative fluxes for the set of operating conditions computed with cooling at the core/reflector cylindrical boundary.

Figures 5.10 and 5.11 show the power generation and temperature distributions for the base-case of $500 \mathrm{~kW}$ power with $930 \mathrm{~K}$ heat sink. These profiles are shapewise representative of the core temperature and power generation profiles for other operating conditions. In these figures, the 2-D map is shown in central position. The curves on top and right positions correspond to cross cuts at the positions defined by the 2-D map's cursor.

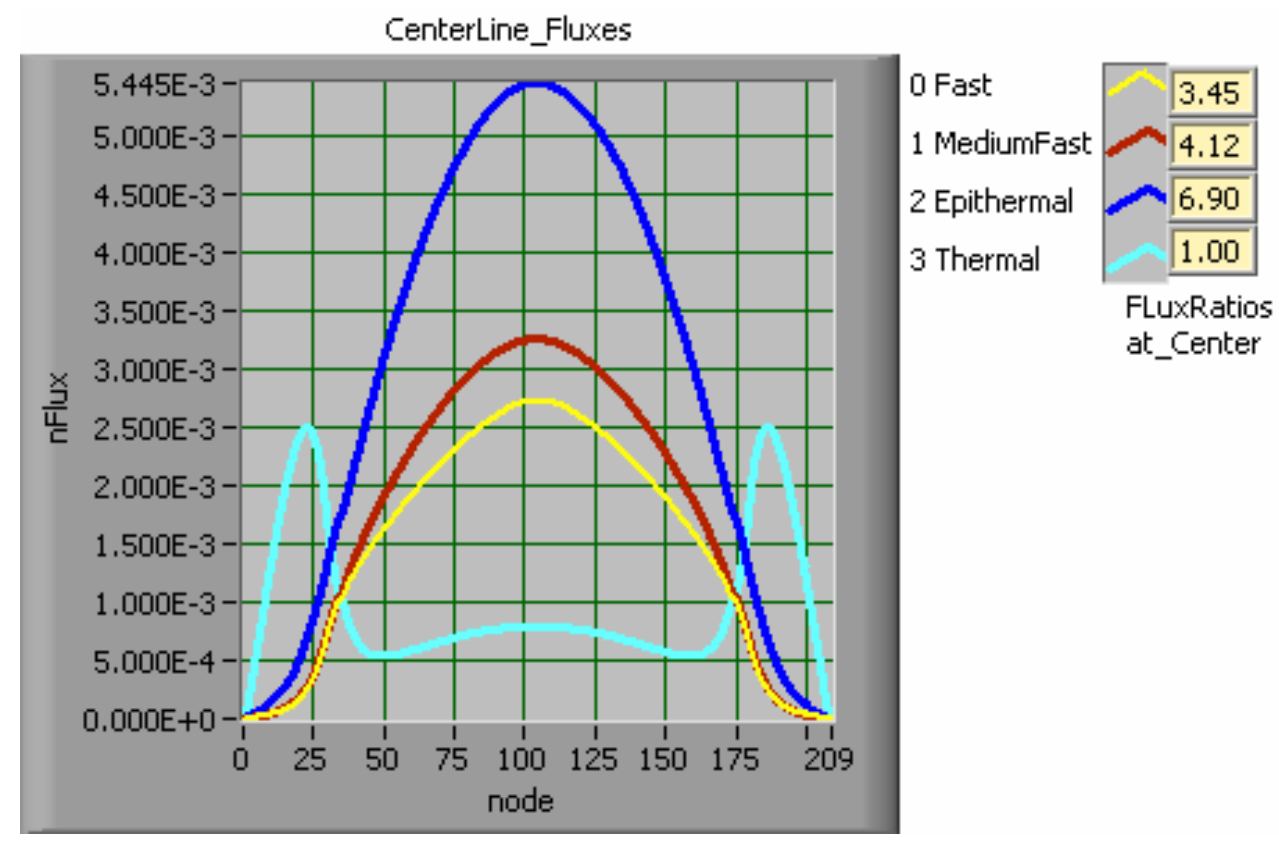

Fig. 5.9. Neutron fluxes along a diameter in the center of the reactor for the base case of $500-\mathrm{kW}$ power with $930 \mathrm{~K}$ heat sink. 
Table 5.3. Core-averaged and peak temperatures and neutronic parameters for cooling at the core/reflector cylindrical boundary

\begin{tabular}{|c|c|c|c|c|c|c|c|c|c|}
\hline & Power & Tsink & Tave & Tpeak & keff & Fast & MidF & Epith & $\operatorname{Max}$ \\
\hline \multirow[t]{7}{*}{ Standby } & 0.00 & 1202.00 & 1202.00 & 1202.00 & 1.00008527 & 3.42 & 4.08 & 6.84 & $5.468 \mathrm{E}-3$ \\
\hline & 62.50 & 930.00 & 953.86 & 982.09 & 1.00009367 & 3.39 & 4.05 & 6.78 & $5.445 E-3$ \\
\hline & 125.00 & 930.00 & 979.12 & 1037.61 & 1.00009266 & 3.40 & 4.06 & 6.79 & $5.445 \mathrm{E}-3$ \\
\hline & 250.00 & 930.00 & 1034.04 & 1321.97 & 1.00009047 & 3.41 & 4.08 & 6.82 & $5.445 E-3$ \\
\hline & 250.00 & 1068.75 & 1183.61 & 1321.97 & 1.00008527 & 3.43 & 4.10 & 6.87 & $5.457 \mathrm{E}-3$ \\
\hline & 500.00 & 330.00 & 441.50 & 580.79 & 1.00012032 & 3.31 & 3.94 & 6.57 & $5.732 \mathrm{E}-3$ \\
\hline & 500.00 & 630.00 & 809.48 & 1032.36 & 1.00009891 & 3.40 & 4.06 & 6.79 & $5.413 \mathrm{E}-3$ \\
\hline \multirow[t]{14}{*}{ Nominal } & 500.00 & 930.00 & 1164.75 & 1454.46 & 1.00008527 & 3.45 & 4.12 & 6.90 & $5.445 E-3$ \\
\hline & 500.00 & 1230.00 & 1518.55 & 1875.66 & 1.00007395 & 3.48 & 4.17 & 7.00 & $5.473 \mathrm{E}-3$ \\
\hline & 600.00 & 900.00 & 1190.35 & 1552.36 & 1.00008411 & 3.46 & 4.13 & 6.93 & $5.443 \mathrm{E}-3$ \\
\hline & 600.00 & 930.00 & 1227.06 & 1597.53 & 1.00008287 & 3.46 & 4.14 & 6.94 & $5.446 \mathrm{E}-3$ \\
\hline & 666.67 & 930.00 & 1272.86 & 1703.62 & 1.00008125 & 3.47 & 4.15 & 6.96 & $5.447 \mathrm{E}-3$ \\
\hline & 775.00 & 743.60 & 1108.25 & 1571.24 & 1.00008629 & 3.46 & 4.14 & 6.93 & $5.432 \mathrm{E}-3$ \\
\hline & 1000.00 & 330.00 & 665.22 & 1107.53 & 1.00010497 & 3.41 & 4.07 & 6.80 & $5.376 \mathrm{E}-3$ \\
\hline & 1000.00 & 630.00 & 1122.03 & 1762.42 & 1.00008541 & 3.47 & 4.16 & 6.97 & $5.423 \mathrm{E}-3$ \\
\hline & 1000.00 & 930.00 & 1562.13 & 2378.27 & 1.00007214 & 3.51 & 4.20 & 7.05 & $5.456 \mathrm{E}-3$ \\
\hline & 1054.50 & 600.00 & 1123.77 & 1809.61 & 1.00008527 & 3.48 & 4.16 & 6.98 & $5.420 \mathrm{E}-3$ \\
\hline & 1250.00 & 479.35 & 1118.75 & 1974.45 & 1.00008527 & 3.49 & 4.18 & 7.01 & $5.409 \mathrm{E}-3$ \\
\hline & 1500.00 & 300.00 & 1077.69 & 2146.89 & 1.00008666 & 3.50 & 4.19 & 7.04 & $5.390 \mathrm{E}-3$ \\
\hline & 1530.00 & 300.00 & 1119.52 & 2247.28 & 1.00008527 & 3.51 & 4.20 & 7.04 & $5.392 \mathrm{E}-3$ \\
\hline & 1681.00 & 300.00 & 1331.59 & 2743.98 & 1.00008008 & 3.51 & 4.20 & 7.05 & $5.410 \mathrm{E}-3$ \\
\hline
\end{tabular}




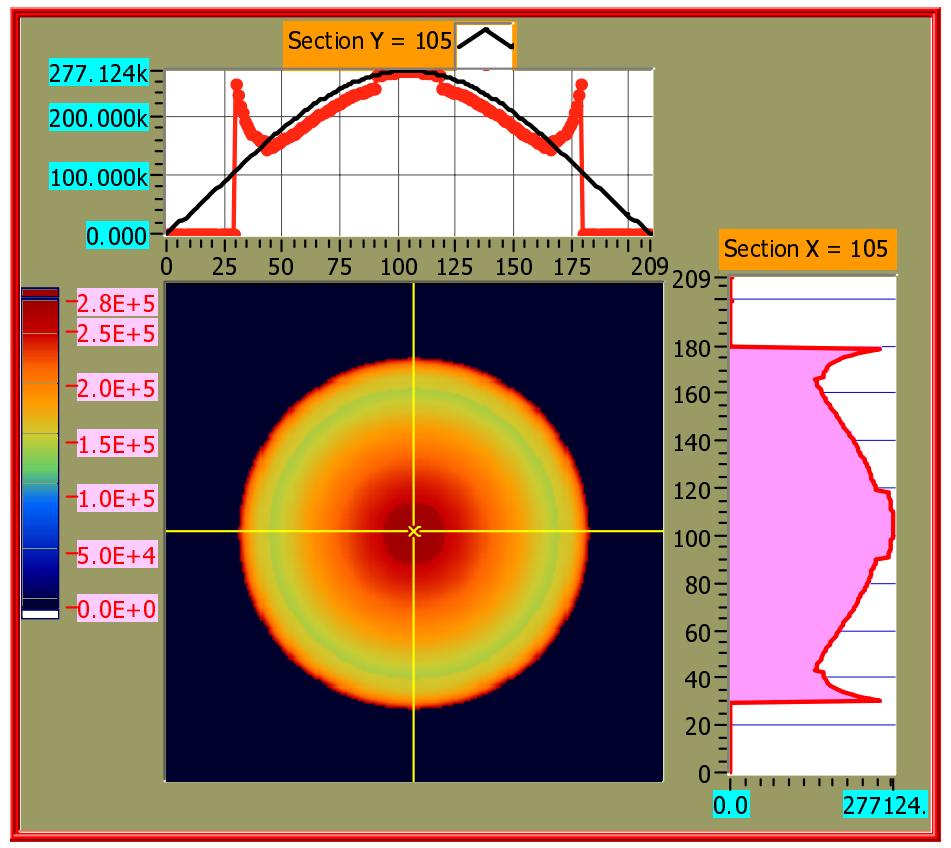

Fig. 5.10. Power generation $\left(\mathrm{W} / \mathrm{m}^{3}\right)$ distribution for the base case of $500-\mathrm{kW}$ power with $930 \mathrm{~K}$ heat sink at the core/reflector boundary.

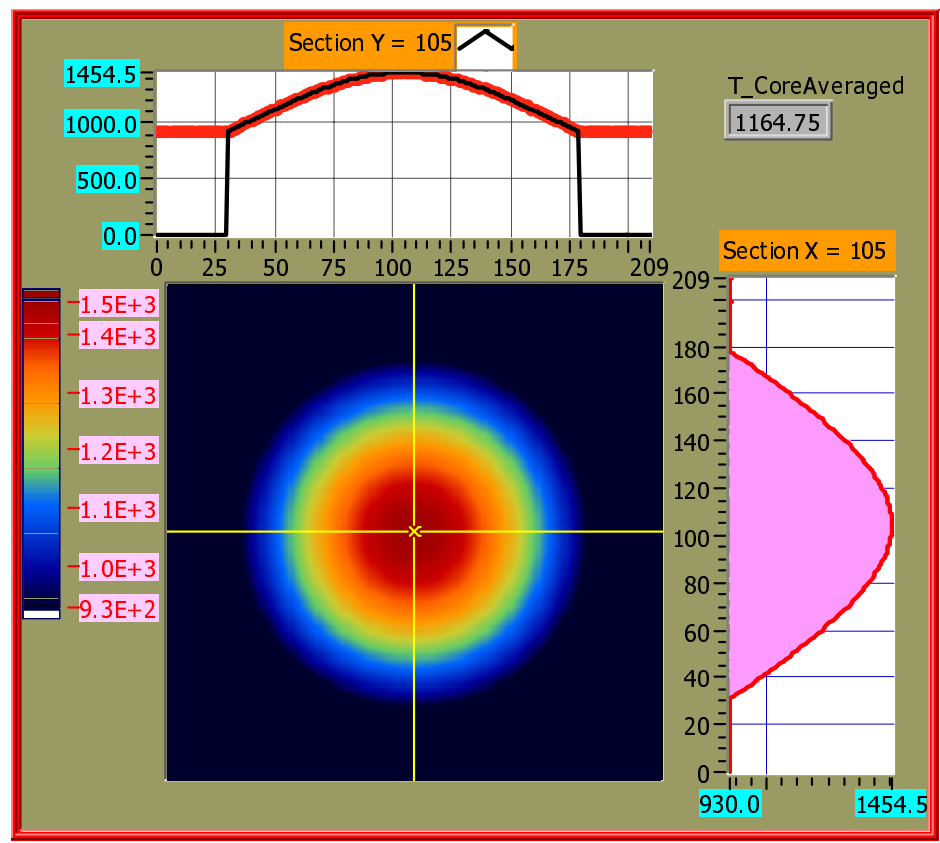

Fig. 5.11. Temperature distribution (K) for the base case of $500-\mathrm{kW}$ power with $930 \mathrm{~K}$ heat sink at the core/reflector boundary. 
Using the data in Table 5.1, the dependence of the average and peak temperatures on the heat sink temperature is shown graphically in Figs. 5.12 and 5.13 for power generation levels of $500 \mathrm{~kW}$ and $1000 \mathrm{~kW}$, respectively.

Table 5.4 is the subset of Table 5.3 corresponding to computed neutron multiplication factors equal to that of nominal operation. This identifies the self-regulating operating map. When the rate of heat removal changes, the temperature at the cooling boundary changes in opposing direction. As the boundary temperature change propagates through the core, it affects the neutron multiplication factor that, in turn, changes the power generation until the original multiplication factor is restored.

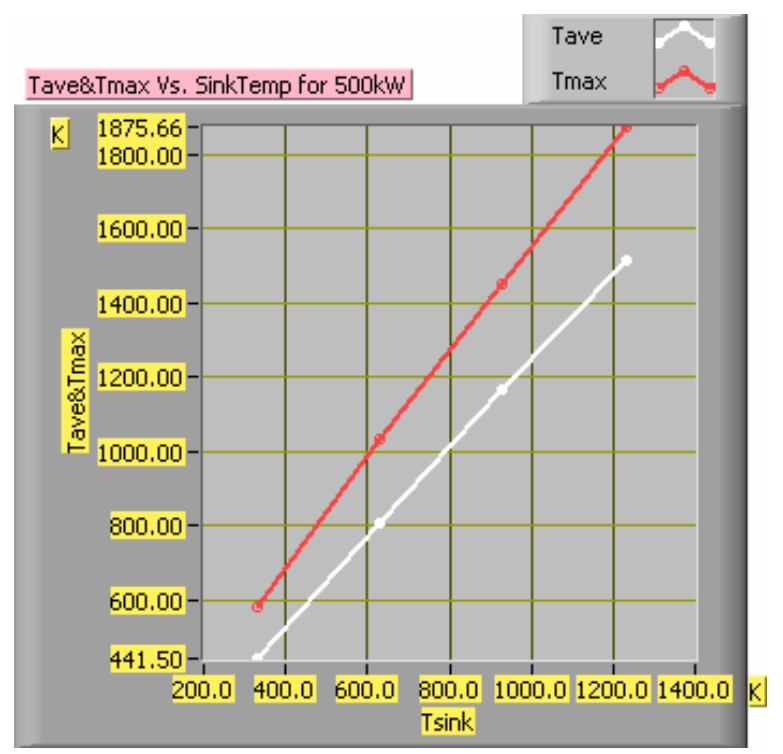

Fig. 5.12. Dependence of the core-average and peak temperatures with the heat sink temperature at the core/reflector boundary for a power generation of $500 \mathrm{~kW}$.

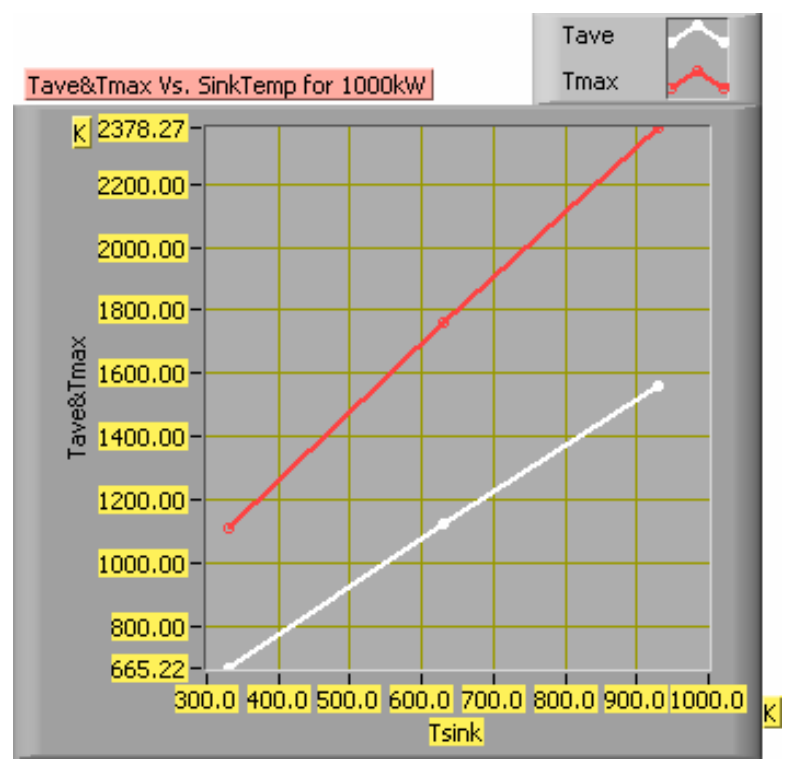

Fig. 5.13. Dependence of the core-average and peak temperatures with the heat sink temperature at the core/reflector boundary for a power generation of $1000 \mathrm{~kW}$. 
Table 5.4. Core-averaged and peak temperatures and neutronic parameters for cooling at the core/reflector cylindrical boundary

\begin{tabular}{|c|c|c|c|c|c|c|c|c|c|}
\hline & Power & Tsink & Tave & Tpeak & keff & Fast & MidF & Epith & $\operatorname{Max}$ \\
\hline \multirow[t]{2}{*}{ Standby } & 0.00 & 1202.00 & 1202.00 & 1202.00 & 1.00008527 & 3.42 & 4.08 & 6.84 & $5.468 \mathrm{E}-3$ \\
\hline & 250.00 & 1068.75 & 1183.61 & 1321.97 & 1.00008527 & 3.43 & 4.10 & 6.87 & $5.457 \mathrm{E}-3$ \\
\hline \multirow[t]{4}{*}{ Nominal } & 500.00 & 930.00 & 1164.75 & 1454.46 & 1.00008527 & 3.45 & 4.12 & 6.90 & $5.445 \mathrm{E}-3$ \\
\hline & 775.00 & 732.70 & 1107.70 & 1571.46 & 1.00008527 & 3.46 & 4.14 & 6.93 & $5.442 \mathrm{E}-3$ \\
\hline & 1054.50 & 600.00 & 1123.77 & 1809.61 & 1.00008527 & 3.48 & 4.16 & 6.98 & $5.420 \mathrm{E}-3$ \\
\hline & 1250.00 & 479.35 & 1118.75 & 1974.45 & 1.00008527 & 3.49 & 4.18 & 7.01 & $5.409 \mathrm{E}-3$ \\
\hline Limit & 1530.00 & 300.00 & 1119.52 & 2247.28 & 1.00008527 & 3.51 & 4.20 & 7.04 & $5.392 \mathrm{E}-3$ \\
\hline
\end{tabular}

For instance, if we start with the reactor operating at the nominal point (i.e., producing $500 \mathrm{~kW}$ with the heat sink at $930 \mathrm{~K}$ ) and the rate of heat extraction in the heat sink is reduced continuously and slowly, then the temperature at the boundary of the core will increase, and power generation will decrease following the curves in Fig. 5.14.

When the temperature at the heat sink boundary reaches $1069 \mathrm{~K}$, the power will be $250 \mathrm{~kW}$. When the heat sink is fully turned off, the boundary temperature reaches $1202 \mathrm{~K}$, and the reactor remains critical but producing zero power. This is the condition labeled as "Standby" in the table. A further increase in heat sink temperature will make the reactor subcritical and act as a heat sink. When the heat sink is turned on again, the core will start generating power again, following the curves in Fig. 5.14.

Moving from the nominal operating point toward increasing energy removal, the temperature at the heat sink boundary of the core will decrease, and power generation will increase. When the temperature at

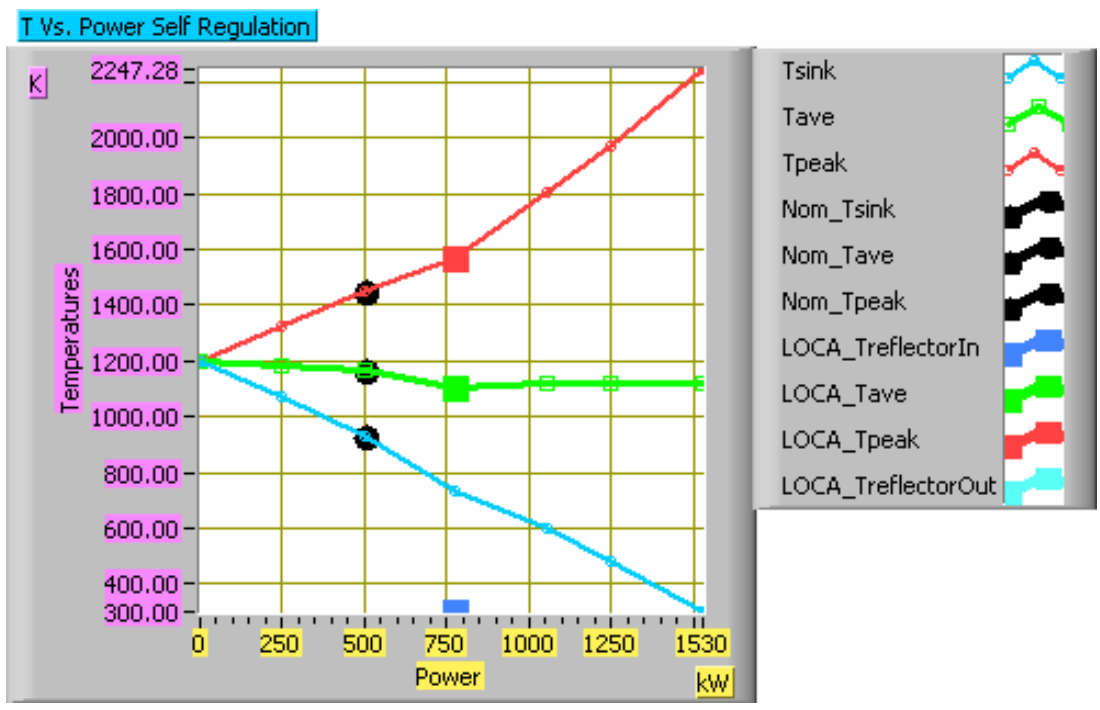

Fig. 5.14. Reactor's self-adjusting operating trajectory with heat sink at the core/reflector boundary: equilibrium power vs temperatures at the heat sink, core averaged, and peak. The large black dots represent the nominal operating point $(500 \mathrm{~kW})$. The large square dots correspond to equilibrium with heat removal at the outside surface of the reflector at $300 \mathrm{~K}$ (see Table 5.5). 
the heat sink boundary reaches $300 \mathrm{~K}$, the power will be $1530 \mathrm{~kW}$. Because $300 \mathrm{~K}$ is ambient temperature, $1530 \mathrm{~kW}$ represents the amount of steady state power generation were the heat sink to be able to absorb all $1530 \mathrm{~kW}$ produced. The peak temperature under these conditions will be in the vicinity of $2250 \mathrm{~K}$.

\subsubsection{Core Temperature and Power Generation Profiles at Off-Normal Operation}

\subsubsection{Nominal power with cooling at outside reflector}

Table 5.5 and Fig. 5.15 show the results of calculations in which it is assumed that the reactor is critical while the heat sink is at the outside cylindrical surface of the reflector. The first case corresponds to the nominal power. It indicates that steady state will be maintained at a temperature of $622 \mathrm{~K}\left(350^{\circ} \mathrm{C}\right)$ with a heat flux density of $5 \mathrm{~W} / \mathrm{cm}^{2}$.

Table 5.5. Core-averaged and peak temperatures and neutronic parameters for cooling at the reflector's external cylindrical boundary

\begin{tabular}{|c|c|c|c|c|c|c|c|c|c|}
\hline Power & Tsink & Treflec_In & Tave & Tpeak & keff & Fast & MidF & Epith & $\operatorname{Max}$ \\
\hline 500.00 & 622.15 & 918.62 & 1147.12 & 1433.95 & 1.00008527 & 3.44 & 4.12 & 6.90 & $5.450 E-3$ \\
\hline 582.15 & 523.15 & 845.56 & 1131.75 & 1469.16 & 1.00008527 & 3.45 & 4.12 & 6.91 & $5.449 \mathrm{E}-3$ \\
\hline 775.00 & 300.00 & 732.70 & 1107.70 & 1571.46 & 1.00008527 & 3.46 & 4.14 & 6.93 & $5.442 \mathrm{E}-3$ \\
\hline
\end{tabular}

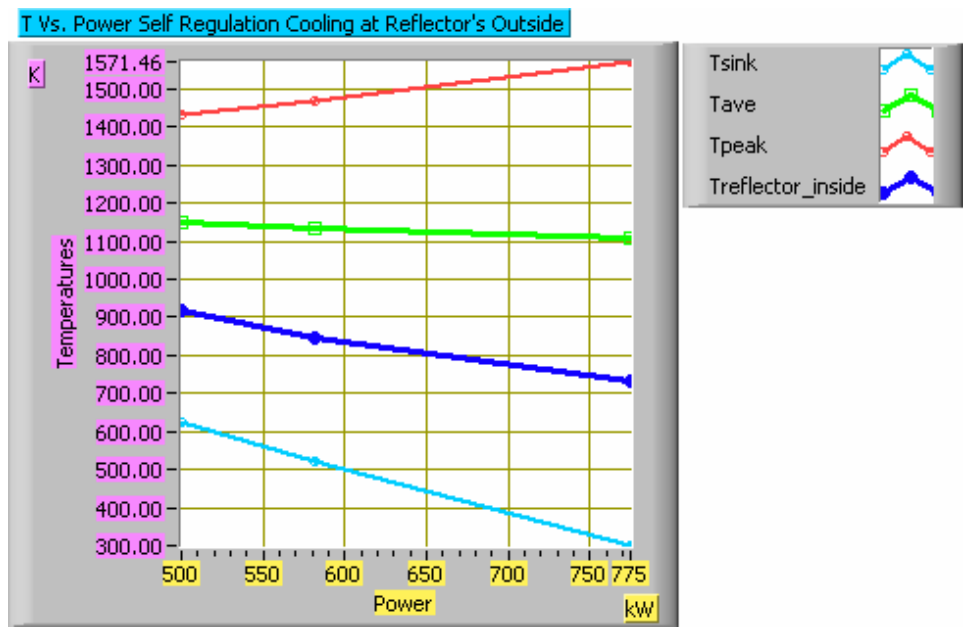

Fig. 5.15. Reactor's self-adjusting operating trajectory with heat sink at the reflector external boundary: equilibrium power vs temperatures at the heat sink, core/reflector boundary, core averaged, and peak.

\subsubsection{Power with cooling at outside reflector at ideal temperature for thermoelectric conversion}

The case of cooling at the reflector boundary at a sink temperature of $523 \mathrm{~K}\left(250^{\circ} \mathrm{C}\right)$ was chosen to match the operating temperature of commercially available Hi-Z's Z-20 thermoelectric cells. The resulting steady state thermal power generation was $582 \mathrm{~kW}$ with a heat flux density of $5.9 \mathrm{~W} / \mathrm{cm}^{2}$. Because the efficiency of Z-20 is $3.1 \%$, up to $18 \mathrm{~kW}$ of electricity will be generated. This will require $1600 \mathrm{Z}-20$ cells attached all around the cylindrical periphery of the reflector up to a height of $150 \mathrm{~cm}$. 
The temperature distribution for this case is shown in Fig. 5.16. Its shape is characteristic of the cases with cooling from the outside of the reflector.

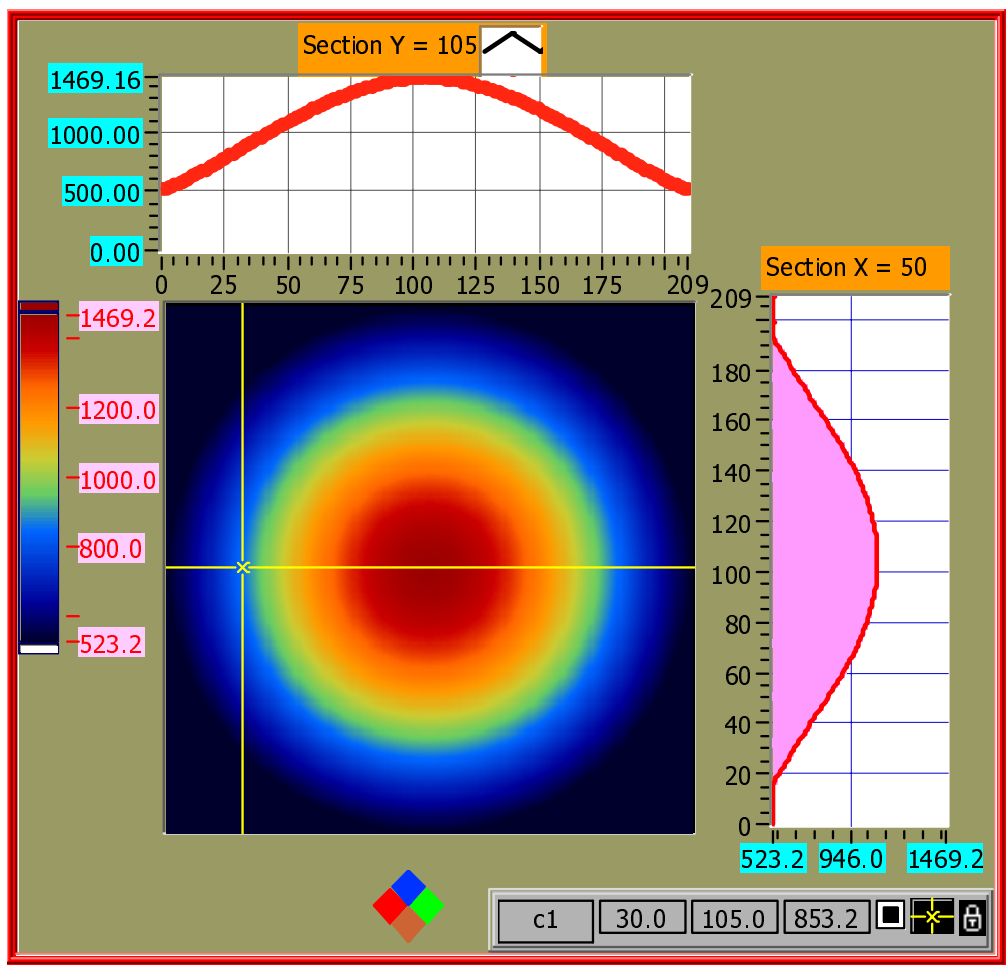

Fig. 5.16. Temperature distribution (K) for the $\mathrm{Z}-20$ match case of $582.15-\mathrm{kW}$ power with $250^{\circ} \mathrm{C}$ heat sink at the reflector's external boundary.

\subsubsection{Power for cooling at reflector boundary at ambient temperature}

The third case was chosen to find the equilibrium power were all of the power be removed from the outside of the reflector at the ambient temperature. The steady state power cooling outside the reflector, $775 \mathrm{~kW}$, is slightly above one-half of the power obtained when cooling at the reactor/reflector boundary under the same conditions. The peak temperature is slightly below half. At this condition the heat flux at the cooling surface will be $7.8 \mathrm{~W} / \mathrm{cm}^{2}$. Note that this third case was also included in Fig. 5.14, shown in large square dots.

Also note the difference in multiplication factor between the 775-kW cases in Tables 5.3 and 5.4. It reflects the neutronic impact of the temperature of the reflector. Although the core temperatures are similar, cooling on the outside of the reflector makes the reflector's temperature nonuniform, varying between $744 \mathrm{~K}$ and $300 \mathrm{~K}$. The colder average temperature at the reflector results in higher $\mathrm{k}_{\mathrm{eff}}$ than for normal cooling at the core/reflector boundary (viz., reflector at uniform $733 \mathrm{~K}$.)

\subsubsection{Potential for Alternative Core Cooling Configurations}

A possibility is to cool the core by means of a neutron transparent fluid circulating through axial passages in the axial direction. In this case a set of 236 holes of 1.6-cm diam each would provide the same flow area as the $1-\mathrm{cm}$-wide channel at the core/reflector interface being considered. These 236 holes would represent $2.67 \%$ of the core's cross-sectional area. A neutron transparent means of removing heat through these holes will let thermal feedback be the dominant reactivity contributor to power generation selfregulation with highly reduced temperature peaking factors. 
Another possibility is that of using molybdenum alloyed heat pipes with lithium as operating fluid to move the heat from the core to the ultimate heat sink outside of the reactor boundaries. For the 500-kW core, a set of 33 heat pipes operating will suffice because each heat pipe will carry a load of $15.15 \mathrm{~kW}$, which is well below the proven capacity of $40 \mathrm{~kW}$ per heat pipe. This heat pipe approach would only require 33 holes of 1.6-cm diam traversing the 1.5-m-diam reactor's core. With an area of $2 \mathrm{~cm}^{2}$ per hole, it will take away a total of $66 \mathrm{~cm}^{2}$ out of $17672 \mathrm{~cm}^{2}$ (i.e., $0.37 \%$ of the core's cross section area).

We assessed placing the 33 holes as shown in Fig. 5.17 (i.e., in four rings of eight each plus one in the center of the reactor). Using the power generation and thermal conductivities described in Appendix C, the Bessel's Jo-shaped radial distribution results in radii of 22, 40, 54, and $68 \mathrm{~cm}$ for placement of the heat pipes, so that each removes the same amount of power.

Figure 5.18 shows the temperature differences expected between the peak and the sink for pipes at the inner and outer ring for different heat sink temperatures. The difference between inner and outer holes exists mainly because the power generation is not uniform, and for equal energy removal the heat path lengths to the holes get longer as the ring's radius increases. The impact of thermal conductivity reduction as temperature increases is reflected in the figure in the positive slopes as well and in their divergence from each other.

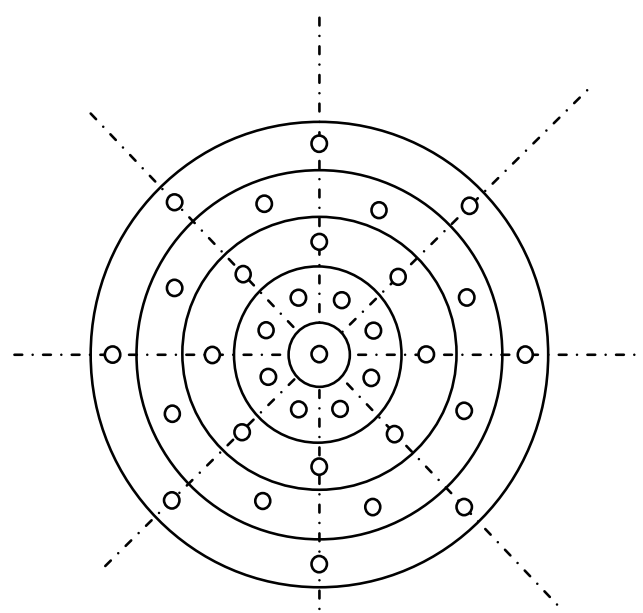

Fig. 5.17. Schematic, not to scale, of the placement of 33 heat pipes in a four-ring configuration. The hole diameters are $1.6 \mathrm{~cm}$, and the core's outside diameter is $150 \mathrm{~cm}$.

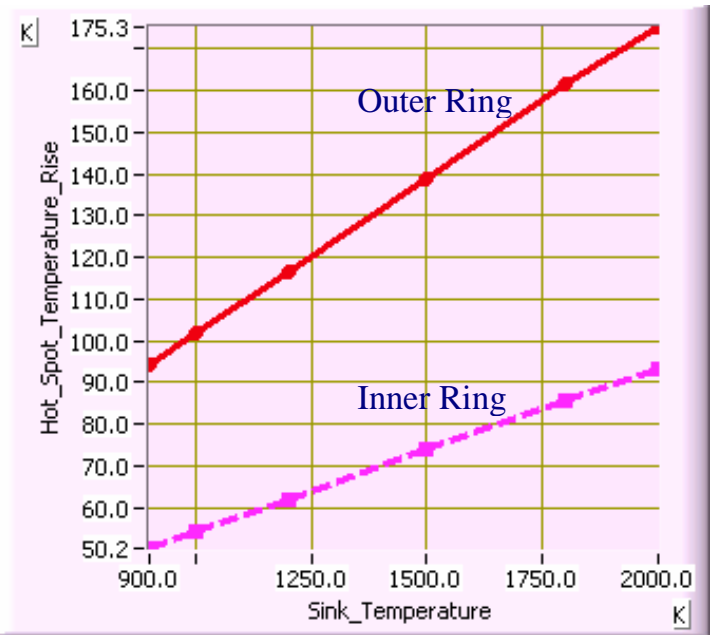

Fig. 5.18. Hot-spot temperature increment as a function of hole surface temperature for holes in the inner and outer rings. 


\subsubsection{Graphite Foam Performance as Heat Transfer Medium}

The thermal conductivity of the core with the pores filled with uranium carbide will exceed that of the graphite foam matrix by itself. Thus, it is computationally conservative to use the thermal conductivity of the foam to represent that of the core. The thermal conductivities used for all of the calculations are described in Appendix C.

\subsubsection{Conclusions}

The 33 heat pipes would remove $500 \mathrm{~kW}$ out of the core at the substantially higher temperature of $1245 \mathrm{~K}$ (i.e., $300 \mathrm{~K}$ increase) with the same core peak temperature of $1367 \mathrm{~K}$ obtained when cooling at the reactor/reflector boundary.

Alternatively, the amount of power that could be removed by the 33 heat pipes would increase to $1930 \mathrm{~kW}$, that is $1430 \mathrm{~kW}$ more (power output up almost by a factor of 4) if the same core outlet and peak temperature constraints were used.

Because heat pipes do not require any external force to operate, a truly passive nuclear heat source without engineered moving parts can be achieved. This passive system will have a thermal power output 4 times higher than if cooled by gas flowing at the core/reflector boundary.

The external part of the heat pipes can be shaped and configured to match the energy conversion method of choice. Transfer of the energy to a working fluid feeding a turbine seems most practical with current technology, but advances in thermionics, thermoelectrics, and thermovoltaics may warrant direct conversion of heat to electricity. This will result in a fully passive electrical generator system.

In addition, high temperature could be used to produce hydrogen. Direct electrolysis of steam and iodine/sulfuric acid production of $\mathrm{H}_{2}$ and $\mathrm{O}_{2}$ and steam reforming of natural gas to produce $\mathrm{H}_{2}$ and methanol are feasible above $1200 \mathrm{~K}$.

\subsection{POWER CONVERSION SYSTEM}

The reference thermal power conversion system consists of the heat transfer geometry surrounding the nuclear core cladding and the closed Brayton cycle components that convert the thermal power generated by the reactor into electrical power. A schematic drawing of the closed Brayton cycle system appears as Fig. 5.19, where the heat sink is the air-source heat exchanger, and the heat source is the reactor.

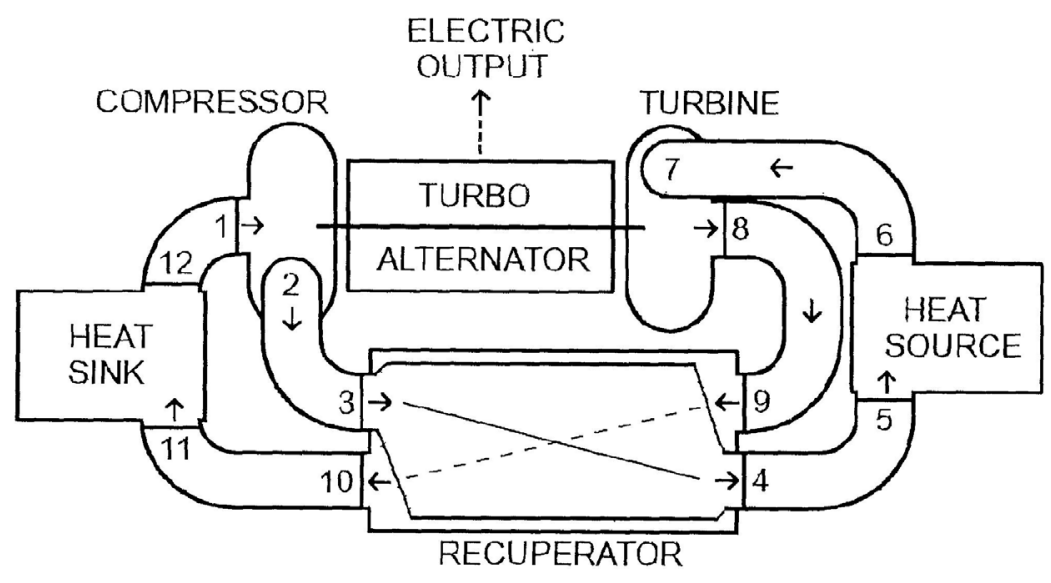

Fig. 5.19. Closed Brayton cycle schematic. 
Heat transfer fins are necessary to increase the effective heat transfer area of the core clad surrounding the nuclear-fueled region. The fins will be made of the same material, a superalloy steel, as the core clad, and the clad surrounding the reflector will serve as an outer shroud to contain the cooling flow. Based on optimization studies, the fin geometry is as follows: fin height of $10 \mathrm{~mm}$, fin width of $5 \mathrm{~mm}$, and fin spacing of $6 \mathrm{~mm}$. This cooling geometry results in a working fluid pressure drop in the finned area of less than $1 \%$.

The working fluid of the recuperated closed Brayton cycle system is chosen to be a mixture of helium and xenon having a molecular weight of $40(\mathrm{HeXe} 40)$. If pure helium were chosen as the working fluid, the relatively high thermal conductivity would result in the recuperator having a minimal necessary heat transfer area as compared to other gases and, thus, minimize the overall volume envelope of the system. However, pure helium also has a high specific heat that would limit the temperature change and thus pressure ratio across a stage. This stage pressure ratio limit would increase the number of turbine and compressor stages and result in complicated turbomachinery. Thus a compromise is necessary between the small recuperator and complicated turbomachinery for pure helium and the larger recuperator with simple turbomachinery of HeXe40. Closed Brayton cycle turbomachines have been successfully designed and tested for space applications using HeXe40 in the electrical power range of interest [ 100 kW(e)], so the $\mathrm{HeXe} 40$ turbomachinery design is chosen here. Because the working fluid is clean and inert, relatively long full-power operating intervals of a decade can be expected.

After the choice of working fluid, operating parameters that need to be specified for a closed Brayton system are the turbine inlet temperature, the compressor inlet temperature, the recuperator effectiveness, the turbine and compressor polytropic efficiency, the operating pressure (usually specified at the compressor discharge), the pressure ratio, and the system pressure drop (specified as the sum of the individual component fractional pressure drops). Appropriate numbers representative of the core operating conditions and existing turbomachine designs have been specified.

Because of core/clad interface temperature limitations, the turbine inlet temperature has been specified as $900 \mathrm{~K}$. Because a terrestrial location is postulated for this reactor concept, a compressor inlet temperature of $310 \mathrm{~K}$ is specified. The ultimate heat sinks of water, forced convection air, and natural convection air were analyzed. While water would result in the smallest heat rejection heat exchanger, and perhaps a lower compressor inlet temperature, the presence of water vapor near the active core during an upset transient might present a nuclear criticality issue. A natural convection heat sink design would require an air chimney and have a large heat rejection heat exchanger. Thus for simplicity, the forced convection air design is chosen as the ultimate heat sink.

The recuperator effectiveness is a measure of the actual heat transferred to the maximum possible from the hot side to the cold side of the recuperator. A reasonably achievable effectiveness is $95 \%$, and 95\% recuperators are within the existing industrial capabilities for manufacturing.

The system pressure drop is defined as the sum of the individual component fractional pressure drops. The component fractional pressure drop is defined as the actual pressure loss divided by the absolute working pressure of the component. This system fractional pressure drop determines how much of the turbine output is absorbed as parasitic pressure loss. A reasonable and realistic value of $5 \%$ is chosen here, where $1 \%$ is budgeted for the core heat transfer fins and $4 \%$ for the remainder of the closed Brayton cycle. To keep the system as uncomplicated as possible, the compressor will not be intercooled.

Industrial firms under contract to NASA have designed HeXe40 turbomachinery appropriate for the electrical power range of interest here, and that radial flow design is chosen. The compressor discharge pressure is $1.48 \mathrm{MPa}$ (14.5 atm or $200 \mathrm{psig}$ ). This pressure, the highest in the system, is relatively low and results in a simple pressure containment boundary. A reasonable compressor polytropic efficiency of $85 \%$ and a turbine polytropic efficiency of $90 \%$ are achievable for this size turbomachinery.

Because the NASA turbomachinery was initially designed to use an $80 \%$ effective recuperator, the pressure ratio across the compressor was designed as 2.2. Using this pressure ratio of 2.2 with the above cycle parameters results in a cycle thermal efficiency of $27 \%$ with a HeXe40 mass flow of $4.33 \mathrm{~kg} / \mathrm{s}$. Thus, for the proposed core thermal power of $500 \mathrm{~kW}, 135 \mathrm{~kW}$ of shaft power is available using the existing 
NASA turbomachine design. With a generator efficiency of $95 \%$, the electrical power resulting from using the existing turbomachinery design is $128 \mathrm{~kW}$.

Because a 95\% effective recuperator is sized here, however, the pressure ratio across the compressor resulting in the optimum cycle efficiency is 1.65 . Using this pressure ratio of 1.65 with the above cycle parameters results in a cycle thermal efficiency of $30 \%$ with a HeXe40 mass flow of $6.28 \mathrm{~kg} / \mathrm{s}$. Thus, for the proposed core thermal power of $500 \mathrm{~kW}, 150 \mathrm{~kW}$ of shaft power is available. With a generator efficiency of $95 \%$, the electrical power resulting from this design is $143 \mathrm{~kW}$. The existing NASA turbomachine design, however, must be modified to the lower pressure ratio. This lower pressure ratio should be easily accommodated in turbomachinery, but does represent additional development.

\subsection{REACTOR OPERATIONS}

\subsubsection{Startup/Shutdown Operations}

The reactor is designed to operate continuously for 10 years, and so, nominally, one would expect only one startup and one shutdown operation. Startup would be staged by symmetric rotation of shutdown cylinders (one or two at a time) with reactor physics tests performed to ensure the integrity of the system. The system would be critical before rotation of all elements, but, as reactor temperature rose, eventually all elements would have to be rotated to the "out" position. The shutdown operation would simply be a scram of all rods to their "in" positions.

\subsubsection{Transient Analysis}

Water ingress accidents have already been addressed in Sect. 4 as a part of the reactor design process. The transient most likely to lead to unacceptable operating conditions is a loss-of-coolant-flow accident. One can assume that the reactor is operating at $500 \mathrm{~kW}$ with normal $\mathrm{He} / \mathrm{Xe}$ flow, and suddenly the flow stops, but, for some unknown reason, the shutdown elements do not scram. Obviously the temperature in the core will rise. The negative temperature coefficient will shut down the reactor, and the power level will drop from $500 \mathrm{~kW}$ to the level provided by decay heat-approximately $0.07 \times 500=35 \mathrm{~kW}$. The temperature (core average and peak) will continue to rise from its nominal value, reach some maximum, and then drop to a profile that corresponds to the decay power level with conduction (with additional contributions from radiation and natural convection of the coolant). The question is, with the change from forced convection to conduction, is the decay power of $35 \mathrm{~kW}$ enough to keep the core temperature at a level higher than the nominal value (500 kW with forced flow)? If not, how much time would pass before the temperature would drop back to nominal values that would then cause the reactor to go critical, heat up (this would oscillate a few times), and then the reactor would run at some power level (less than $500 \mathrm{~kW}$ ) where the system would have a temperature that would correspond to the nominal one? Even if decay power is enough to keep the temperature above the nominal value, at what decay power (and, thus, time after the coolant flow stops) would the system return to critical?

Time and funds were insufficient to study this situation. However, it is noteworthy that the coolant channel thickness could be significantly increased from its nominal value of $1 \mathrm{~cm}$ without significantly affecting the neutronic design of the core. The design is robust relative to being able to enhance natural convection if necessary. 


\section{FUTURE RESEARCH AND DEVELOPMENT}

The SSR operates with a neutron energy spectrum quite unlike any gas-cooled reactor concept studied during the past 20 years. Nuclear data evaluations for uranium, carbon, oxygen, and cadmium isotopes for the epithermal and fast energy ranges must be reviewed, probably reevaluations performed, and likely additional cross section measurements made. Because the concept relies on low excess reactivity, the predicted critical mass should be confirmed. The value of the temperature coefficient must be confirmed. Subcriticality under accident conditions should be assured through applicable benchmark experiments.

Though the fluence experienced by the fuel and the clad will be low, it is likely that insufficient irradiation history data will exist for these materials. A series of material irradiation measurements should be planned.

Which of several possible methods for loading/depositing the uranium into the graphite foam will need to be determined. The method ultimately identified will depend largely on the required volumetric concentration of ${ }^{235} \mathrm{U}$ and on the required $\mathrm{C} / 235 \mathrm{U}$ ratio.

With regard to the carbon foam itself, further research and study are needed for several areas as well. These include (1) evaluating the manufacturing processes of the carbon foam that have been developed since the inception of this project to evaluate the extent to which the anisotropic properties of the original foam have been reduced or eliminated and (2) conducting further irradiation experiments to establish a broader baseline data for thermal properties of the foam. This research is particularly needed because the carbon foam is now being produced commercially with apparently improved properties.

Additional materials research for cladding and core/reflector coatings with high-performance characteristics at high temperatures should be considered. Advanced technologies, such as electron-beam vapor deposition, permit dithering and layering of diverse materials and open the possibility of producing composite materials (rhenium, iridium, carbon, etc.) with optimal thermal, mechanical, neutronic, and environmental resistance properties. 
6-2 
Appendix A

MELTING POINT OF ULTRA HIGH TEMPERATURE MATERIALS 


$$
\text { A-2 }
$$




\section{Appendix A \\ MELTING POINT OF ULTRA HIGH TEMPERATURE MATERIALS}

Table A.1. Melting point of high-temperature materials in elemental, carbide, oxide, and boride forms

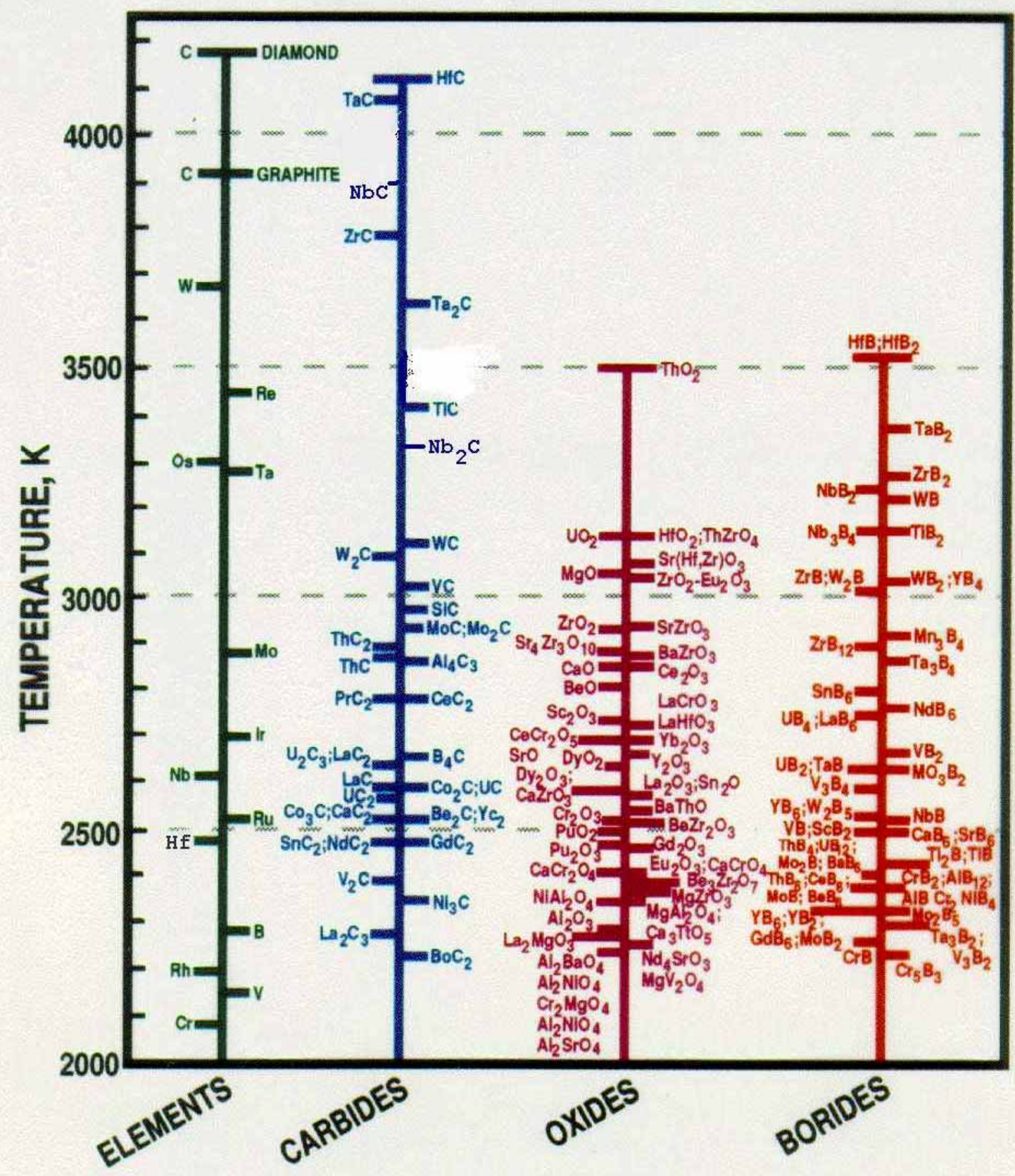


Table A.2. Melting point of high-temperature materials in nitride, intermetallic, silicide, phosphide, and silicate forms

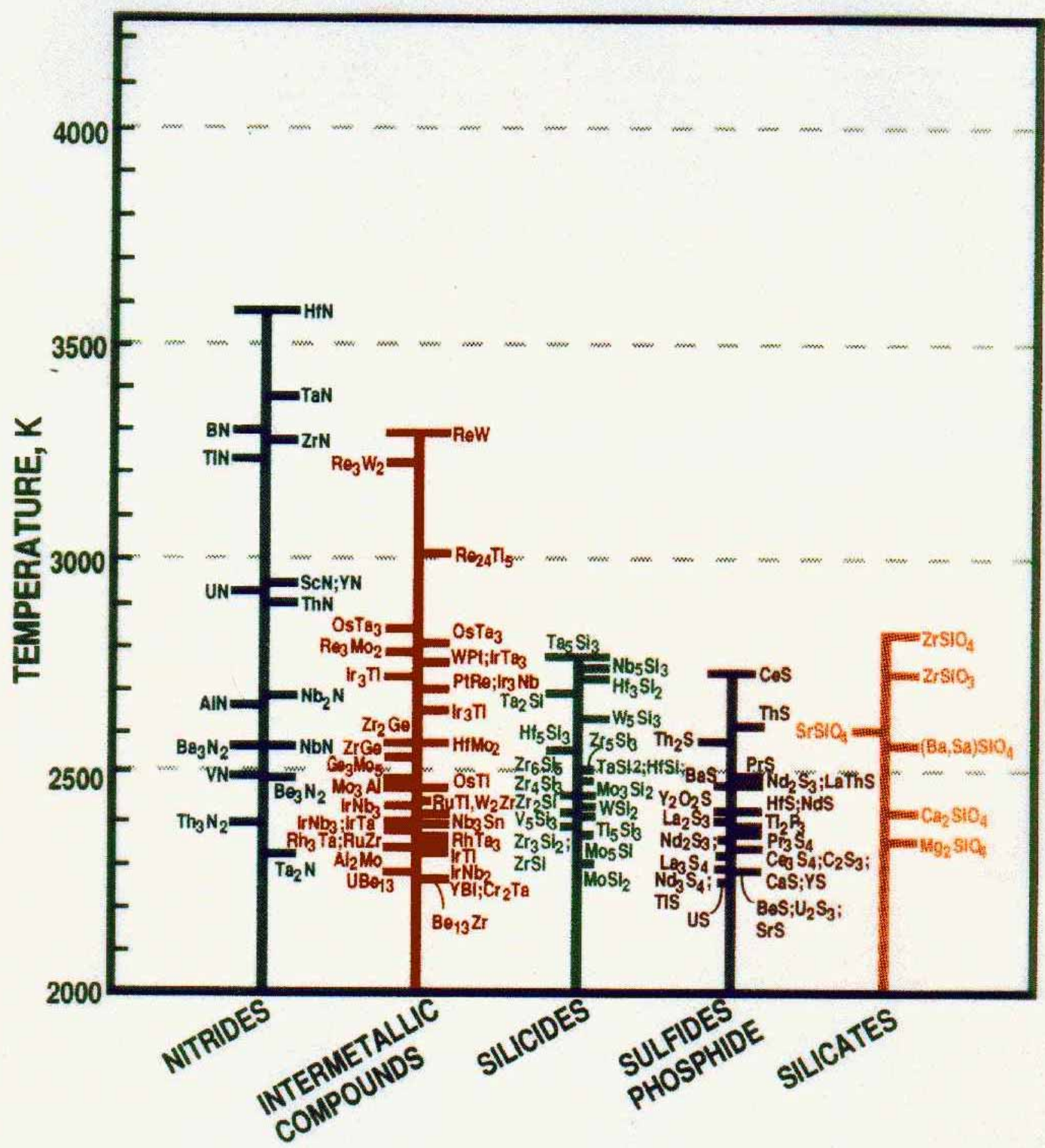


Appendix B

NEUTRONIC PARAMETERS AND THEIR TEMPERATURE DEPENDENCE FOR EACH OF THE FOUR MATERIAL REGIONS AND FOUR ENERGY GROUPS 
B-2 


\section{Appendix B}

\section{NEUTRONIC PARAMETERS AND THEIR TEMPERATURE DEPENDENCE FOR EACH OF THE FOUR MATERIAL REGIONS AND FOUR ENERGY GROUPS}

Below is a graphical depiction of the set of four-group neutronic cross sections for the reflector and three concentric regions inside the core at temperatures of 300,900, 1200, and $2100 \mathrm{~K}$ in percent of the reference value for $300 \mathrm{~K}$ (Figs. B.1 and B.2). They were derived using the HELIOS code. They allow the coupled computation of power generation, temperature distribution, and the neutron multiplication factor with temperature and thermal conductivity feedback.

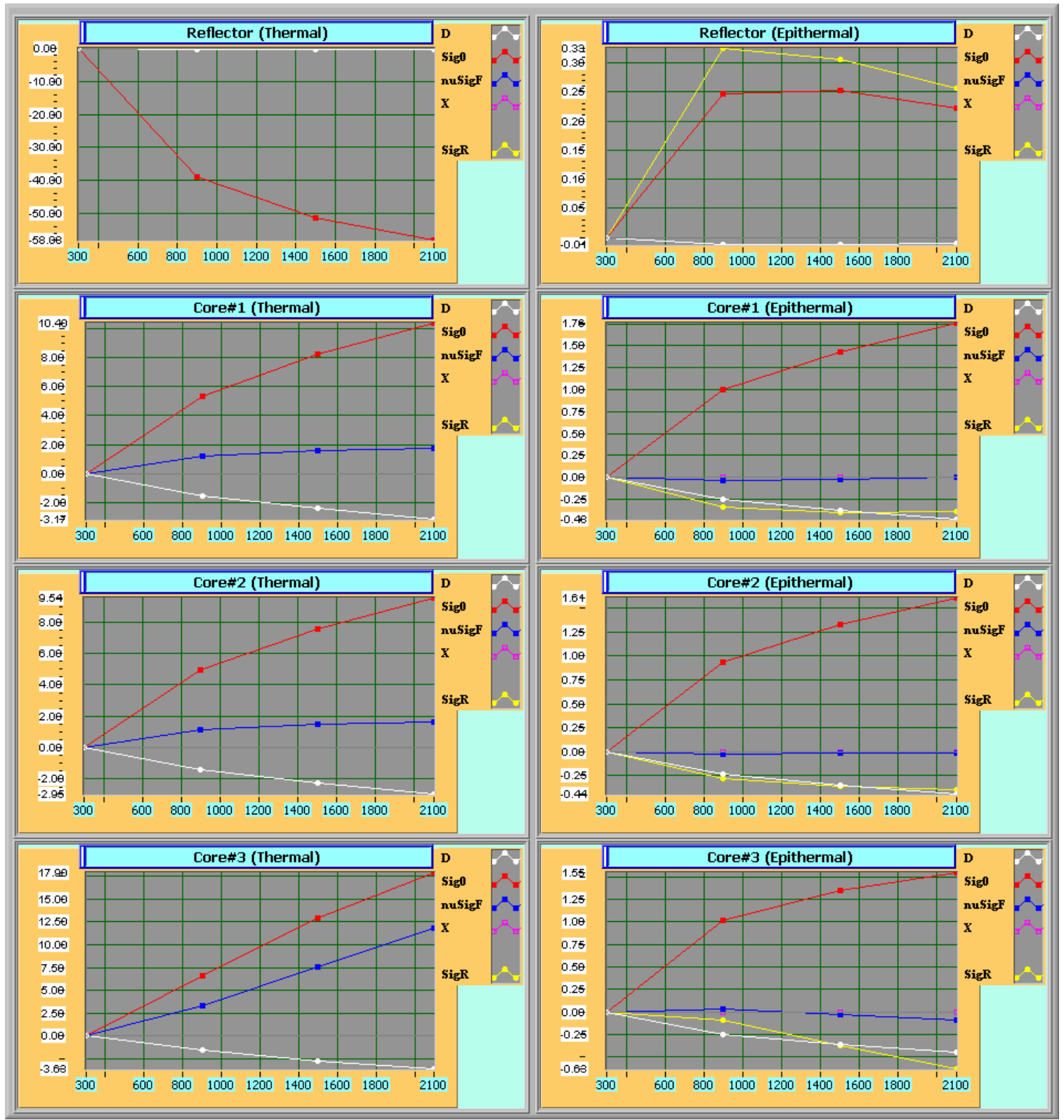

Fig. B.1. Percent of the value for $300 \mathrm{~K}$ for the thermal and epithermal energy groups. 


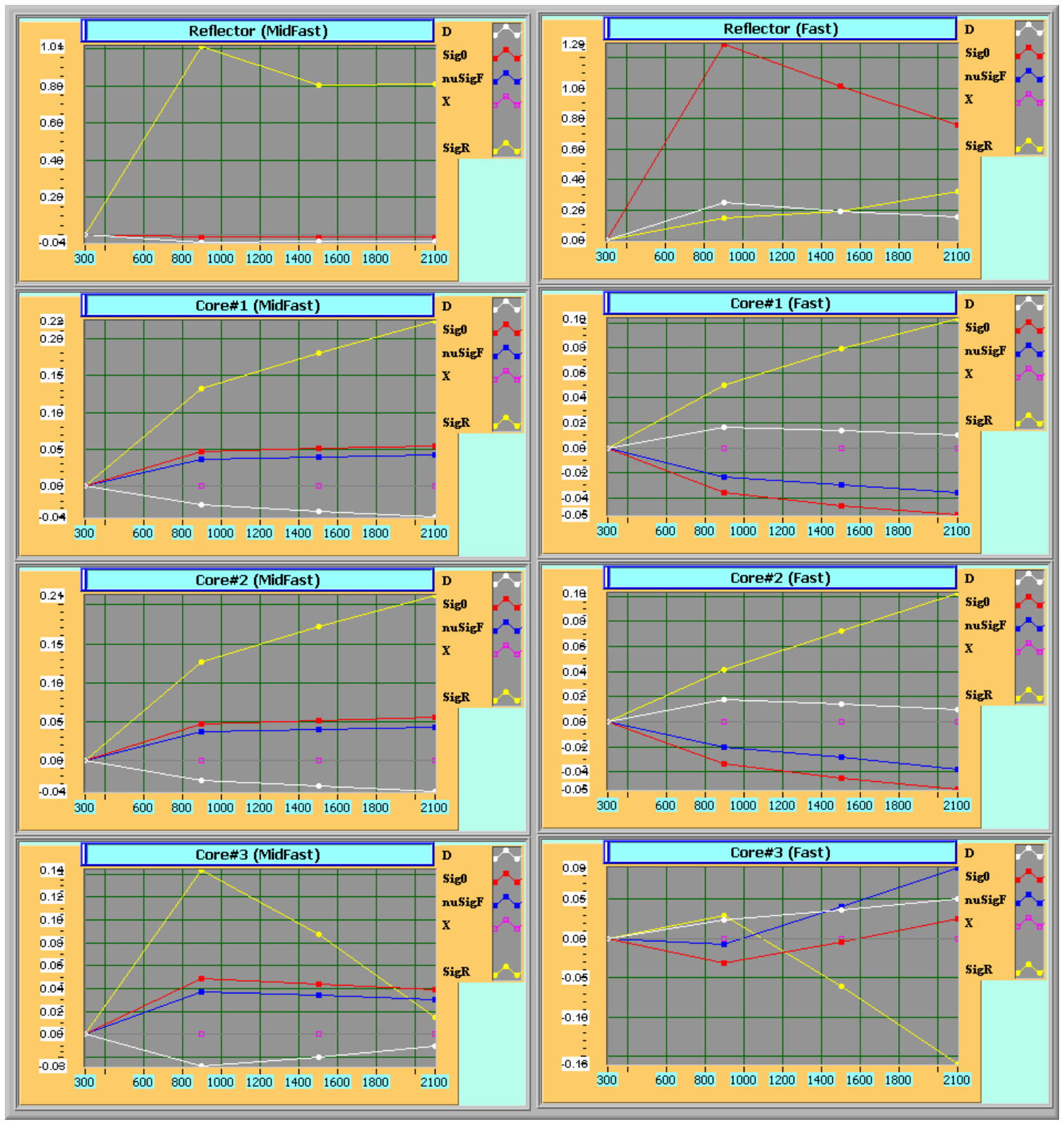

Fig. B.2. Percent of the value for $300 \mathrm{~K}$ for the midfast and fast energy groups. 
Appendix C

SCOPING THERMAL COMPUTATIONS FOR COOLING AT THE BOUNDARIES AND COMPARISON OF SIMPLIFIED

INFINITE-CYLINDER 1-D MODEL AND A DETAILED 2-D FINITE-ELEMENT MODEL 


$$
\text { C-2 }
$$




\section{Appendix C}

\section{SCOPING THERMAL COMPUTATIONS FOR COOLING AT THE BOUNDARIES AND COMPARISON OF SIMPLIFIED INFINITE-CYLINDER 1-D MODEL AND A DETAILED 2-D FINITE ELEMENT MODEL}

For the thermal computations, the power generation in the reactor is assumed to have a cosine-shaped distribution in the axial direction and a Bessel's Jo-shaped in the radial direction as in Eq. (C.1):

$$
\mathrm{q}^{\prime \prime \prime}(\mathrm{z}, \mathrm{r})=500 \mathrm{~kW} * \mathrm{~A} * \mathrm{~J}_{0}(2.40482556 * \mathrm{r} / \mathrm{Rx}) * \cos (\mathrm{pi} * \mathrm{z} / \mathrm{Hx})
$$

for all $\mathrm{r}$ from 0 to $\mathrm{Rc}$, and $\mathrm{z}$ from $-\mathrm{Hc} / 2$ to $+\mathrm{Hc} / 2$, where

$$
\begin{aligned}
\mathrm{J}_{0}= & \text { the Bessel function of the first kind and order } 0, \\
\mathrm{z}= & \text { the vertical ordinate with the center of the core as reference, } \\
\mathrm{Rc}= & \text { the core radius, } \\
\mathrm{Rx}= & \text { the extrapolated radius, } \\
\mathrm{Hc}= & \text { the core height, } \\
\mathrm{Hx}= & \text { the buckling height, } \\
\mathrm{A}= & \text { a normalization factor given by Eq. }(\mathrm{C} .2): \\
\mathrm{A}= & 1 /\left(\text { Double Integral of }\left[\mathrm{J}_{0}(2.405 * \mathrm{r}) * \cos (\mathrm{pi} * \mathrm{z} / \mathrm{H}) * 2 \mathrm{pi} \mathrm{dr} * \mathrm{dz}\right] \text { between } \mathrm{r}=0 \geq \mathrm{Rc},\right. \\
& \quad \text { and } \mathrm{z}=-\mathrm{Hc} / 2 \geq \mathrm{Hc} / 2 .
\end{aligned}
$$

For the 1-m-diam preliminary reactor size in the following computations: $\mathrm{Rc}=0.5 \mathrm{~m}$ and $\mathrm{Hc}=1.0 \mathrm{~m}$ with Hex $=1.4 \mathrm{~m}$, and $\mathrm{Rx}=0.7 \mathrm{~m}$; then the value of $\mathrm{A}$ is 2.3531 .

For the 1.5-m-diam design basis reactor: $\mathrm{Rc}=0.75 \mathrm{~m}$ and $\mathrm{Hc}=1.5 \mathrm{~m}$ with $\mathrm{Hx}=2.1 \mathrm{~m}$, and $\mathrm{Rx}=$ $1.05 \mathrm{~m}$, which yields a value of A equal to 0.697216 .

The axial peaking factor for the distribution in Eq. (C.1) to be used in the 1-D radial calculations is 1.245 .

The thermal conductivity of the core is assumed to be that of the foam alone. This yields conservative estimates because the bulk conductivity is larger with the pores filled with fuel.

In the radial direction (see Fig. C.1):

$$
\begin{aligned}
\mathrm{k}_{\mathrm{Cr}}(\mathrm{T})= & 3.167 \mathrm{E}+2-6.912 \mathrm{E}-1 * \mathrm{~T}+8.269 \mathrm{E}-4 * \mathrm{~T}^{2}-5.535 \mathrm{E}-7 * \mathrm{~T}^{3}+2.072 \mathrm{E}-10 \\
& * \mathrm{~T}^{4}-4.044 \mathrm{E}-14 * \mathrm{~T}^{5}+3.202 \mathrm{E}-18 * \mathrm{~T}^{6}[\mathrm{~W} / \mathrm{m} / \mathrm{K}]
\end{aligned}
$$

where $\mathrm{T}$ is in Kelvin. Note, at $300 \mathrm{~K}$, the thermal conductivity is $\mathrm{k}_{\mathrm{Cr}}(300 \mathrm{~K})=170 \mathrm{~W} / \mathrm{m} / \mathrm{K}$.

1. In the axial direction:

$$
\mathrm{k}_{\mathrm{Cz}}(\mathrm{T})=\mathrm{k}_{\mathrm{Cr}}(\mathrm{T}) / 6 \text { (i.e., at } 300 \mathrm{~K} \geq 28 \mathrm{~W} / \mathrm{m} / \mathrm{K} \text { ) . }
$$

Thermal conductivity of reflector's solid graphite is in $\mathrm{W} / \mathrm{m} / \mathrm{K}$.

2. In the radial direction:

$$
\mathrm{k}_{\mathrm{Rr}}(\mathrm{T})=\mathrm{k}_{\mathrm{Cr}}(\mathrm{T}) / 1.7,
$$

where $\mathrm{T}$ is in Kelvin. Note, at $300 \mathrm{~K}$, the thermal conductivity is $\mathrm{k}_{\mathrm{Rr}}(300 \mathrm{~K})=100 \mathrm{~W} / \mathrm{m} / \mathrm{K}$. 
3. In the axial direction:

$$
\mathrm{k}_{\mathrm{Rz}}(\mathrm{T})=\mathrm{k}_{\mathrm{Rr}}(\mathrm{T}) / 1.6
$$

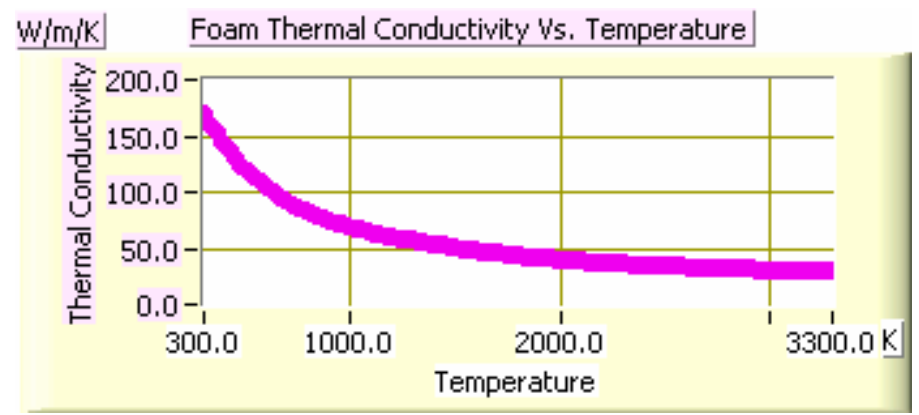

Fig. C.1. Thermal conductivity of graphitized foam in radial direction as a function of temperature. 